Portland State University

PDXScholar

\title{
A Numerical Model Investigation of the Role of the Glacier Bed in Regulating Grounding Line Retreat of Thwaites Glacier, West Antarctica
}

Michael Scott Waibel

Portland State University

Follow this and additional works at: https://pdxscholar.library.pdx.edu/open_access_etds

Part of the Environmental Sciences Commons, and the Geomorphology Commons Let us know how access to this document benefits you.

\section{Recommended Citation}

Waibel, Michael Scott, "A Numerical Model Investigation of the Role of the Glacier Bed in Regulating Grounding Line Retreat of Thwaites Glacier, West Antarctica" (2017). Dissertations and Theses. Paper 3467.

https://doi.org/10.15760/etd.5351

This Dissertation is brought to you for free and open access. It has been accepted for inclusion in Dissertations and Theses by an authorized administrator of PDXScholar. Please contact us if we can make this document more accessible: pdxscholar@pdx.edu. 
A Numerical Model Investigation of the Role of the Glacier Bed in Regulating Grounding Line Retreat of Thwaites Glacier, West Antarctica

by

Michael Scott Waibel

A dissertation submitted in partial fulfillment of the requirements for the degree of

Doctor of Philosophy

in

Environmental Sciences and Resources: Geology

Dissertation Committee:

Scott F. Burns, Chair

Christina L. Hulbe

Charles S. Jackson

Andrew G. Fountain

Brittany A. Erickson

Portland State University

2017 


\begin{abstract}
I examine how two different realizations of bed morphology affect Thwaites Glacier response to ocean warming through the initiation of marine ice sheet instability and associated grounding line retreat. A state of the art numerical ice sheet model is used for this purpose. The bed configurations used are the $1-\mathrm{km}$ resolution interpolated BEDMAP2 bed and a higher-resolution conditional simulation produced by John Goff at the University of Texas using the same underlying data. The model is forced using a slow ramp approach, where melt of ice on the floating side of the grounding line is increased over time, which gently nudges the glacier toward instability. Once an instability is initiated, the anomalous forcing is turned off, and further grounding line retreat is tracked.
\end{abstract}

Two model experiments are conducted. The first experiment examines the effect of different anomalous forcing magnitudes over the same bed. The second experiment compares the generation and progress of instabilities over different beds. Two fundamental conclusions emerge from these experiments. First, different bed geometries require different ocean forcings to generate a genuine instability, where ice dynamics lead to a positive feedback and grounding line retreat becomes unstable. Second, slightly different forcings produce different retreat rates, even after the anomalous forcing is shut off, because different forcing magnitudes produce different driving stresses at the time the instability is initiated. While variability in the retreat rate over time depends on bed topography, the rate itself is set by the magnitude of the forcing. This signals the importance of correct knowledge of both bed shape and ocean circulation under floating 
portions of Antarctic ice sheets. The experiments also imply that different ocean warming rates delivered by different global warming scenarios directly affects the rate of Antarctic contribution to sea level rise. 


\section{ACKNOWLEDGEMENTS}

Writing a dissertation is a long, difficult endeavor. Fortunately, I had help and support from individuals and organizations along the way. This is where I acknowledge the assistance and support provided to me. However, I want to be clear that the following paragraphs do not form a comprehensive list. There are many people and conversations that have been influential to my studies over the years, and I'm grateful to have had the opportunity of being in an environment that encourages scholarly discourse as well as achievement. Thank you Portland State and the community that is Portland. No matter what the future holds, I will always have fond memories of my time here.

I'm going to begin my list of specific acknowledgements with funding and supporting organizations that enabled me to conduct this research. NASA award number NNX11AH89 to the University of Texas and Portland State funded this work while additional support was provided SciDac's PISCEES project. A profuse thanks to both NASA and PISCEES is in order, and I laud these organizations' efforts contributing to our increasing understanding of the past and future evolution of ice sheets as well as their influence on climate and sea level.

Next, I would like to collectively thank my dissertation committee: Dr. Scott Burns, Dr. Christina Hulbe, Dr. Charles Jackson, Dr. Andrew G. Fountain, and Dr. Brittany Erickson. I appreciate all members' questions and guidance throughout this process. Additionally, I appreciate the thoughtful edits provided to improve the dissertation. 
A special thank you goes to Dr. Scott Burns, the chair of my dissertation committee. Scott is a knowledgeable, dedicated geologist and emeritus professor at PSU who is frequently consulted even in his retirement. There is no one quite like Dr. Burns when it comes to navigating PSU's bureaucracy. Furthermore, Scott is an incredibly kind and compassionate human being. If there were more people in this world like Dr. Burns, the world would be a happier, kinder place.

A special thank you goes to Dr. Charles Jackson as well. Dr. Jackson was essentially a co-advisor (along with Dr. Christina Hulbe) for me and ultimately this research would not have been possible without his guidance. I appreciate the opportunity he provided me for travelling to the University of Texas so that I could learn how to use the computing resources provided by the Texas Advanced Computing Center. Moreover, my other trips to UTIG for research were invaluable, and I was pleased to meet so many knowledgeable and gifted scholars there.

I'd like to acknowledge Dr. John Goff at the University of Texas Institute for Geophysics. Dr. Goff created a topographic bed model that is an integral part of this research. The conclusions reached by this research certainly validate his effort.

I would like to thank Nancy Eriksson, PSU Geology Department's former office coordinator. Like Dr. Burns, Nancy was adept at navigating the bureaucracy and cutting through red tape, and I am indebted to her. Another fact about Nancy is that she is an excellent cook. The newer geology students at PSU don't know what they are missing.

I owe a debt of gratitude to Dr. Dan Martin at Lawrence Berkeley National Laboratory. As a model developer, Dan provided invaluable guidance for the numerical 
model used in this research. I learned much from Dan, and he was an integral part of the effort.

I would like to thank my family for their support. Erin, my wife, and Pat, my mother, are both strong women; and they probably deserve a medal for putting up with me. Erin has often been a sounding board for my ideas, and I hold her insights in high esteem. In response to my wishes, my mother began teaching me to read when I was four years old and has always been extremely supportive of my academic endeavors ever since. Additionally, I would like to say that I consider Erin's family as my own, and I sincerely appreciate their encouragement.

I would also like to thank Alisa Humphrey, the current office coordinator at PSU's Geology Department, and Paul Brooks, a computer systems analyst. I judge Alisa to be a fine addition to the office staff as she undertakes administrative tasks allowing students to focus on their work. Paul was a tremendous help as I transitioned to Unix-like systems.

I've saved my most profuse and heartfelt thanks for last. Thank you, Dr. Christina Hulbe, for everything that you have done to further my career. There really are no words that can amply express my gratitude. Christina was my original advisor and the one who set me on the path to this academic achievement. Christina's faith in me gave me the confidence to carry on and overcome obstacles along the way (and there were some big ones). I feel very privileged and humbled to have had the opportunity to work with one of the most highly respected minds in ice dynamics. 


\section{TABLE OF CONTENTS}

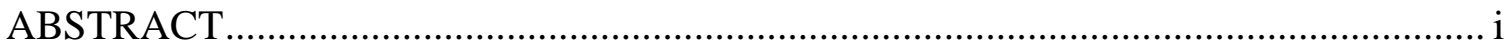

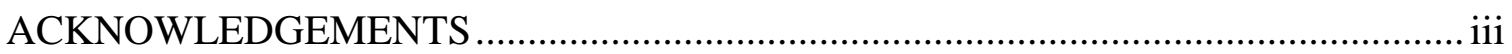

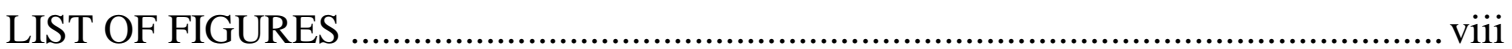

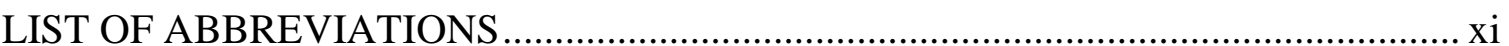

LIST OF SYMBOLS _................................................................................. xii

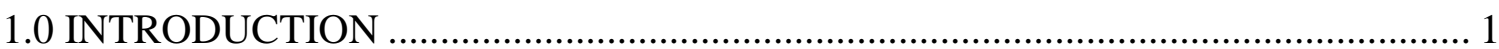

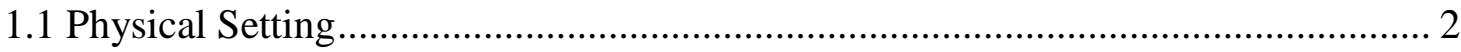

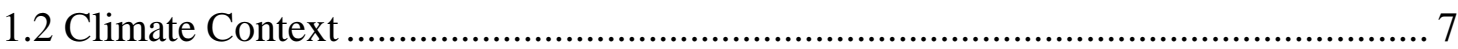

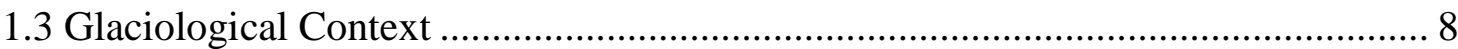

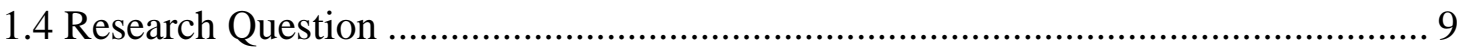

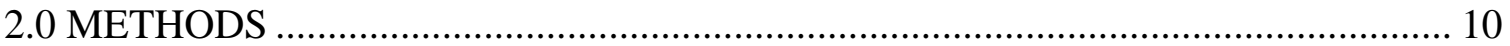

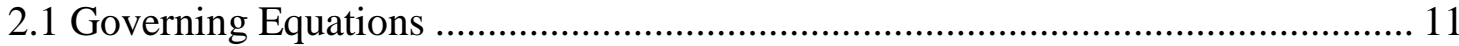

2.2 Constitutive Equations ..................................................................................... 13

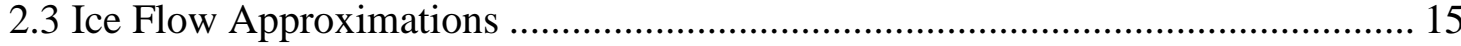

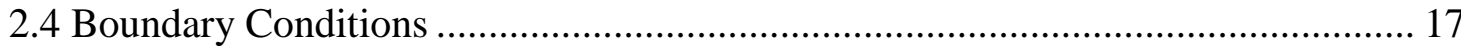

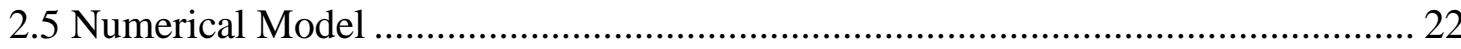

2.6 Model Domain and Boundaries ........................................................................ 26

2.7 Bed Topography ............................................................................................... 27

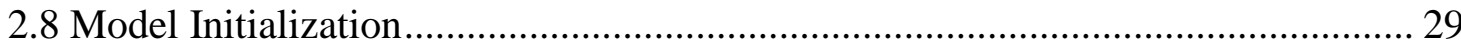

2.8.1 Implementation and Spatial Maps ……………................................................ 33

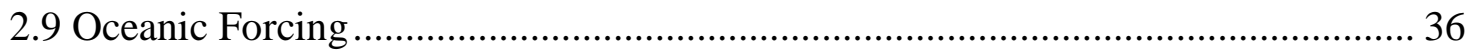

2.9.1 Perturbation and Experiment Design ............................................................. 41

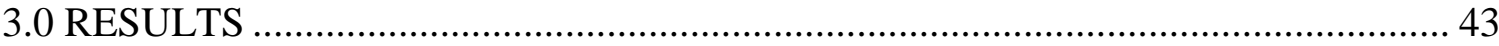




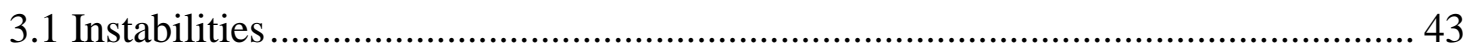

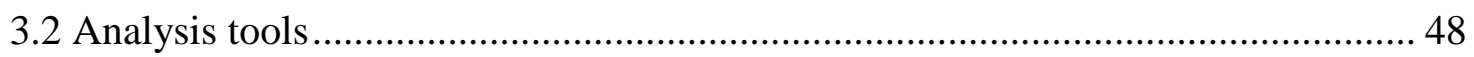

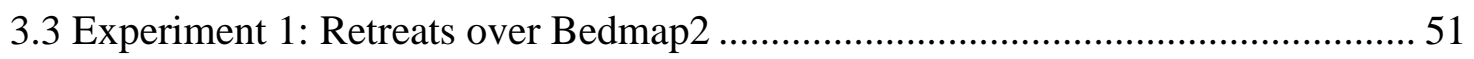

3.4 Experiment 2: Comparison to Retreat over Goff Bed ............................................... 67

3.5 Summary of Mass Loss for all Simulations ........................................................... 78

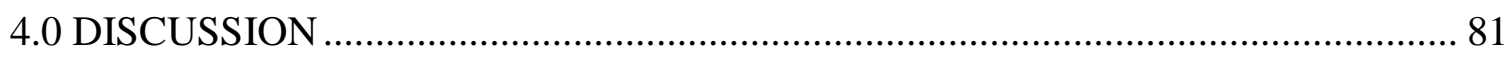

4.1 Spatial Patterns of Difference in Driving Stress .................................................. 88

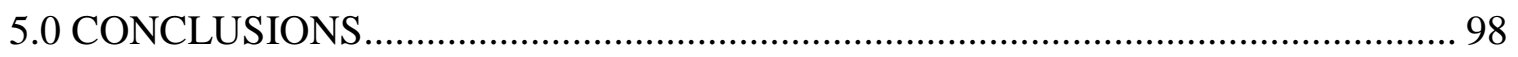

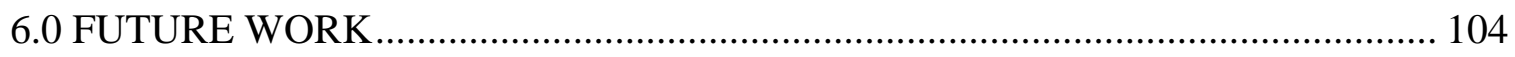

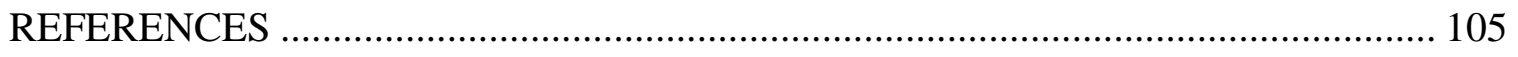

Appendix A Experiment 1 Summary Table................................................................... 112

Appendix B Experiment 2 Summary Table ............................................................... 156

APPENDIX C Grounding Line Retreat Over Beds ...................................................... 169

APPENDIX D Ice Thickness Evolution .................................................................. 170

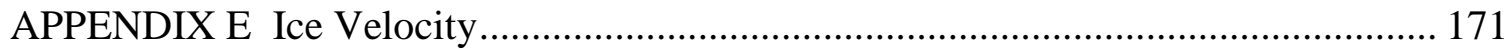

APPENDIX F Effective Strain Rate .................................................................... 172

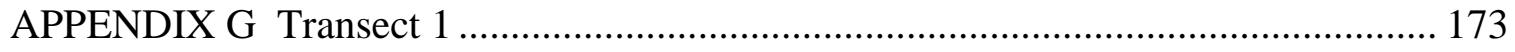

APPENDIX H Transect 2 …………………......................................................... 174

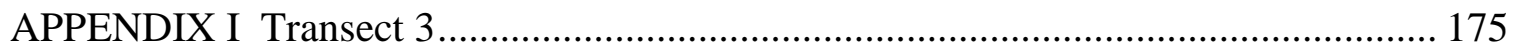

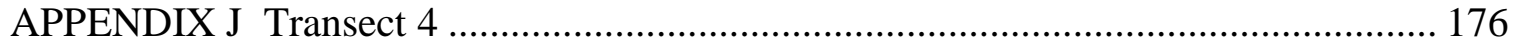

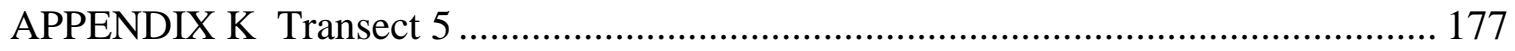

APPENDIX L Experiment 1 Co-location .................................................................... 178

APPENDIX M Experiment 2 Co-location................................................................ 179 


\section{LIST OF FIGURES}

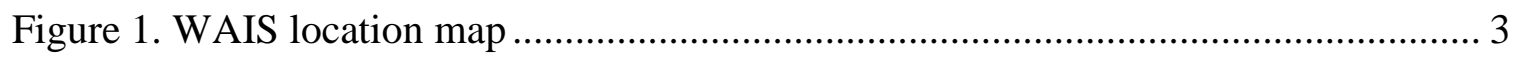

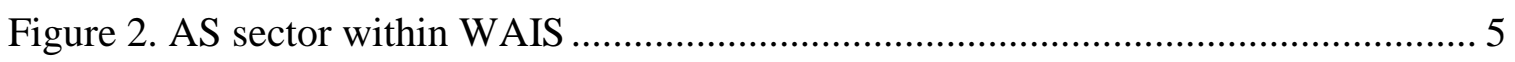

Figure 3. An example of a block-structured mesh....................................................... 25

Figure 4. The new $250 \mathrm{~m}$ resolution bed of the Thwaites catchment............................ 28

Figure 5. Flowchart showing how model initialization is implemented......................... 34

Figure 6. Basal traction coefficients for Bedmap2 and Goff beds ................................ 35

Figure 7. Stiffening coefficients over Bedmap2 ........................................................ 35

Figure 8. Stiffening coefficients over the Goff bed ................................................. 36

Figure 9. Simplified cartoon depiction of transitional regions of a marine terminating

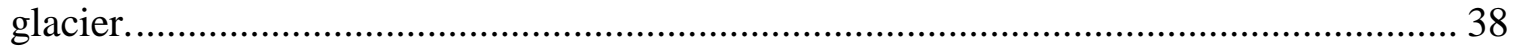

Figure 10. Ice grounded over a bedrock high under Thwaites tongue........................... 39

Figure 11. Change in smoothed grounded ice area vs anomalous melt rate / time.......... 44

Figure 12. Example of grounding line stall along T3 after a local instability. ................ 45

Figure 13. Example of grounding line stall along T3 when there is no instability.......... 45

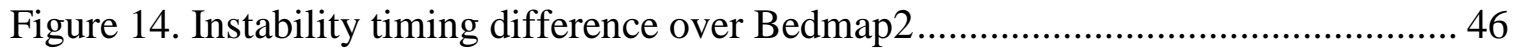

Figure 15. Instability timing difference over the Goff bed......................................... 47

Figure 16. The region of interest for calculating driving stress.................................. 49

Figure 17. A cartoon demonstrating the effect of bumps and large basal tractions on ice

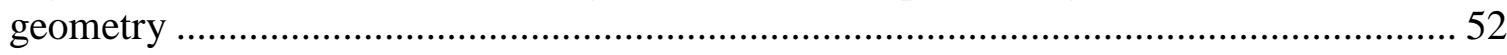

Figure 18. The grounding line positions over Bedmap2 after ramp shutoffs .................. 53

Figure 19. Driving stress at $4 \mathrm{~km}$ resolution over Bedmap2 in the ROI and surrounding

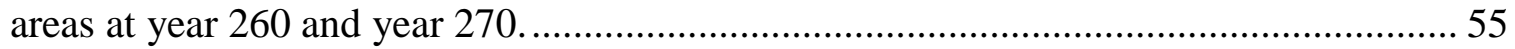

Figure 20. Contours of grounding line retreat for B260 ......................................... 56

Figure 21. Contours of grounding line retreat for B270 ....................................... 57

Figure 22. The difference in mean driving stress over Bedmap2 ................................ 58

Figure 23. The spatial difference in driving stress B270 minus B260.......................... 59

Figure 24. Spatial differences in driving stress for the $18^{\text {th }}$ co-located observation of retreats over Bedmap2

Figure 25. Spatial difference of overlapping ROIs in driving stress for co-location observation number 60 in experiment 1 
Figure 26. Spatial difference of overlapping ROIs in driving stress for co-location observation number 861 in experiment 1

Figure 27. A cartoon depicting the transient advance observed after ramp shutoff in some locations of the B270 simulation 64

Figure 28. Volumetric flux across the grounding line for B260 and B270 65

Figure 29. The grounding line positions for both simulations over Bedmap2 at the

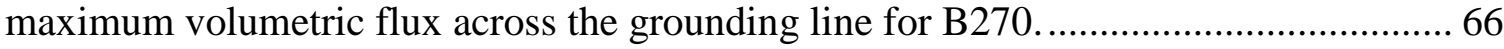

Figure 30. Grounding line position at ramp shutoff over the Goff bed.......................... 68

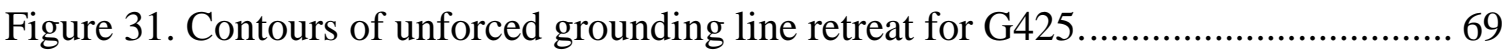

Figure 32. The differences in mean driving stress for B270 vs G425 ......................... 72

Figure 33. The first spatial observation (4 km resolution) of difference in driving stress $(\mathrm{kPa})$ in overlapping ROIs for co-located grounding lines in the second experiment...... 73

Figure 34. Observation 78 of the difference in mean driving stress for overlapping ROIs (4 $\mathrm{km}$ resolution) in experiment 2 74

Figure 35. Observation 79 of the difference in mean driving stress for overlapping ROIs

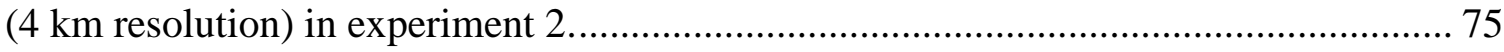

Figure 36. Year of co-located position in the B270 and G425 simulations.................... 76

Figure 37. Spatial series of volumetric flux across Thwaites grounding line for B270 and

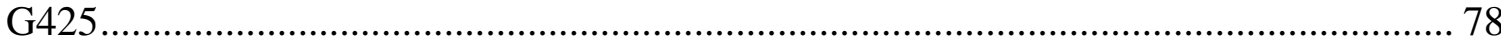

Figure 38. Ice mass loss in terms of SLE over the first 500 years for all simulations...... 79

Figure 39. Ice mass loss in terms of SLE over the course of all simulations ................... 80

Figure 40. The first 1,360 years of committed retreat along T1 for B260 ...................... 82

Figure 41 . The first $4 \mathrm{~km}$ resolution co-located grounding line position difference in

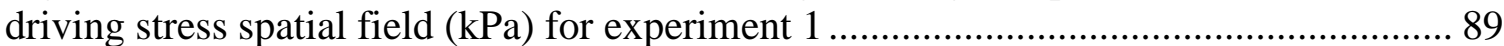

Figure 42. The first $4 \mathrm{~km}$ resolution co-located grounding line position driving stress difference spatial field $(\mathrm{kPa})$ for experiment 2

Figure 43. The $4 \mathrm{~km}$ resolution bed elevations $(\mathrm{m})$ at the first co-located observation for Bedmap2 and Goff Bed 91

Figure 44. The $4 \mathrm{~km}$ resolution ice thickness (m) at the first co-located observation for Bedmap2 and Goff Bed. 92

Figure 45 . The $4 \mathrm{~km}$ resolution thickness difference $(\mathrm{m})$ at the 186 th observation of

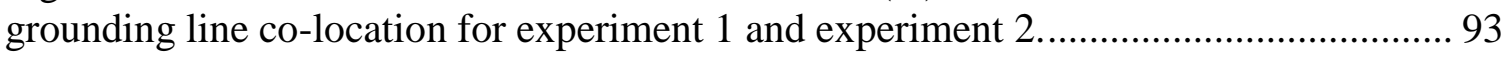

Figure 46. Difference in basal traction coefficients for Goff minus Bedmap2 ............... 94

Figure 47. $4 \mathrm{~km}$ resolution Goff bed minus Bedmap2 difference in basal traction in areas

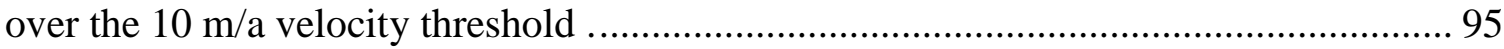


Figure 48. Surface gradients at $4 \mathrm{~km}$ resolution at the first instance of grounding line co-

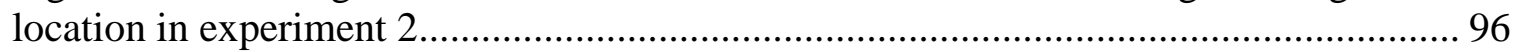

Figure 49. Driving stress $(\mathrm{kPa})$ and surface gradient differences at the first observation of grounding line co-location for experiment 2 


\section{LIST OF ABBREVIATIONS}

AMR adaptive mesh refinement

AS

Amundsen Sector

ASE

Amundsen Sea Embayment

B260

Simulation over Bedmap2 in which the anomalous forcing (slow ramp) was turned off at model year 260.

B270 Simulation over Bedmap2 in which the anomalous forcing (slow ramp) was turned off at model year 270 .

BEDMAP bed topography of the Antarctic

BISICLES Berkeley Ice Sheet Initiative for Climate at Extreme Scales

EAIS East Antarctic Ice Sheet

FDM Finite Difference Method

FEM Finite Element Method

FVM Finite Volume Method

G425 Simulation over the Goff bed in which the anomalous forcing (slow ramp) was turned off at model year 425 .

MCDW Modified Circumpolar Deep Water

PLF piecewise linear form (or piecewise linear function)

ROI region of interest

SLE sea level equivalent

SSA Shallow Shelf Approximation aka Shelfy-Stream Approximation

SSA* modified Shallow Shelf Approximation

TAM Transantarctic Mountains

T1 - T5 Transects that are flow paths

UTIG University of Texas Institute for Geophysics

VAF volume above floatation

WAIS West Antarctic Ice Sheet 


\section{LIST OF SYMBOLS}

$\dot{a} \quad$ accumulation or ablation rate at the ice surface

$a^{\perp} \quad$ ice volume flux perpendicular to the ice surface

$\dot{b} \quad$ melting or freezing rate at the ice base

$b^{\perp} \quad$ ice volume flux perpendicular to the ice base

$c_{i} \quad$ expansion coefficients

f body force acting on ice

g, $g \quad$ gravitational acceleration $\left(=9.81 \mathrm{~ms}^{-2}\right)$

$h \quad z$-coordinate of the ice surface

$k \quad$ ice thermal conductivity

$l \quad$ exponent taken to be 1

n unit normal vector

$n \quad$ exponent usually taken to be 3

p 1) pressure

2) exponent for $e$

$q \quad$ exponent for $e$

$r \quad$ bedrock elevation below sea level

$s \quad$ ice surface elevation

$t \quad$ time

u velocity vector in three Cartesian dimensions

$u_{i}, u_{j} \quad$ horizontal components of velocity (index notation)

$u_{x}, u_{y}, u_{z} \quad$ Cartesian components of velocity

$\mathbf{u}_{s} \quad$ ice surface velocity vector

w velocity vector of free surface

$\mathbf{x} \quad$ position vector

$x_{i}, x_{j} \quad$ horizontal Cartesian coordinates (index notation)

$x, y \quad$ horizontal Cartesian coordinates 
$z$

\begin{tabular}{|c|c|}
\hline$A$ & rate factor \\
\hline$B_{b}$ & free surface boundary at ice base \\
\hline$B_{s}$ & free surface boundary at ice surface \\
\hline$C$ & coefficient representing basal properties \\
\hline$J$ & cost function \\
\hline$J^{\prime}$ & cost function with outside constraint \\
\hline$J_{m}$ & misfit function \\
\hline$J_{p}$ & Tikhonov penalty function \\
\hline$H$ & ice thickness \\
\hline$T$ & temperature \\
\hline
\end{tabular}

$\alpha_{u}^{2}(x, y) \quad$ coefficient equal to 1 where velocity data is available and zero otherwise in misfit function, $J_{m}$

$\alpha_{C}^{2} \quad$ coefficient in basal traction term of Tikhonov penalty function, $J_{p}$

$\alpha_{\phi}^{2} \quad$ coefficient in stiffening term of Tikhonov penalty function, $J_{p}$

$\beta(x, y) \quad$ spatially variable basal traction field

$\dot{\varepsilon}_{i j} \quad$ component of strain rate tensor

$\dot{\varepsilon}_{I I} \quad$ effective strain

$\eta \quad$ effective viscosity

$\lambda, \mu \quad$ components of Lagrange-multiplier vector

$\rho, \rho_{i} \quad$ density of ice $\left(=918 \mathrm{kgm}^{-3}\right)$

$\rho_{w} \quad$ density of water $\left(=1028 \mathrm{kgm}^{-3}\right)$

$\rho \mathbf{g} \quad$ effective force of gravity

$\sigma \quad$ Cauchy stress tensor

$\tau$ deviatoric stress tensor 
$\tau_{i j}$

$\tau_{x z}, \tau_{y z} \quad$ vertical shear components in the horizontal plane

$\tau_{I I} \quad$ effective stress

$\tau_{b}$

$\tau_{b}^{x}, \tau_{b}^{y} \quad$ basal drag in the superscripted direction

$\tau_{d}$

$\phi$

$\Lambda$

$\Phi$

$\Phi_{i}$

$\Omega$

$\Omega_{V}$ driving stress

coefficient representing ice stiffness

Lagrange-multiplier vector

heat source term

basis functions

model domain

model domain where ice volume above floatation is present 


\subsection{INTRODUCTION}

Recently, much Antarctic research has been focused on the marine terminating glaciers of the West Antarctic Ice Sheet (WAIS) (e.g. Anandakrishnan et al., 2007; Bindschadler et al., 2001; Gudmundsson, 2006; Joughin and Tulaczyk, 2002; Pollard and DeConto, 2009; Ross et al., 2012). The glaciers of the Amundsen Sea Embayment (ASE) have been of particular interest due to their physical setting that includes beds on a regional reverse slope (e.g. Holt et al., 2006; Joughin et al., 2014; Parizek et al., 2013; Rignot, 2001; Rignot et al., 2014; Shepherd et al., 2002). The presence of a reverse slope means the bedrock on which the glaciers lie dips landward such that it becomes deeper inland. This creates the potential for rapid, unstable ice mass loss and grounding line retreat according to the Marine Ice Sheet Instability Hypothesis (Mercer, 1978). In flowline models, no steady state grounding line positions can be obtained over reverse bed slopes (Schoof, 2007; Weertman, 1974).

Two (horizontal) dimensional grounding lines are more complicated than the 1dimensional case examined in flowline models. This is because the plan-view shape of the ice shelf generates resistive stresses that balance part of the gravitational driving stress, reducing longitudinal stresses at the grounding line. If the longitudinal stresses are sufficiently reduced, a steady state grounding line may be found on a reverse slope (Dupont and Alley, 2005; Goldberg et al., 2009; Gudmundsson et al., 2012). This is often called ice shelf buttressing although the analogy to an engineering buttress is inappropriate as a compressional term opposing longitudinal stretching is not involved. Whether or not a steady state configuration exists depends on the width of the floating ice 
shelf, traction at the base of the grounded ice, and of course environmental boundary conditions such as the surface accumulation rate. This current work examines the generation and propagation of an ice sheet instability over a reverse slope using a twodimensional depth integrated numerical model.

\subsection{Physical Setting}

The WAIS is one of three distinct regions of Antarctic ice, along with the ice caps, mountain glaciers, and ice shelves of the Antarctic Peninsula and the very large East Antarctic Ice Sheet (King and Turner, 2007). The WAIS covers about 15\% of the continent (King and Turner, 2007), has a volume of approximately 2 million $\mathrm{km}^{3}$, and is estimated raise the global sea level by about 4.3 meters if converted entirely to water (Fretwell et al., 2013). The WAIS is separated from the East Antarctic Ice Sheet (EAIS) by the Transantarctic Mountains (TAM) and adjoined to the Antarctic Peninsula (Figure $1)$.

These three glaciated regions are distinguished by the tectonic history of the underlying continent and sea floor (Anderson, 1999). East Antarctica is comprised of thick Precambrian to Ordovician basement of igneous and sedimentary rocks, locally overlain by younger sedimentary rocks, and intruded by igneous and volcanic rocks of various ages. Together, these form the East Antarctic Shield except near its western edge where it is underlain by a Paleozoic mobile belt terminating at the TAM (Anderson, 1999). West Antarctica is underlain by four microplates (Dalziel and Lawver, 2001; Mukasa and Dalziel, 2000). These crustal blocks have moved relative to each other and 
East Antarctica since the breakup of Gondawana in the early Jurassic to their present day configuration (Anderson, 1999; Cande et al., 2000; Mukasa and Dalziel, 2000). The mountainous Antarctic Peninsula is underlain by a single block that has experienced

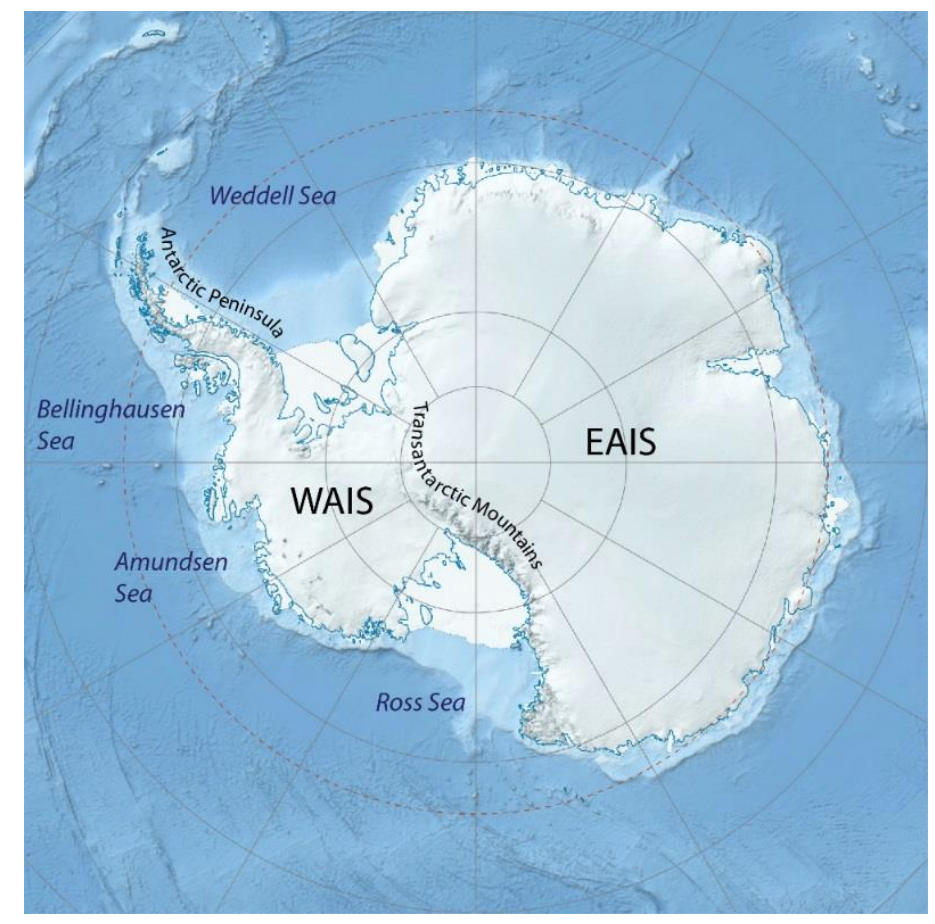

Figure 1. The West Antarctic Ice Sheet is adjoined to the Antarctic Peninsula and separated from the larger EAIS by the Transantarctic Mountains. The continental shelf is seen in light blue surrounding the continent. Adapted from a University of Texas Institute for Geophysics figure.

phases of subduction due to a convergent margin near its western edge since the middle Jurassic (Anderson, 1999). Outlet, valley, and piedmont glaciers are prevalent in this region (Anderson, 1999). The remainder of West Antarctica has been in an extensional tectonic regime forming a rift system as the blocks moved relative to each other with some rifts active into the Cenozoic (Anderson, 1999; Behrendt, 1999; Cande et al., 2000). 
The former rift system underlying the WAIS has implications for ice dynamics. Continental crust is thinner here than in East Antarctica. In fact, the majority of the EAIS except near the coast is a high plateau that is grounded well above sea level due to the thick crust on which it lies (Anderson, 1999). This is not the case for the WAIS which is termed a marine ice sheet because the majority of the bed on which it rests is well below sea level. Prior to glaciation, most of the region was below sea level and as a result, is blanketed by poorly consolidated marine sediments. The sediments can contribute to fast ice flow rates due either to the high basal water pressure it supports or to deformation within the sediment itself (Cuffey and Paterson, 2010). Another consequence of thinner crust evolved in an extensional setting is relatively high heat flux into the base of the WAIS. One research team found that heat fluxes increase from $51 \mathrm{~mW} / \mathrm{m}^{2}$ in East Antarctica to $68 \mathrm{~mW} / \mathrm{m}^{2}$ near the coast in West Antarctica (Llubes et al., 2006). This has implications for flow as it increases the likelihood of melting at the base of the ice sheet and because the deformation rate of ice is strongly dependent on temperature (Cuffey and Paterson, 2010). Complicated subglacial hydrologic networks have been observed in many parts of the WAIS (Carter et al., 2011; Carter et al., 2013; Rémy and Legresy, 2004). Finally, the generally lower surface elevations of the WAIS as compared to the other Antarctic ice regions allow higher snow accumulation rates farther inland, as the lack of topographic barriers can allow cyclones to more readily move toward the interior of the WAIS (King and Turner, 2007).

Ice flow within the WAIS is generally convergent to ice streams (Bindschadler et al., 2001). Ice divides form three distinct regional catchments that are named after the 
seas into which the ice flows: the Weddell Sea sector, the Amundsen Sea sector, and the Ross Sea sector. The focus here is on the Amundsen Sea (AS) sector (Figure 2).

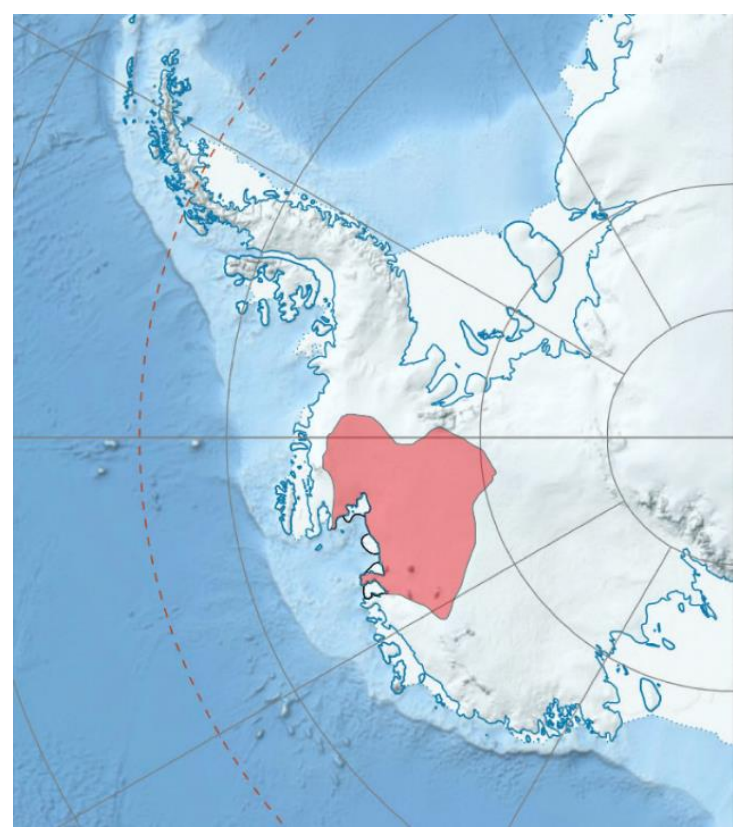

Figure 2. The location of the Amundsen Sea sector catchment area is shown in red. Note that the areas of white between the red region and ocean are showing small ice shelves and the Thwaites Glacier Tongue.

The geography and mass balance of the AS region are two factors that distinguish it from the other WAIS sectors. The subglacial topography of the AS region includes deep channels that connect coastal outlets to the interior of the ice sheet (Goff et al., 2014; Holt et al., 2006). This suggests ice flow in these areas may more resemble isbrae in Greenland than the ice streams in the Ross Sea sector of West Antarctica (Truffer and Echelmeyer, 2003). Also, the AS is much less embayed than the margins on the Ross and Weddell Seas (Figure 1). This geometry suggests that the formation of very large ice shelves, which affect stress balance at the grounding line, are not likely here (Parizek et 
al., 2013). However, small ice shelves and the Thwaites ice tongue exist today at the marine margin in the ASE (Figure 2). The continental shelf near the ASE narrows from over $400 \mathrm{~km}$ north of Pine Island Bay to between 100 and $200 \mathrm{~km}$ west of Siple Island (Nitsche et al., 2007). This is important because relatively warm Modified Circumpolar Deep Water (MCDW) is found near continental shelf breaks around the majority of the continent (Dinniman et al., 2012).

The snow accumulation rate is higher over the AS sector than elsewhere in West Antarctica because it is at the end of a major storm track that begins in the mid-latitudes and directs relatively moist air to the region (King and Turner, 2007). However, the rate of new mass accumulation over much of the AS sector has not kept pace with increasing ice discharge. The net effect of the imbalance is thinning of glaciers and grounding line retreat (Rignot et al., 2014; Shepherd et al., 2002). Today, the AS sector is one of the most rapidly changing regions in Antarctica (Parizek et al., 2013; Rignot, 2008; Rignot et al., 2002; Shepherd et al., 2012; Shepherd and Wingham, 2007; Thomas et al., 2004; Wåhlin et al., 2010).

The physical setting of the AS sector must influence the recent mass loss. The lack of a large ice shelf and the proximity of MCDW exposes the ice front to climate forcings such as ocean variability and ocean warming (Gille, 2014; Pritchard et al., 2009) and indeed, the intrusion of relatively warm MCDW beneath the small ice shelves is thought to be driving present changes in the ASE (Shepherd et al., 2004). The geomorphology of the bed beneath the grounded ice will determine how the interior responds to that forcing. 


\subsection{Climate Context}

The expected future high atmospheric $\mathrm{CO}_{2}$ world is one in which the WAIS will be smaller than at present and may retreat to isolated ice caps and mountain glaciers (Golledge et al., 2012; Naish et al., 2009; Pollard and DeConto, 2009). According to the physics as it is understood, the change will be driven from the sea, but may also involve warming in the atmosphere above (Mayewski et al., 2009; Nowicki et al., 2013). As deglaciation proceeds, sea level will rise, sea ice extent will change, and the circulation of both the ocean and the atmosphere will be modified. These changes will affect Antarctic ecosystems and will propagate northward through the climate system (Ainley et al., 2005; Smith et al., 1999; Trathan et al., 2007). What is less clear, however, is at what rate key changes will take place. Both direct observation and paleoclimate proxies show that rates in cryosphere systems are not uniform over time, a situation that confounds direct comparison between observations and climate models, and that makes understanding sources of variability in the coupled ice — ocean — atmosphere system of particular scientific and social relevance.

The rate at which the WAIS responds to climate forcing depends on a set of processes and process interactions involving ice, ocean, atmosphere, and the terrestrial subglacial environment. Substantial gaps exist in the scientific understanding of most of these. This is the case because direct observation in the Antarctic is challenging and because time and spatial scales of observation are often mismatched with the fundamental scales of the underlying processes. Nevertheless, model projections of future change are 
of critical importance and are routinely produced (Goelzer et al., 2013; Golledge et al., 2015; Nowicki et al., 2013). Here I focus on the subglacial environment of Thwaites Glacier in the AS sector of the West Antartica, and in particular the influence of (estimated) bed morphology on model projections. As the shape of the ice sheet base is inferred from geophysical observations, many realizations are possible and thus, many ice sheet model outcomes are also possible.

\subsection{Glaciological Context}

The WAIS is thought to be particularly prone to rapid mass loss due to its marine setting. The grounded inland ice sheet rests on an inland-deepening bed and terminates in a deeply embayed floating ice shelf. The marine ice sheet instability hypothesis first put forward in the 1970s holds that a perturbation causing thinning of ice at the transition from grounded to floating ice could yield runaway retreat of that boundary (Mercer, 1978). In brief: when ice upstream of the grounding line thins and goes afloat, it can flow more rapidly than was previously possible, generating additional thinning and additional speedup at the grounding line. The dynamical connection between floating and grounded ice is particularly strong because the ice sheet is drained by fast-flowing ice streams that, due to the unconsolidated, water saturated sediments over which they flow, are only weakly coupled to the bed (Bougamont et al., 2003).

The grounding zone is the gateway through which terrestrial ice must pass before entering the floating ice shelf and contributing to sea level. The geographic setting of the grounding zone influences the rate at which ice flows through this gateway such that any 
processes influencing its position must be well understood if credible assessments of ice sheet vulnerability to warming and likely future rates of change are to be made.

In a real-world setting, the transition from grounded to floating ice occurs as ice passes over a strip of bed, hence the term grounding zone. However, it is conceptually simpler to discuss processes related to this zone by expressing it in terms of a line. Models treat the grounding zone as a line, and any reference in this work to a grounding line implies grounding zone.

\subsection{Research Question}

Accurately modeling marine ice sheet response to environmental forcing requires good fidelity to a variety of physical processes. The importance of grounding line dynamics and downstream processes like ice shelf basal melting are widely addressed. My focus is directed upstream to the influence of bed morphology on ice sheet retreat. This is accomplished using accurate sub-kilometer scale topographic data and a highresolution ice sheet model with appropriate grounding line physics.

My primary goal is to understand how and why the more realistic bed geometry affects model behavior and projections of future change. I use the same type of forcing as prior work on the Thwaites and Pine Island Glacier systems - parameterized warm water incursion beneath the floating glacier terminus - and compare the resulting ice sheet retreat across simulations using different basal elevation data sets. This allows me to consider how representation of the bed affects the simulation. 


\subsection{METHODS}

The transition from grounded (ice flowing over bedrock) to floating (ice flowing over water) is also a transition in flow regime. On the floating side, basal shear stress is very small, so that vertical shearing does not occur and the stress balance is dominated by horizontal shear and normal stresses. On the grounded side, basal traction ranges from small but non-zero to nearly equal the gravitational driving stress and so vertical shearing ranges from negligible to dominant in the balance of stresses, with horizontal shear and normal stresses making up the rest of the balance (Cuffey and Paterson, 2010). The relative magnitudes of the stresses depend on spatially variable conditions such as properties of the basal material and bed morphology. The physics necessary to reasonably model grounding line retreat must accommodate flow regime on either side of the transition, as well as the transition itself.

The flow of ice can be described by a system of partial differential equations. Such a system is derived from conservation laws (governing equations) and constitutive equations and can be solved, at least through numerical approximations, with the addition of boundary and initial conditions. A very brief description of the governing equations and constitutive relationships that lead to ice flow approximations is provided in this section. In order to provide context, some of the more widely used approximations for fast flowing regimes such as Thwaites Glacier are shown. The hybrid approximation implemented in the model used here is discussed at the beginning of the 2.5 Numerical Model section. 


\subsection{Governing Equations}

Ice is a viscous, non-Newtonian fluid. Like all fluids it must obey the conservation laws of mass, energy, and momentum. In all cases, ice deformation is treated as an irrotational flow of an incompressible fluid.

The general form of mass conservation is:

$$
\frac{\partial \rho}{\partial t}+\nabla \cdot \rho \mathbf{u}=0
$$

where $\rho$ represents ice density and $\mathbf{u}$ represents the velocity vector in three Cartesian dimensions. Boldface is used to indicate a vector-valued quantity.

Incompressibility leads to:

$$
\nabla \cdot \mathbf{u}=0
$$

Equation (2.1.2) can be vertically integrated using the Leibniz integral rule to obtain mass continuity for ice thickness in terms of mass flux divergence and melting \& freezing:

$$
\frac{\partial H}{\partial t}=-\nabla \cdot(\overline{\mathbf{u}} H)+\dot{b}-\dot{a}
$$

where $H$ represents ice thickness, $\dot{b}$ represents melting or freezing rate at the base, and $\dot{a}$ represents accumulation or ablation rate at the surface. The overbar indicates a depthaveraged value.

Following Fourier's law of heat conduction, the equation for the conservation of energy can be written as:

$$
\rho c \frac{\partial T}{\partial t}=k \frac{\partial^{2} T}{\partial z^{2}}-\rho c \mathbf{u} \cdot \nabla T+\Phi
$$


where $T$ represents temperature, $c$ represents the ice heat capacity, $k$ represents the ice thermal conductivity, and $\Phi$ is a heat source term. The first term on the right represents vertical heat diffusion, the second term represents advection, while the third heat source term may include viscous dissipation and latent heat (freezing). The small aspect ratio of ice sheets, about $10^{-3}$, means that horizontal diffusion may be neglected (Cuffey and Paterson, 2010). The material properties $c$ and $k$ are temperature-dependent (Cuffey and Paterson, 2010).

The Navier-Stokes equation for the conservation of linear momentum is:

$$
\rho \frac{d \mathbf{u}}{d t}=-\nabla p+\nabla \cdot \boldsymbol{\tau}+\mathbf{f}
$$

where $p$ represents pressure, $\boldsymbol{\tau}$ is the deviatoric stress tensor, and $\mathbf{f}$ represents the body force acting on the ice. The effective force of gravity, $\rho \mathbf{g}$, and the Coriolis force, which is an inertial force, comprise $\mathbf{f}$. However, scaling arguments lead to simplifications of the complete Navier-Stokes equation for conservation of linear momentum using typical values for the horizontal and vertical ice sheet extent, the typical horizontal and vertical flow velocities, typical pressure, and typical time-scale (Greve and Blatter, 2009). The Froude number, a ratio involving acceleration and pressure gradient, is about $10^{-15}$ in the horizontal direction and about $10^{-21}$ in the vertical direction. The acceleration term on the left-hand side of equation (2.1.5) is very small compared to the viscous terms on the right so it is neglected. Similarly, a scaling argument is used to estimate the ratio between the Coriolis force and pressure gradient is about $5 \times 10^{-8}$, which is still very small compared 
to viscous terms. As a result, the Coriolis force inertial term is also neglected and the equation for the conservation of linear momentum for ice is:

$$
-\nabla p+\nabla \cdot \boldsymbol{\tau}+\rho \mathbf{g}=0
$$

where $\mathbf{g}$ represents the acceleration due to gravity. Equation (2.1.6) describes what is known as Stokes flow (Greve and Blatter, 2009).

\subsection{Constitutive Equations}

Ice sheets are in static equilibrium even while in motion, as expressed in equation (2.1.6) (Cuffey and Paterson, 2010). This balance is often represented in terms of driving and resisting stresses. The divergence of the stress deviator in equations (2.1.5) and (2.1.6) can be written using the effective fluid viscosity, $\eta$.

$$
\nabla \cdot \tau=\eta \nabla^{2} \mathbf{u}
$$

and the viscosity, then, should be written in terms of the effective strain rate.

A constitutive relation between stress and strain is needed. For an incompressible, isotropic material, each strain rate component must be proportional to its corresponding deviatoric stress component. Treating ice as such a material leads to the power-law relation known as the generalized Glen's Law or the Nye-Glen Isotropic Law:

$$
\dot{\varepsilon}_{i j}=A \tau_{I I}^{n-1} \tau_{i j} \quad i, j \in\{x, y, z\}
$$

where $\dot{\varepsilon}_{i j}$ is a component of the strain rate tensor and $\tau_{i j}$ is a component of the deviatoric stress tensor. The second invariant of the deviatoric stress tensor is known as the effective deviatoric stress, $\tau_{I I}$. The exponent in the flow law, $n$, is usually 3 . The rate factor $A$ is 
a spatially variable parameter that is strongly dependent on temperature and fabric of the ice. This temperature dependence is described by an Arrhenius relationship with different constants above and below $263 \mathrm{~K}$ (Cuffey and Paterson, 2010). Some of the pioneering work for the flow relation in equation (2.2.2) was accomplished by Nye who proposed that:

$$
\dot{\varepsilon}_{I I}=A \tau_{I I}^{n}
$$

where once again the subscript $I I$ denotes the second invariant or effective strain rate and effective deviatoric stress respectively (Cuffey and Paterson, 2010). Considering equations (2.2.2) and (2.2.3), deviatoric stress can be written as:

$$
\tau_{i j}=A^{-(1 / n)} \dot{\varepsilon}_{I I}^{(1-n) / n} \dot{\varepsilon}_{i j}
$$

The flow relation in equation (2.2.2) can be written in the inverse form and expressed in terms of effective viscosity and strain rate as:

$$
\tau_{i j}=2 \eta \dot{\varepsilon}_{i j}
$$

Setting the right side of equation (2.2.5) equal to the right side of equation (2.2.4), the effective viscosity of ice may be expressed as:

$$
\eta=\frac{1}{2} A^{-(1 / n)} \dot{\varepsilon}_{I I}^{(1-n) / n}
$$

This shows that viscosity decreases (ice softens) with increasing strain rate, which is analogous to increasing deviatoric stress, and that viscosity is strongly dependent on ice temperature and fabric. 


\subsection{Ice Flow Approximations}

The incompressibility equation (2.1.2) and force balance represented by the conservation of momentum in equation (2.1.6) comprise the field equations that describe ice flow. Using the relation between strain rate and velocity shown here in tensor notation:

$$
\dot{\varepsilon}_{i j}=\frac{1}{2}\left(\frac{\partial u_{i}}{\partial x_{j}}+\frac{\partial u_{j}}{\partial x_{i}}\right)
$$

and the constitutive relationship between stress and strain in Glen's Law leads to the following 3D representation known as the full-Stokes model:

$$
\left\{\begin{array}{c}
\frac{\partial}{\partial x}\left(2 \eta \frac{\partial u_{x}}{\partial x}\right)+\frac{\partial}{\partial y}\left(\eta \frac{\partial u_{x}}{\partial y}+\eta \frac{\partial u_{y}}{\partial x}\right)+\frac{\partial}{\partial z}\left(\eta \frac{\partial u_{x}}{\partial z}+\eta \frac{\partial u_{z}}{\partial x}\right)-\frac{\partial p}{\partial x}=0 \\
\frac{\partial}{\partial x}\left(\eta \frac{\partial u_{x}}{\partial y}+\eta \frac{\partial u_{y}}{\partial x}\right)+\frac{\partial}{\partial y}\left(2 \eta \frac{\partial u_{y}}{\partial y}\right)+\frac{\partial}{\partial z}\left(\eta \frac{\partial u_{y}}{\partial z}+\eta \frac{\partial u_{z}}{\partial y}\right)-\frac{\partial p}{\partial y}=0 \\
\frac{\partial}{\partial x}\left(\eta \frac{\partial u_{x}}{\partial z}+\eta \frac{\partial u_{z}}{\partial x}\right)+\frac{\partial}{\partial y}\left(\eta \frac{\partial u_{y}}{\partial z}+\eta \frac{\partial u_{z}}{\partial y}\right)+\frac{\partial}{\partial z}\left(2 \eta \frac{\partial u_{z}}{\partial z}\right)-\frac{\partial p}{\partial z}-\rho g=0 \\
\frac{\partial u_{x}}{\partial x}+\frac{\partial u_{y}}{\partial y}+\frac{\partial u_{z}}{\partial z}=0
\end{array}\right.
$$

where $\eta$ is effective viscosity, $p$ is the ice pressure, $g$ is the acceleration due to gravity and $u_{x}, u_{y}$, and $u_{z}$ are the three Cartesian components of velocity. This system, including the strain-rate dependent viscosity, is computationally challenging. Due to this, glacier and ice sheet modelers take advantage of scaling arguments and boundary conditions to reduce the order of the equations.

Various simplifications have been developed that depend on assumptions about stress boundary conditions and relative magnitudes of stress gradients in the ice (see 
Hindmarsh, 2004; Hutter, 1983; MacAyeal, 1989; Morland, 1985). The Blatter-Pattyn first order ice sheet model makes the assumption that the horizontal derivatives of the vertical velocity component are negligible (Blatter, 1995; Pattyn, 2003):

$$
\frac{\partial u_{z}}{\partial x} \approx 0 \text { and } \frac{\partial u_{z}}{\partial y} \approx 0
$$

Furthermore, bridging effects are considered negligible so that the vertical momentum balance at a location is independent of horizontal coordinates. This means that the horizontal components of velocity may be uncoupled from the system leading to the following system of equations:

$$
\left\{\begin{array}{l}
\frac{\partial}{\partial x}\left(2 \eta \frac{\partial u_{x}}{\partial x}\right)+\frac{\partial}{\partial y}\left(\eta \frac{\partial u_{x}}{\partial y}+\eta \frac{\partial u_{y}}{\partial x}\right)+\frac{\partial}{\partial z}\left(\eta \frac{\partial u_{x}}{\partial z}\right)=\rho g \frac{\partial s}{\partial x} \\
\frac{\partial}{\partial x}\left(\eta \frac{\partial u_{x}}{\partial y}+\eta \frac{\partial u_{y}}{\partial x}\right)+\frac{\partial}{\partial y}\left(2 \eta \frac{\partial u_{y}}{\partial y}\right)+\frac{\partial}{\partial z}\left(\eta \frac{\partial u_{y}}{\partial z}\right)=\rho g \frac{\partial s}{\partial y}
\end{array}\right.
$$

where $s$ is the surface elevation and as an input it can be determined by the ice thickness evolution equation (2.1.3). This also simplifies the constitutive relations between stress, strain, and viscosity, equations (2.2.2) through (2.2.6), so that now they only depend on the horizontal velocity components. After solving for the horizontal velocities, the vertical velocity component may be determined by vertical integration of:

$$
\frac{\partial u_{z}}{\partial z}=-\frac{\partial u_{x}}{\partial x}-\frac{\partial u_{y}}{\partial y}
$$

The MacAyeal-Morland "shelfy-stream" equations, which are also known as the shallow-shelf approximation (SSA), takes the first order model one step further. For this ice flow approximation, vertical shear is treated as negligible so that: 


$$
\frac{\partial u_{x}}{\partial z} \approx 0 \text { and } \frac{\partial u_{y}}{\partial z} \approx 0
$$

(MacAyeal, 1989; Morland, 1985). This leads to the following model that when integrated yields the horizontal components of velocity:

$$
\left\{\begin{array}{l}
\frac{\partial}{\partial x}\left(4 H \bar{\eta} \frac{\partial u_{x}}{\partial x}+2 H \bar{\eta} \frac{\partial u_{y}}{\partial y}\right)+\frac{\partial}{\partial y}\left(H \bar{\eta} \frac{\partial u_{x}}{\partial y}+H \bar{\eta} \frac{\partial u_{y}}{\partial x}\right)=\rho g H \frac{\partial s}{\partial x}-\tau_{b}^{x} \\
\frac{\partial}{\partial y}\left(4 H \bar{\eta} \frac{\partial u_{y}}{\partial y}+2 H \bar{\eta} \frac{\partial u_{x}}{\partial x}\right)+\frac{\partial}{\partial x}\left(H \bar{\eta} \frac{\partial u_{x}}{\partial y}+H \bar{\eta} \frac{\partial u_{y}}{\partial x}\right)=\rho g H \frac{\partial s}{\partial x}-\tau_{b}^{y}
\end{array}\right.
$$

where $\bar{\eta}$ is the depth-averaged viscosity, $H$ is ice thickness, and $\tau_{b}$ is the basal drag in the superscripted direction.

\subsection{Boundary Conditions}

Suitable boundary conditions must be applied in order to solve any system of equations describing ice motion. Kinematic boundary conditions are applied at impermeable boundaries, and define the conditions where fluid flow normal to the boundary must be zero at a stationary boundary or equal to the velocity of a moving boundary normal to itself. The first case essentially describes the situation for a solid/fluid boundary such as that at the bedrock/ice interface while the second case can describe the situation for a fluid/fluid boundary such as that at the atmosphere/ice interface. The derivation and application of kinematic boundary conditions at the ice surface and ice base will now be discussed in greater detail.

If the boundary at the free surface (atmosphere/ice interface) is defined by the implicit equation 


$$
B_{s}(\mathbf{x}, t)=z-h(x, y, t)=0
$$

where $z$ is a vertical coordinate, $t$ is time, and $h$ is the $z$-coordinate of the ice surface (Greve and Blatter, 2009) then, equation (2.4.1) describes a zero-equipotential surface where the unit normal vector pointing toward the atmosphere is defined as

$$
\mathbf{n}=\frac{\nabla B_{s}}{\left|\nabla B_{s}\right|}=\left(\left(\frac{\partial h}{\partial x}\right)^{2}+\left(\frac{\partial h}{\partial y}\right)^{2}+1\right)^{-1 / 2}\left[\begin{array}{c}
-\frac{\partial h}{\partial x} \\
-\frac{\partial h}{\partial y} \\
1
\end{array}\right]
$$

As flow evolves, particles can only remain on $B_{s}$ if

$$
\frac{D B_{s}}{D t}=\frac{\partial B_{s}}{\partial t}+\mathbf{w} \cdot \nabla B_{s}=0
$$

where $\frac{D}{D t}$ is the notation for the material derivative and $\mathbf{W}$ represents the velocity of the free surface. An ice volume flux perpendicular to the free surface can be specified by letting $\mathbf{u}_{s}$ equal the surface velocity in the mass balance equation:

$$
a^{\perp}=\left(\mathbf{w}-\mathbf{u}_{s}\right) \cdot \mathbf{n}
$$

For this surface mass balance equation, the sign is typically chosen such that accumulation is positive and ablation is negative. Now equation (2.4.3) can be rewritten using equation (2.4.2) and the definition provided by equation (2.4.4) as

$$
\frac{\partial B_{s}}{\partial t}+\nabla B_{s} \cdot \mathbf{u}_{s}=-\left|\nabla B_{s}\right| a^{\perp}
$$

which, using $B_{s}=z-h$ and the definitions in equation (2.4.2), is equivalent to 


$$
\frac{\partial h}{\partial t}+u_{s}^{x} \frac{\partial h}{\partial x}+u_{s}^{y} \frac{\partial h}{\partial y}-u_{s}^{z}=a_{s}^{\perp} \sqrt{\left(\frac{\partial h}{\partial x}\right)^{2}+\left(\frac{\partial h}{\partial y}\right)^{2}+1}
$$

in which a superscript on a vector component indicates the Cartesian coordinate direction. This is the kinematic boundary condition for the freely evolving surface of an ice sheet (Greve and Blatter, 2009).

The dynamic boundary condition for the free surface is derived from a momentum jump condition. Since the atmospheric stress is small compared to typical stresses in an ice sheet and ice flow velocities are small, the end result is the stress-free condition

$$
\boldsymbol{\sigma} \cdot \mathbf{n}=0
$$

for the surface (Greve and Blatter, 2009).

Additionally, thermodynamic boundary conditions are required for the energy equation (2.1.4). This is accomplished by specifying the surface temperature $T_{s}$,

$$
T=T_{s}
$$

which can be approximated in sub-zero $\left({ }^{\circ} \mathrm{C}\right)$ regions by the mean annual surface temperature (Greve and Blatter, 2009). Similarly, if the basal temperature is at the pressure melting point, the basal temperature can be specified as

$$
T=T_{m}
$$

where the subscript $m$ indicates the pressure melting point.

The kinematic boundary condition for the ice base is derived in a similar manner to that of the free surface. The normal vector points into the bedrock, so that the components of the gradient at the boundary between ice and bedrock $\nabla B_{b}$ have the 
opposite sign than in equation (2.4.2). Similarly, the ice volume flux perpendicular to the basal boundary is

$$
b^{\perp}=\left(\mathbf{u}_{s}-\mathbf{w}\right) \cdot \mathbf{n}
$$

so that positive values for $b^{\perp}$ indicate mass loss due to basal melting.

Since the normal component of ice velocity vanishes at the basal boundary in the same manner as the free surface, the end result for the basal kinematic boundary condition is analogous to equations (2.4.5) and (2.4.6) (respectively):

$$
\frac{\partial B_{b}}{\partial t}+\nabla B_{b} \cdot \mathbf{u}_{b}=-\left|\nabla B_{b}\right| b^{\perp}
$$

and

$$
\frac{\partial b}{\partial t}+u_{b}^{x} \frac{\partial b}{\partial x}+u_{b}^{y} \frac{\partial b}{\partial y}-u_{b}^{z}=a_{b}^{\perp} \sqrt{\left(\frac{\partial h}{\partial x}\right)^{2}+\left(\frac{\partial h}{\partial y}\right)^{2}+1}
$$

where the subscript $b$ indicates the base and superscripts indicate the Cartesian coordinate direction for $u$-velocity components.

The upper and lower surfaces may have any orientation relative to the fixed coordinate system and the fluxes perpendicular to the free surface and ice base can be written in terms of the vertical coordinate as

$$
\dot{a}=\left|\nabla B_{s}\right| a^{\perp}
$$

for accumulation and ablation rates, and

$$
\dot{b}=\left|\nabla B_{b}\right| b^{\perp}
$$


for basal melt rate. With these fluxes in the vertical direction, these kinematic boundary conditions can be used with the Leibniz integral rule to form the mass continuity equation (2.1.3) as previously mentioned.

The momentum jump condition for the basal interface is simplified once again as the advective ice flow term is small, so that

$$
\boldsymbol{\sigma} \cdot \mathbf{n}=\boldsymbol{\sigma}_{\text {lith }} \cdot \mathbf{n}
$$

where $\boldsymbol{\sigma}_{\text {lith }}$ indicates lithospheric stresses. Equation (2.4.15) shows continuity of the stress vector across the interface, but this is inadequate for a dynamic boundary condition as it provides no information about the stress regime in the underlying material (Greve and Blatter, 2009). Stress state and deformation in the subglacial material is a topic of ongoing research and various parameterizations are used to represent the effect of the material on ice flow (Bougamont et al., 2015; Bougamont et al., 2011). In the model implemented here, sliding creates resistance according to a viscous law (Cornford et al., 2015). The resulting basal traction term, $\tau_{b}$, is spatially variable according to the motion of the ice and a coefficient $C$ that represents basal properties

$$
\tau_{b}=\left\{\begin{array}{rr}
-C|u|^{l-1} u & \text { if } \frac{\rho_{i}}{\rho_{w}} H>-r \\
0 & \text { otherwise }
\end{array}\right.
$$

The coefficients $C$ are determined during model initialization by the adjoint equations. For this equation, $l=1$ and $r$ represents the bedrock elevation below sea level. 


\subsection{Numerical Model}

The Berkeley Ice Sheet Initiative for Climate at Extreme Scales (BISICLES) ice sheet model is used here. BISICLES applies a block-structured finite volume method with adaptive mesh refinement (AMR) to solve the governing equations for ice sheet dynamics (Cornford et al., 2013). The momentum equations are simplified using the Schoof-Hindmarsh model (Cornford et al., 2013). As this approximation was similar to the SSA at the time the modeling in this paper took place, it is hereafter informally referred to as $\mathrm{SSA}^{*}$. SSA* is like other approaches that make use of the small aspect ratio and near-zero basal traction, but treats the effective viscosity differently. In brief, the deviatoric stress tensor $\boldsymbol{\tau}$ is split into a tensor representing the horizontal and vertical normal components together with the horizontal shear, and a tensor representing the vertical shear components. The first tensor is the usual case of the MacAyeal-Morland SSA. In the case of a near-zero basal shear condition, the second tensor is very small, compared to the first, and may be neglected when computing velocity terms. It is, however, of use in computing the effective viscosity. For that purpose, vertical shear components are computed using the shallow ice approximation of Hutter (1983) and Morland (1984)

$$
\left\{\begin{array}{l}
\tau_{x z}=-\rho g(h-z) \frac{\partial h}{\partial x} \\
\tau_{y z}=-\rho g(h-z) \frac{\partial h}{\partial y}
\end{array}\right.
$$

in which $\tau_{x z}$ and $\tau_{y z}$ represent the vertical shear components in the horizontal plane and $z$ represents the vertical Cartesian coordinate. 
Cornford et al. (2013) tested the SSA* model using steady-state grounding line experiment for an ice stream with a simple geometry. Comparison against a full-Stokes solution showed that the modification increased the accuracy of a steady-state grounding line about 10 times over the standard SSA. Although this experiment incorporated simple ice stream and basal geometry with the assumption of isothermal ice, it does provide evidence that the SSA* approximation may be more accurate in determining grounding line position than the shelfy-stream approximation alone.

The finite volume method (FVM) is similar to both the finite difference method (FDM) and finite element methods (FEM). All three methods solve discretized governing equations over discretized domains. In particular, the governing equations of a system are solved over a structured grid for both the FVM and FDM. In contrast to the FDM in which a truncated Taylor series is used to approximate governing equations at each node, the FVM and FEM solve the integral form of the governing equations. the strong formulation is discretized for the FVM while the weak formulation is discretized for the FEM (Patankar, 1980; Price et al., 2007; Versteeg and Malalasekera, 2007).

Discretizing the domain into cells, creating control (or finite) volumes that surround grid points, and evaluating the integral strong form of governing equations over each cell is distinguish the FVM from other approximation methods (Patankar, 1980; Versteeg and Malalasekera, 2007). The numerical scheme implies that the integral conservation of a conserved quantity is exact over any number of control volumes up to and including the entire domain (Patankar, 1980; Versteeg and Malalasekera, 2007). 
Furthermore, the exact integral balances apply to a domain consisting of coarse cells or fine cells alike, not just in the limiting case of sufficiently high resolution.

The block structured AMR facilitates efficient modeling of ice sheet regions that include a grounding line. Numerical models always require compromises between resolution (and thus computation time) and convergence. Problems involving a grounding line tend to exhibit decreasing rates of convergence with increasing mesh spacing (Cornford et al., 2013). Therefore, it is desirable to have a mesh with the smallest spacing at the grounding line which quickly coarsens away from it and that is able to evolve over time as the grounding line migrates, and this is exactly what the AMR in BISICLES accomplishes

AMR in BISICLES is hierarchical with the coarsest mesh spacing on the bottom in plan view (Figure 3). The mesh spacing of a level divided by the mesh spacing of the level immediately below it is known as the refinement ratio. The refinement ratio is always an even integer and each level domain is properly nested. The stress balance equations are first solved for the coarsest level mesh and progresses upward where refinement criteria have been applied, using the previous coarser mesh solution as a starting point. Refinement criteria can be based on the Laplacian of the velocity field, 


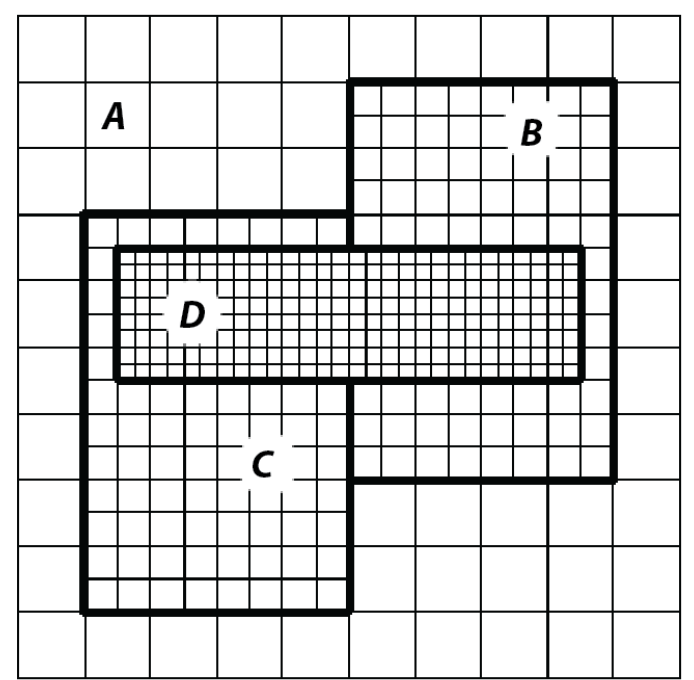

Figure 3. An example of a block-structured mesh. The first discrete level domain is comprised of the coarsest mesh labeled $A$. Overlaying this is the next discrete level domain comprised of meshes in the rectangular blocks labeled $B$ and $C$. The finest mesh comprises the discrete level domain in block $D$. The valid domain includes the subsets of discrete levels that are not overlain by other discrete levels. In other words, what one sees in plan view is the valid domain. Figure adapted from Cornford et al., 2013.

by tagging cells adjacent to the grounding line, or both (Cornford et al., 2013). However, modifications to the FVM discretization on meshes must be made to accommodate the coarse-fine boundaries separating valid regions of the domain. The flux of a vector field across a coarse-fine boundary is handled by modifying the following three discrete operators: the flux divergence term in the thickness evolution equation (2.1.3), the driving stresses on the right hand side of SSA*, which can be seen in equation (2.3.7), and the viscous terms on the left hand side of SSA*, equation (2.3.7) (Cornford et al., 2013). These modifications simply partition the flux from a coarse cell correctly into the bordering finer cells. 


\subsection{Model Domain and Boundaries}

The model domain includes the entire ASE sector, both grounded and floating ice. The boundary is the union of ice in contact with the atmosphere, ice in contact with the ocean, and ice in contact with the bed. For our simulations, ice thickness and ice surface elevation come from the standard Bedmap2 dataset (Fretwell et al., 2013). The ice accumulation field (ice equivalent surface snow accumulation), is provided in conjunction with the Bedmap2 data (Arthern et al., 2006).

Thermal boundary conditions at the base and surface derive from an estimation of spatially varying ice temperatures provided by Pattyn (2010). This dataset is used to specify an initial temperature distribution in the ice. No geothermal flux under grounded ice is specified. Instead, the model initialization technique used here accounts for the contribution to ice velocity from basal melt.

Boundary conditions are also needed for the ice shelf and lateral boundaries. For the shelf, the normal stress at the lower surface is equal to the hydrostatic water pressure (Cornford et al., 2013). At ice divides, the flow velocity normal to the divide is zero, a Dirichlet condition, while a Neumann condition is applied to the tangential velocity such that its derivative is zero (Cornford et al., 2013). A Neumann condition is applied at the calving front such that the normal stress across it is equal to the hydrostatic pressure there (Cornford et al., 2013). 


\subsection{Bed Topography}

Two realizations of the Earth surface beneath the ice sheet are used. These include a benchmark data set widely used by ice sheet modelers, and a new data set produced by colleagues associated with this research project (Goff et al., 2014).

The BEDMAP project (Fretwell et al., 2013; Lythe et al., 2001) is the cryosphere community standard suite of boundary condition data sets. The Bedmap2 topography is a $1 \mathrm{~km}$ resolution gridded dataset of subglacial topography and seabed elevation for the Antarctic region extending from the South Pole to $60^{\circ} \mathrm{S}$ (Fretwell et al., 2013). The Bedmap2 collection of gridded datasets also includes ice thickness and surface elevation. Over grounded regions and away from rock outcrops, the bed topography was created by subtracting $5 \mathrm{~km}$ gridded ice thickness data from $1 \mathrm{~km}$ gridded surface elevation data. In order to fill in detail close to outcrops, a denser $1 \mathrm{~km}$ coverage of ice thickness from a thin-ice-model was subtracted from the surface elevation data within $10 \mathrm{~km}$ of rock outcrops but not including the rock, which is an expression of surface elevation. These data were combined with ocean and sub-ice-shelf bathymetry and gridded, interpolating where necessary, to produce the final $1 \mathrm{~km}$ gridded topography (Fretwell et al., 2013).

The second realization of the subglacial bed was created by project partners at the University of Texas Institute for Geophysics (UTIG) using the same airborne radar observations of the ice surface and thickness as the Bedmap2, but with a novel computational approach. This approach summarizes the along track radar data into $250 \mathrm{~m}$ resolved bed geometries. The new $250 \mathrm{~m}$ resolution conditional simulation, combines a 
stochastic realization with a deterministic surface of the bed beneath Thwaites Glacier and its catchment area (Goff et al., 2014) (Figure 4).

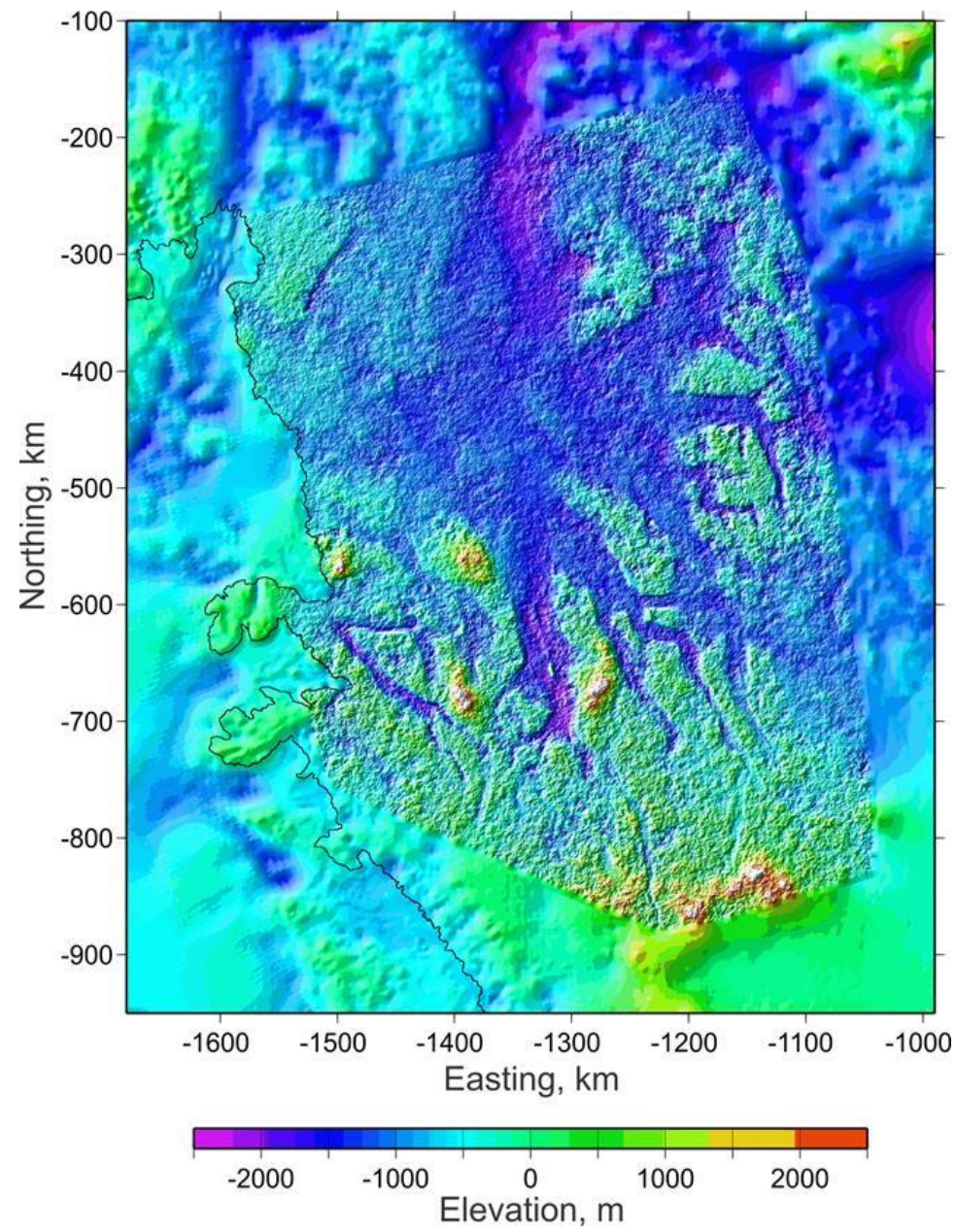

Figure 4. The new $250 \mathrm{~m}$ resolution bed of the Thwaites catchment created by UTIG researchers. This bed has been "sewn into" a $250 \mathrm{~m}$ interpolation of the Bedmap2 bed for the sake of continuity.

The aerogeophysical observations over the Thwaites catchment were interpolated to the fine grid using inhomogeneous statistics with channelized morphology and a realistic small-scale roughness to create this new bed topography (Goff et al., 2014). A conditional simulation is non-unique. It allows multiple realizations of the features that 
could lie between radar flight lines to be generated using the statistics of the features that do lie along the flight lines (Goff et al., 2014). Multiple bed models could be used to quantify uncertainty in ice sheet model projections, however, only one realization is used here. The UTIG conditional simulation will hereafter be referred to as the Goff bed, named after the bed's principal creator.

\subsection{Model Initialization}

Model initialization is based on optimal control theory, in which unknown values of parameter fields and boundary conditions are estimated using known (observed) fields and the fundamental dynamics of the model (MacAyeal, 1993). The goal is to find, as efficiently as possible, the best fit between the observed and modeled fields. A cost function that quantifies the quality of the fit is minimized by repeated estimation of the unknown parameters, that is, by iterating on those parameters. In this case, basal traction and ice stiffening coefficients, which locally modify ice viscosity, are estimated through minimization of the cost function for the BISICLES control problem (Cornford et al., 2015).

While not fully developed in the present work, a brief example of a control method application is provided here so that both the benefits and the limitations of the approach may be discussed later. In this example, basal traction coefficients are sought.

The spatially variable basal traction field $\beta(x, y)$ can be represented by an infinite two-dimensional Fourier series: 


$$
\beta(x, y)=\sum_{n=1}^{\infty} c_{i} \Phi_{i}(x, y)
$$

in which $c_{i}$ represents the expansion coefficients and $\Phi_{i}$ represents basis functions that are assumed to span the associated function space (MacAyeal, 1993). In practice, this series is truncated which is both a practical limitation and reflects the fact that distribution of observed surface velocity data may not allow $\beta(x, y)$ to be calculated beyond some spatial resolution. The cost function can be written as:

$$
J=\iint_{\Omega} \frac{1}{2}\left(u_{x}-u_{x, o b s}\right)+\frac{1}{2}\left(u_{y}-u_{y, o b s}\right) d \Omega
$$

in which the subscripted obs indicates observational data and $\Omega$ represents the domain. Considering the SSA system of equations in equation (2.3.7) and recognizing that $-\boldsymbol{\tau}_{b}=\beta^{2} \mathbf{u}=\left(\sum_{n=1}^{\infty} c_{i} \Phi_{i}\right)^{2} \mathbf{u}$, where the square is used to enforce the constraint that basal traction is positive,

$$
\begin{aligned}
f_{1}(x, y) & =\frac{\partial}{\partial x}\left(4 H \bar{\eta} \frac{\partial u_{x}}{\partial x}+2 H \bar{\eta} \frac{\partial u_{y}}{\partial y}\right)+\frac{\partial}{\partial y}\left(H \bar{\eta} \frac{\partial u_{x}}{\partial y}+H \bar{\eta} \frac{\partial u_{y}}{\partial x}\right) \\
& -\rho g H \frac{\partial s}{\partial x}-\left(c_{i} \Phi_{i}\right)^{2} u_{x}
\end{aligned}
$$

and

$$
\begin{aligned}
f_{2}(x, y)= & \frac{\partial}{\partial y}\left(4 H \bar{\eta} \frac{\partial u_{y}}{\partial y}+2 H \bar{\eta} \frac{\partial u_{x}}{\partial x}\right)+\frac{\partial}{\partial x}\left(H \bar{\eta} \frac{\partial u_{x}}{\partial y}+H \bar{\eta} \frac{\partial u_{y}}{\partial x}\right) \\
& -\rho g H \frac{\partial s}{\partial y}-\left(c_{i} \Phi_{i}\right)^{2} u_{y}
\end{aligned}
$$

The summation convention is used to drop the summation sign. 
The method of Lagrange multipliers can be used to find minima for functions like $J^{\prime}$, on which there is an outside constraint (see Bryson, 1975; MacAyeal, 1993):

$$
\begin{aligned}
J^{\prime} & =\iint_{\Omega} \frac{1}{2}\left[\left(u_{x}-u_{x, o b s}\right)+\left(u_{y}-u_{y, o b s}\right)\right] d x d y+\iint_{\Omega} \lambda(x, y) f_{1}(x, y) d x d y \\
& +\iint_{\Phi} \mu(x, y) f_{2}(x, y) d x d y
\end{aligned}
$$

where a Lagrange-multiplier vector $\Lambda=(\lambda, \mu)$ has been used.

Minimizing $J^{\prime}$ requires that the variation of $J^{\prime}$ with respect to velocity components $u_{x}, u_{y}$, expansion coefficients $\boldsymbol{c}_{i}$, and the Lagrange-multiplier components $\lambda, \mu$ be zero. A common simplification to achieve this is to ignore the relationship between effective viscosity and velocity (MacAyeal, 1993). When the SSA equations (2.3.7) are satisfied, the variation in $\lambda$ and $\mu$ is zero, and the variation of $J^{\prime}$ with respect to arbitrary variations in $u_{x}$ and $u_{y}$ is zero when the following are satisfied:

$$
\left\{\begin{array}{l}
\frac{\partial}{\partial x}\left(4 H \bar{\eta} \frac{\partial \lambda}{\partial x}+2 H \bar{\eta} \frac{\partial \mu}{\partial y}\right)+\frac{\partial}{\partial y}\left(H \bar{\eta} \frac{\partial \lambda}{\partial y}+H \bar{\eta} \frac{\partial \mu}{\partial x}\right)-\left(C_{i} \Phi_{i}\right)^{2} \lambda=\left(u_{x, o b s}-u_{x}\right) \\
\frac{\partial}{\partial y}\left(4 H \bar{\eta} \frac{\partial \mu}{\partial y}+2 H \bar{\eta} \frac{\partial \lambda}{\partial x}\right)+\frac{\partial}{\partial x}\left(H \bar{\eta} \frac{\partial \lambda}{\partial y}+H \bar{\eta} \frac{\partial \mu}{\partial x}\right)-\left(C_{i} \Phi_{i}\right)^{2} \mu=\left(u_{y, o b s}-u_{y}\right)(2.8 \\
\lambda=\mu=0 \text { on the boundary of } \Omega
\end{array}\right.
$$

Equations (2.8.6) are known as adjoint equations since they are adjoint to the linear forms of the SSA equations (2.3.7) (MacAyeal, 1993). When the variation of $J^{\prime}$ with respect to the arbitrary variations in expansion coefficients $C_{i}$ is zero a solution to the inverse problem is found, and this condition is fulfilled when

$$
\nabla J^{\prime}=0
$$


Smooth fields of basal traction coefficients, $C(x, y)$, and ice stiffening coefficients, $\phi(x, y)$, are similarly estimated by the BISICLES control problem using a nonlinear conjugate gradient method to minimize a cost function (Cornford et al., 2015). This cost function is represented as

$$
J=J_{m}+J_{p}
$$

and consists of a misfit function

$$
J_{m}=\frac{1}{2} \int_{\Omega_{V}} \alpha_{u}^{2}(x, y)\left(|\mathbf{u}|-\left|\mathbf{u}_{o b s}\right|\right) d \Omega
$$

and a Tikhonov penalty function

$$
J_{p}=\frac{\alpha_{C}^{2}}{2} \int_{\Omega_{v}}\left|\nabla C^{2}\right| d \Omega+\frac{\alpha_{\phi}^{2}}{2} \int_{\Omega_{V}}|\nabla \phi|^{2} d \Omega
$$

where the subscripted omega symbol, $\Omega_{V}$, indicates that the calculations are carried out in the domain where ice volume above floatation is present. Importantly, $\alpha_{u}^{2}(x, y)$ is a coefficient that is equal to 1 where velocity data is available and zero otherwise (Cornford et al., 2015). Both $\alpha_{C}^{2}, \alpha_{\phi}^{2}>0$ and are chosen such that lower values cause faster growth in $J_{p}$ than decay in $J_{m}$, and conversely that higher values cause a greater decay in $J_{m}$ and slower growth in $J_{p}$ (Cornford et al., 2015). Essentially, optimization is achieved by minimizing the cost function based on observed velocity and field smoothness. Where no observational velocity data is available, smoothness is principally being optimized. 
To successfully minimize equation (2.8.8) can begin, initial estimates for the fields to be optimized must be provided. These initial estimates for the basal traction and stiffening factors are represented as

$$
\begin{aligned}
& C_{0}=\left\{\begin{array}{cc}
\frac{\rho_{i} g h|\nabla s|}{\left|\mathbf{u}_{o b s}\right|+1} & \text { if } \alpha_{u}^{2}>0 \\
10^{5} & \text { otherwise }
\end{array}\right. \\
& \text { and } \phi_{0}=1
\end{aligned}
$$

while the following representations

$$
C=C_{0} e^{q} \text { and } \phi=\phi_{0} e^{p}
$$

guarantee positive definitiveness and equation (2.8.8) can be minimized with respect to $q$ and $p$ (Cornford et al., 2015).

\subsubsection{Implementation and Spatial Maps}

The BISICLES control problem is run for the entire continent over Bedmap2 topography and then again for the model domain over each bed (Figure 5). The process begins and proceeds using data comprising the geometry of the problem (bed elevation, ice thickness); ice temperature; and control data (ice velocity, initial estimates of the fields in question) to generate basal traction and ice stiffening coefficients (Figure 6, Figure 7, \& Figure 8). The sole purpose of the continental run is to establish a realistic velocity field so that the model AS catchment may be delineated and used to create the experiment model domain. This is accomplished by first subregioning a rectangular domain that includes the AS catchment. Then the velocity components are used to 
identify and exclude areas where ice is not flowing into catchment. Exclusion is accomplished by turning off flow outside the AS catchment and raising basal coefficients to a high value, $1 \times 10^{5}$. The necessary input files are then subregioned and the process is repeated to give basal traction and stiffening coefficients corresponding to the Bedmap2 and Goff beds (Figure 5). Differences in basal traction between the beds will be addressed in Section 4.1 Spatial Patterns of Difference in Driving Stress.

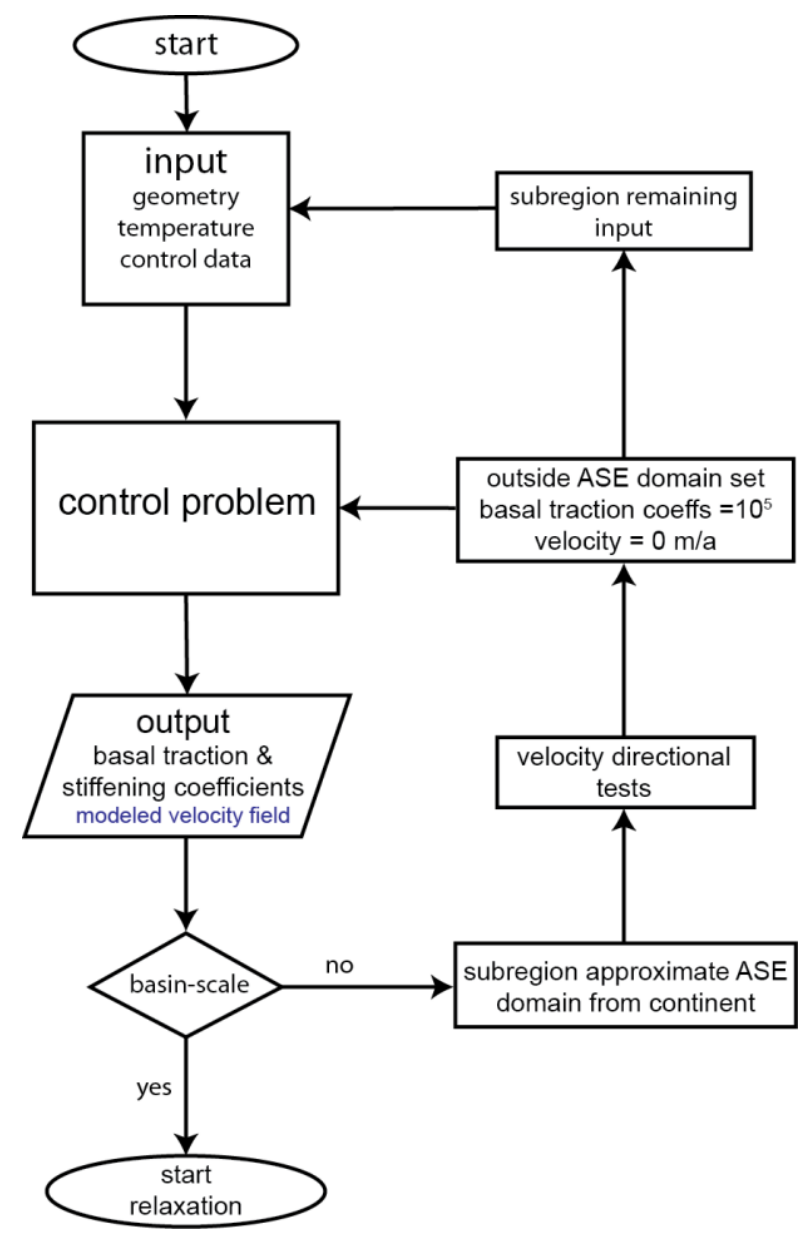

Figure 5. Flowchart showing how model initialization is implemented. The control problem is run twice; first at the continental scale then at the basin-scale. The objective of the continental control run is to obtain a realistic velocity field that can be used to delineate the ASE sector catchment basin. The basin-scale control run finalizes the basal traction and stiffening coefficients over each bed. 

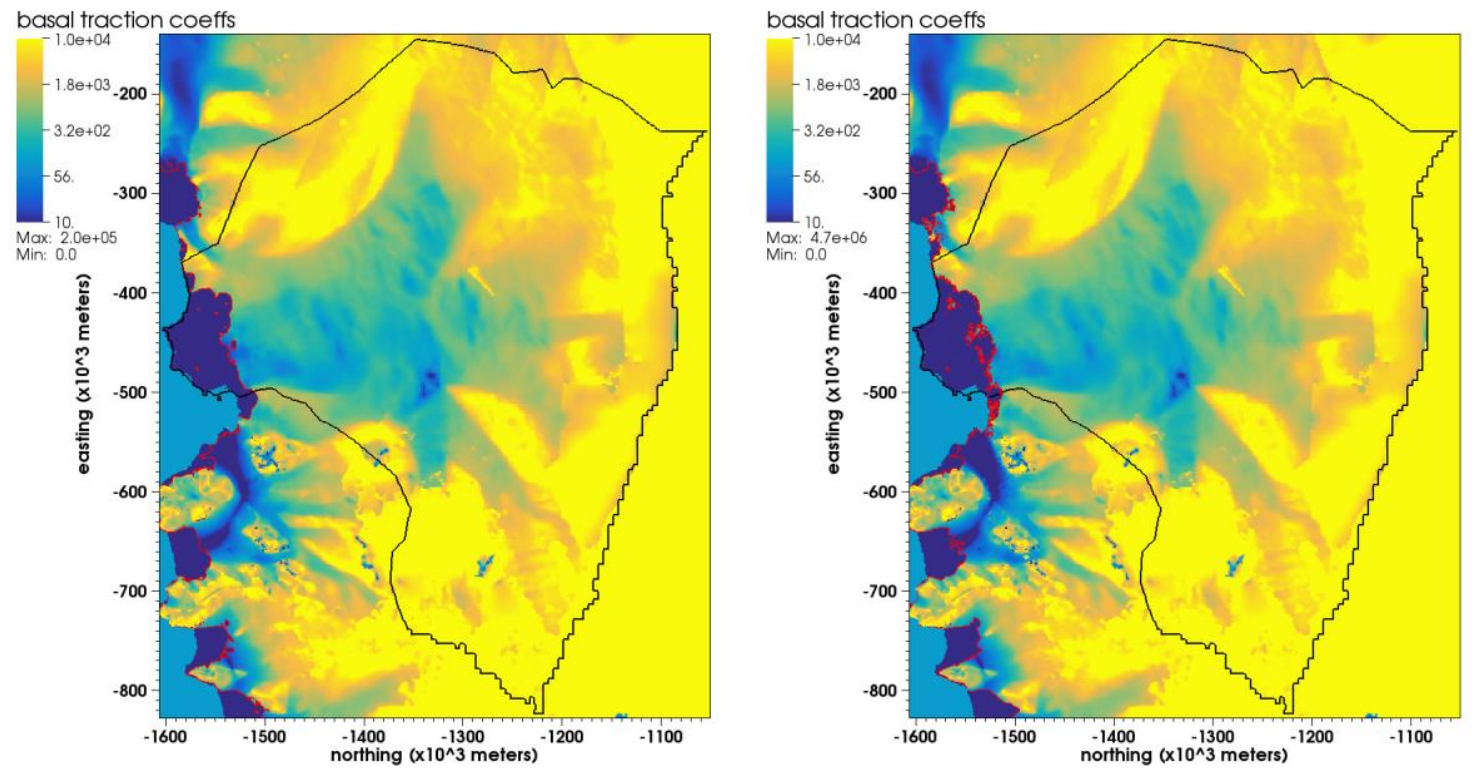

Figure 6. (LEFT) Basal traction coefficients for Bedmap2 with the Thwaites catchment delineated in black. (RIGHT) Basal traction coefficients for the Goff Bed. (BOTH) The red line indicated the grounding line position after relaxation. A log scale for basal traction is used for both panes
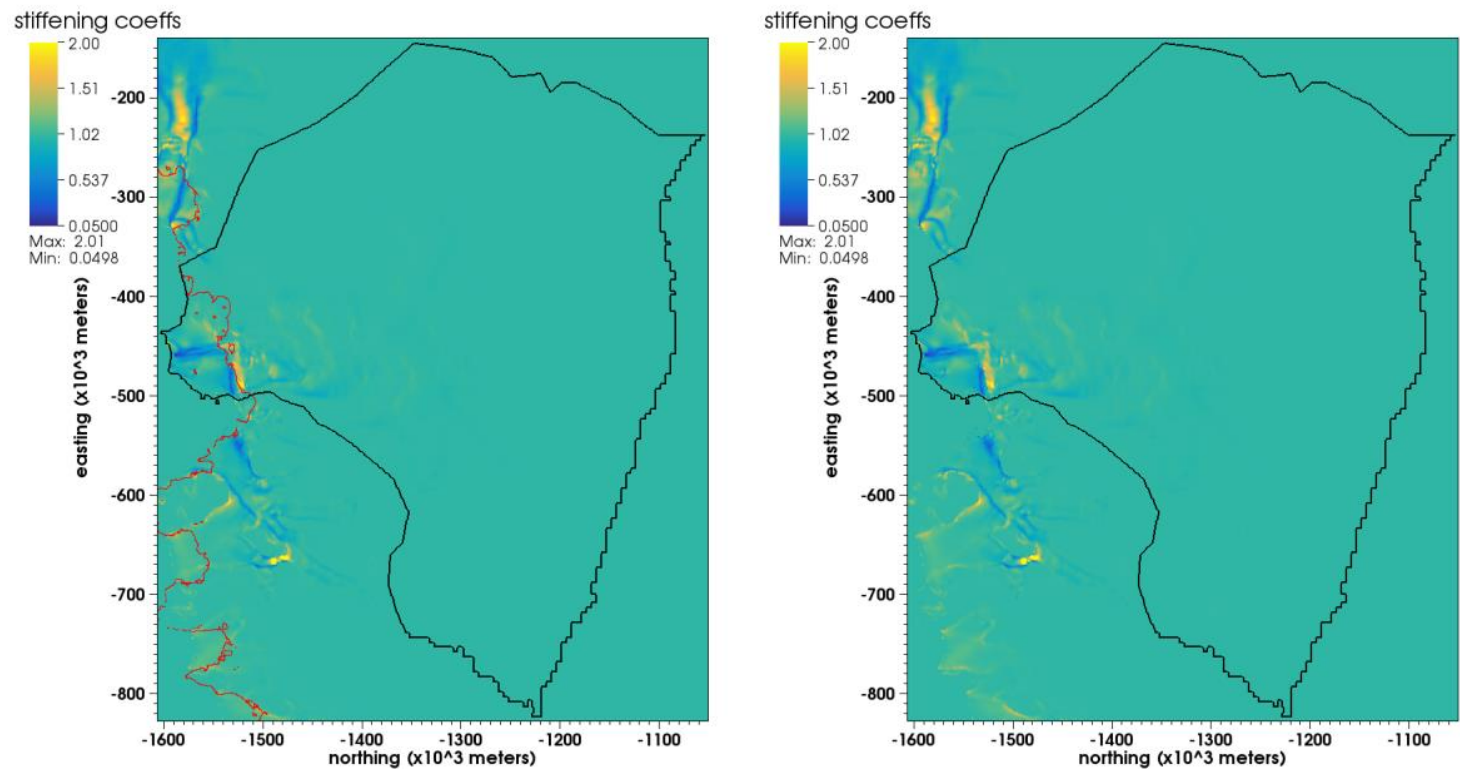

Figure 7. (LEFT) Stiffening coefficients over Bedmap2 in the Thwaites catchment with the grounding line at the end of relaxation shown in red. (RIGHT) Same as left pane but with grounding line removed to provide more detail. 

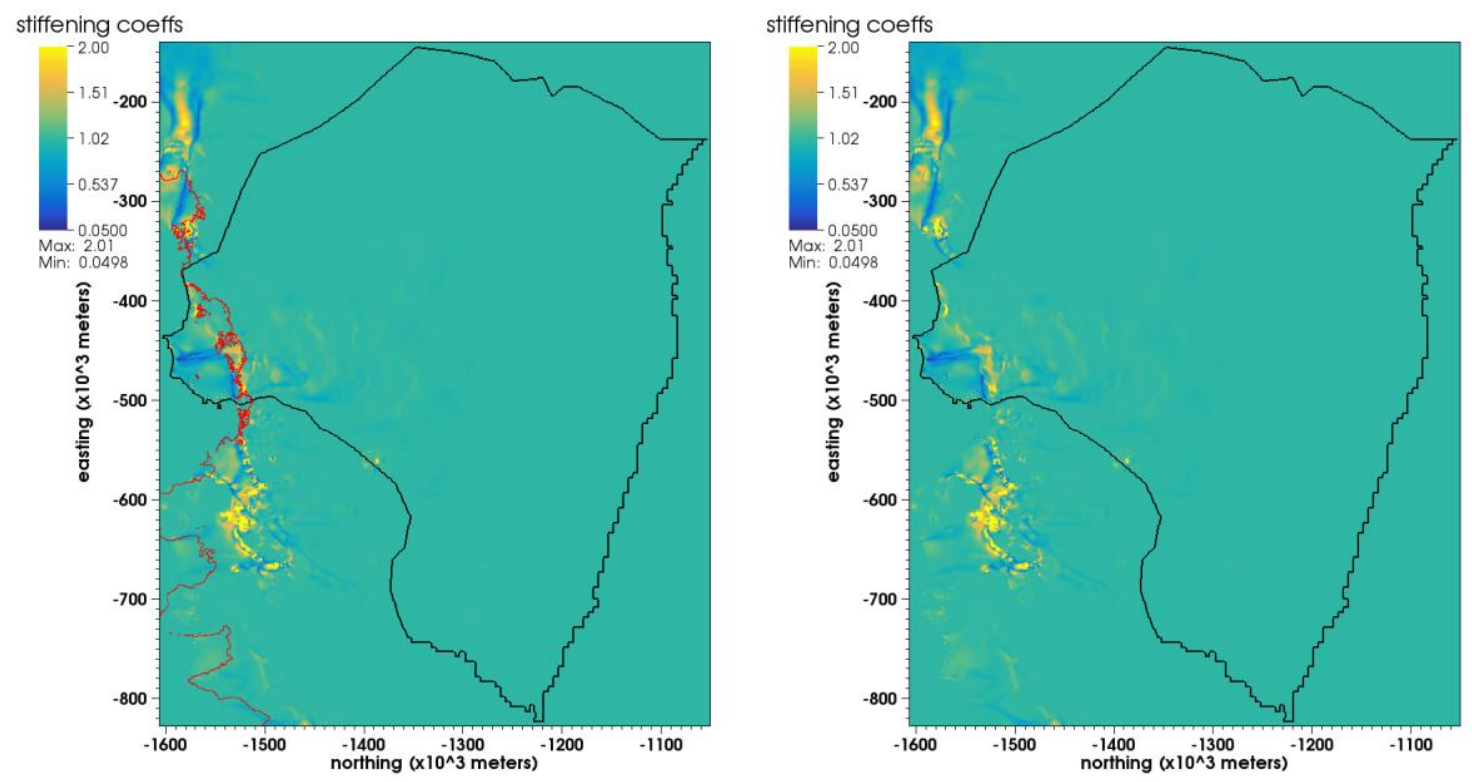

Figure 8. (LEFT) Stiffening coefficients over the Goff bed in the Thwaites catchment with the grounding line at the end of relaxation shown in red. (RIGHT) Same as left pane but with grounding line removed to provide more detail.

\subsection{Oceanic Forcing}

Parameterized basal melt rates are applied to floating ice in order to simulate an oceanic forcing to which the ice sheet responds. The goal in developing this forcing is to perturb it such that an instability is initiated within the model ice sheet, that is, a sustained retreat that does not depend on the external processes. Thus, while the ocean melting parameterization should be realistic, absolute fidelity to ocean processes is not required. The melting parameterization is only applied to floating ice because the basal traction coefficients for grounded ice, optimized by the control problem, include a basal melt contribution. The surface accumulation field is constant through time, with the result that in model experiments, the ice sheet solely responds to an oceanic forcing. 
The parameterization has a piecewise linear form (PLF), with coefficients informed by the work of other authors (e.g. Joughin et al., 2014) and short trials. Using the rationale that melt rates vary in part according to the circulation of water under the shelf, a simple dependence on the thickness of the water layer under the floating ice is

$$
\dot{m}=f\left(w c_{t h k}\right)= \begin{cases}-1 & \text { for } w c_{t h k} \leq 100 \mathrm{~m} \\ 0.005 w c_{t h k}-1.5 & \text { for } 100 \mathrm{~m}<w c_{t h k} \leq 200 \mathrm{~m} \\ 0.004 w c_{t h k}-1.3 & \text { for } 200 \mathrm{~m}<w c_{t h k} \leq 250 \mathrm{~m} \\ -0.3 & \text { for } w c_{t h k}<250 \mathrm{~m}\end{cases}
$$

used during relaxation where the mean annual melt rate, $\dot{m}$ in $\mathrm{ma}^{-1}$, is a function of water column thickness, $w c_{t h k}$ (Figure 9). Following the inverse approximation of other model parameters, the basal melt parameterization is applied during the model relaxation toward steady state.

In order to represent spatial control on heat transport under the shelf, the basal melting parameterization is only applied to floating ice where the bedrock beneath is at least 420 meters below sea level. If the bed is not at least this far below sea level, then no melt is applied to the ice above regardless of the water column depth. In effect, this restriction limits the locations where warm water (which can be thought of as MCDW) interacts with floating ice beneath. As the MCDW flows near the continental slope, submarine channels provide conduits that can allow it to maintain a higher heat content to locally interact with ice (Sergienko, 2013; Thoma et al., 2008). This implies that melting 
is not likely to be spatially uniform and that stronger melting is possible over features like the head of a canyon.

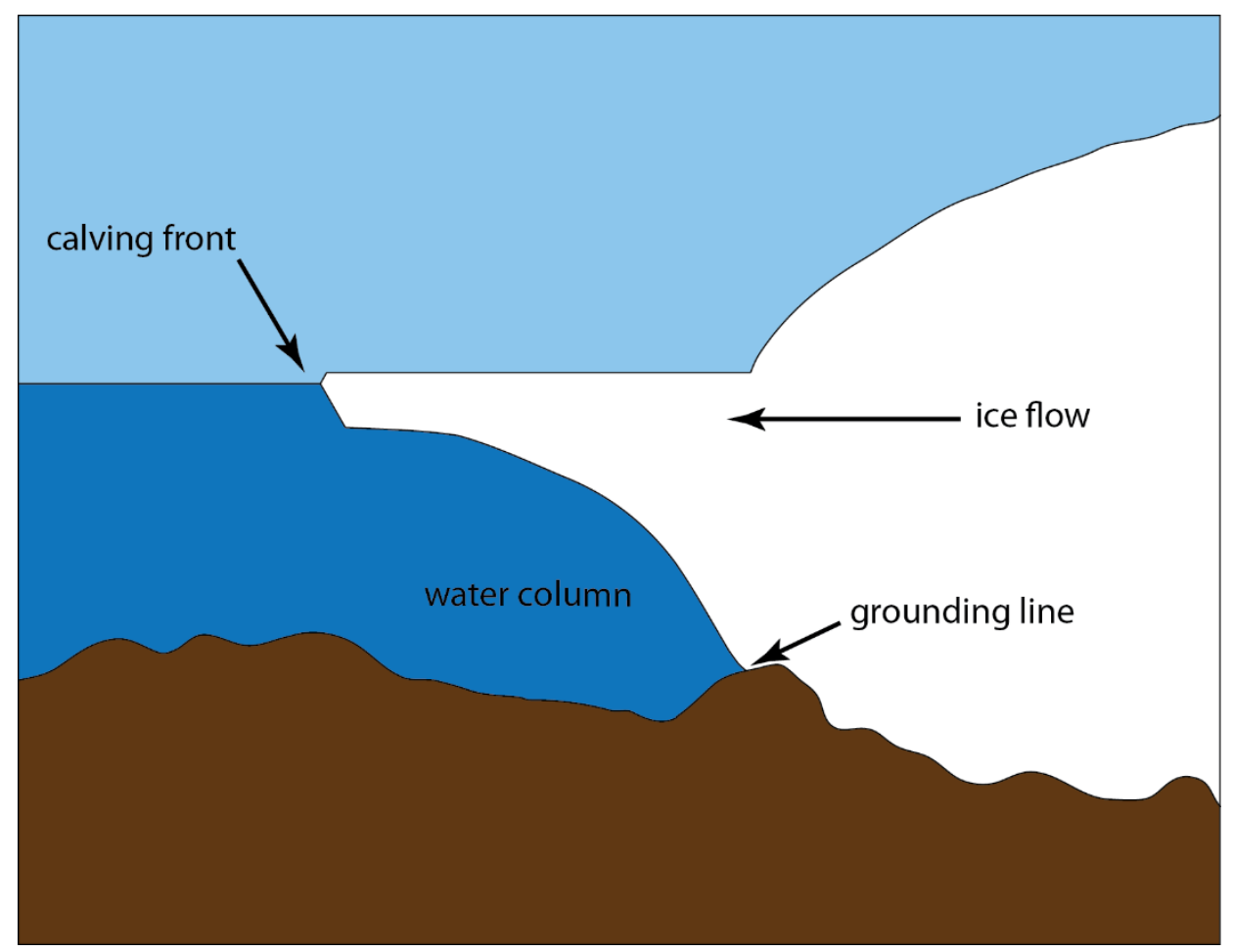

Figure 9. Simplified cartoon depiction of transitional regions of a marine terminating glacier. Grounded ice transitions to floating ice beyond the grounding line. At the calving front, the ice shelf ends with detached icebergs located beyond. The water column beneath the ice shelf tends to narrow as it approaches the grounding line.

Once the ocean parameterization is turned on in the model, a new steady state must be found. Artifacts arising from the inversion may complicate this step because adjustments made to force agreement among present-day boundary conditions may not represent a realistic steady state configuration. An unperturbed simulation with melting applied to achieve steady-state may be used to identify long-lived transients, should they arise. 
Localized transients remained after 200 years into the relaxation when the model was run forward in time using the coefficients in equation (2.9.1). This is because the regional effects of ice grounded over an artificial bedrock high on the outer upper portion of the tongue, are long-lived, even though the pinning point ungrounded within the first decade of simulation (Figure 10). The bedrock high was constructed by BISICLES

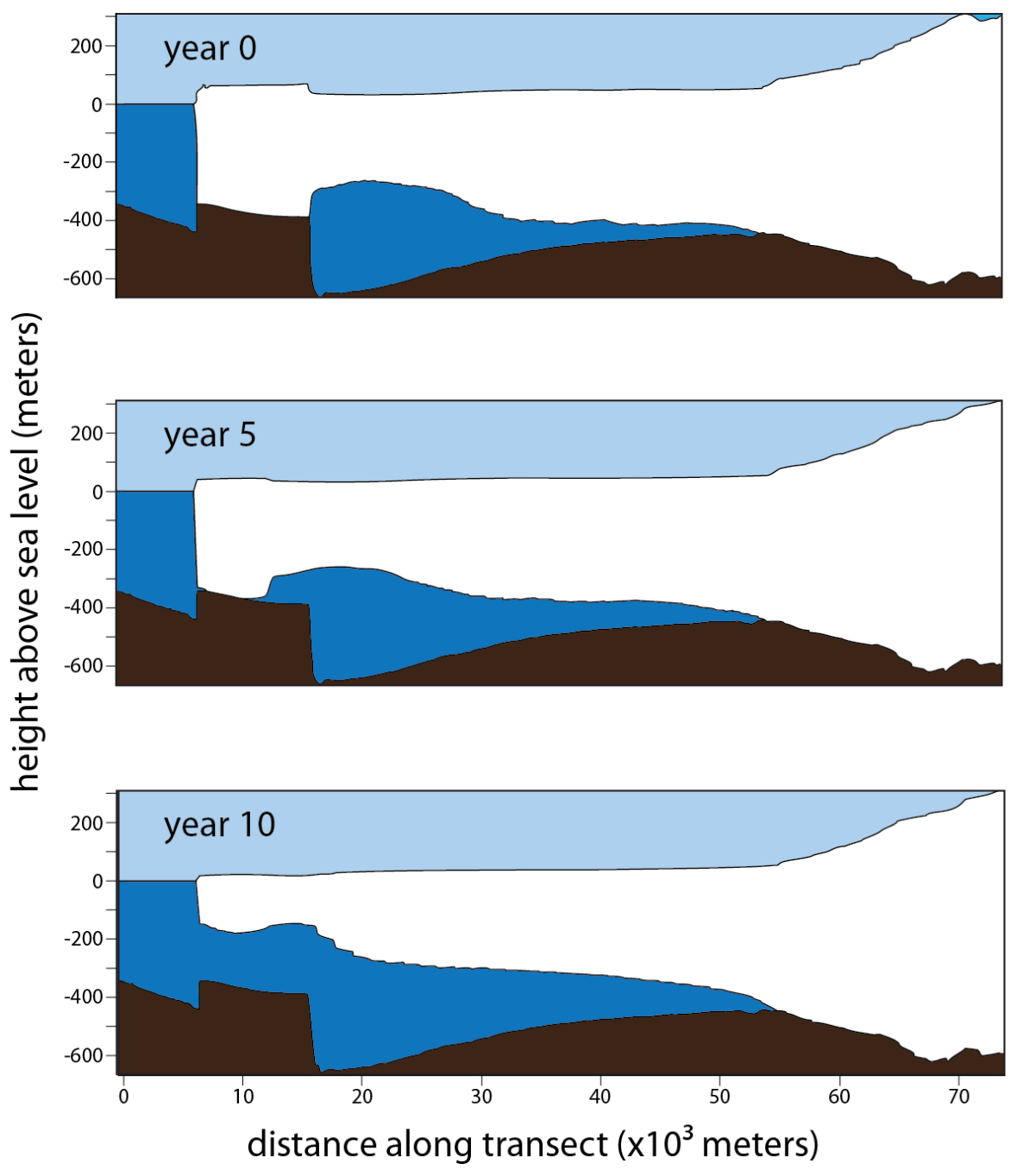

Figure 10. Ice grounded over a bedrock high under Thwaites tongue quickly becomes ungrounded once a simulation begins, even if no forcing is applied. A model steady-state with an ice geometry that conforms to the current observed coastline cannot be achieved with the fields used to run the model. 
developers to accommodate initialization (Martin, 2014). In other words, a reasonable model match to observed ice flow velocities on Thwaites tongue via the control problem was not be achieved without it. The initial geometry of the floating ice over this bedrock high and thinner floating ice immediately south, toward the continent, plays a major role once ice advection begins (Figure 10). Advection pushes the thinner ice toward the bedrock high, but as it is thinner the high can no longer act as a pinning location. As the system adjusts to the accumulation field used, the floating ice never gets thick enough to ground on this high again.

As model steady-state is not achieved within a reasonable amount of runtime and ice geometry in this location cannot conform to the current observed coastline, the final stages of model initialization were adapted. A new PLF is used for the first 40 years of relaxation while equation (2.9.1) is used for the last 60 years. Note that both functions

$$
\dot{m}=f\left(w c_{t h k}\right)= \begin{cases}-10 & \text { for } w c_{t h k} \leq 100 \mathrm{~m} \\ 0.08 w c_{t h k}-18 & \text { for } 100 \mathrm{~m}<w c_{t h k} \leq 200 \mathrm{~m} \\ 0.034 w c_{t h k}-8.8 & \text { for } 200 \mathrm{~m}<w c_{t h k} \leq 250 \mathrm{~m} \\ -0.3 & \text { for } w c_{t h k}<250 \mathrm{~m}\end{cases}
$$

are implemented over the AS in an attempt to bring Thwaites into model steady-state. There does not appear to be a single PLF that optimizes a model steady-state for all glaciers in this region. The effect of using equation (2.9.2) for the first 40 years is to save time and computational expense while bringing the coastline into the configuration that it would achieve with a much longer relaxation run using only equation (2.9.1). Model 
steady-state is still not satisfactorily achieved within 100 years using both equations (2.9.1) \& (2.9.2). As the experiments are run, however, their steady-state run counterpart, using equation (2.9.1) as the only forcing, is continued so that differences between the two can be accounted for until such time as the transient disappears or becomes negligible.

\subsubsection{Perturbation and Experiment Design}

The system is perturbed after the 100 -year relaxation runs. The perturbation consists of a constant increase of melt rate applied to all floating ice with time, which is applied in addition to the PLF in equation (2.9.1). This slow ramp (aka anomalous forcing) increases melt by 1 meter every 20 years. The objective here is simply to generate a genuine marine ice sheet instability such that grounding line retreat down the reverse slope and thinning of ice in the interior will continue via positive feedback if the ramp is turned off. This is opposed to a situation where the ramp is turned off and the grounding line stalls.

Two model experiments are conducted and each experiment involves two simulations. For experiment 1, both simulations are conducted over Bedmap2 with different picks for the time of instability. This allows us to examine the effect of a small difference in the magnitude of the forcing on grounding line retreat. Once the instability is detected, the anomalous forcing is turned off and the ice sheet is allowed to iterate further with only the steady ocean boundary condition at work. The forcing is turned off a decade later for the second simulation in this experiment. Experiment 2 proceeds in the 
same manner as experiment 1 but addresses the effect of bed topography on retreat by comparing the generation of instabilities and resulting retreat rates over different beds. The Bedmap2 simulation with the latter ramp shutoff time is compared to a third simulation conducted over the Goff bed for this experiment.

Unfortunately, after year 200 in the first experiment, the PLF parameterization was overwritten during a migration from one computing cluster to another due to complications with the revision control permissions. A similar event occurred at the start of the anomalous forcing in the Goff Bed simulation. The intended PLF was replaced with a simpler parametrization: constant melt rate of $0.3 \mathrm{ma}^{-1}$ applied to all Thwaites floating ice except at the fringe near the calving front where it increases to a maximum of $1 \mathrm{~m}$ melt. This event was not detected until analysis of the model outcomes was underway. That it was not detected sooner is a sign that the effect of the mistake was minor. This is because the anomalous forcing overwhelms the PLF and the smaller melt rate was only applied during the unstable retreat phase, when a small melting rate is desirable (the attention should be on the instability, not the ocean forcing).

Additional experiments were run in order to ensure directly comparable model time series. These experiments are corrected runs that use the slow ramp with the PLF as intended to examine differences in the timing of instability. The results are addressed in Section 3.1 Instabilities. 


\subsection{RESULTS}

Applying the slow ramp forcing has three main effects relevant to the evolution of the unforced system. In the case of a later (earlier) onset of instability, these are decreased (increased) area of floating ice, a general increase (decrease) in surface gradients near the grounding line, and thicker (thinner) grounded ice at the grounding line when the instability initiates. Thwaites' geographic setting does not include a large embayment to provide large lateral resistive stresses via contact with the coastline so the loss of floating ice here (i.e., initially Thwaites Tongue) is not as important to flow and retreat rates as it might be otherwise. This leaves driving stress, offset by basal resistive stresses, as the principal control on retreat rate.

\subsection{Instabilities}

The slow ramp produced instabilities over both beds. Three spatial scales are used when discussing instabilities and unforced retreat: basin-scale, the entire Thwaites catchment; regional, involving thousands of square kilometers of the basin or a significant portion of the length of the grounding line within Thwaites catchment; and local, which involves hundreds of square kilometers down to sub-kilometer scale. It is important to note that in this basin-scale study, regional retreat trends and effects may vary at any given time. That is, each location on the grounding line is affected by adjacent regions and different regions may be experiencing different trends. Regional instability is identified as the time when the magnitude of glacier response exceeds the magnitude of the forcing and leads to basin-scale retreat. This can be visualized by 
comparing the change in grounded ice area vs the anomalous melt rate (Figure 11). Local instabilities, for example near year 170 over Bedmap2, support unforced retreat for decades in some cases but retreat eventually stalls (Figure $11 \&$ Figure 12). Turning off the slow ramp prior to the initiation of any scale of instability leads to rapid grounding line stall (Figure 13).

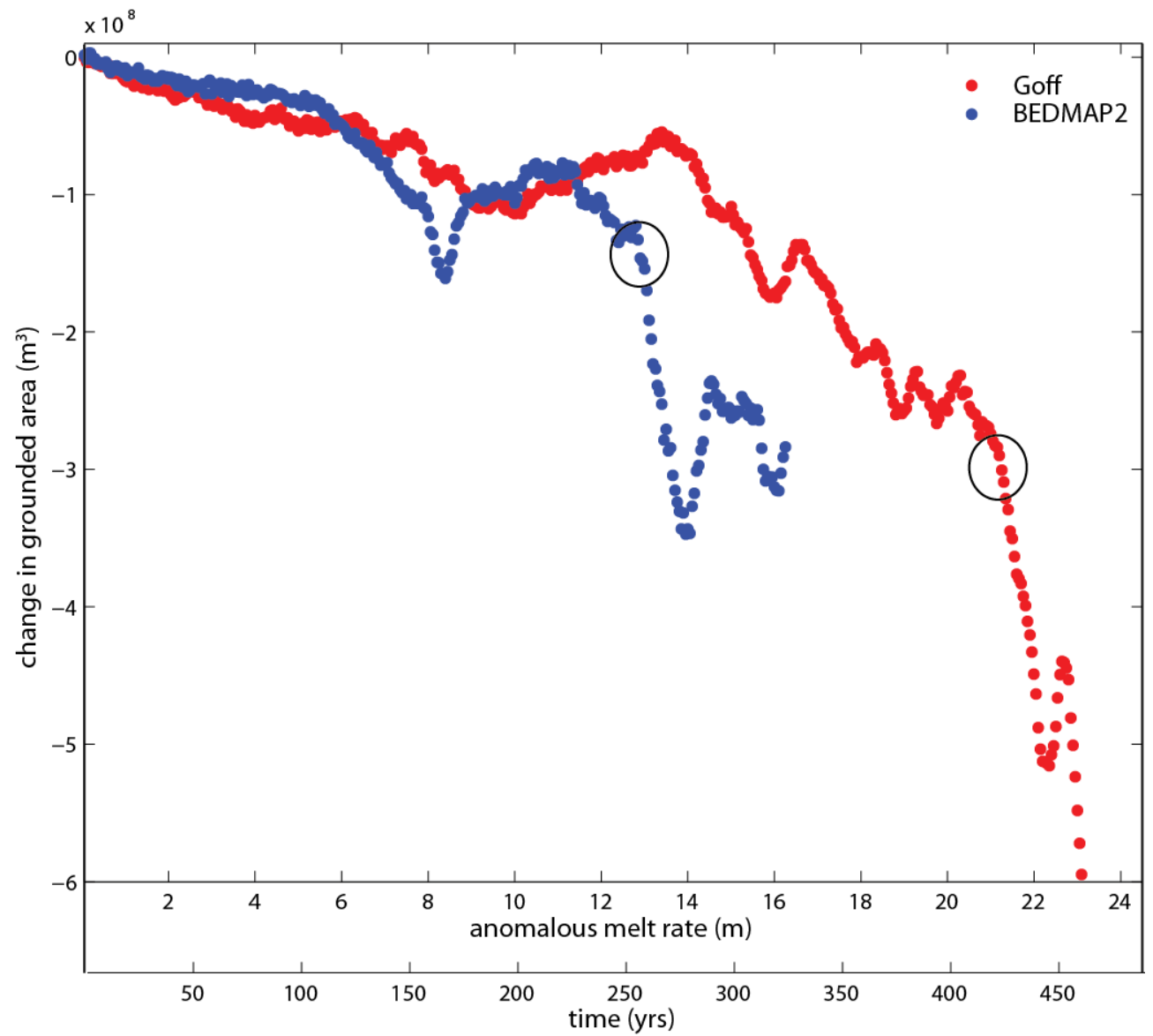

Figure 11. Change in smoothed grounded ice area vs anomalous melt rate / time. The ellipses indicate the approximate rate / time where basin-scale instabilities were detected. Therefore, slow ramp shutoff times for all simulations in the model experiments are demarcated by these ellipses. 


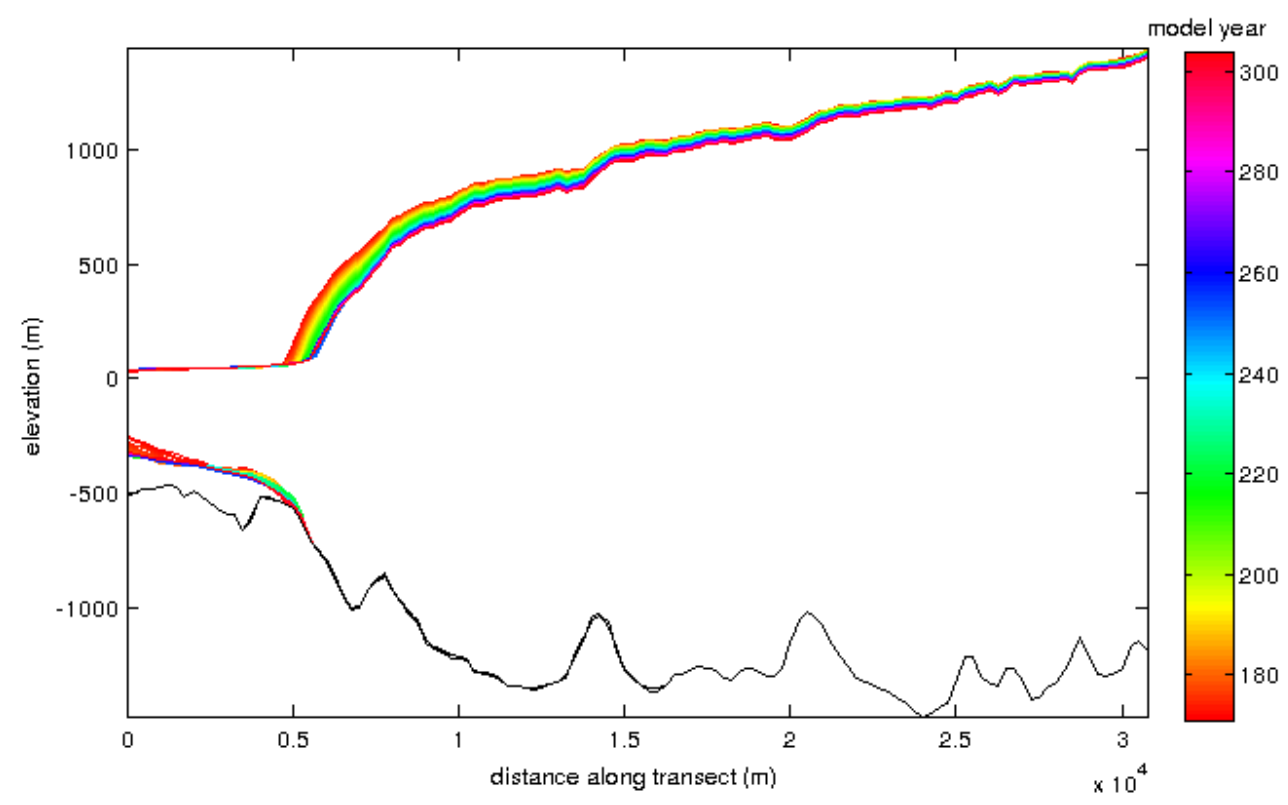

Figure 12. Example of grounding line stall along the approximate centerline after a local instability. The slow ramp was turned off at the initiation of the local instability over Bedmap2 at year 170. Although difficult to discern at the bed, the grounding line ultimately retreated about $750 \mathrm{~m}$ along this transect. Time interval is 1 year.

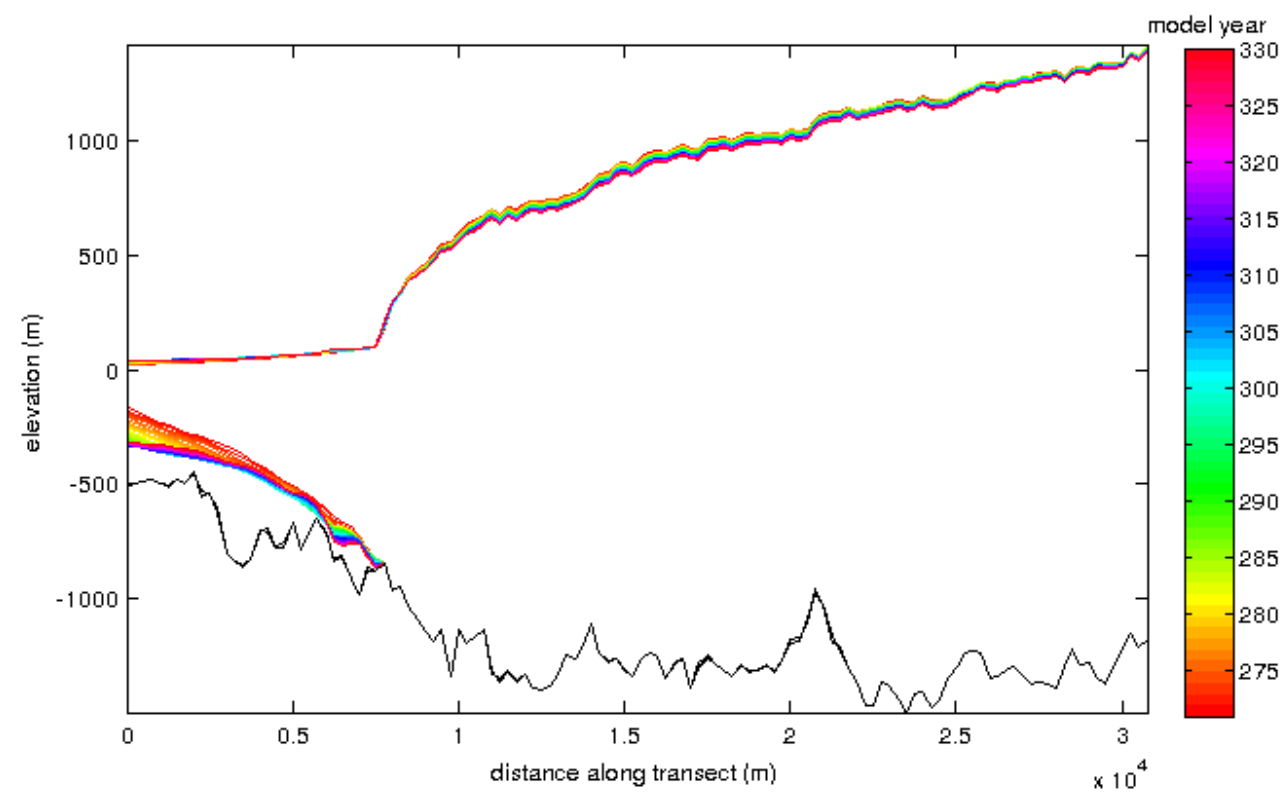

Figure 13. Example of grounding line stall along the approximate centerline when there is no instability. The slow ramp was turned off at year 270 over the Goff and retreat quickly stalled. Time interval is 1 year. 
The simulations comprising the experiments are termed B260, B270, and G425, respectively, in which the number indicates the model year in which the anomalous ocean forcing is shut off (Figure 11). Hereafter, the results for experiment 1: B260 vs B270 and experiment 2: B270 vs G425 will be presented independently.

The corrected runs, used to ensure comparability of the series in experiments 1 and 2 , show that the timing of instability does not greatly change over either bed when the slow ramp is used with the intended PLF (Figure 14 \& Figure 15). Over Bedmap2,

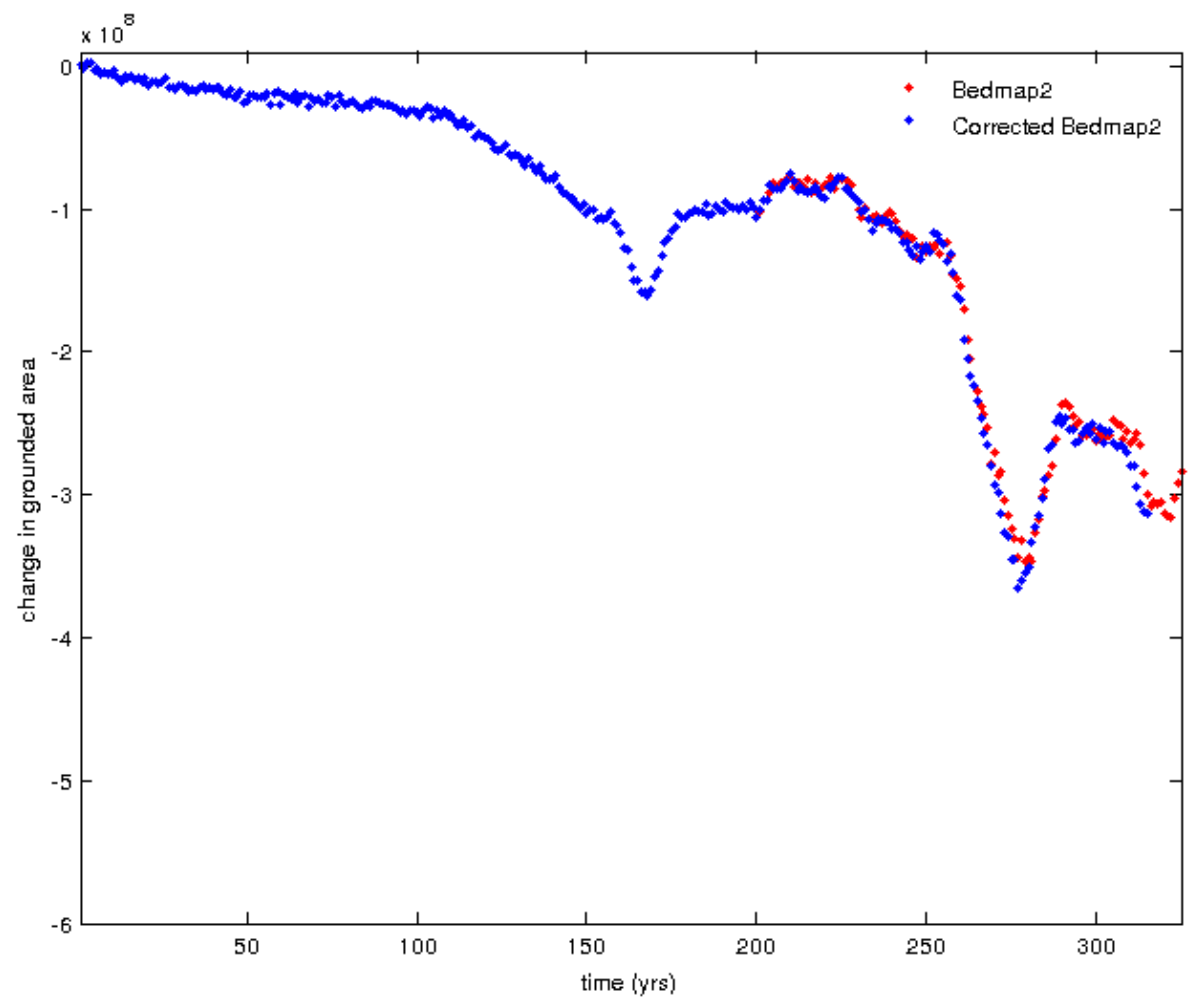

Figure 14. Instability timing difference over Bedmap2. The model run consisting of the slow ramp plus constant rate is shown in red, and the corrected slow ramp plus PLF shown in blue. There is a maximum of three years difference in the timing of regional instability. 
The correction shows that regional instability occurs closer to year 257, a difference of three years from the pick for instability. Over the Goff bed, the correction shows instability occurring about year 417, eight years difference from the Goff simulation pick used in experiment 2. As the differences in instability timing between the corrected model runs are minor compared with those incorporating the constant melt rate, the blunder will not have a significant impact on experiment outcomes.

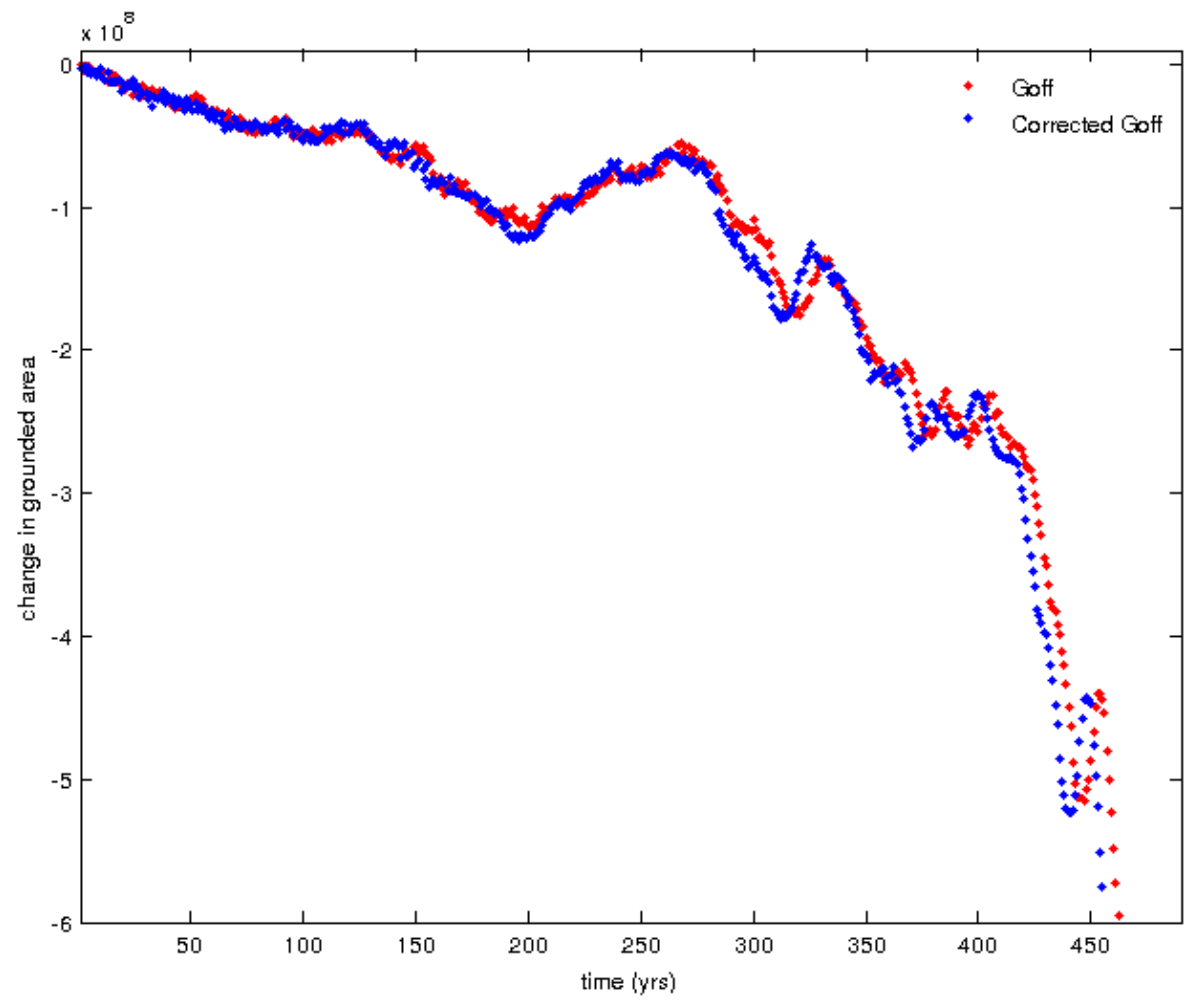

Figure 15. Instability timing difference over the Goff bed. The model run consisting of the slow ramp plus constant rate is shown in red, and the corrected slow ramp plus PLF shown in blue. There is a maximum of eight years difference in the timing of regional instability over this bed. 


\subsection{Analysis tools}

Comparisons across the two simulations are presented both as maps and as summary statistics plotted against grounding line position during the retreat. The latter is accomplished by co-locating the grounding line across along fixed transects in the model domain. The transects were created following particle flowpaths (Childs et al., 2012) although one path, uppermost in the figures, was altered in the interior of the basin to follow the centerline of a deep channel (Figure 20). While the map view is comprehensive, the transects allow comparisons to be made across many intervals of time. Additionally, animations of fields of interest and ice profiles along transects aid in interpretations (Appendices $\mathrm{C}-\mathrm{M}$ ).

Retreat is presented and discussed in terms of driving stress and ice flux (discharge) across the grounding line. The reasons for this are twofold. First, driving stress encapsulates several related state variables. Ice flow is the result of surface slope, ice thickness, and basal sliding, all of which both depend on driving stress. Second, discharge of ice across the grounding line causes the center of the ice sheet to thin, which drives further retreat.

In order to focus the analysis, spatially-varying and summary statistics are restricted to a region of interest (ROI) around Thwaites glacier (Figure 16) The ROI includes the glacier and its tributaries but excludes areas where flow is less than $10 \mathrm{ma}^{-1}$. This removes effects arising in the low-flow boundary regions from the calculation. The ROI boundary is not fixed through time or across simulations although differences are 
small and by definition occur well away from areas subject to rapid change (Appendices

$\mathrm{L} \& \mathrm{M})$.

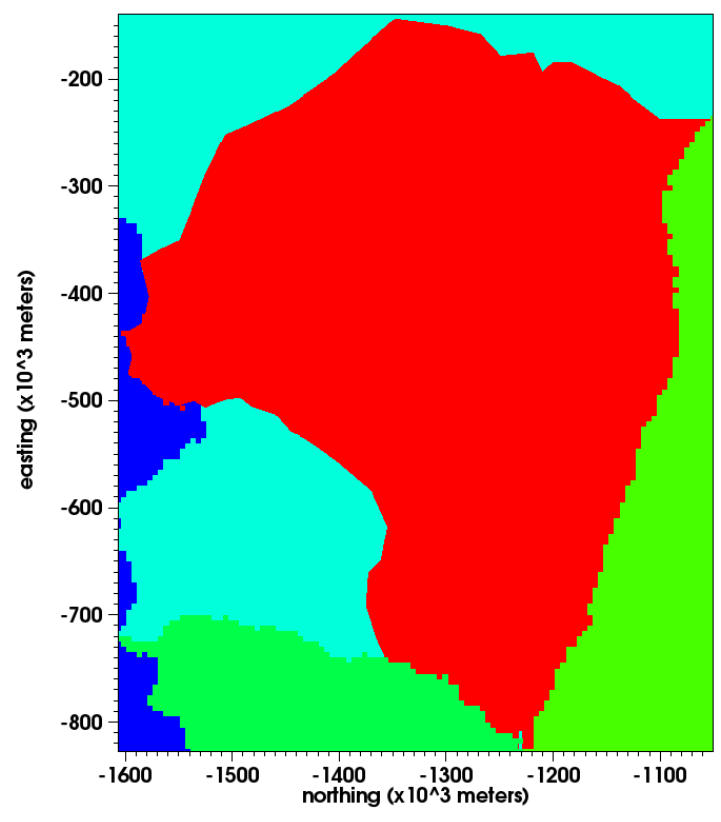

Figure 16. The region of interest (ROI) for calculating driving stress is within the Thwaites catchment shown in red. Note, however, that Driving stress is only calculated only over grounded ice where the flow velocity exceeds $10 \mathrm{ma}^{-1}$. Thwaites glacier is a part of the partially shown AS sector (light blue). Other portions of regional drainage catchments are shown in shades of green.

Driving stress $\tau_{d}$ is calculated as

$$
\tau_{d}=\rho g H|\nabla s|
$$

Ice flux across the grounding line is calculated for the entire Thwaites basin and where each of five transects cross the grounding line.

Differences in grounding line position across the experiments will be evident in a side-by-side comparison of the plan view maps but a quantitative assessment of the associated model fields is less simple. Differencing model fields at equivalent times would be complicated and possibly misleading because some ice that is grounded in one 
case is floating in the other. A better approach is to compare times of equivalent grounding line position. Co-location in time identifies genuine differences in the state of the ice sheet that are due solely to the slightly different conditions at the time the unstable retreat begins.

Perfect co-location between simulations along the entire length of the grounding line is impossible because spatial patterns of retreat are complicated (Appendices L \& M). For comparisons over the same bed, the criterion for co-location is that the two grounding lines are separated by less than 250 meters along the transect that represents the approximate centerline, T3. Note that the five curvilinear transects throughout the Thwaites catchment are referred to and labeled as T1 (uppermost) through T5 (lowermost) (see Figure 20) When the overall grounding line configurations do not match well using T3, another transect can often be substituted (Appendix A). The general shapes with both retreats over Bedmap2 along the entire lengths of the grounding lines are most similar when points along this transect are compared. The total number of colocated grounding line positions is limited by the differences in retreat rates such that if rapid retreat occurs in one simulation but not the other the distance criterion won't always be met. Also, the lobate patterns of retreat and differences therein between the simulations can eliminate instances of co-location. As a result, there are occasional discontinuities in time (forward jumps) for co-located grounding line positions (Appendices A \& B). 


\subsection{Experiment 1: Retreats over Bedmap2}

The progress of an unforced retreat depends on the state of the system at the end of the forced retreat. The position of the grounding line in the basin is important because it dictates ice thickness at that boundary, and the surface gradient induced by the forced response is important because it dictates basin-scale driving stress at shutoff. Since the instability is generated over a reverse slope, ice thickness generally increases in the retreat direction (upstream), tending to maintain the driving stress. However, the presence of bumps on the bed locally modulates the surface gradient and this can either promote or retard retreat. As the grounding line moves up toward the crest of a bump, the flux through the grounding zone is reduced, temporarily slowing retreat and leading to a locally larger surface gradient (Figure 17). The opposite is true as the grounding line crests a bump and moves in the direction leeward to the direction of retreat. Furthermore, large bumps and linear features on the bed tend to have been assigned higher basal traction coefficients in the model initialization, which also tends to cause a steepening in the gradient while temporarily slowing retreat (Figure 17). All together, bumps may locally or regionally increase or decrease surface gradients, flow velocity, and discharge in ways that generate considerable spatial and temporal variability in the overall retreat. 


\section{flow direction}
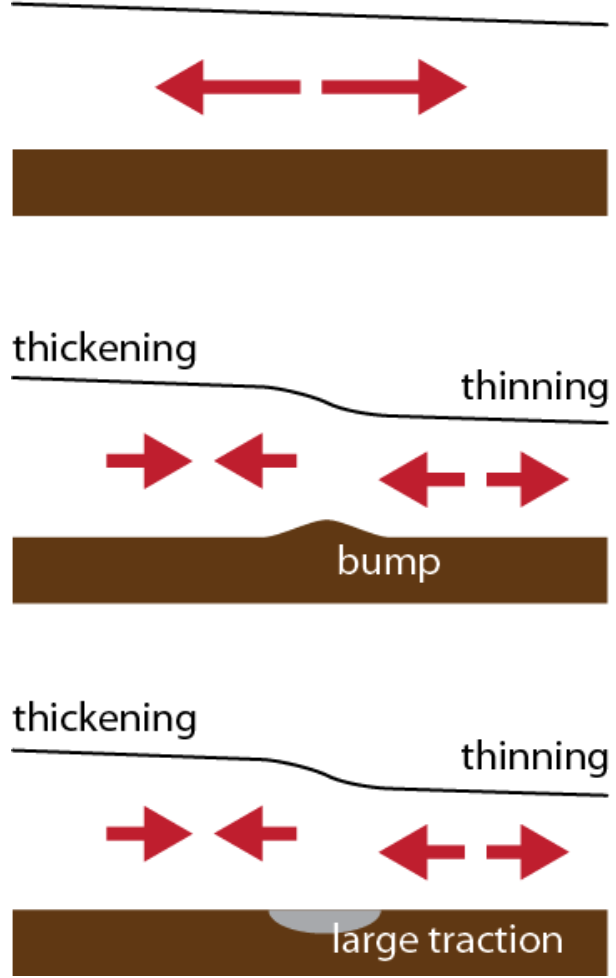

Figure 17. A cartoon demonstrating the effect of bumps and large basal tractions on ice geometry. Ice flows in the direction dictated by the surface gradient (blue arrow), and if flow is unimpeded and the ice supply is finite this leads to thinning as shown by the diverging red arrows (TOP). A bump in the bed causes thickening and a local increase in the surface gradient on the "windward" side and thinning on the leeward side. Should the grounding line retreat through a geometry like this, a local decrease and then increase in retreat rate would result (MIDDLE). A large basal traction has a similar effect to a basal high (BOTTOM).

An instability is first detected at year 260 and this is when the first retreat

simulation, B260, begins (Figure 11). The anomalous forcing at that time is $13 \mathrm{ma}^{-1}$. Ten years later, when the B270 simulation begins, the anomalous melting rate is $13.5 \mathrm{ma}^{-1}$.

Despite the closeness in time and similarity in the anomalous forcing ice sheet 
configurations have important differences at the start of the two retreat simulations. As a result, the unforced retreats over the Bedmap2 bed also have significant differences.

Both grounding lines have an arcuate shape at the start of the two retreat simulations, though this shape is more pronounced in B270. Near the centerline of the glacier, (ordinate $2.645 \times 10^{6}$ meters on the model grid), the B260 grounding line has retreated about $57.5 \mathrm{~km}$ while the B270 grounding line has retreated about $66 \mathrm{~km}$ (Figure 18). The maximum horizontal distance between the two grounding line positions is about

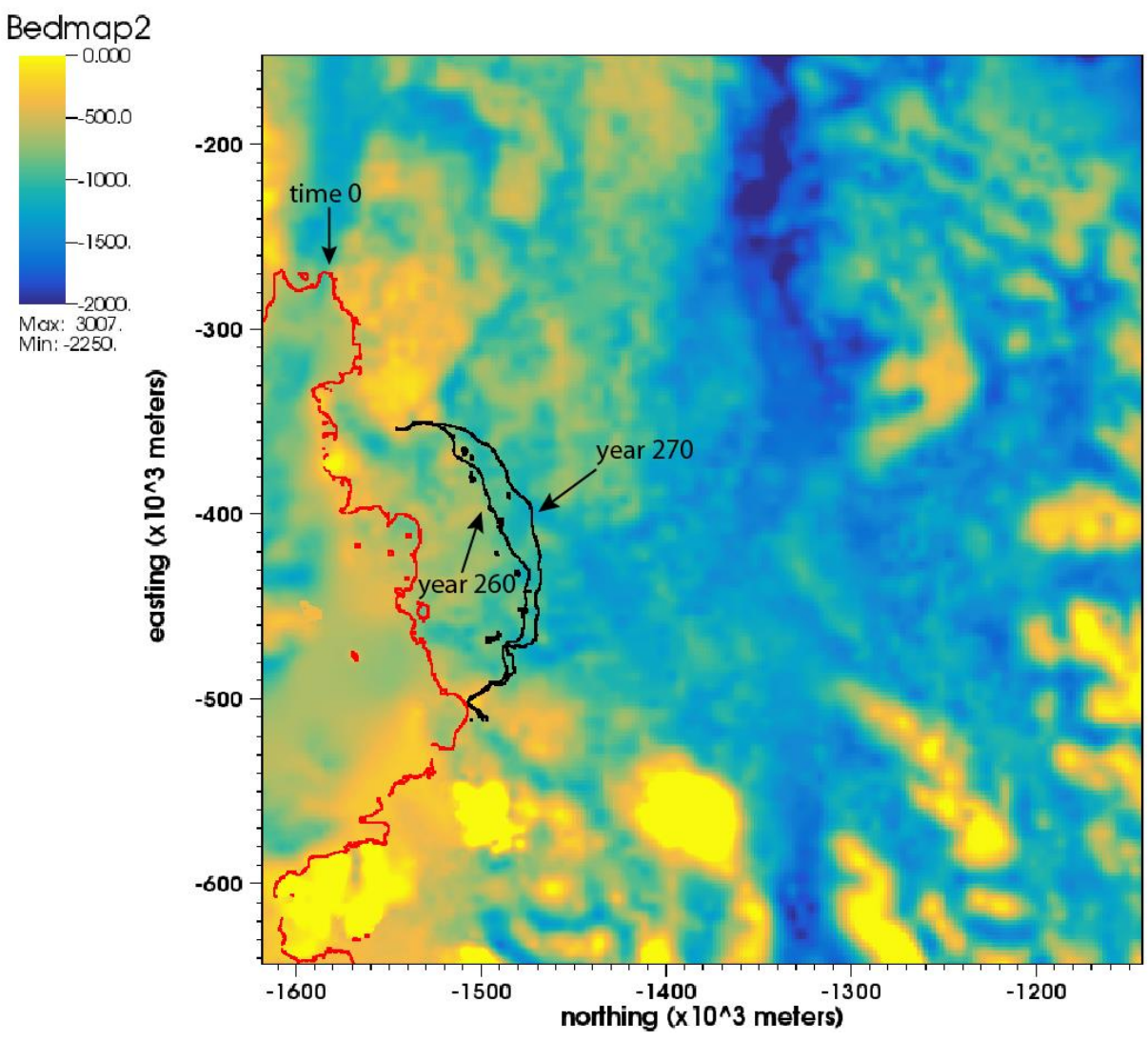

Figure 18. The grounding line positions at the years of slow ramp shutoff over the Bedmap2 bed elevation. The grounding line positions are shown as black lines. The red line shows the grounding line position at the initiation of the slow ramp in anomalous forcing. 
$22 \mathrm{~km}$. The average ice thickness at the grounding line is $858 \mathrm{~m}$ at the start of B260 and $930 \mathrm{~m}$ when the shutoff is at year 270. Small ice rises tend to confound examination of surface gradients in the vicinity of the grounding line but in general, the surface gradient near the grounding line is lower at the start of B260 than at the start of B270. Grounded ice volumes at the start of B260 and B270 are $4.657 \times 10^{5} \mathrm{~km}^{3}$ with a volume of flotation (VAF) of $2.442 \times 10^{5} \mathrm{~km}^{3}$ and $4.623 \times 10^{5} \mathrm{~km}^{3}$ and $2.425 \times 10^{5} \mathrm{~km}^{3}$, respectively. The longer forcing period leads to a larger mean driving stress at the start of the B270 scenario relative to $\mathrm{B} 260,90.2 \mathrm{kPa}$ and $88.0 \mathrm{kPa}$, over the respective ROIs. Viewed spatially, the driving stress is larger near the grounding line for B270 (Figure 19). This is because thinner, lower slope ice has already been lost that was still present at B260. Put another way, the B270 grounding line has moved back into thicker, steeper ice at the start of the instability. 

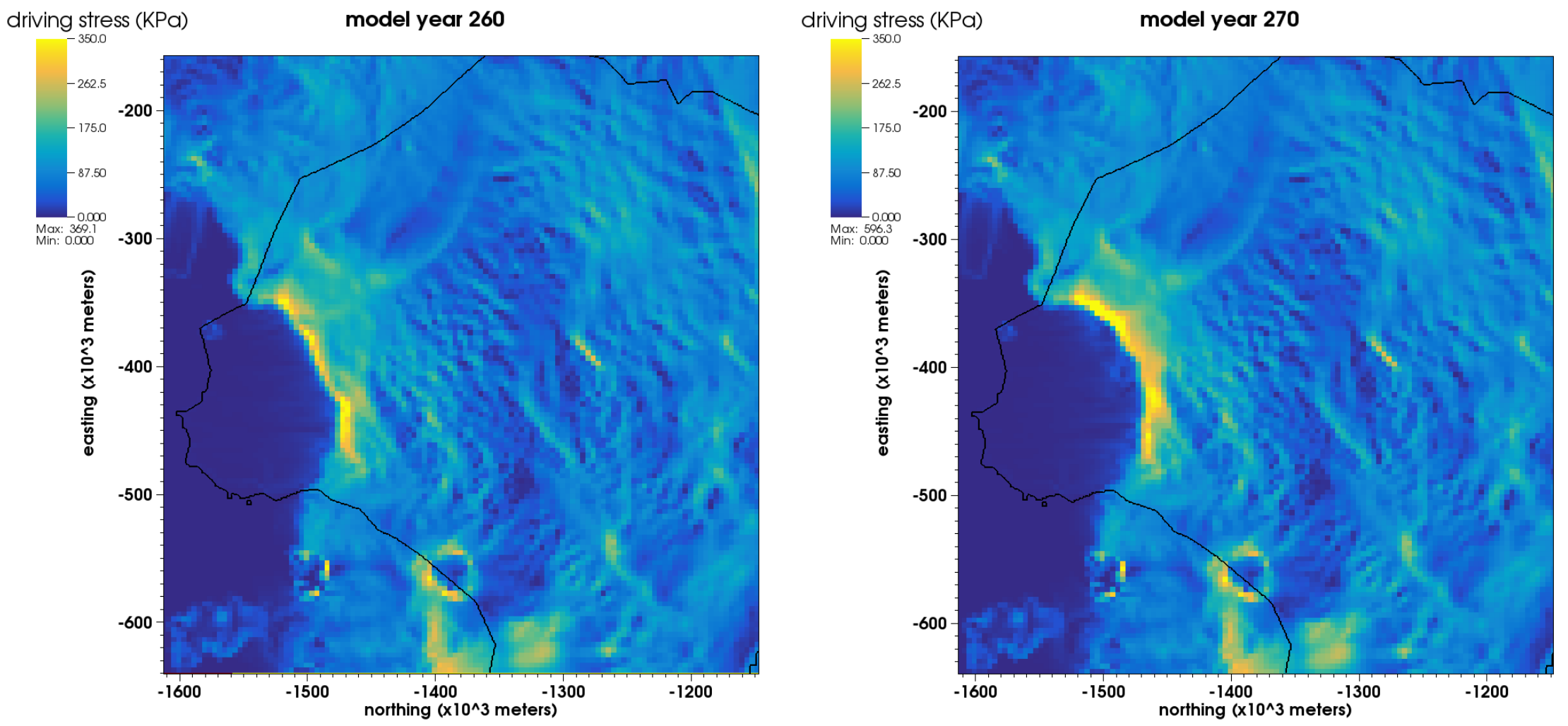

Figure 19. Driving stress at $4 \mathrm{~km}$ resolution in the ROI and surrounding areas at year 260 (RIGHT) and year 270 (LEFT). Higher intensity colors represent larger stress. Driving stress near the grounding line is higher at year 270 than at year 260 due to a longer period of forcing increasing surface gradients and thicker ice down the reverse slope (toward interior of basin). 
The unforced retreat progresses more rapidly in the B270 simulation than in B260. The difference between the two simulations grows until the ice supply begins to dwindle and the faster retreat starts to slow down (Figure 20 \& Figure 21). Spatial details in the time co-located grounding line position vary across the two simulations, even though the retreats play out over the same bed geometry. These differences are both causes and effects of differences in the driving stress.

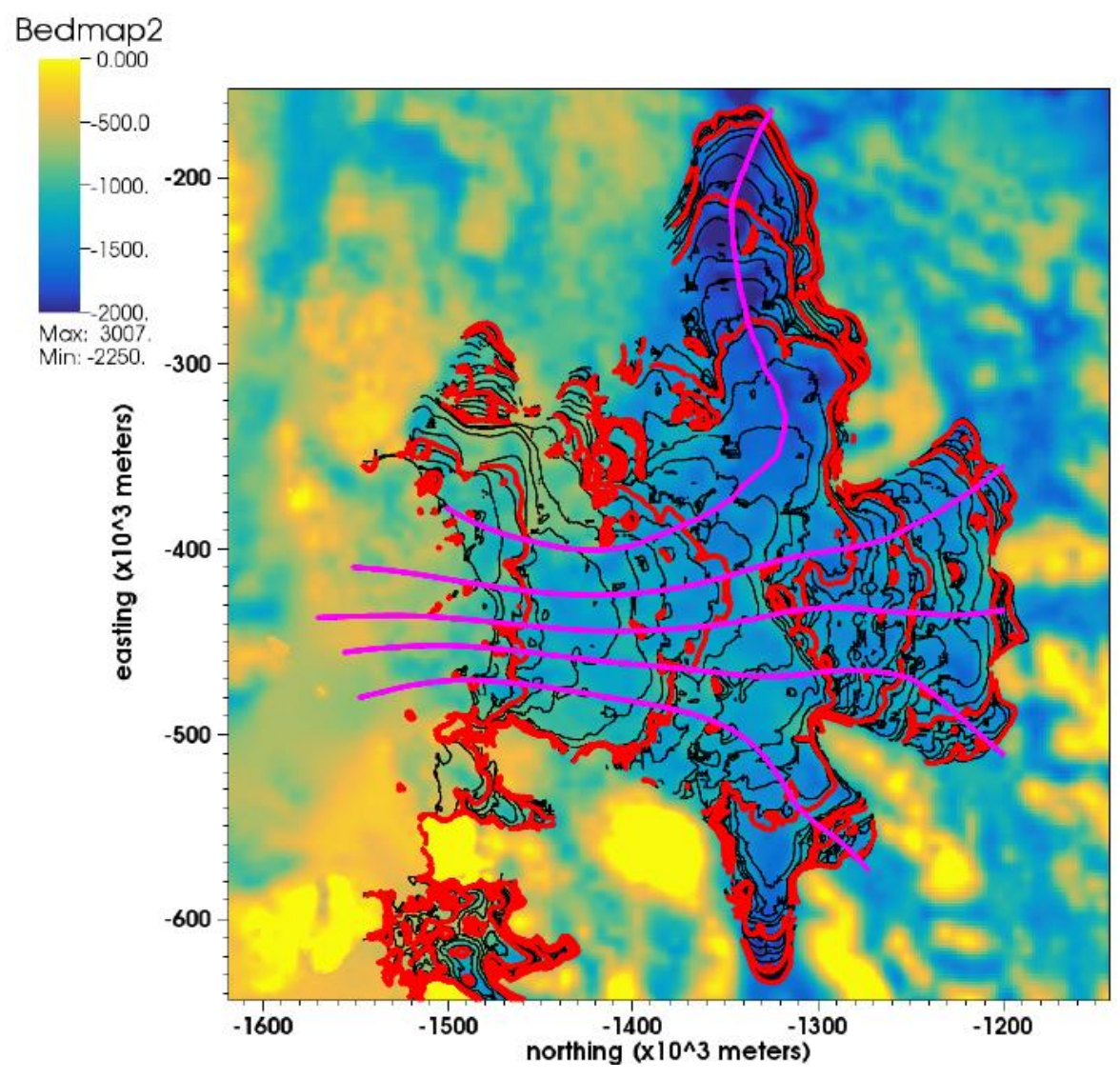

Figure 20. Contours of grounding line retreat for $\mathbf{3 2 6 0}$. The contour interval for black lines is 100 years starting the year 261. The contour interval for red lines is 500 years starting at year 500 . The magenta lines indicate the location of transects with $\mathrm{T} 1$ being the uppermost and $\mathrm{T} 5$ the lowermost. 


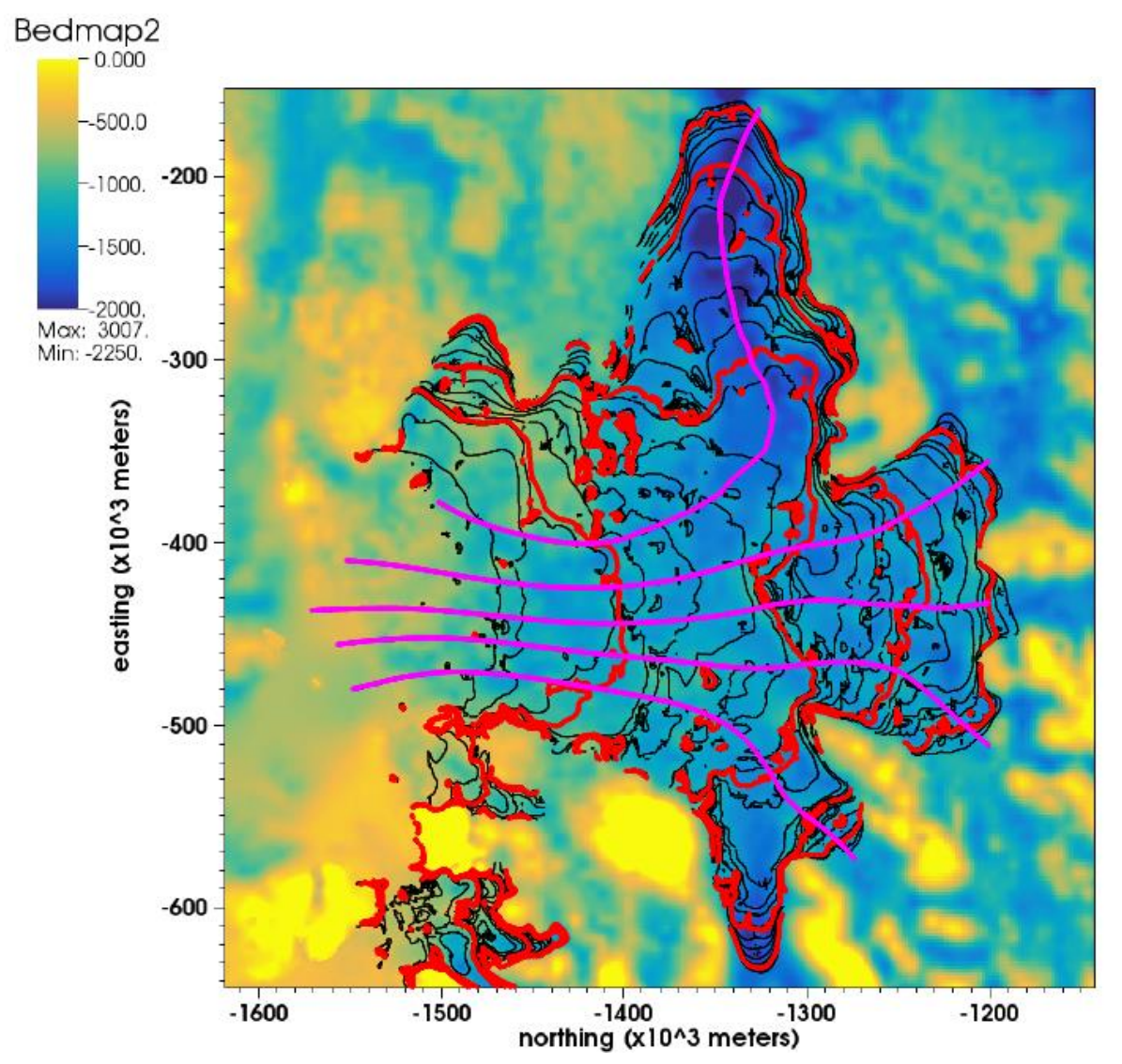

Figure 21. Contours of grounding line retreat for B270. The contour interval for black lines is 100 years starting at year 271. The contour interval for red lines is $\mathbf{5 0 0}$ years starting at year 500. The magenta lines indicate the location of transects.

Overall, the mean driving stress over the ROIs is larger in the B270 simulation than in B260 and the difference increases over time (Figure 22). However, there are important details in the driving stress difference and these must be interpreted with care. From the $1^{\text {st }}$ observation until the $17^{\text {th }}$, the difference in model years decreases. This is because the grounding line for B270 advances locally (below about -425 E) between model years 273, (observation 3) and 287 (observation 17). Grounding line advance does not happen everywhere, but instead is associated with highs on the sea floor, where re-grounding is possible, and where basal traction may be locally large. After the $17^{\text {th }}$ observation, the 


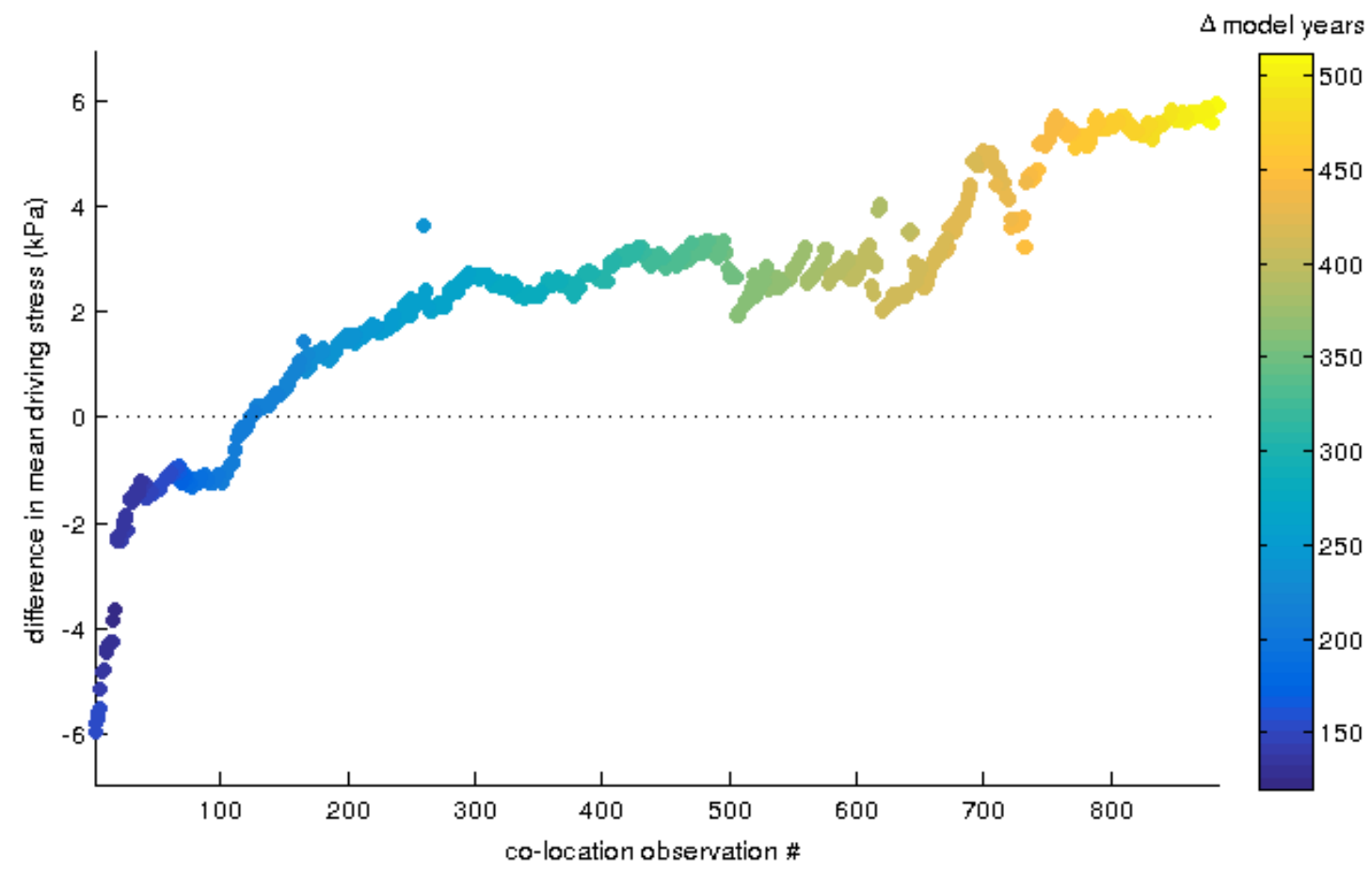

Figure 22. The difference in mean driving stress over Bedmap2 (B270 - B260). The colorbar indicates the difference in model years as B260 minus B270. Initially there is an approximate 150-year difference between co-located positions that decreases to a minimum of 120-years difference associated with local grounding line advance in B270 before increasing again as the grounding lines retreat over the basin.

difference in model years generally tends to increase as the observation numbers increase (Figure 22).

Another important detail emerges during the first 17 co-located observations.

While the western portion of the grounding line for B270 advances below about $-425 \mathrm{E}$, there is an unrelated grounding line configuration mismatch in the eastern region, between approximately $-350 \mathrm{~km} \mathrm{E}$ and $-400 \mathrm{~km} \mathrm{E}$, with the grounding line for B260 retreated farther into the basin here (Figure 23). The grounding lines are retreating into a region of relatively high basal traction here so surface gradients, hence driving stress, will 
be relatively high also. The effect on driving stress is brief, and as the overall grounding line retreat proceeds, the difference between B270 and B260 grows increasingly positive (Figure 24).

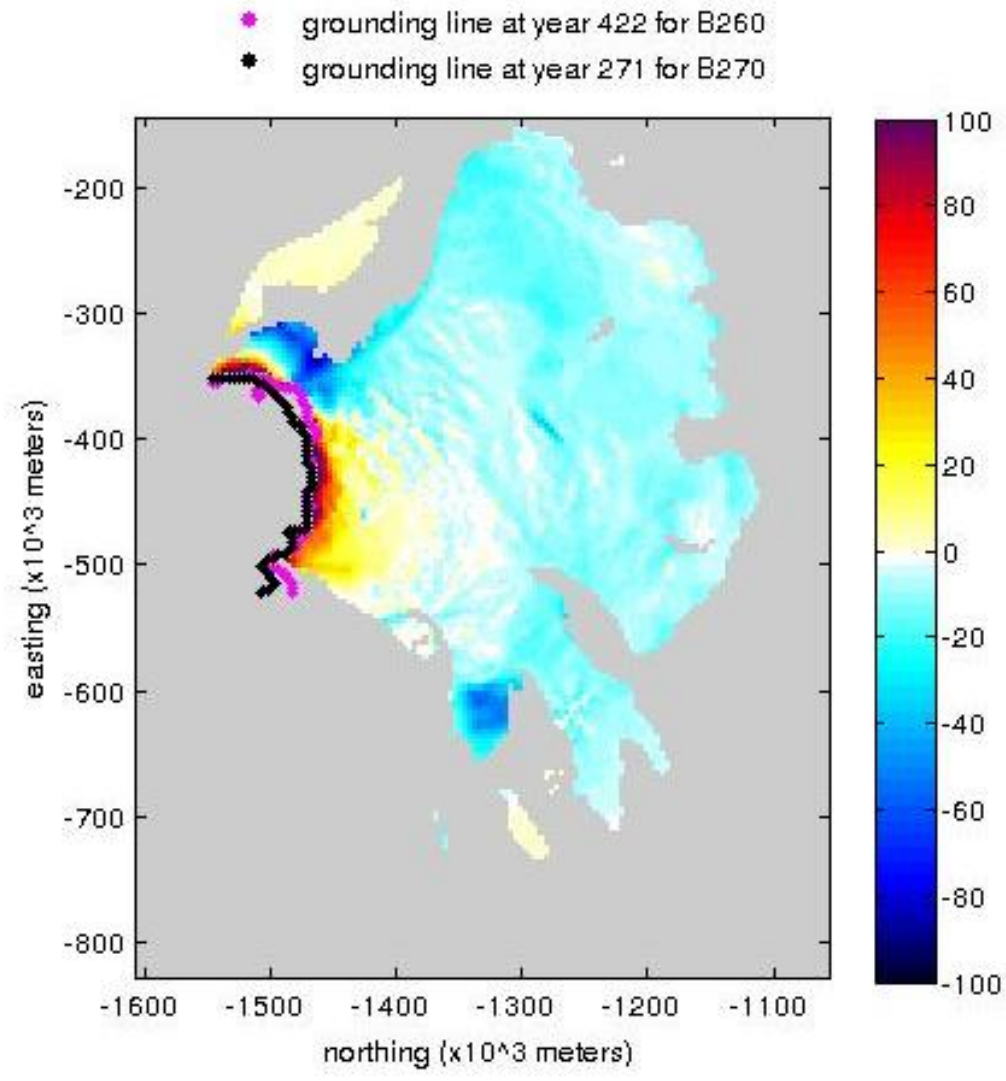

Figure 23. The spatial difference in driving stress B270 minus B260 (only where ROIs overlap) for the first co-located observation for both retreats over Bedmap2. This observation corresponds to model year 422 for $\mathrm{B260}$ and model year 271 for $B 270$. Between about $-350 \mathrm{~km} \mathrm{E}$ and $-400 \mathrm{~km} \mathrm{E}$, the grounding line of $B 260$ is in an advanced position relative to $\mathrm{B} 270$. 


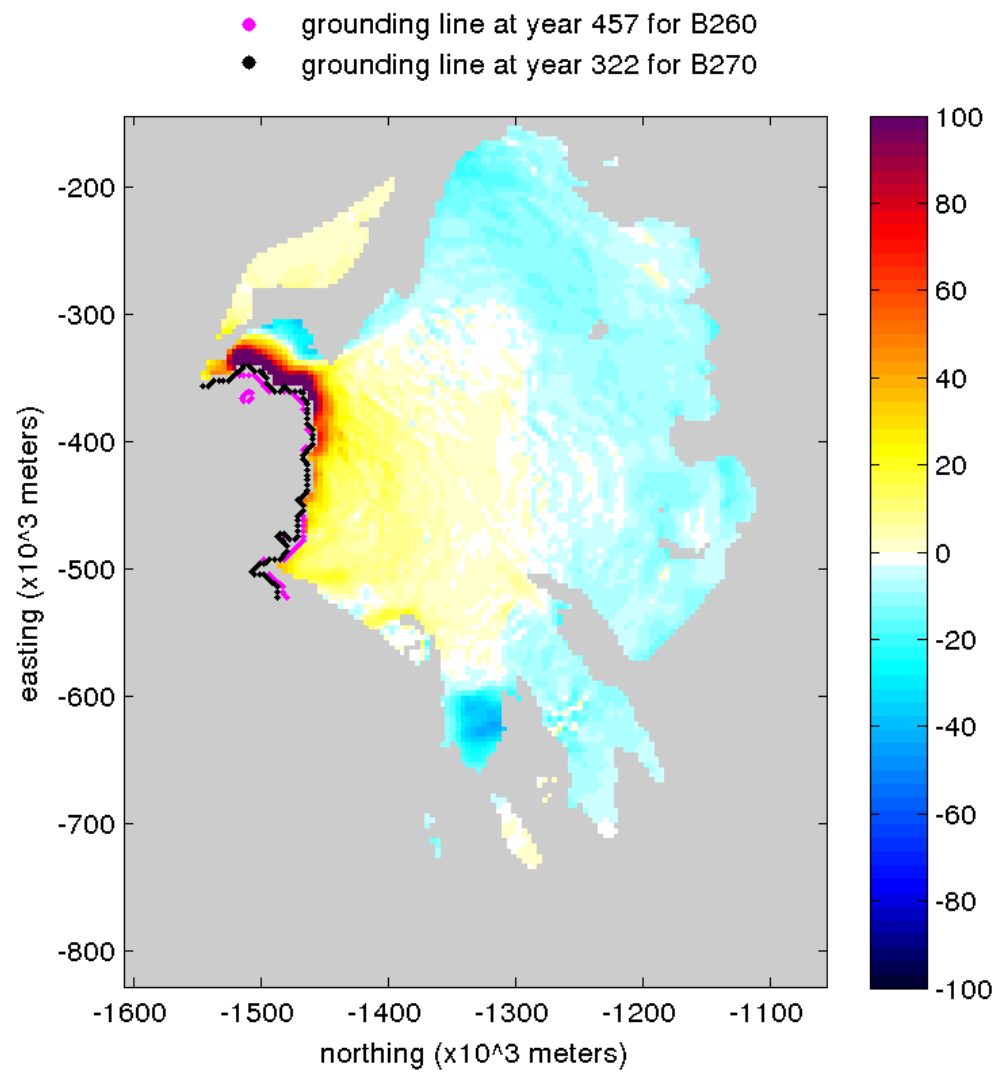

Figure 24. Spatial differences in driving stress for the $18^{\text {th }}$ co-located observation of retreats over Bedmap2. The grounding line of B270 has caught up to that of B260 between about $-300 \mathrm{~km} \mathrm{E}$ and $-400 \mathrm{~km} \mathrm{E}$ by model year 457 for $\mathrm{B} 260$ and model year 322 for B270.

The summary driving stress comparison reflects different total elapsed times and thus different basin-wide thickness and surface slope when the grounding line arrives at any particular location (Figure 22). Therefore, care must be taken when interpreting the result. The negative differences for the initial comparisons seem to imply that the B270 grounding line retreats more slowly than B260 grounding line over a particular region of the bed. However, this is not the case. Even for the first 17 co-located observations, the driving stress near the grounding line is generally higher for B270 than it is for B260 (for 
example see Figure 23). This is indicative of faster movement of the grounding line though the magnitude of the difference in driving stress indicates nothing of the direction of movement. However, starting with the $18^{\text {th }}$ co-located observation there is no longer any advance occurring. So another issue dominates at the other

- grounding line at year 526 for B260

- grounding line at year 370 for B270

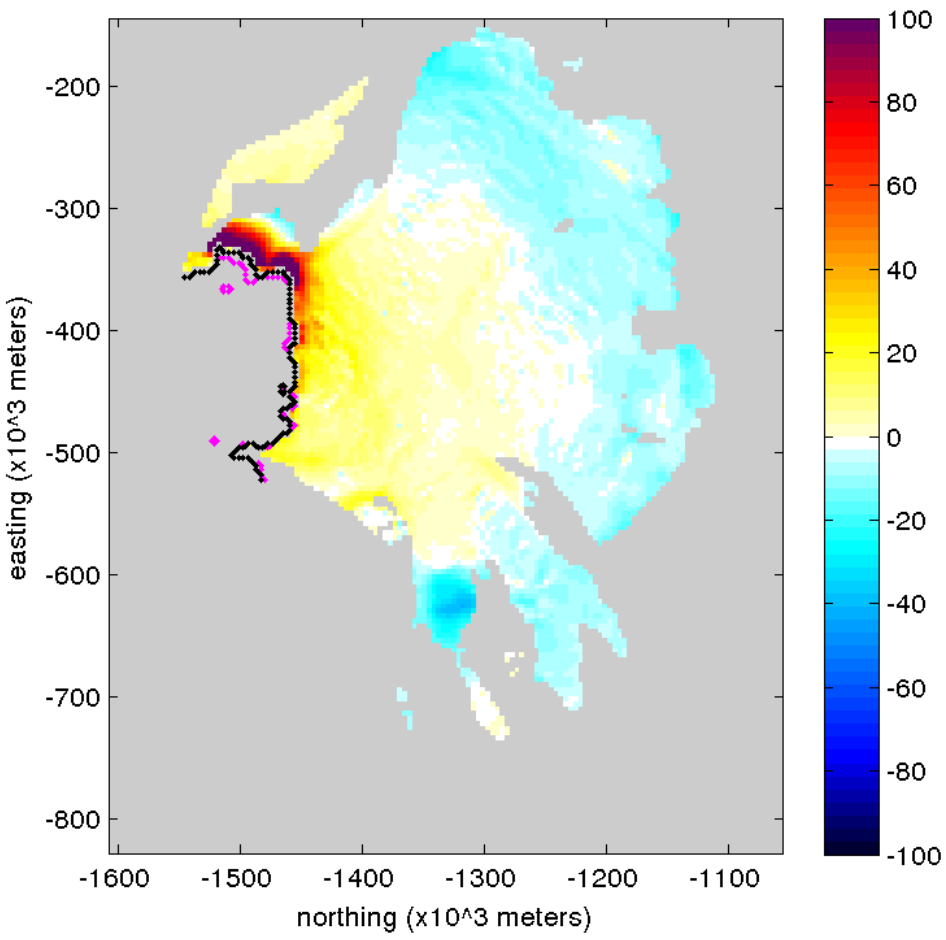

Figure 25. Spatial difference of overlapping ROIs in driving stress for co-location observation number 60 , an arbitrarily chosen example of the limitation of using regional mean driving stresses for comparison purposes. This observation (colocated position) corresponds to year 526 of B260 and year 370 of B270. Although the difference in mean driving stress is $\mathbf{- 1 . 3} \mathbf{~ k P a}$, it is apparent that there is higher driving stress near the grounding line for B270. Note that the area shown is only the overlapping ROIs for the two simulations. The difference in mean driving stress for the overlapping region shown is about $-0.3 \mathrm{kPa}$. 
co-located positions. For these observations, higher surface gradients in the interior of the basin for B260 have created higher driving stresses away from the grounding line (for example Figure 25). The B260 grounding line retreats more slowly such that the B260 ice sheet has been thinning for 151 years longer than the B270 ice sheet when grounding line co-location begins (Appendix A). The discharge causes a surface deflation signal which propagates toward the interior of the B260 basin that hasn't happened in the B270 retreat. While the faster B270 retreat maintains a higher driving stress near the grounding line than does the slower B260 retreat, it is possible for the difference in driving stress ROI means to be negative (Figure $22 \&$ Figure 25). Spatially, it is observed that at the beginning of grounding line co-location, the driving stress at the grounding line is greater for B270, the ice in the basin is thicker for B270; and the surface gradient in the interior is higher for B260 due to the earlier downstream thinning. These patterns persist through the simulation, via the increasing difference between model years, and the interior surface gradient signal of B260 propagates farther back into the interior of the basin as grounding line retreat continues. The continuing retreat increases the length of the grounding line and decreases the area of the ROIs (for example Figure 26). This increasing length, with greater driving stress at the grounding line for B270, along with the interior surface deflation signal being pushed farther toward the basin margins causes the apparent increasing trend in difference of mean driving stress (Figure 22). 


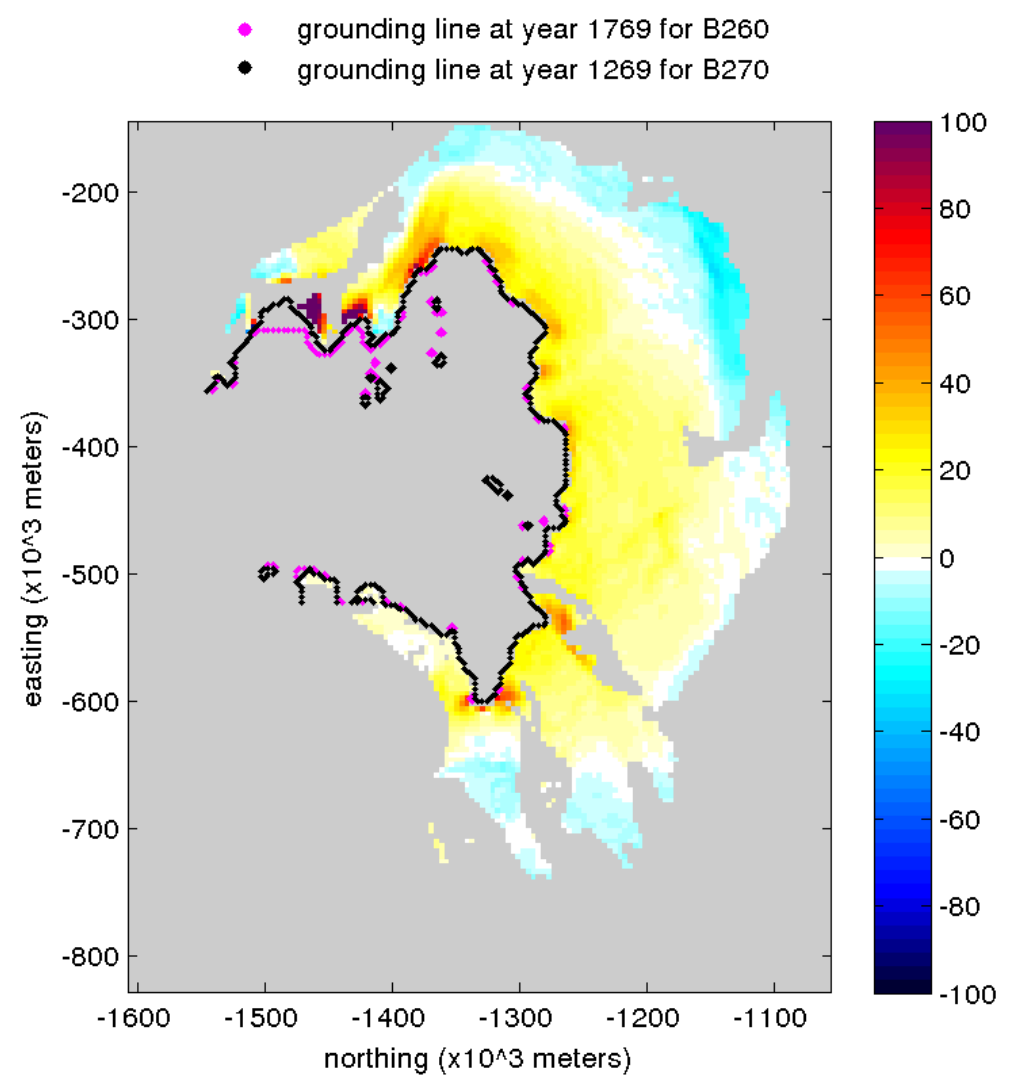

Figure 26. Spatial difference of overlapping ROIs in driving stress for co-location observation number 861 . The length of the grounding line has increased with retreat and the area of the ROIs where driving stress is calculated has decreased. The surface deflation signal of B260, causing a greater surface gradient in the interior of the basin and a negative difference in mean driving stress, has been pushed back toward the margins of the catchment.

The short-lived grounding line advance at some locations at the start of the B270 unforced retreat is interesting in its own right. To understand the effect, we must recognize that the anomalous melting yields anomalous local steepening, and so when the anomalous melting is shut off, so too is the steepening. Re-advance along the eastern section of the grounding line is due to local details of the bed shape relative to the location of the grounding line when the anomalous melting stops. Without the extra 
melting, ice that is close to the floatation limit may re-ground. If the grounding line is located on the leeward (relative to the direction of retreat) side of a subglacial high, it advances upslope and accommodates reduced ice flux through the grounding line via lowering of the surface gradient (Figure 27). This is the reverse of the
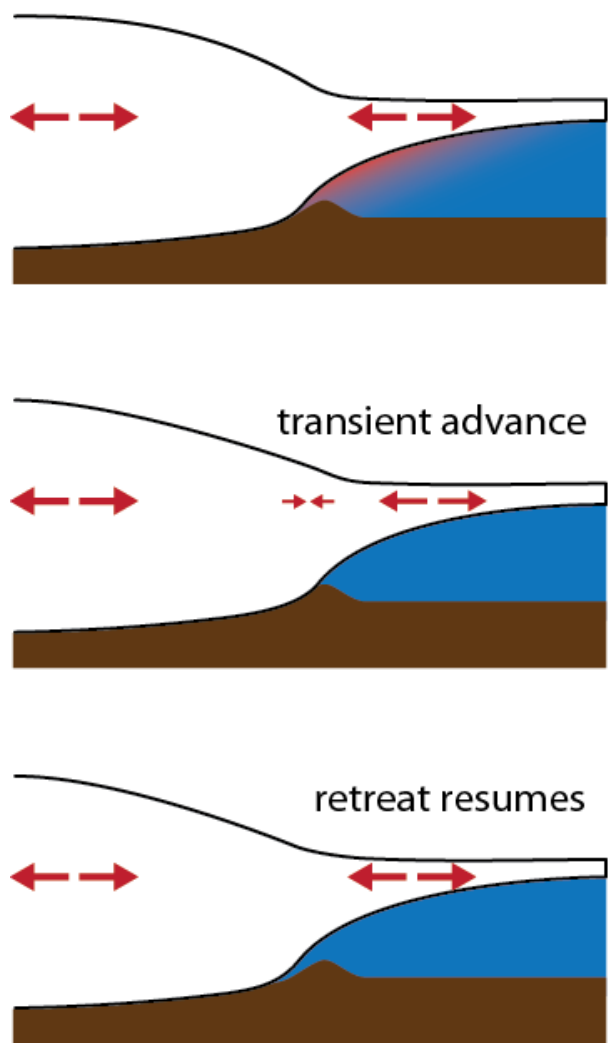

Figure 27. A cartoon depicting the transient advance observed after ramp shutoff in some locations of the B270 simulation. The grounding line is located on the leeward side of a bump in direction of retreat (TOP). As the surface gradient adjusts (lowers) to the lack of forcing after the slow ramp is turned off, the grounding line is able to advance a distance back up the bump (MIDDLE). After the system has adjusted to the new condition, retreat resumes (BOTTOM).

process in the direction of retreat, in which movement of the grounding line upslope on a bump is associated with reduced flux and an increase in the surface gradient. 
Driving stress and ice flux are coupled attributes of the system, yet they reveal different aspects of the instability as it progresses. While the difference in mean driving stress diverges over time, this is not the case for ice flux through the grounding line (Figure 20). Flux across the B270 grounding line initially decreases, when the larger anomalous melting rate is turned off and the grounding line advances, but after that, the primary difference is B270's overall larger rate.

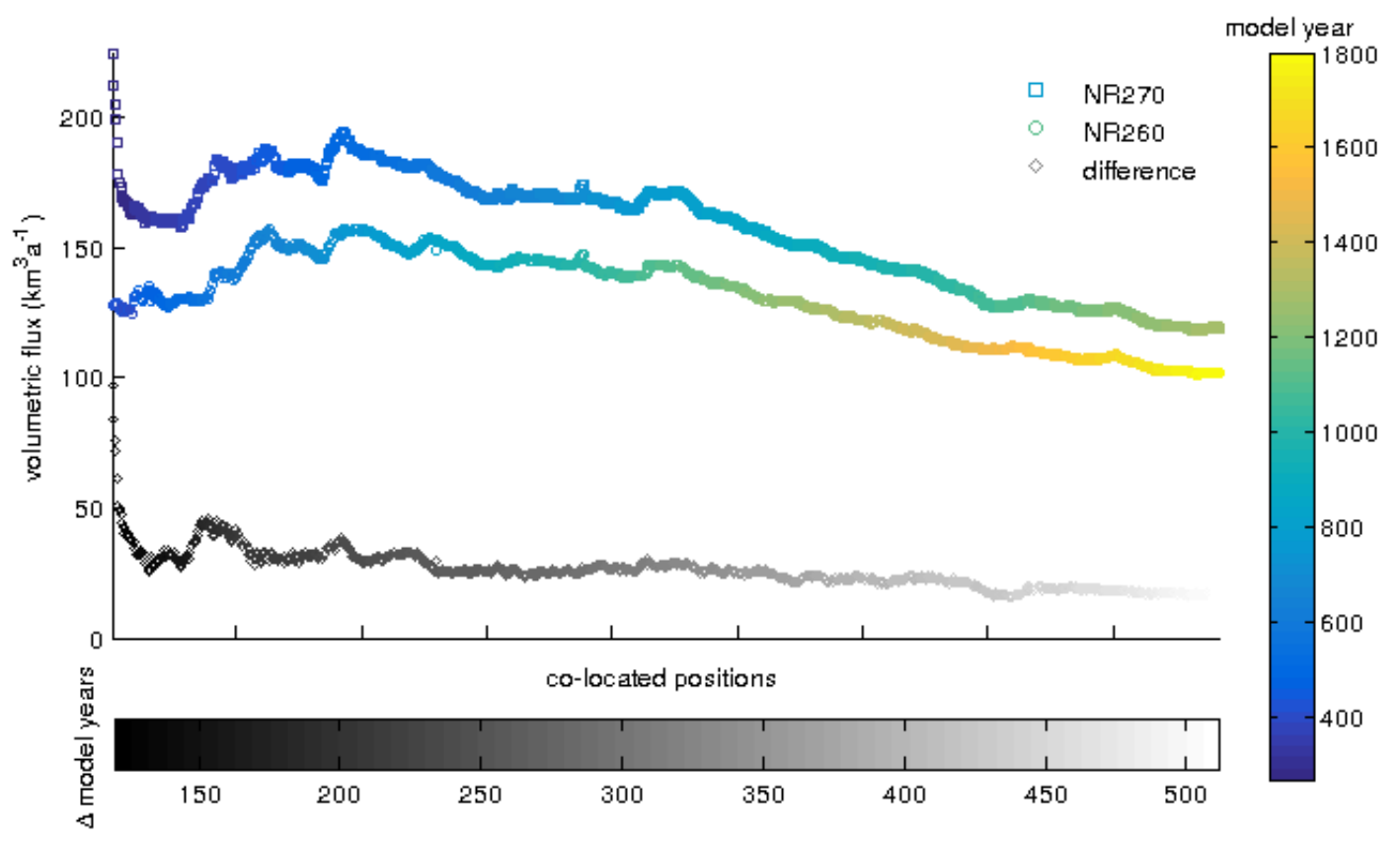

Figure 28. Volumetric flux across the grounding line for B260 and B270 over Bedmap2.

Through most of the simulation, the temporal patterns of change in ice flux across the co-located grounding line are very similar, with a Pearson correlation coefficient of 0.96 (Figure 28). In a general sense, then, the largest fluxes are associated with the same regions of the bed in both cases, irrespective of differences in driving stress. There is no 
simple relationship between grounding line location, relative to the bed shape, and overall peak discharge. Instead, the grounding line positions at this time highlight the complicated 3-D nature of retreat as at some locations they are located near crests of bed features while at others they are passing through troughs (Figure 29).

Peak discharge is followed by a slow, steady decline in flux showing that the effect of grounding line retreat is dwindling over time (Figure 28), However, this is complicated by the competing fact that the length of the grounding line is increasing with time which increases the total volumetric flux. Additionally, the flux rates tend to converge over time. There is a statistically significant negative linear trend in the flux difference when the first 17 observations are not included in the trend analysis (Figure 28). This makes sense, as the ice supply is relatively more depleted in the B270

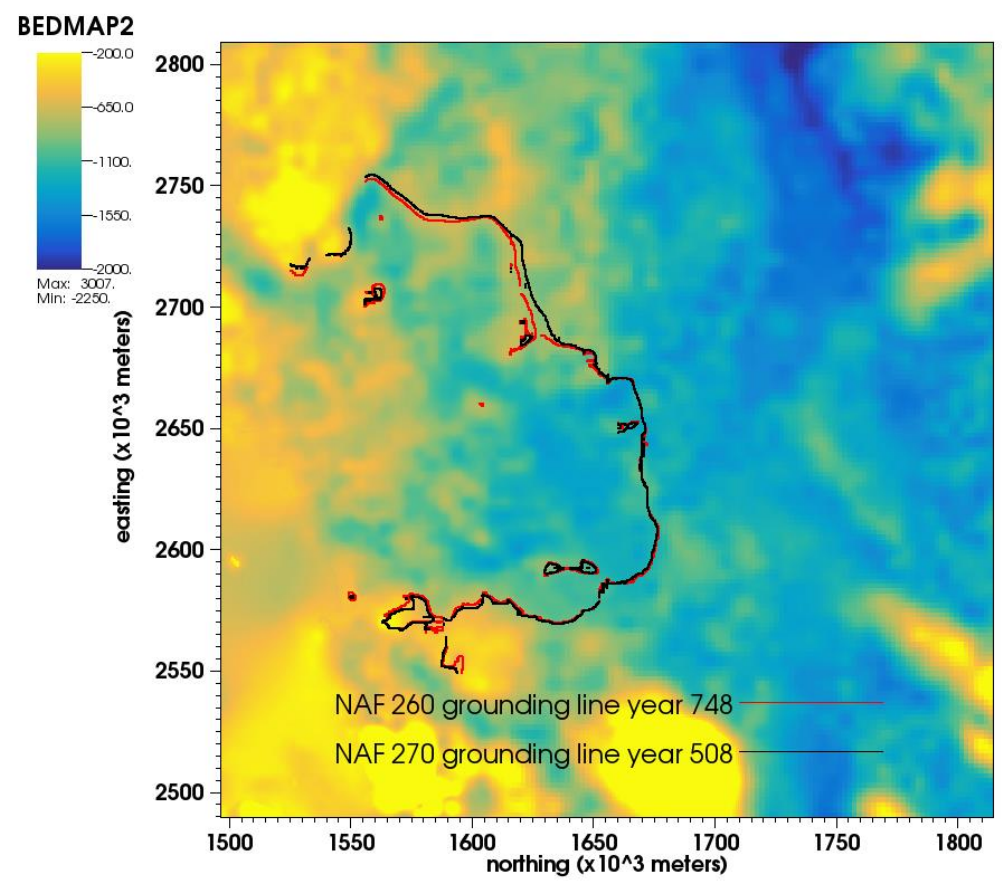

Figure 29. The grounding line positions for both simulations over Bedmap2 at the maximum volumetric flux across the grounding line for B270. 
simulation compared to the B260 simulation. Overall, the instability initiated with slightly larger melting yields a larger flux response but it also has a more complicated history, with an initial decrease and a more rapid slow-down once peak discharge is achieved.

\subsection{Experiment 2: Comparison to Retreat over Goff Bed}

A regional instability was detected over the Goff bed at year $425(21.25 \mathrm{~m} / \mathrm{a}$ melt $)$ of the anomalous forcing (Figure 11). This is an additional 155 years (165 years) and $7.75 \mathrm{~m} / \mathrm{a}$ additional melt $(8.25 \mathrm{~m} / \mathrm{a})$ relative to the B270 (B260) scenario. Consequently, the grounding is approaching the center of the basin by the time a true instability is initiated (Figure 30). The arcuate shape of the retreating grounding line is even more pronounced than it was in the other simulations (Figure $18 \&$ Figure 30) and the grounding line has retreated to a much deeper part of the reverse slope. The G425 grounding line does not experience re-advance when the anomalous forcing is shut off. It might be expected, then, that the retreat rate over the Goff bed is greater than the retreat rate over Bedmap2 (Figure 31). However, the higher resolution, rougher Goff bed supports more complicated grounding line geometry and retreat pattern than the lower resolution, smoother bed (Figure 31). 


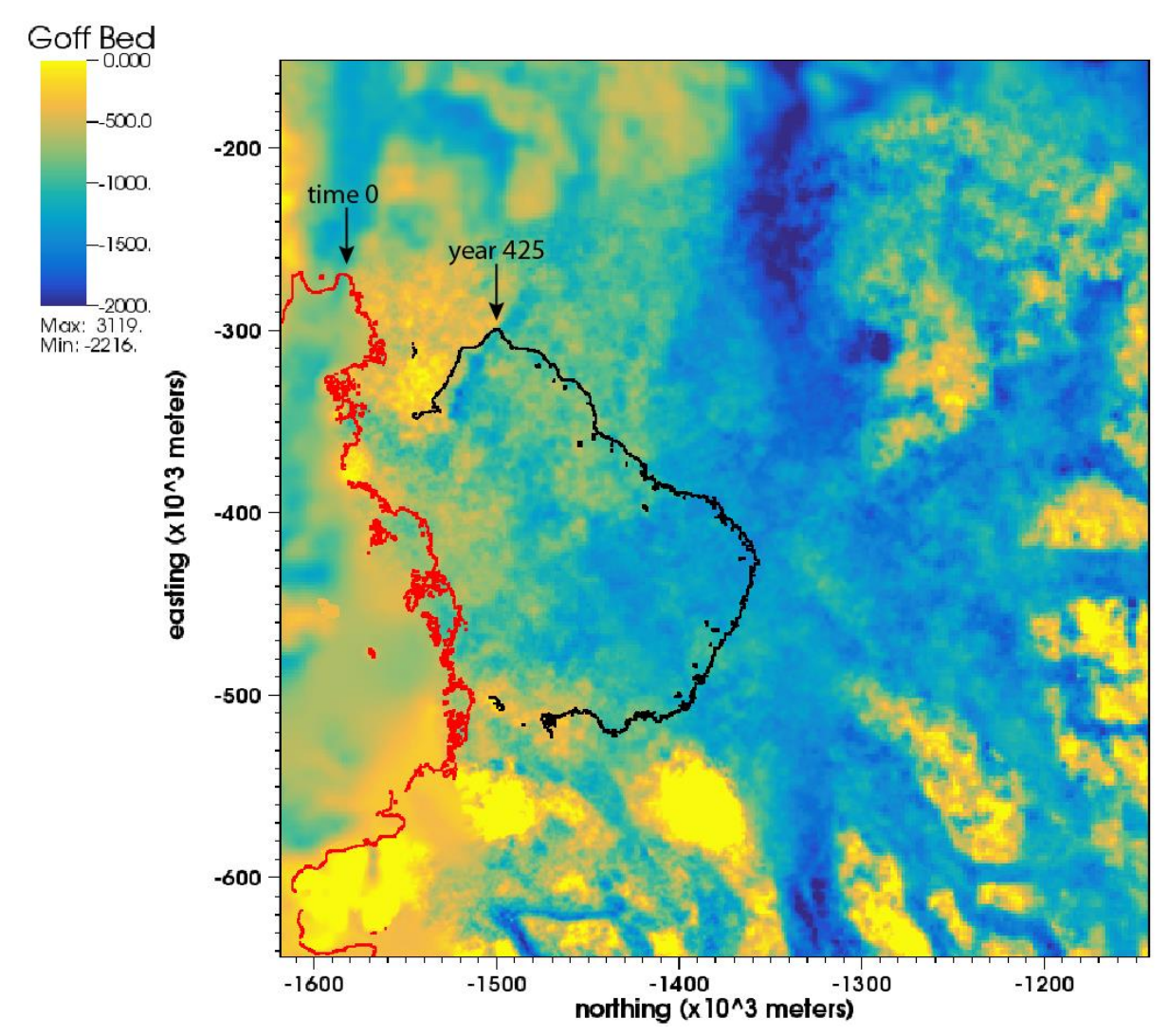

Figure 30. Grounding line position at the start of the anomalous forcing (red line) and at the year an instability is detected (black line) over the Goff bed.

As B270 is the faster of the two unforced retreats over Bedmap2, it will be used for comparison to G425. Results of this comparison are presented in a similar manner as the first experiment, focusing on driving stress and discharge. but co-location of the grounding line is more challenging. For retreats over Bedmap2, co-location by matching grounding line positions along a single transect through the basin generally provided a reasonable result. When the first transect did not produce a good match over a number of model years, another transect usually did and could be substituted in the comparison. Different sub-basins experienced similar retreat rates and while the timing differed, the spatial pattern of retreat was similar for B270 and B260. This does not hold for 
comparisons across different bed geometries, meaning that a more complicated approach is required to co-locate grounding lines between B270 and G425.

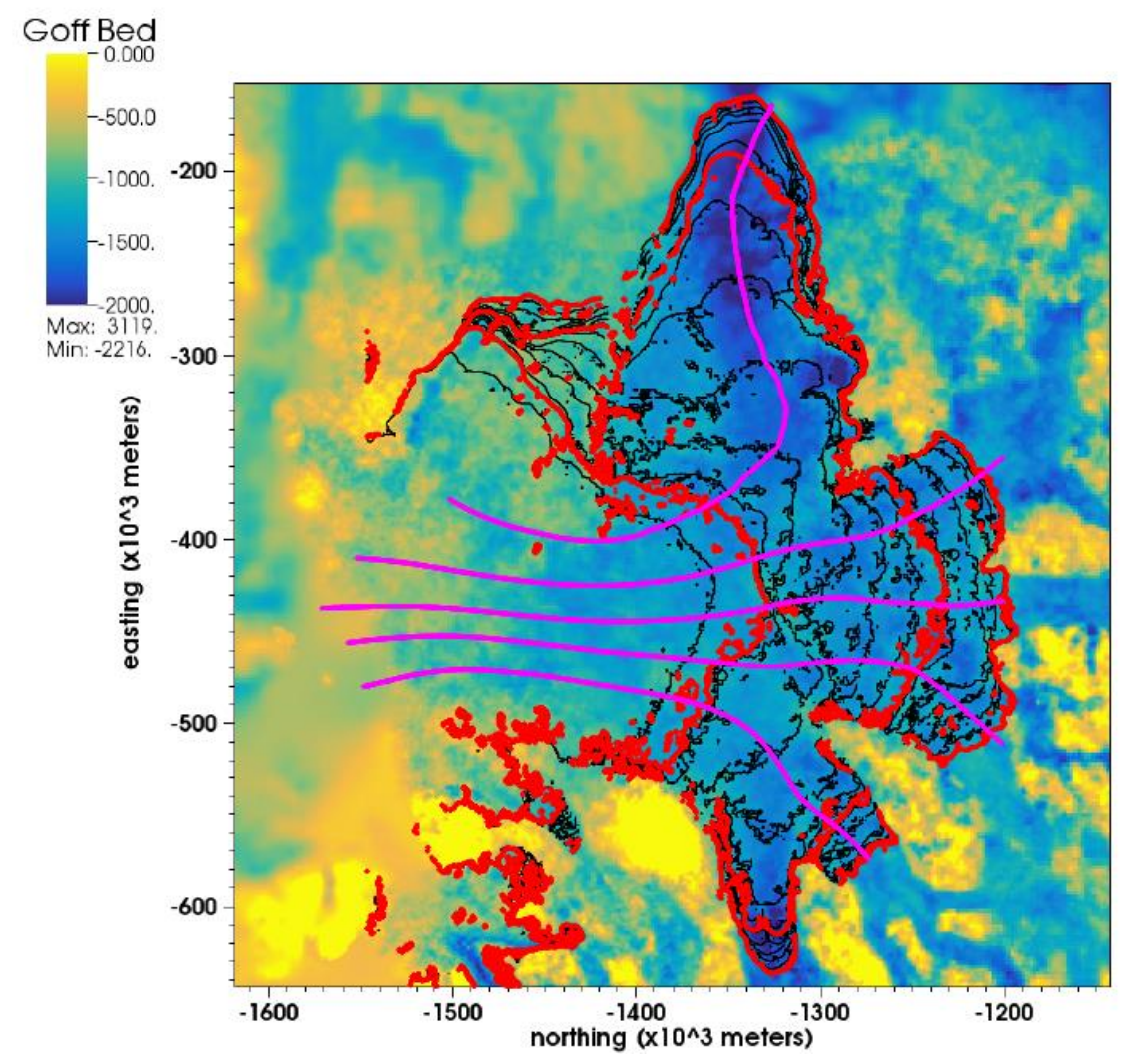

Figure 31. Contours of unforced grounding line retreat for G425. The contour interval for black lines is 100 years starting at year 425 . The contour interval for red lines is 500 years starting at year $\mathbf{5 0 0}$. The magenta lines indicate transect locations used for the co-location procedure and in other figures. The final contours are at model year 1500 .

Initial attempts at grounding line co-location for retreats over different beds showed that poor grounding line configuration matches result in greater thickness differences between the ROIs. This is due to the lobate shape of the grounding line during retreat and the fact that usually when there is a mismatch it is because the grounding line is co-located at the transect but the slower scenario is in an advanced retreat position 
elsewhere. This exaggerates the positive differences in ice thickness between ROIs. On the other hand, in the fewer instances where the faster simulation's grounding line is in an advanced position, negative thickness differences tend to be localized near the grounding line and do not cause the mean difference to be negative at any position determined to be co-located.

The following approach was developed to find the best possible co-located grounding line positons between B270 and G425. Transects T1, T2, and T4 were used, while T3 and T5 proved to have very limited grounding line position matches between the two simulations (Appendix B).

1. For any given year in the G425 simulation, the grounding line matches, if any available, were collected and the one with the lowest positive difference in thickness between G425 minus B270 was selected. Note that this is using the 10 $\mathrm{m} / \mathrm{a}$ velocity cutoff in the ROIs.

2. Overall, thickness differences should decline as time and spatial positions advance from the relatively high starting values along the transects. Therefore, any records that had a higher value than the initial difference along $\mathrm{T} 1$ were discarded. The initial thickness difference for the grounding line position match at $\mathrm{T} 1$ is the median of the three transects used.

3. Any records where the thickness difference increases more than $20 \mathrm{~m}$, an arbitrarily selected value, from the previous record are discarded.

4. Since more than one transect is involved in providing grounding line position matches, thus far it is possible that an increase in model year for G425 from the 
previous observation may be accompanied by a decrease in model year for the B270 simulation when switching transects for successive observations. For example, if the grounding line match was best using T1 for model year 450 (G425) and model year 680 (B270), and T2 provided best grounding line position match for next observation at year $451(\mathrm{G} 425)$ the co-located position along this transect may be model year 679 (B270). Therefore, any records where B270 moves back in time are removed so that co-location always involves increasing model year for G425 and B270.

5. Eight records were removed by visual inspection due to a lack of continuity concerning matching positions.

This procedure improves continuity in time above what could be achieved along any single transect though the co-locations are not as precise as in the B270 to B260 comparison. Inspection of many outcomes gives some confidence that the co-location is suitable to make comparisons (Appendix M).

The initial G425 grounding line is co-located with the year 659 grounding line in the B270 scenario. The G425 retreat proceeds more quickly over the same region of the bed (Figure 18, increasing difference in model year at co-location) and as in the B270 to B260 comparison, the difference in mean driving stress is higher for the simulation in which the anomalous forcing is shut off at a later time (Figure 32; using the same $10 \mathrm{~m} / \mathrm{a}$ velocity cutoff as in the first experiment). This is primarily a result of the larger of driving stress difference near the grounding line (for example Figure 33). The driving 
stress difference grows for the first 571 years of the G425 simulation (to observation 106) but then begins to decline as the model ice sheet experiences surface lowering in its interior. Short-lived variations in the driving stress difference, as between observations 10 and 50, are due to local across-flow differences in grounding line order (in some locations, at some times, the B270 grounding line leads the G425 grounding line).

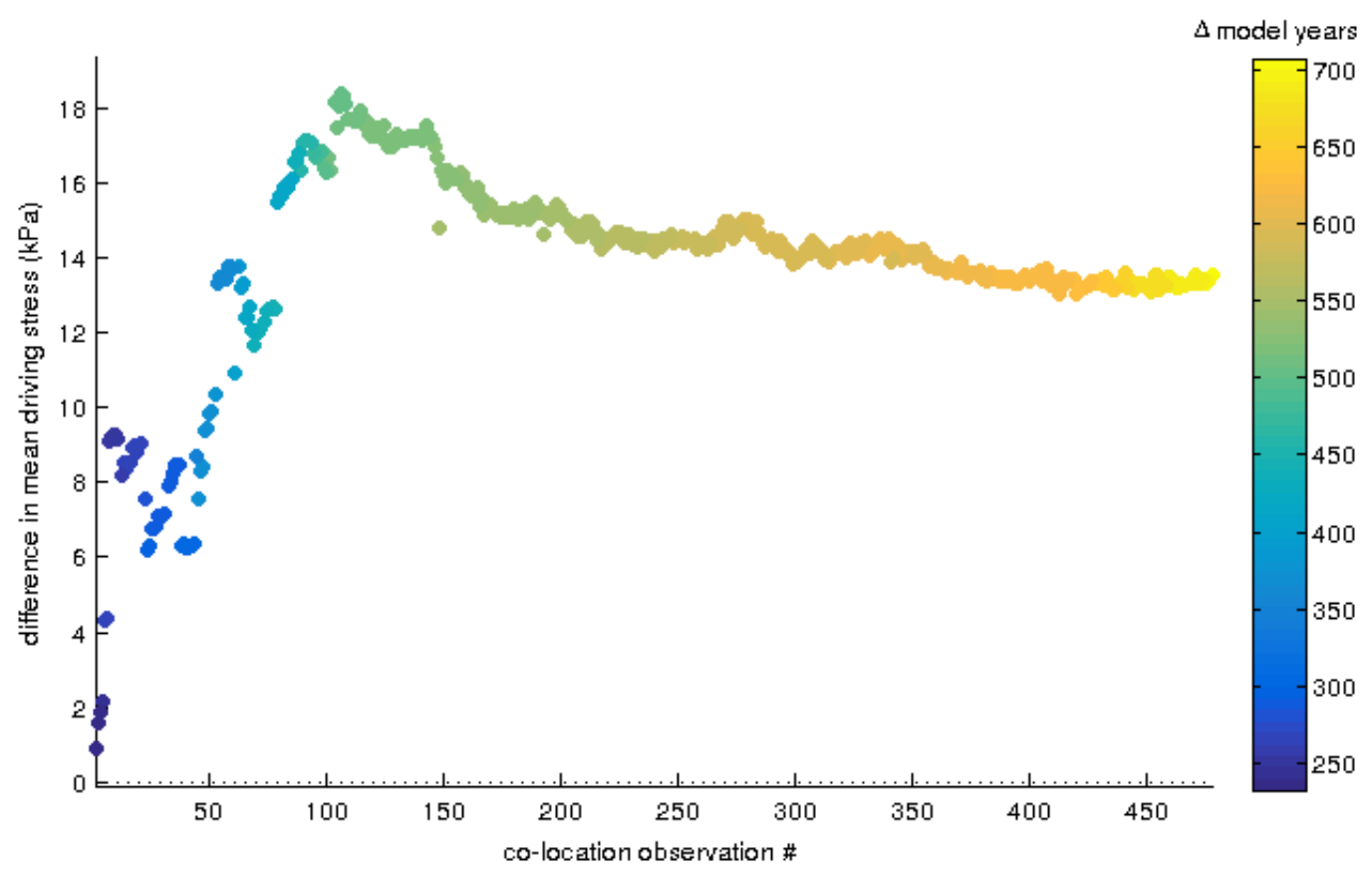

Figure 32. The differences in mean driving stress for B270 vs G425 (G425 - B270). 


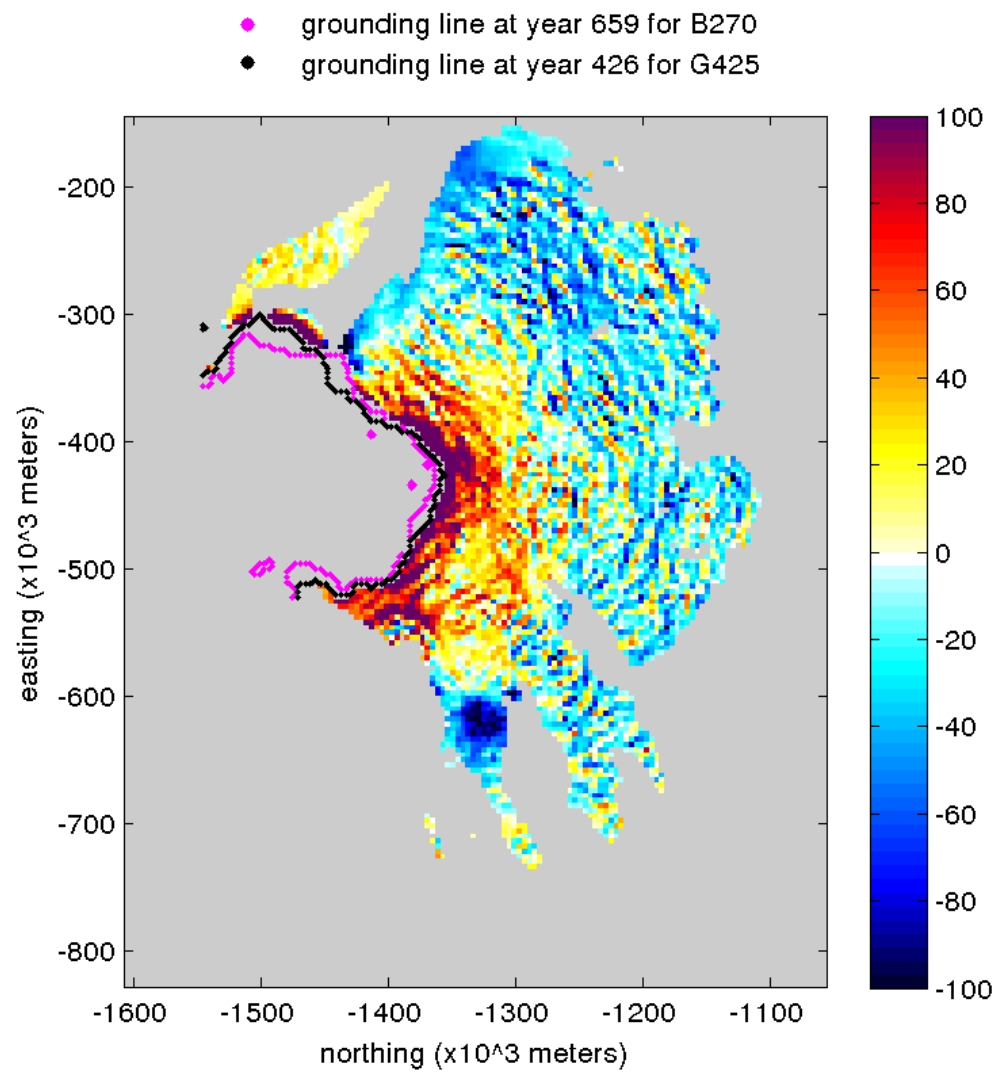

Figure 33. The first spatial observation ( $4 \mathrm{~km}$ resolution) of difference in driving stress (kPa) in overlapping ROIs for co-located grounding lines in the second experiment (G425 minus B270). The magnitude of the difference is generally greater than the B270 - B260 comparison.

Different bed geometries yield different spatial patterns of grounding line retreat.

For example, at the first co-location (Figure 33), the B425 grounding line leads (in the upstream sense) in some locations while it lags in others. Switches in the lead/lag relationship also occur (Figure 34 \& Figure 35). Leads and lags sometimes generate gaps in the comparison series during which the grounding line geometries are so different that co-location is not possible., 
- grounding line at year 1305 for B270

- grounding line at year 863 for G425

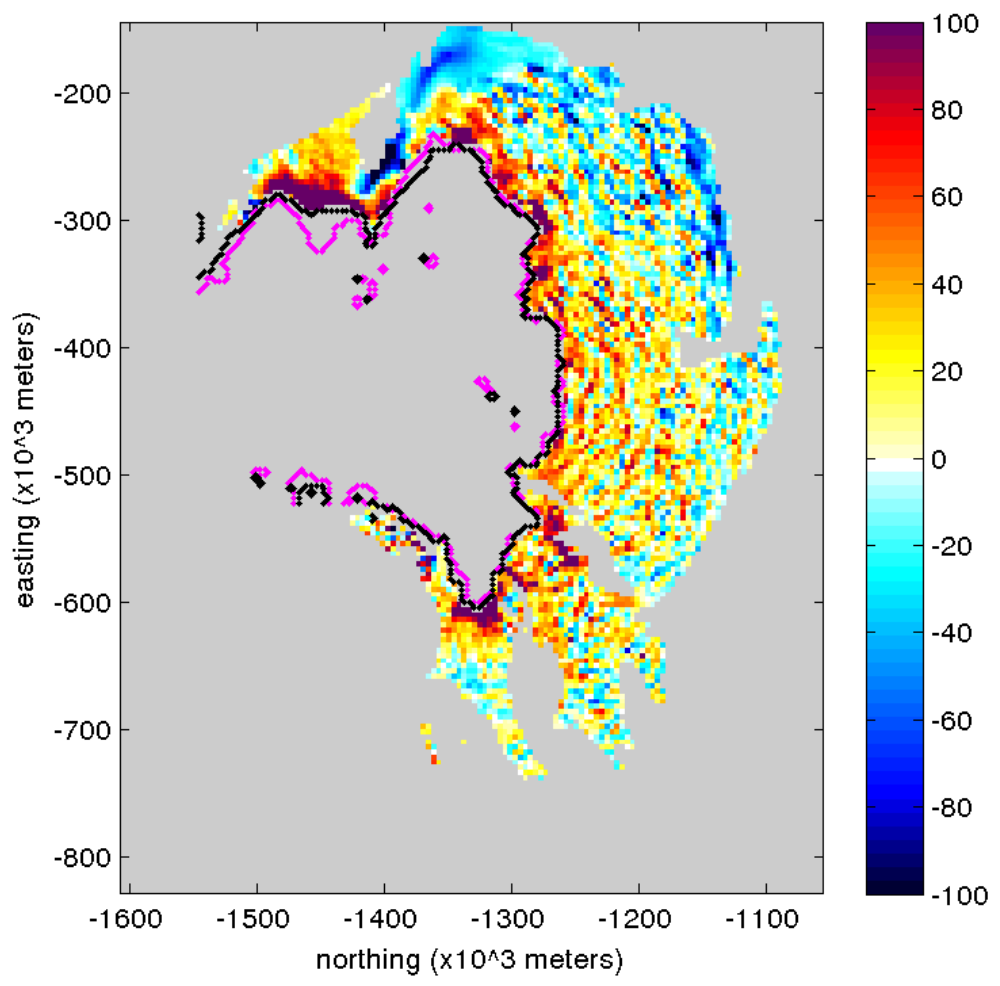

Figure 34. Observation 78 of the difference in mean driving stress for overlapping ROIs (4 km resolution). The grounding line of B270 is leading that of G425 in most of the locations in the lobe above $-\mathbf{3 0 0} \mathrm{m} \mathrm{E}$. In the lobe near $-600 \mathrm{~m} \mathrm{E}$, the grounding line of G425 leads. 


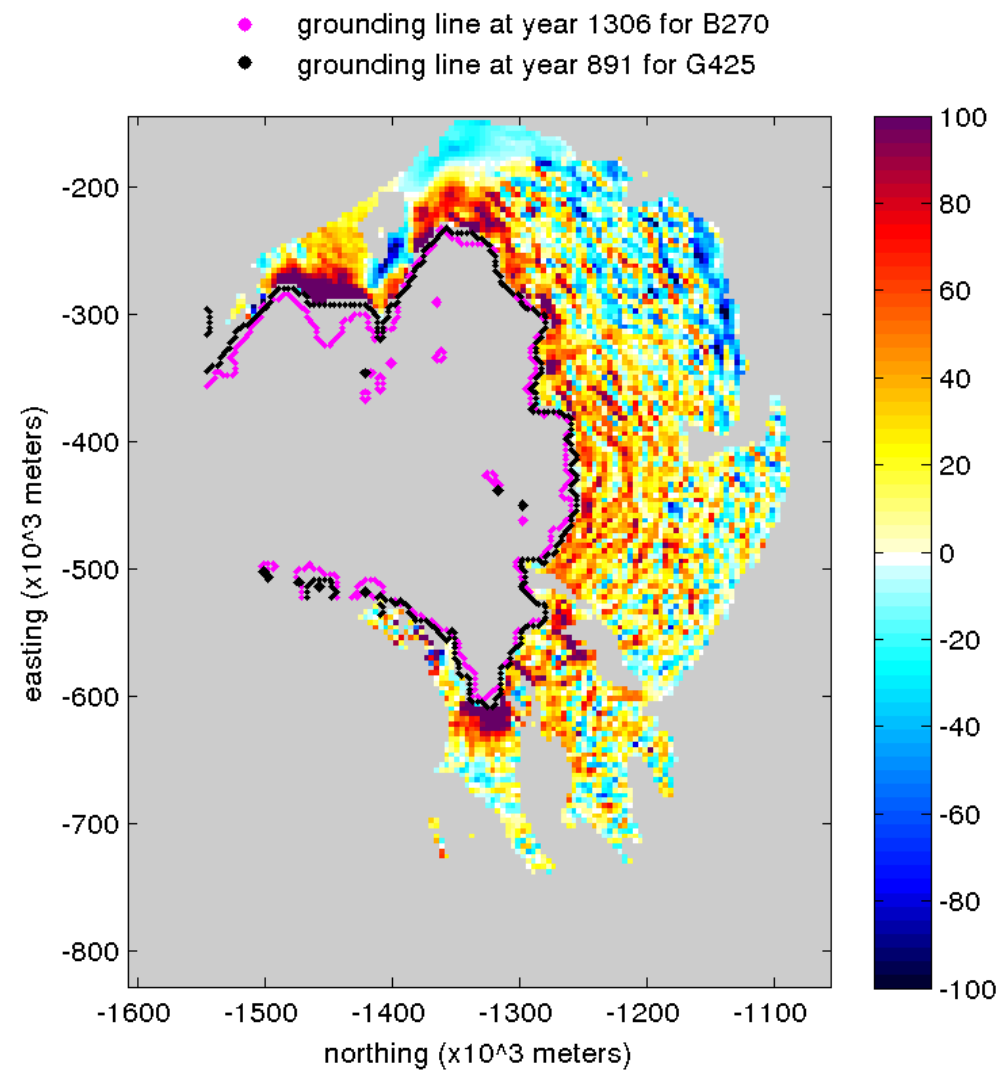

Figure 35. Observation 79 of the difference in mean driving stress for overlapping ROIs (4 km resolution). The grounding line of $\mathbf{G 4 2 5}$ is either co-located in an advanced position of retreat relative to that of $B 270$ in the lobe above $-300 \mathrm{~m} \mathrm{E}$. This results in greater positive differences and a lessening in the magnitude of negative differences in this location. Furthermore, the grounding line of G425 has retreated farther than B270 at the lobe near $-600 \mathrm{~m} \mathrm{E}$ causing greater positive differences in driving stress here.

Gaps are not characteristic of the entire simulation comparison. Instead, they are a feature of the time when the model grounding line is retreating over the widest part of the catchment basin. The largest co-location gap, between observations 43 and 44, is 215 years for B270 and 166 years for B425 (Figure 36). The maximum difference in mean driving stress of $14.8 \mathrm{kPa}$ is reached at observation 106 corresponding to model year 
1498 for B270 and model year 997 for G425 (Figure 32). After this, the difference in means decreases slowly toward a minimum of $13.1 \mathrm{kPa}$ is at observation 403 , beyond which, the difference in mean driving stress holds relatively steady (Figure 32). This is an interval during which the grounding line is retreating up different tributary subbasins.

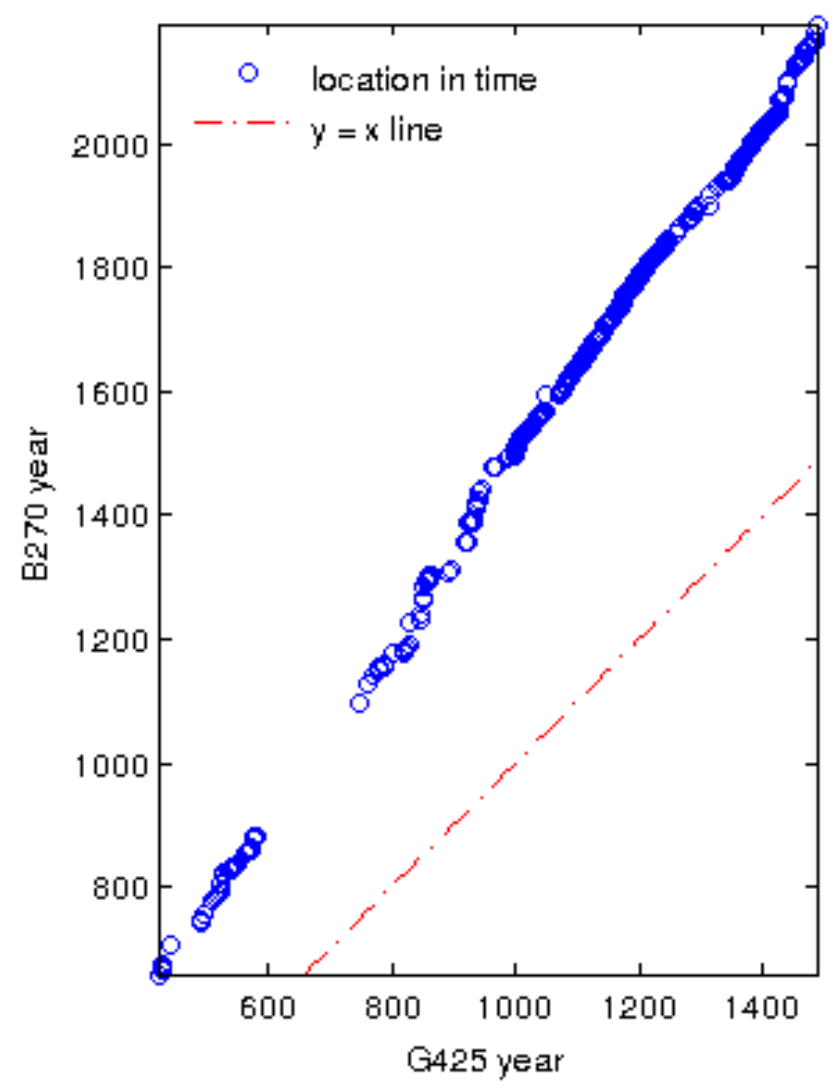

Figure 36. Year of co-located position in the B270 and G425 simulations. The largest gap, between observations 43 and 44, spans 215 years of B270 model time and 166 years of G425 model time. The trend for locations in time is nearly linear with a slope greater than 1.

The volume flux rate is relatively high when the G425 instability is triggered and declines from that time forward. Meanwhile, the B270 ice sheet is well past peak discharge (Figure 28) when the co-located flux comparison begins (Figure 28 \& Figure 
37). The G425 flux rate is larger than the B270 rate but the difference between the two declines toward a nearly constant, and relatively small, offset as the grounding line retreats into the upper reaches of the basin (Figure 37).

All three simulations are characterized by different rates of grounding line retreat and the spatial patterns of retreat are more similar for simulations over the same bed than for simulations over different bed geometries. Nevertheless, important similarities also exist. While the flux rate difference is more variable for the B270 to B260 comparison, the pattern of change is overall more similar than for the G425 to B270 comparison (Pearson correlation coefficient of 0.90 for G425 vs B270 and 0.97 for B270 vs B260). Yet both correlation coefficients are relatively large and this yields important insight into the role of the bed. Local and regional scale relief determine the timing of instability onset, and thereby set the time trajectory for each scenario, but the basin scale geometry appears to set the longer time scale response of the system. Were this not the case, the flux rate patterns of all three scenarios would not be so similar. 


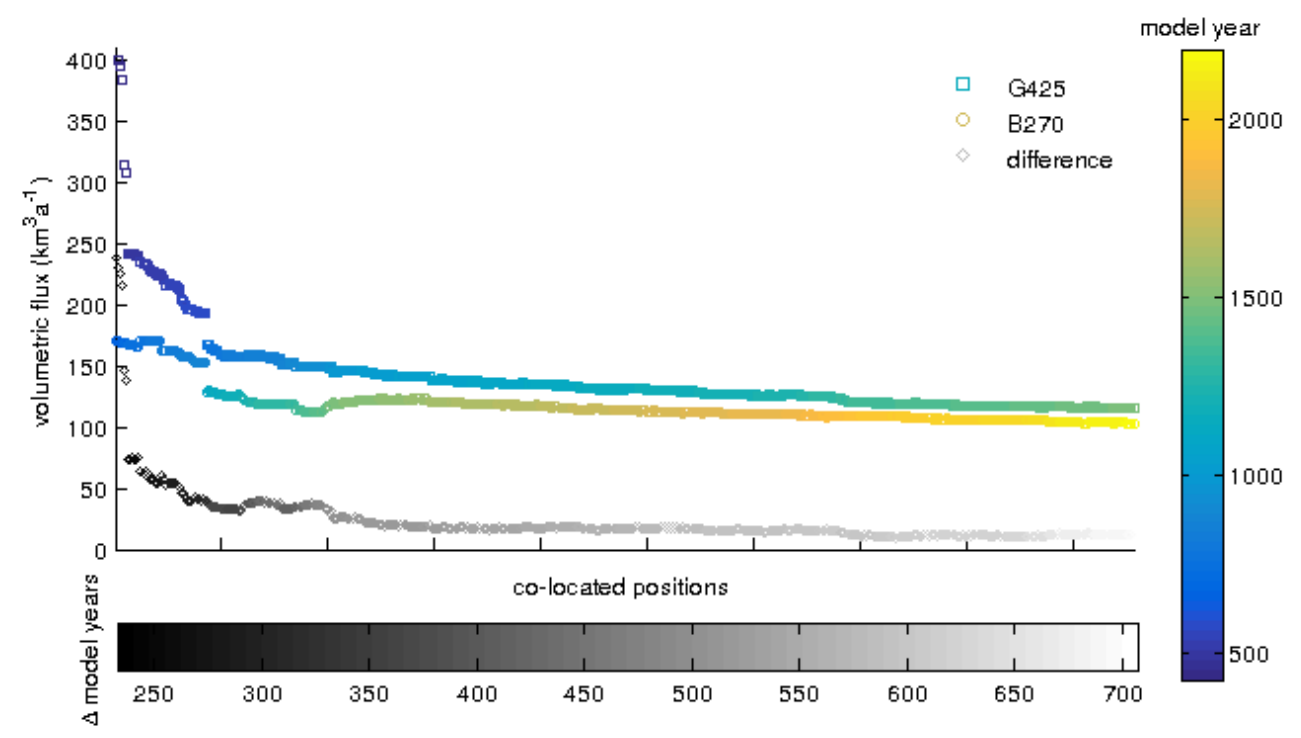

Figure 37. Spatial series of volumetric flux across Thwaites grounding line for B270 over Bedmap2 and G425 over the Goff Bed.

\subsection{Summary of Mass Loss for all Simulations}

The three scenarios yield different contributions to global mean sea level in both amplitude and timing. Using $918 \mathrm{~kg} \mathrm{~m}^{-3}$ as the density of glacier ice, the global sea level equivalent (SLE) is calculated from the VAF (Figure 38 \& Figure 39). In order to examine the total contribution to sea level, year 0 is set to be when the anomalous forcing begins. Thus, these figures are time series rather than co-located spatial series. Dashed lines indicate when the ramp was turned off for each simulation (Figure $38 \&$ Figure 39). These are not forecasts of sea level rise but rather a means to compare the loss of ice across all simulations. 


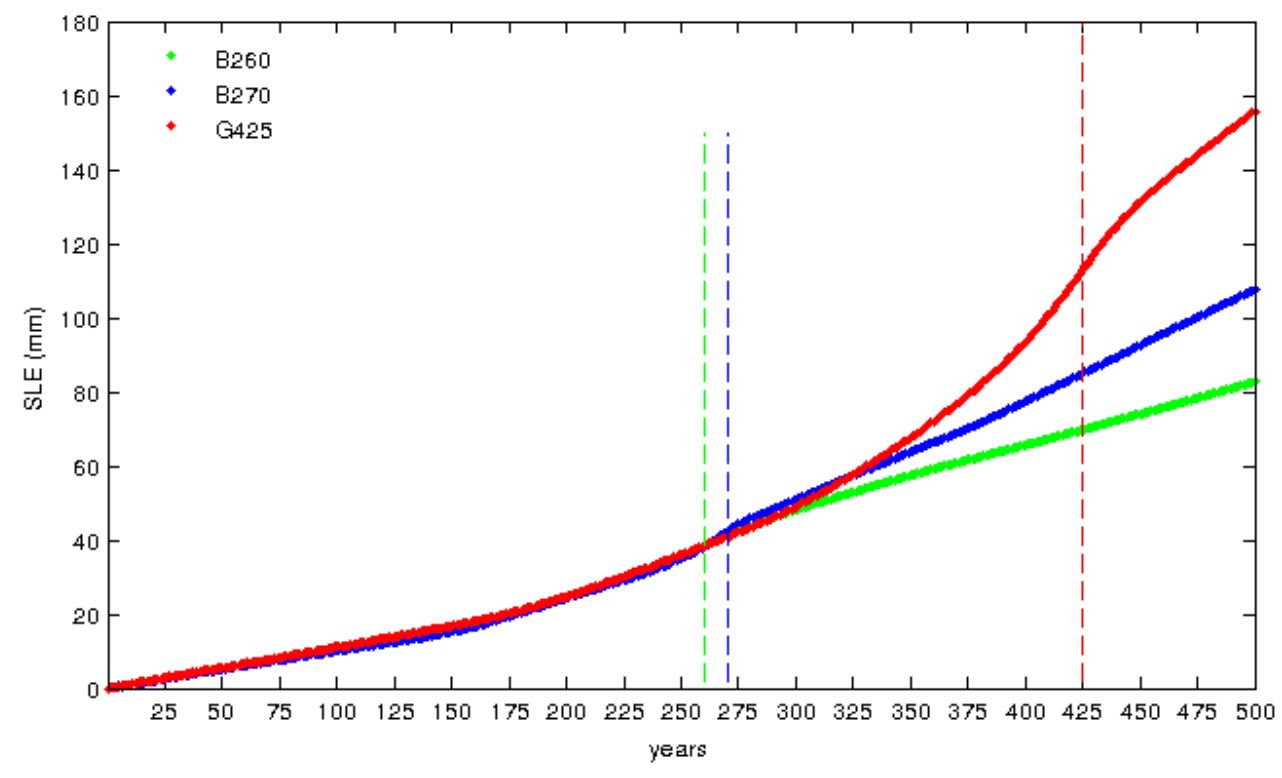

Figure 38. Ice mass loss in terms of SLE over the first 500 years for all simulations. Year 0 is when the slow ramp in anomalous forcing begins. Dashed vertical lines show when the ramp was shut off for each simulation and the unforced system was allowed to evolve.

The total mass loss for all simulations over both beds is similar until year 300 (Figure 38). The three models experienced similar anomalous forcing for most of that time. After year 300, mass loss for both B270 and G425 exceeds mass loss for B260. At year 323, mass loss for G425 begins to exceed that of B270. However, the anomalous forcing was still applied to G425 at this time. In all three cases, turning off the anomalous forcing is associated with an inflection in the time trajectory-from an increasing to a decreasing flux rate (Figure 39). Unstable retreat contributes less, overall, to sea level than forced retreat. Although a steady state is not achieved in any of the simulations, the total mass loss in terms of sea level rise are within $7.5 \%$ of each other at the end of the model runs (Figure 39). This end is where the final grounding line contours are most colocated in the catchment. 


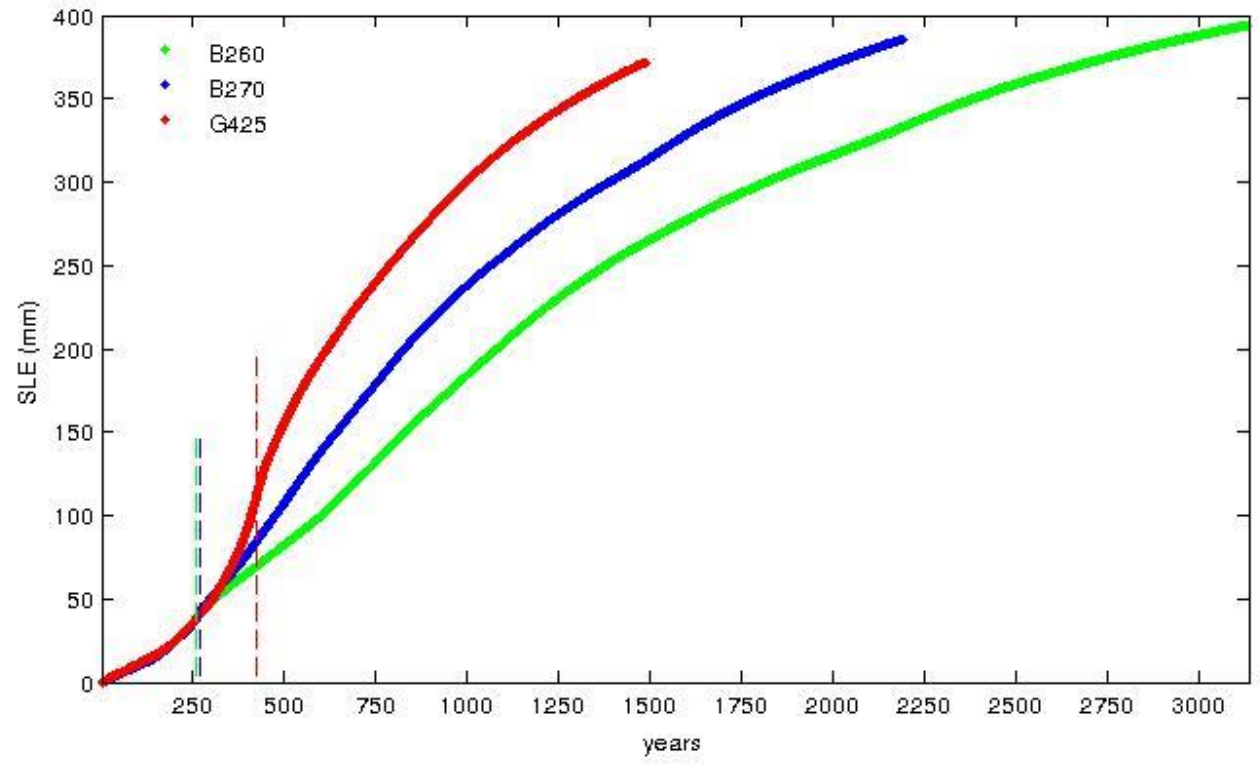

Figure 39. Ice mass loss in terms of SLE over the course of all simulations. Year 0 is when the slow ramp in anomalous forcing begins. Dashed vertical lines show when the ramp was shut off for each simulation and the unforced system was allowed to evolve. Note the inflection points for all series between years 250 and $\mathbf{5 0 0 .}$ 


\subsection{DISCUSSION}

Change initiated at its marine margins has the potential to drive rapid change in the West Antarctic Ice Sheet. Rapid retreat may arise via an instability associated with the inland-deepening bed beneath the ice. It may also be driven simply by large melting at the grounding line, without ever triggering an instability. Either situation may apply to a given grounding line, but the two are not the same and the distinction is important. A genuine instability will sustain itself if the initial forcing is removed while a melt-driven retreat will not. Here, the focus is on finding and understanding a genuine instability, and in particular the role of the bed in both the onset and progress of unstable grounding line retreat.

The choice of bed for modeling a system like Thwaites Glacier and its role in ice sheet evolution is important for several reasons. Contact with the land surface, both at the base and along the sidewalls of outlet glaciers, provides resistance to the driving stress. Bed topography strongly influences the basal traction field, both in the actual system and as obtained in model initialization. Large-scale bed features also play a role in guiding the flow path (e.g. Sun et al., 2014). As discussed in Section 4.1 Spatial Patterns of Difference in Driving Stress for Thwaites Glacier and in detail for general cases by several other authors, bed features also influence the surface topography of the ice sheet, and therefore the driving stress, because surface undulations are formed by ice flowing over bed features (Gudmundsson, 2003; Rydt et al., 2013; Schoof, 2002; Sergienko et al., 2014). Now, this study shows that bed resolution is important to the initiation of an instability and the resulting retreat rate as the ice evolves. 
A key finding of this study is that bed resolution appears to set the threshold for the initiation of an instability. This is shown by the second experiment, in which $8.25 \mathrm{~m}$ more anomalous melt, which led to a grounding line configuration extending far into the basin was required to generate an instability over the higher resolution Goff bed compared to what was required over the Bedmap2 bed. When the retreat response is not dominated by a very large forcing, the grounding line retreat rate is paced by the shape of the bed. Retreat slows as the grounding line approaches the crest of a local topographic high and in some cases pauses at the crest before rapidly continuing the retreat. This is due to induced changes in ice flux across the grounding line (Figure 40 \& Appendices G $\mathrm{K})$. It appears that this spatial variation in retreat rate along the length of a grounding line has a net effect influencing the forcing magnitude necessary to generate an instability.

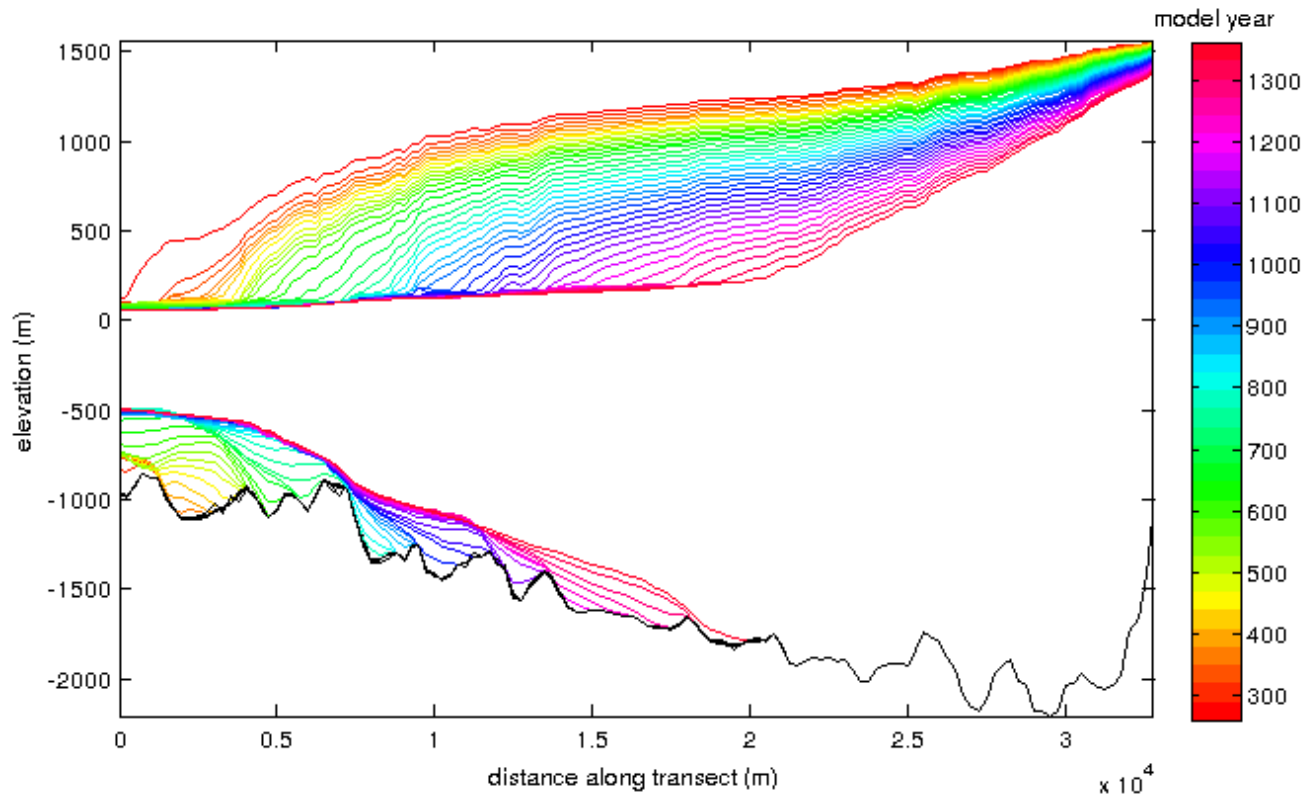

Figure 40. The first 1,360 years of unforced grounding line retreat along $\mathrm{T} 1$ for B260. Time interval is 30 years. Note that the grounding line slows or appears to hang near the crest of a bedrock bump before rapidly descending. 
The magnitude of anomalous forcing required and the location in the basin of the grounding line at the time the instability initiates together effect the ensuing rate of retreat. It seems reasonable to suppose that when summed together, the local rate changes around highs on the bed (slower on the forward slope, faster on the reverse, inlanddeepening, slope) would produce the same overall rates over the higher and lower resolution beds. This is not the case. The location of the grounding line on an inlanddeepening bed generally means thicker ice toward the interior of the basin. A larger surface gradient caused by larger anomalous forcing at shutoff means the surface gradient during unforced retreat is higher than it would otherwise. My model experiment results show that both greater thickness and a larger surface gradient near the grounding line create greater driving stress here, hence a faster retreat rate, for an instability generated over the higher resolution bed, or when anomalous forcing beyond that required to generate an instability is applied.

Faster unforced retreat for a higher resolution and more realistic bed has implications for basins in similar settings. Projections of future contributions to sea level will be much less accurate if they are not made over higher resolution beds. Furthermore, correct representation of the marine forcing is clearly important in conditioning the unstable retreat. Overall, it is the combination of the bed shape and the anomalous forcing that set both the transition to unstable retreat and overall rate at which the retreat progresses. 
An interesting outcome of the experiments using a slow ramp forcing approach is that slight changes to the duration and magnitude of the forcing send the system along different trajectories. This emphasizes the importance of improved knowledge of the real world forcing for models intended to make high temporal resolution projections of future sea level change. It also indicates that even in the case that an instability is initiated, the magnitude of the climate change that led to the retreat matters. Ongoing retreat may be inevitable, even in the case that the ocean forcing is removed, but the rate of the retreat is not locked in. Perhaps models such as this can be used to help global communities understand the importance of carbon emissions policy settings.

The melting parameterization used here takes a particular point of view on the ocean that comes into contact with the grounding line. By setting a water layer thickness limit on the maximum melt rate, we envision a seawater wedge moving inland, modified by mixing with cold meltwater as the ice lifts off the bed. This approach places the maximum melting rate where the slope of the ice base is relatively large, and away from the point where the ice lifts off from the bed. As the slow ramp grows, the geometric effect of the piecewise function decreases and the anomalous forcing comes to dominate the melting pattern. Although simplified as compared to the real-world setting, the melting parameterization is meant to capture the basin-scale retreat effect. As no forecasts or focus on the timing of retreat over particular subbasins are involved, there is no reason to include a more complicated parameterization. Moreover, a more complicated melt parameterization such as a plume model, would deliver warm water differently over different beds, confounding our aim of comparing the effect of the bed 
on ice sheet evolution and grounding line retreat. It is worth noting that a simplified meltforced retreat assumes that warm water will continually reach the grounding line. However, as retreat proceeds and the fetch to the ocean increases, there is no guarantee that this would occur.

The surface accumulation rate is fixed in the model. This means that the increase in snow accumulation that is in general associated with lower elevations is not accounted for as the grounding line retreats and the model ice sheet lowers. The result may be a slightly faster retreat than would otherwise be the case.

As with all numerical models, the ice sheet model used here has limitations. Three related issues should be considered here. First, the inverse initialization generates a fixed basal traction field and no processes that might modify the traction are represented in the model. Yet certainly, as ice thickness and surface slope change, the properties governing basal traction will change as well. Second, SSA* is used everywhere, yet clearly vertical shearing drives ice flow in the thinner, frozen bed areas of the Thwaites basin. Third, the model assumes a viscous till rheology.

Problems with the fixed basal traction involve both is initial setting and the fact that it does not change in response to changing ice conditions. The largest blunders associated with assigning the initial basal traction are probably close to the grounding line, where slope and thickness change the most. In fact, zero and first order ice flow approximations assume bridging forces are negligible which lead to a higher, compensating basal traction near the grounding line (Morlighem et al., 2010). Inland of the grounding line, basal traction may vary as the hydraulic gradient and basal thermal 
condition change but this cannot be accounted for in the present model. The situation is no different than for other models initialized using an adjoint approach. Fortunately, this is a comparative study and no projections are being made so issues associated with a fixed basal traction field are not as important as they might be otherwise.

The model could be improved by inclusion of a parameterization that routes ice sheet basal meltwater and connects that water with basal properties (Creyts and Schoof, 2009; Flowers, 2015; Flowers and Clarke, 2002; Hiester et al., 2016). However, such an addition would add poorly constrained parameters to the initialization and would require thorough investigation. Well constrained parameters lead to a straightforward interpretation of results. However, a parameter space investigation using a Bayesian approach may enable the addition of processes and parameters to improve the model fidelity with a real-world system.

Vertical shearing occurs where the ice sheet flows over a bed that provides significant resistance to ice flow, for example where sliding ice is in direct contact with bedrock or where the ice is frozen to the bed (Cuffey and Paterson, 2010; Greve and Blatter, 2009; Schoof, 2007). Another model study showed that vertical shear can be important for initiating the transition from ice sheet to ice stream flow (Hulbe et al., 2003). Many marine terminating glaciers display fast flow principally via the effects of very weak subglacial material, in which case vertical shearing is small and longitudinal stresses are large (Cuffey and Paterson, 2010; Greve and Blatter, 2009; Pattyn et al., 2012). In the present situation, the focus is on wide, deep, and fast-flowing coastal outlet glacier flow, where the SSA approximation is suitable. Slow-flowing regions of the 
basin, where vertical shearing dominates, are peripheral to the experiments conducted here. Furthermore, the results of the Marine Ice Sheet Intercomparison Project suggest that assumptions about material properties may introduce larger errors than the ice flow approximation used, particularly in regard to sliding behavior (Pattyn et al., 2012). Nevertheless, the lack of vertical shear for the BISISCLES model used in this project is a limitation that could not be overcome at the time the simulations were run. Since this time, model developers have more fully established an ice flow approximation for BISICLES known as L1L2 that does account for vertical shearing.

Accurate resolution of the momentum balance around the grounding zone is essential for correct representation of grounding line motion (Pattyn et al., 2012). This can be accomplished by implementing high model grid resolution near the grounding line or a moving grid that focusses high resolution and computational effort around the grounding zone (Pattyn et al., 2012; Vieli and Payne, 2005). The AMR of the BISICLES model down to 250 meter resolution is beneficial in this regard.

Ideally, the subglacial till should be parameterized by considering its rheology and subglacial transport of sediments, as well as the timescales involved with transport, in a numerical model used for predictive purposes. The basal traction approach used here assumes a viscous rheology. However, most laboratory experiments have shown plastic rheology for till (Hindmarsh, 1997; Iverson et al., 1998; Tulaczyk, 2006). Some researchers have suggested that the aggregate of plastic failures at the fine scale lead to an apparent viscous behavior at the ice stream scale justifying the viscous model of till deformation (Hindmarsh, 1997). Alternatively, field observations of Whillans Ice Stream 
in West Antarctica are consistent with plastic rheology determined from laboratory tests (Tulaczyk, 2006). If the model is incorrect, the bed might provide either more or less resistance to flow than is appropriate for the real-world system.

The notion of till, and hence till rheology, only matters to the basal traction field if it includes time varying properties of the bed. Otherwise, the role of the till is to provide a basal boundary condition for the ice. However, there are currently no constraints for the inversion of a time varying process in the adjoint model that comprises the BISICLES control problem. By design, the singular focus here is how the shape of the bed affects model projections. It is thus advantageous to hold model parameters constant through time.

\subsection{Spatial Patterns of Difference in Driving Stress}

Driving stress in the vicinity of the grounding line is clearly important to the initiation and progression of the ice sheet instability but this is not the only difference apparent across the model simulations. The driving stress difference field for experiment 1 , in which both simulations are over Bedmap2, tends to vary smoothly away from the grounding line (Figure 41) while the Bedmap2 to Goff bed comparison in experiment 2 yields driving stress variations over shorter wavelengths that are locally-organized into distinct bands of highs and lows (Figure 42). Comparing the two difference fields, it is clear that higher resolution spatial variability is present in the G425 simulation than in the B260 and B270 simulations. This difference must arise from the influence of the bed shape during model initialization and grounding line retreat. 
- grounding line at year 422 for NAF 260

- grounding line at year 271 for NAF 270

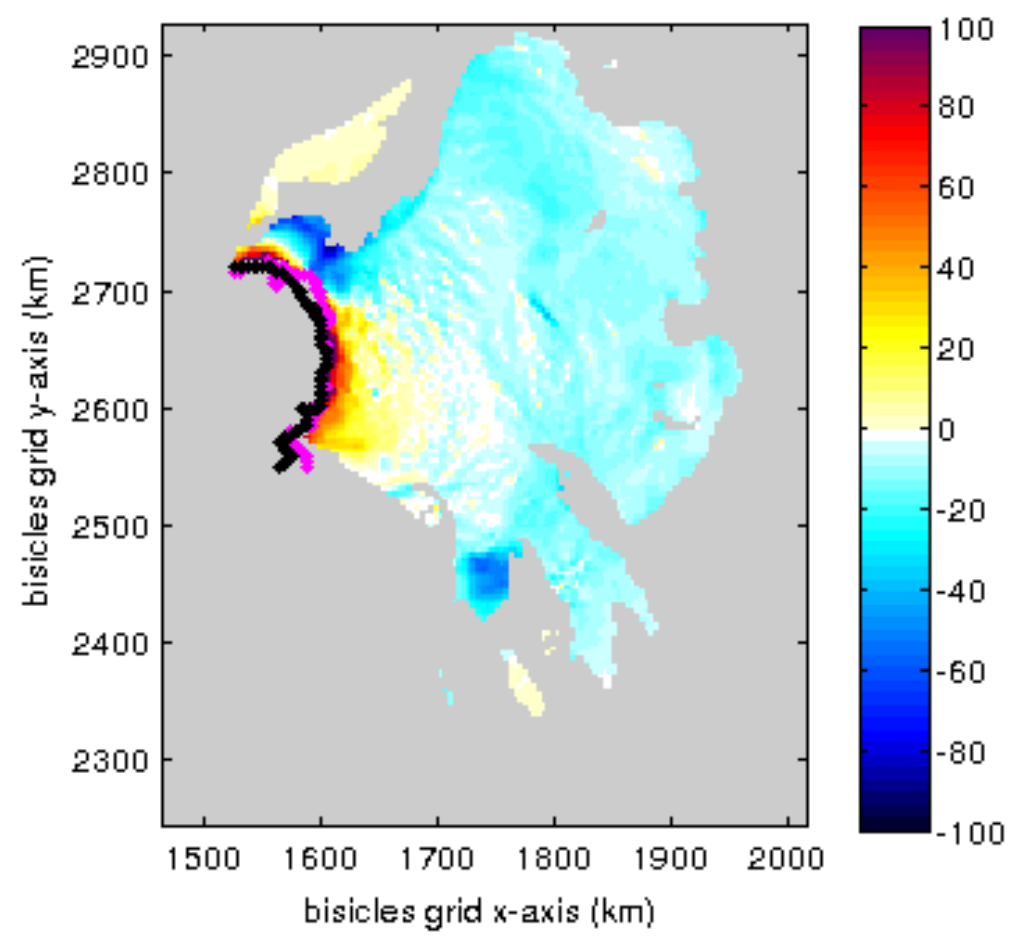

Figure 41. The first $4 \mathrm{~km}$ resolution co-located grounding line position difference in driving stress spatial field (kPa) for experiment 1 . The driving stress varies smoothly away from the grounding line. Only the intersection of ROIs is shown and ROIs are constrained by the $10 \mathrm{~m} / \mathrm{a}$ cutoff value. 


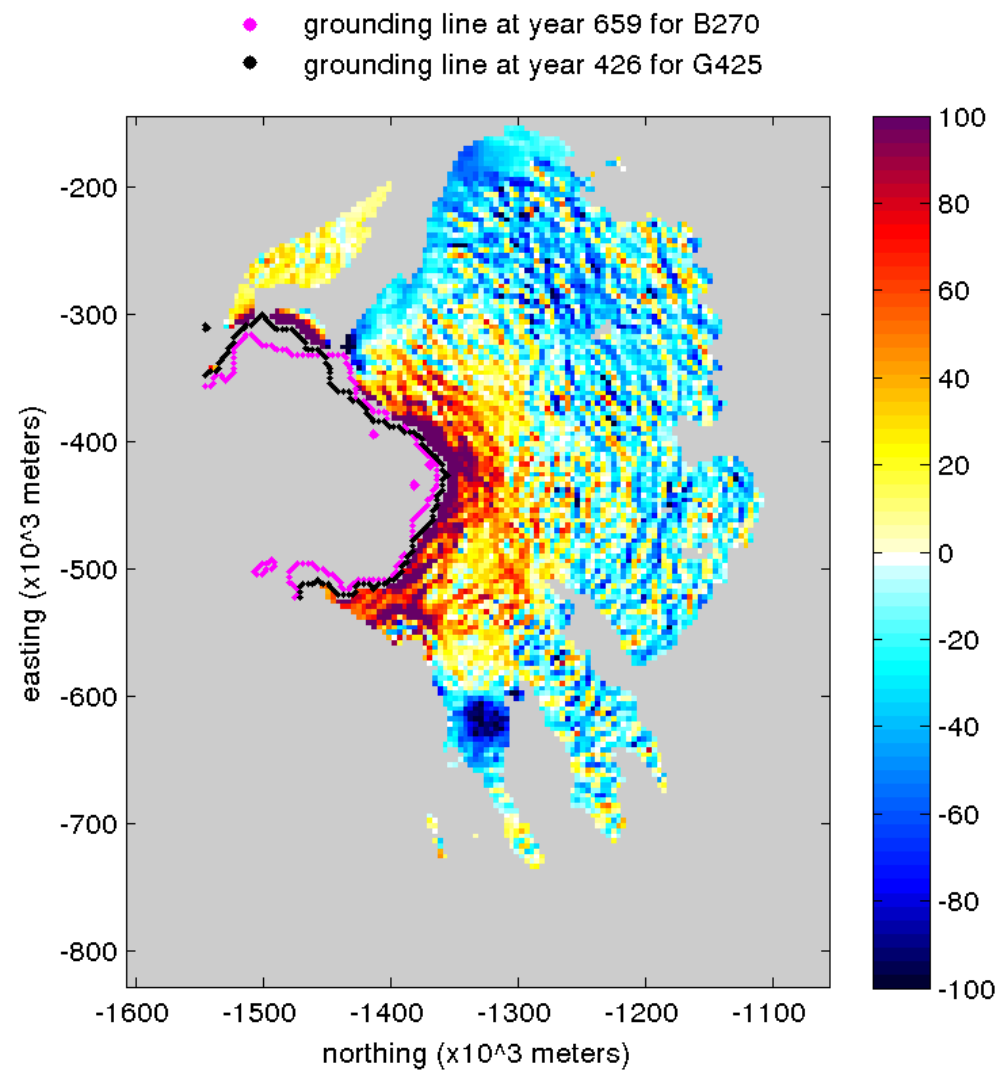

Figure 42. The first $4 \mathrm{~km}$ resolution co-located grounding line position driving stress difference spatial field (kPa) for experiment 2. The driving stress field appears rough in many locations with bands of high and low values apparent. Only the intersection of ROIs is shown and ROIs are constrained by the $10 \mathrm{~m} / \mathrm{a}$ cutoff value

The fundamental difference between experiment 1 and experiment 2 is that the shapes of the subglacial beds differ in experiment 2. The two bed realizations capture the same broad features but they differ in detail and this is apparent even after the two data sets, which have different fundamental resolutions (1 $\mathrm{km}$ and $250 \mathrm{~m}$ respectively) are coarsened to a $4 \mathrm{~km}$ grid. This is primarily noticeable as steeper horizontal gradients on the Goff bed, giving it a more detailed appearance relative to Bedmap2 (e.g. Figure 43). 
This difference has implications for ice thickness and basal drag, and through these, the evolution of the ice surface slope and driving stress over time.
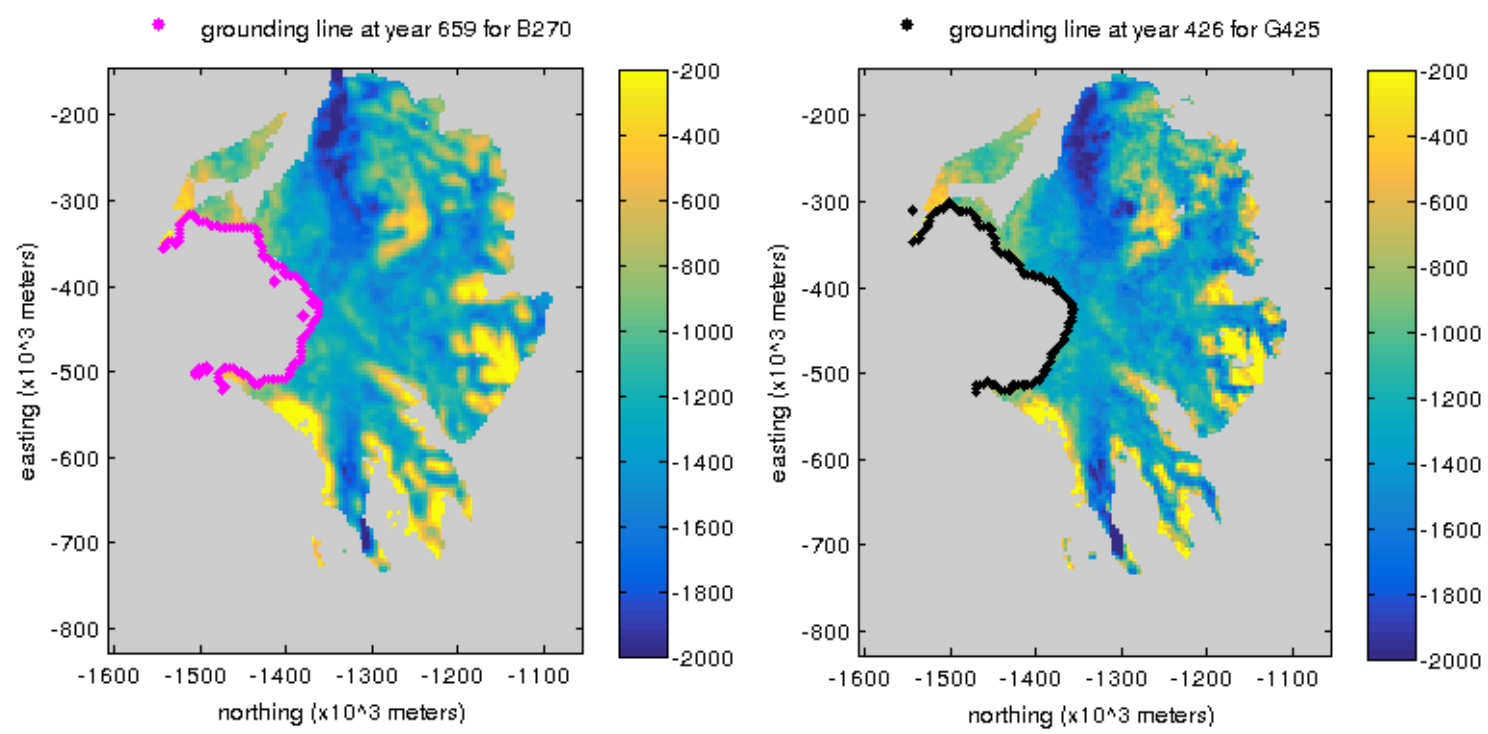

Figure 43. (LEFT) The $4 \mathrm{~km}$ resolution bed elevations (m) at the first co-located observation for Bedmap2 and (RIGHT) the Goff Bed. Only the ROIs with the 10 $\mathrm{m} / \mathbf{a}$ velocity cutoff are shown.

Different bed elevations yield different ice thickness fields under the fixed initial surface elevation. Therefore the ice thickness field is less smooth and more detailed over the Goff bed (Figure 44). As driving stress is proportional to ice thickness, which can be seen by examination of equation (3.2.1), the differences in thickness between the two beds contribute to large local variation in the driving stress in experiment 2 (Figure $42 \&$ Figure 45). 

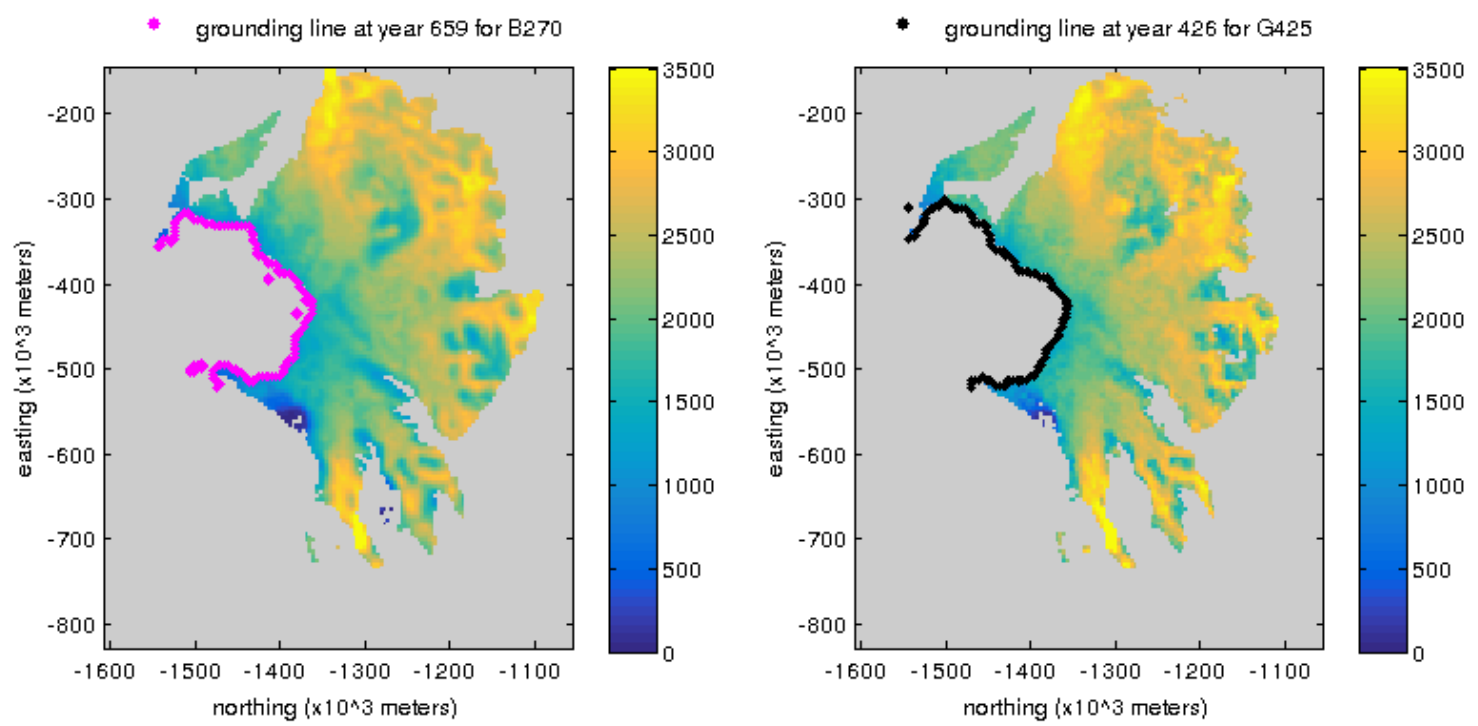

Figure 44. (LEFT) The $4 \mathrm{~km}$ resolution ice thickness $(\mathrm{m})$ at the first co-located observation for Bedmap2 and (RIGHT) the Goff Bed in the second experiment. Only the ROIs with the $10 \mathrm{~m} / \mathrm{a}$ velocity cutoff are shown. 

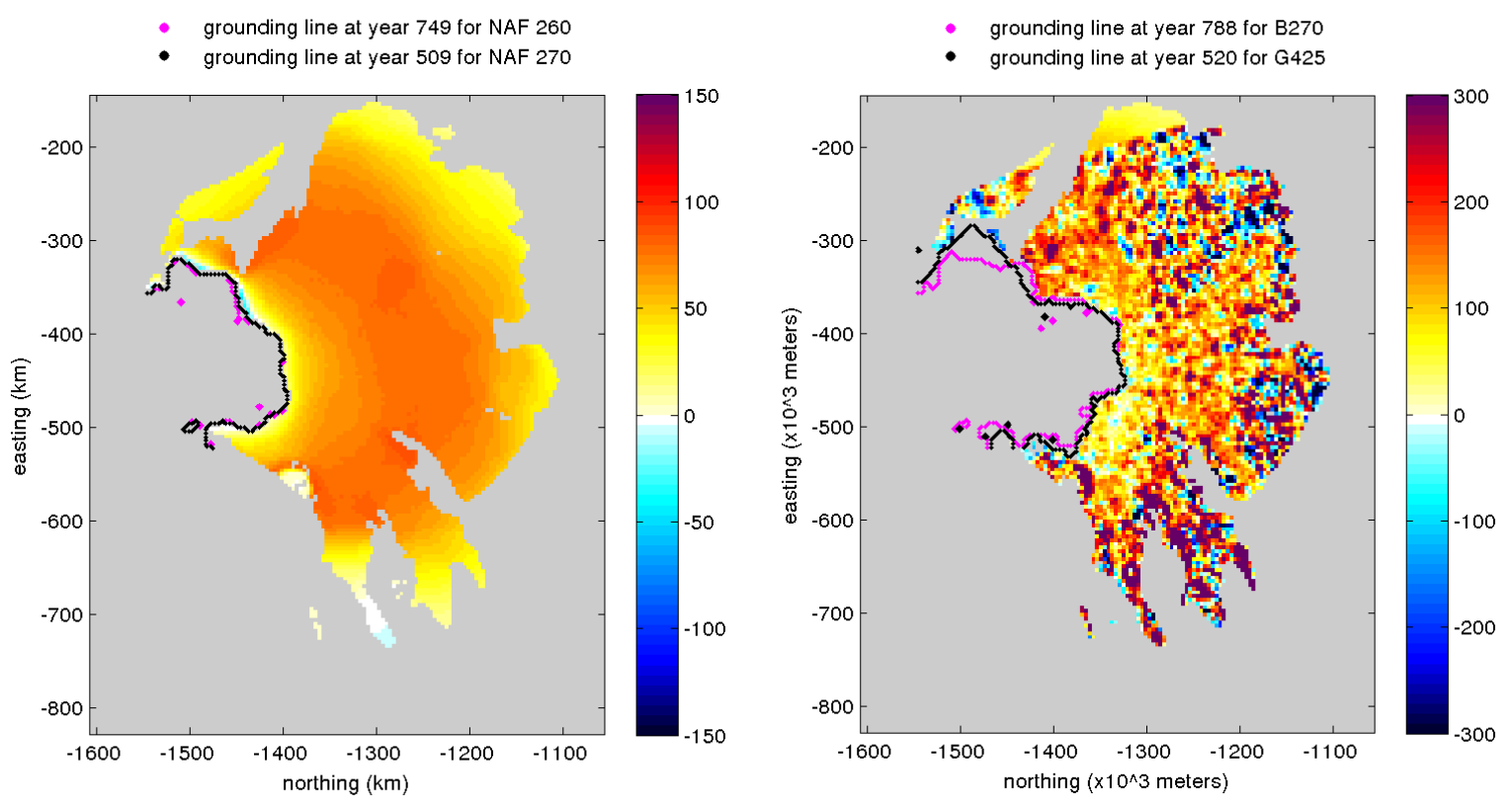

Figure 45. (LEFT) The $4 \mathrm{~km}$ resolution thickness difference $(\mathrm{m})$ at the $186^{\text {th }}$ observation of grounding line co-location for experiment 1, B260 vs B270. (RIGHT) The $4 \mathrm{~km}$ resolution thickness difference $(\mathrm{m})$ at the $17^{\text {th }}$ observation of grounding line co-location for experiment 2, B270 vs G425. The magnitude of differences tends to increase with grounding line mismatch so the observations were only selected to show differences in the general spatial patterns. Only the ROIs with the $10 \mathrm{~m} / \mathrm{a}$ velocity cutoff are shown.

Differences in bed shape also yield differences in the basal traction field. Basal traction is, overall, lower in the downstream reach and higher in the upstream reach of B260 and B270 than in the G425 simulation (Figure 46). Basal traction differences are apparent even at the coarse $4 \mathrm{~km}$ resolution (Figure 47). These are the result of differences in the bed shapes and ice thicknesses with which the basal traction field was found by inverting these together with the surface velocity. When the model relaxes to a steady state during the next phase of initialization, the more detailed bed, thickness, and basal drag together tend to preserve a more detailed surface shape. The surface undulations and thickness then generate the higher resolution and spatial detail in the driving stress over 


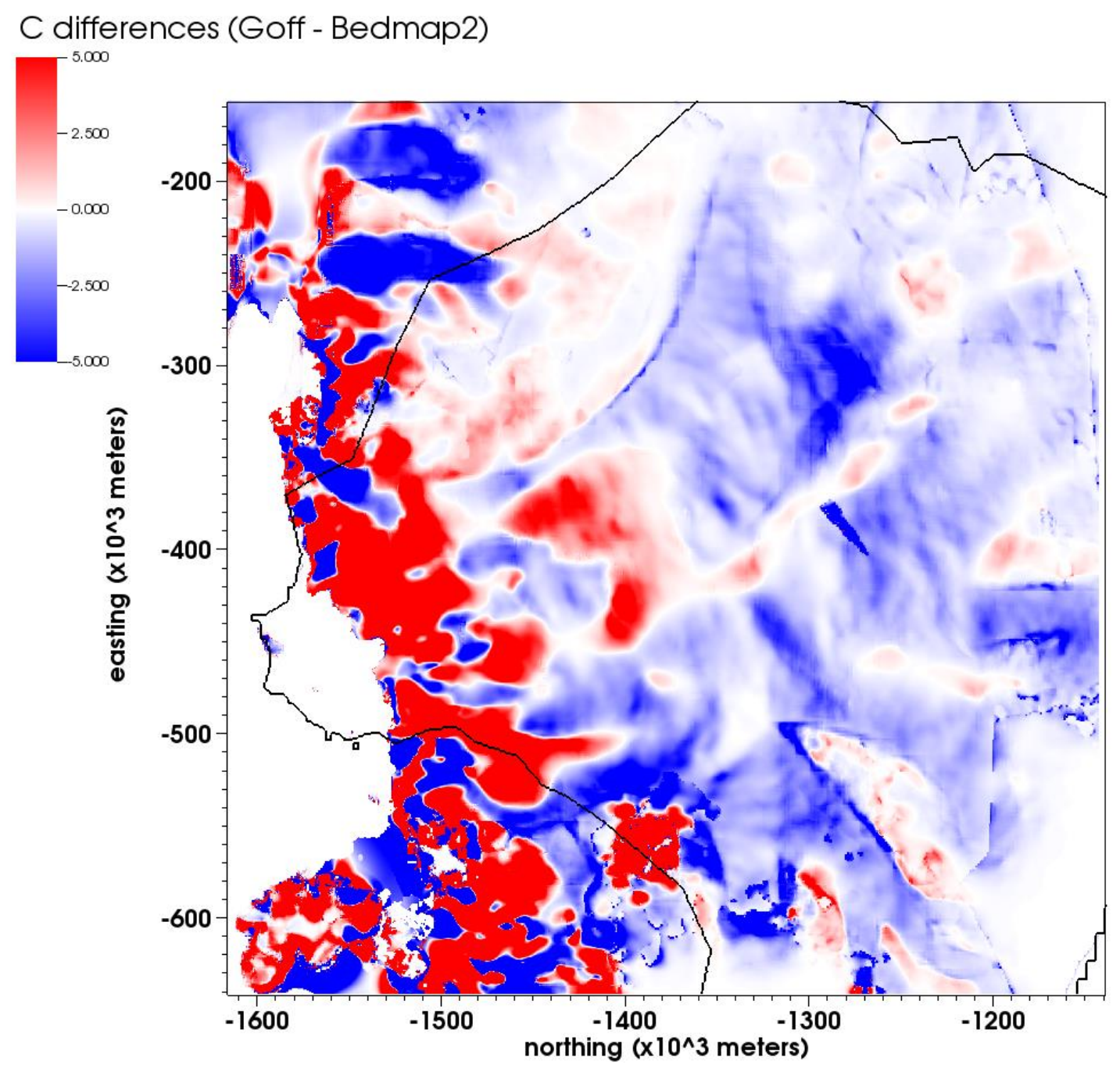

Figure 46. Difference in basal traction coefficients for Goff minus Bedmap2. Basal traction coefficients are generally higher for Bedmap2 in the lower reaches and higher for Goff in the upper reaches. The color scale limits shown here are -5 to 5 although higher and lower values are present. The greatest differences in basal traction occur where relatively high surface gradients are present at the start of the simulations.

the more detailed Goff bed. This outcome mimics the effect investigated by Sergeinko et al. (2014), in which varying topography and basal traction produces undulations on the surface which in turn produce spatial variation in the driving stress. However, without 
incorporating a transient basal traction field via parameterized physical processes, the effect in these simulations is static.

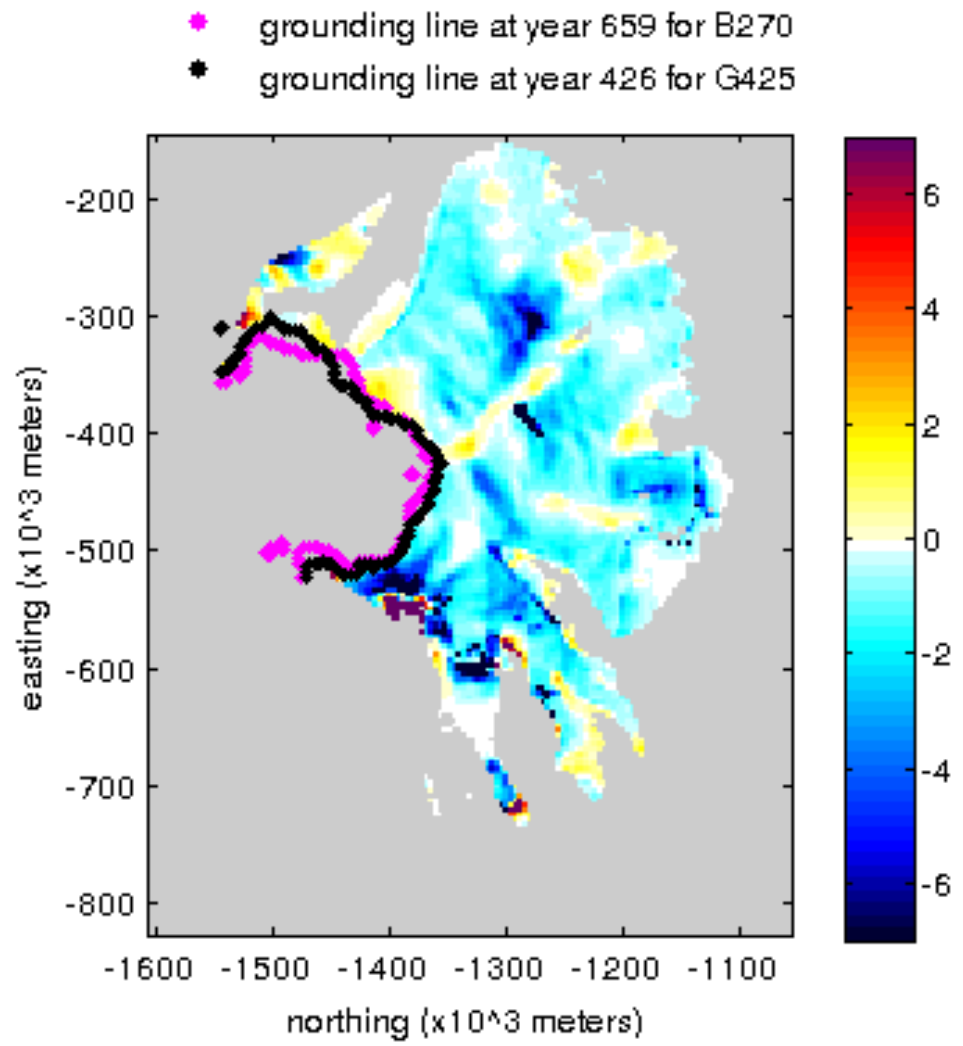

Figure 47. 4km resolution Goff bed minus Bedmap2 difference in basal traction in areas over the $10 \mathrm{~m} / \mathrm{a}$ velocity threshold for the first co-located grounding line position in experiment 2 . Note that by the time the instability is initiated on the Goff bed, the grounding line has retreated to a region where basal drag is lower than for the Bedmap2 case.

All together, these effects produce the band-like alternating highs and lows in the spatial difference of mean driving stress field for experiment 2 (Figure 42). Examination of the surface gradients through time does show stationary spatial patterns of surface gradients over Bedmap2 and the Goff bed that differ somewhat from each other (Figure 48). The primary difference between the two is that the surface gradient for G425 appears 
sharper and more resolved with more and narrower bands that tend to follow distribution of the bands in B270 (Figure 48). The magnitude of the differences along these features change as the location of the grounding line changes, placement is stationary (Figure 49).
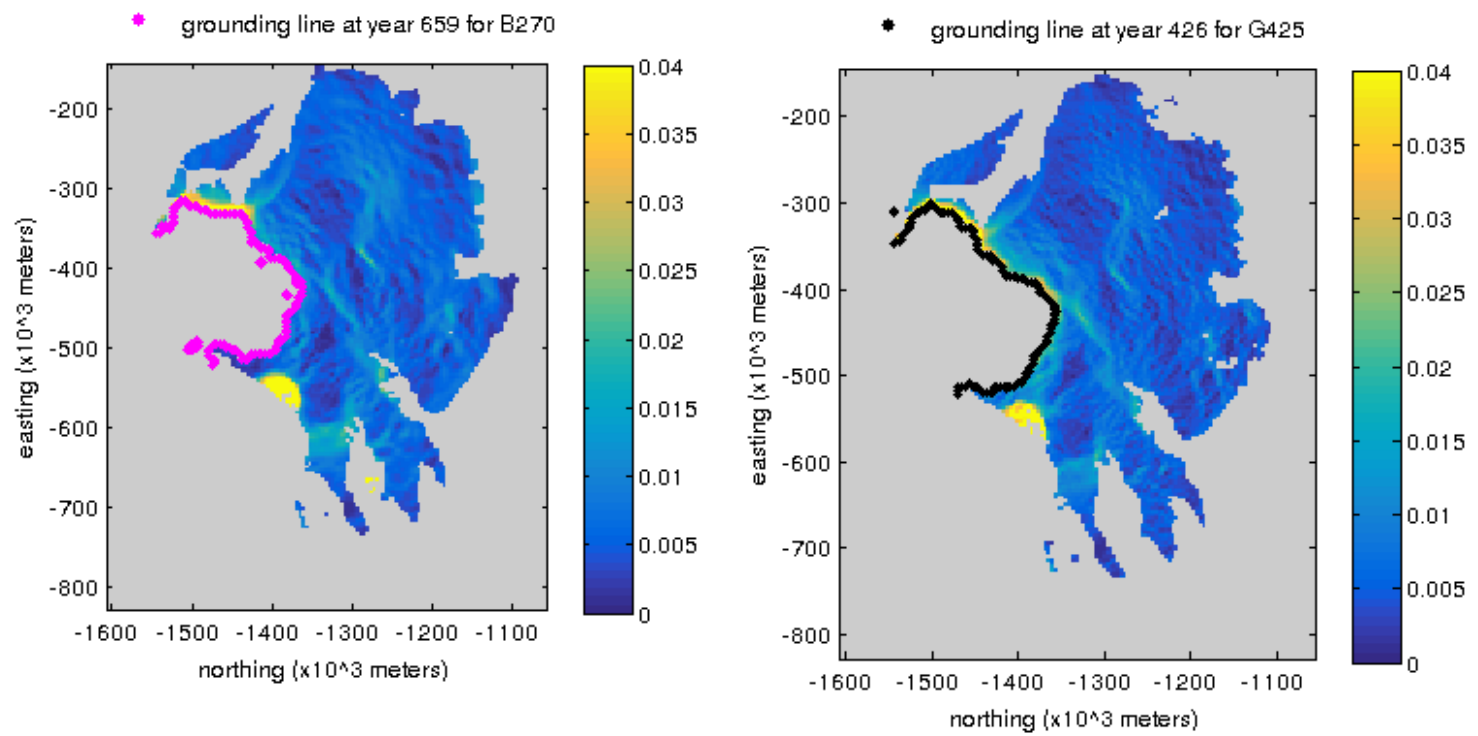

Figure 48. (LEFT) Surface gradient at $4 \mathrm{~km}$ resolution for $\mathrm{B270}$ at the first instance of grounding line co-location in experiment 2. (RIGHT) Surface gradient at $4 \mathbf{k m}$ resolution for $\mathbf{G 4 2 5}$ at the first instance of grounding line co-location in experiment 2. Gradients are only shown over ROIs (where velocities are greater than $10 \mathrm{~m} / \mathbf{a}$ ). There are differences with the G425 gradient appearing more resolved.

In summary, the difference in driving stress field through time for the first experiment, B260 vs B270, appears smoother spatially than that for the second experiment, B270 vs G425, for two reasons. First, the difference in thickness fields through time are smoother with differences in the first experiment being controlled solely by flux rates across the grounding line as opposed to any topographical differences. Second and most importantly, surface gradient patterns are the same for both simulations 
over the same bed in the first experiment. These two reasons are directly related to the differences between Bedmap2 and the Goff Bed.
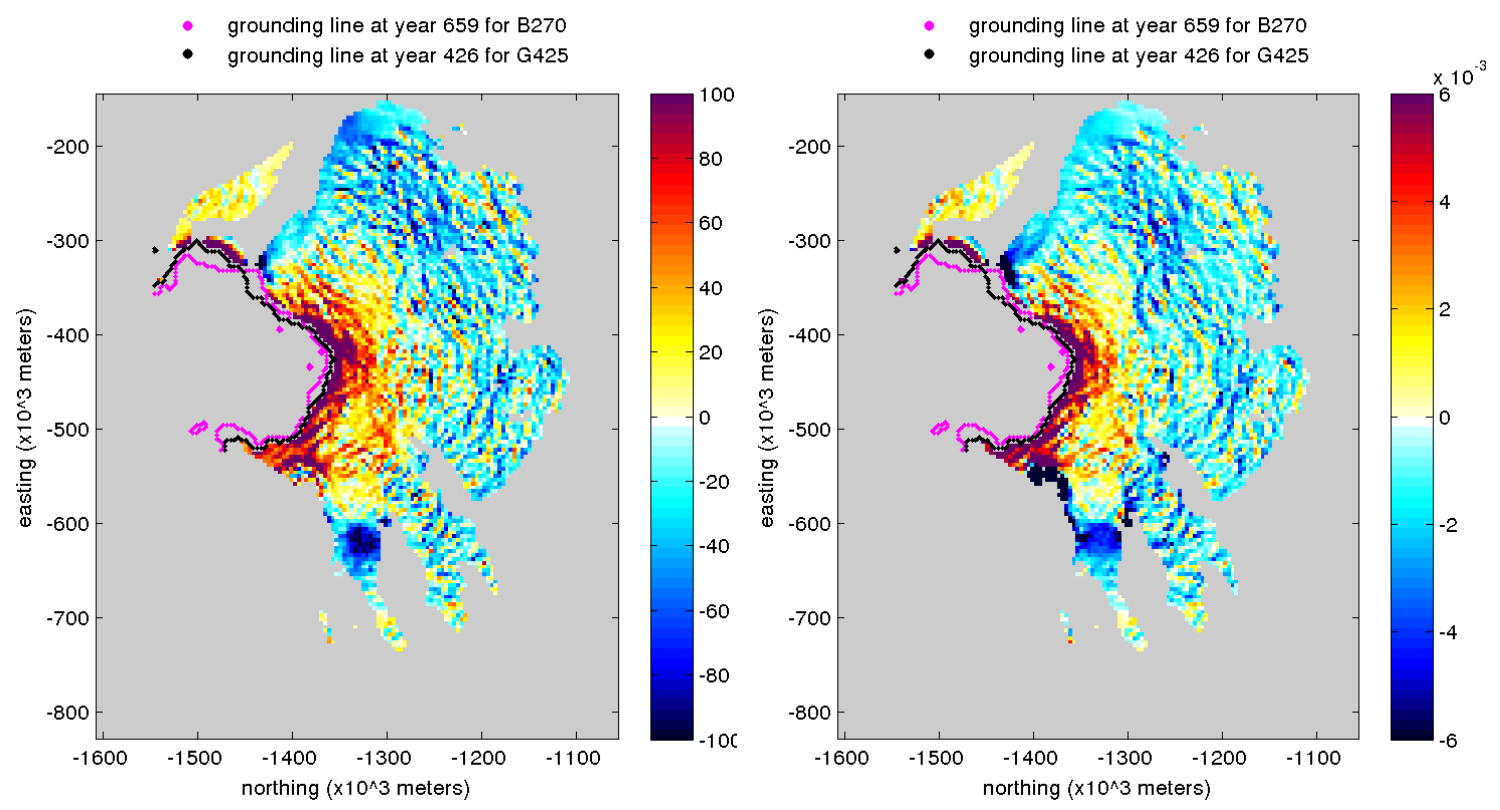

Figure 49. (LEFT) Driving stress difference (kPa) at the first observation of grounding line co-location for the second experiment, B270 vs G425. (RIGHT) Surface gradient difference at the first observation of grounding line co-location for the second experiment. Alternating bands of highs and lows appear well correlated for these fields. 


\subsection{CONCLUSIONS}

The marine ice sheet instability is topic of a long-standing interest and concern in glaciology. This phenomenon is often investigated along two-dimensional flowlines but transverse-direction effects can be important. Here, the problem has been expanded to three dimensions, so that the influence of bedrock geometry in initiating and propagating unstable grounding line retreat can be explored. An instability is defined as a situation in which the dynamics of the system responding to an external forcing experiences a positive feedback such that external forcing is no longer required to sustain the mode of response. To find this transition in the ice sheet model, a slowly increasing anomaly (melt), is superimposed over a steady-state ocean forcing. The slow ramp, an increase of $0.05 \mathrm{~m} \mathrm{a}^{-1}$ melt, is turned off once an instability is identified, after which the retreat continues. Different forcing rates would trigger instability at different grounding line locations but the conclusions drawn here would remain largely the same.

Two model experiments were designed to investigate the role of the bedrock geometry in the initiation and propagation of a marine instability in the Thwaites Glacier system. The experiments also provide insight into how instabilities arise. The first experiment compares the effects of different magnitudes of anomalous forcing over the same bed. The second experiment compares instabilities invoked over different beds. Small changes in forcing duration and magnitude lead to grounding line retreats that diverge in time. Different beds require different forcings in order to generate a genuine instability. 
Three-dimensional basin morphology sets the stage for unstable grounding line retreat. The first model experiment shows generally the same spatial pattern of retreat over the same bed, but with rates that vary with the magnitude of the anomalous forcing, even after the forcing is turned off. This has two important implications. First, the reverse slope alone does not dictate unstable retreat. Even though the spatial pattern of retreat over the Goff bed in the second experiment is less similar to retreat over Bedmap2 than the two Bedmap2 retreats are to each other, it is nevertheless apparent that large-scale three-dimensional bed features shape the spatial pattern of both the forced and unforced retreat. Second, the state of the system at the end of forced retreat, namely the specific location of the grounding line and the surface gradient of ice near the grounding line, determine the rate of retreat.

Fine-scale features on the bed determine where and when the instability is initiated. A significantly larger anomalous forcing is required to generate an instability over the rougher Goff bed than over the smoother Bedmap2. Put another way, the bed morphology is a primary factor for establishing the ice sheet's sensitivity to the ocean forcing. Correct knowledge of the bed shape is thus essential to projection of future change. This result supports the conclusions of Parizek et al. (2013) in this regard, and we show that morphology matters because the rougher bed is associated with overall steeper surface slope near the grounding line, which produces larger ice flux. However, when surface slope is anomalously steepened by a large marine forcing, the bed features become less influential. When the anomalous forcing ends, bed features become more important again. 
Local apparent instabilities arise as the grounding line retreats in response to the anomalous forcing. These are not the same as the basin-scale effects associated with a genuine instability but might be mistaken for such effects in the natural world. Local instabilities tend to involve relatively short distances of grounding line retreat within subbasins. They have the excess mass flux characteristic of unstable retreat but begin to slow soon after initiation. Local instabilities play out over decades to 200 hundred years. This implies that care must be taken in the attribution of modern observed retreat. Neither retreat nor its pace over short time scales is sufficient to indicate an actual instability. And if an instability has not been invoked by the marine forcing, then the grounding line may quickly come to a new equilibrium position if the anomalous forcing halts.

This new steady state shape is obtained because the ice now experiences different boundary conditions in association with its new extent. Flowline models generally do not consider transverse effects of flow and resistance beyond the inclusion of a width parameter. On the other hand, a plan view model does such that deflating interior surface of an ice sheet with a mass accumulation field that is spatially variable but constant through time creates the potential for new steady-states when shutoff prior to an instability occurs.

The shape of the bed influences ice sheet configuration at the start of the transient simulation. The adjoint initialization requires agreement between known and unknown variables and parameters. Changing the bed shape under a fixed surface elevation changes the ice thickness, which in turn changes the basal drag required to support the observed surface velocity. Once the basal traction is set, relaxation occurs and bed 
features propagate upward through the ice flow to modify the initial surface elevation. The end result is an undulating pattern like the patterns identified in Sergienko et al. (2014). This happens on both the Bedmap2 bed and the Goff bed but is more pronounced in the latter due to its finer resolution topographic features.

The magnitude of the anomalous forcing also affects model outcome. As the larger of the two forcings in experiment 1 results in a more inland (down reverse slope) location for the grounding line when the instability is left to run on its own, the driving stress near the grounding line is larger and the ensuing retreat proceeds more rapidly than for the smaller forcing case. This implies that accurate knowledge of the marine forcing is critical to correctly projecting unstable retreat. Very different future scenarios can be invoked by small differences in anomalous forcings, as shown by the $0.5 \mathrm{ma}^{-1}$ melt difference at the time of ramp shutoffs in experiment 1. It also implies that decisions about carbon emission pathways and ensuing ocean warming can have meaningful influence on ice sheet retreat, even after marine ice sheet retreat is invoked. Retreat may be inevitable past a certain dynamical threshold, but the rate at which the retreat proceeds is not. Moreover, this research suggests that the threshold for instability is not a specific boundary on the sea floor, but is instead a synthesis of sea floor shape and forcing magnitude.

Projection of future change in the Thwaites Glacier region, and presumably other outlets of the Antarctic ice sheet, is clearly connected to the realism and the resolution of the of the glacier bed geometry. The two bed realizations used here generate different rates of retreat in the forced phases of the experiments unforced phases of the simulations 
and the difference is larger when the anomalous forcing is larger. This is the case even though our parameterization of bed processes is simple and the effect of time-varying bed properties should also be investigated.

The experiments conducted here also demonstrate the difference between a purely marine forcing and a marine-triggered instability. Overall, the rate of mass loss is larger during the forced phase of a retreat than during the purely unstable retreat phase. If an instability is not triggered, grounding line retreat ceases when the forcing is removed and the ice sheet relaxes to a new steady state shape associated with that grounding line position, even if it is locally on a reverse slope. Large melting during the forced part of the retreat maintains (or enhances) a large surface slope near the grounding line and thus large flux across it. When the anomalous forcing is reduced, so is that effect. In the case that an instability has been triggered, the two effects proceed together. This is why the ice flux declines during the unstable, committed retreat phase of our experiments. The positive feedback is controlled by the floatation criterion as the grounding line retreats into deeper water.

Strictly, no ice shelf melting is required to sustain the instability. Retreats continue in our experiments when the background marine forcing is very small; a value of 0.30 ma- 1 is applied after the slow ramp ended.

The increased grounding line fluxes associated with retreat in the model simulations are the result of surface steepening near the grounding line. That is, there is no requirement for changes in ice-shelf "buttressing" to generate rapid retreat. As the grounding line retreats upstream into the very wide Thwaites catchment, the distance to 
lateral margins of the ice shelf increases and thus their effect on the budget of forces at the grounding line decreases. 


\subsection{FUTURE WORK}

Coupling an ocean warming model to the BISICLES model could provide additional insights. These would likely pertain to distinguishing the areas of the Thwaites catchment that are most vulnerable to unstable retreat initiation, with all other factors being the same, on local as well as regional scales. This would be accomplished by a spatially variable melt parameterization. The slow ramp could be implemented as a boundary condition on the ocean circulation model or spatial variations of melt could be incorporated in the PLF.

Similarly, other processes could be incorporated such as isostatic rebound, spatially variable geothermal heat flow, and water routing. These, including spatially variable ocean warming, are a collection of processes that are important, but they won't change the conclusions about bed shape. Rather, they should provide additional details about instability initiation and unstable retreat. 


\section{REFERENCES}

Ainley, D. G., Clarke, E. D., Arrigo, K., Fraser, W. R., Kato, A., Barton, K. J., and Wilson, P. R., 2005, Decadal-scale changes in the climate and biota of the Pacific sector of the Southern Ocean, 1950s to the 1990s: Antarctic Science, v. 17, no. 02, p. 171-182.

Anandakrishnan, S., Catania, G. A., Alley, R. B., and Horgan, H. J., 2007, Discovery of till deposition at the grounding line of Whillans Ice Stream: Science, v. 315, no. 5820, p. 1835-1838.

Anderson, J. B., 1999, Antarctic Marine Geology, Cambridge University Press.

Arthern, R. J., Winebrenner, D. P., and Vaughan, D. G., 2006, Antarctic snow accumulation mapped using polarization of $4.3-\mathrm{cm}$ wavelength microwave emission: Journal of Geophysical Research: Atmospheres (1984-2012), v. 111, no. D6.

Behrendt, J. C., 1999, Crustal and lithospheric structure of the West Antarctic Rift System from geophysical investigations - a review: Global and Planetary Change, v. 23, no. 1, p. 25-44.

Bindschadler, R., Bamber, J., and Anandakrishnan, S., 2001, Onset of streaming flow in the Siple Coast region, West Antarctica, The West Antarctic Ice Sheet: Behavior and Environment, Volume 77, American Geophysical Union, p. 123-136.

Blatter, H., 1995, Velocity and stress fields in grounded glaciers: a simple algorithm for including deviatoric stress gradients: Journal of Glaciology, v. 41, no. 138, p. 333344.

Bougamont, M., Christoffersen, P., Price, S., Fricker, H., Tulaczyk, S., and Carter, S., 2015, Reactivation of Kamb Ice Stream tributaries triggers century-scale reorganization of Siple Coast ice flow in West Antarctica: Geophysical Research Letters, v. 42, no. 20, p. 8471-8480.

Bougamont, M., Price, S., Christoffersen, P., and Payne, A., 2011, Dynamic patterns of ice stream flow in a 3-D higher-order ice sheet model with plastic bed and simplified hydrology: Journal of Geophysical Research: Earth Surface, v. 116, no. F4.

Bougamont, M., Tulaczyk, S., and Joughin, I., 2003, Response of subglacial sediments to basal freeze-on 2. Application in numerical modeling of the recent stoppage of Ice Stream C, West Antarctica: JGRB Journal of Geophysical Research: Solid Earth, v. 108 , no. B4.

Bryson, A. E., 1975, Applied optimal control: optimization, estimation and control, CRC Press.

Cande, S. C., Stock, J. M., Müller, R. D., and Ishihara, T., 2000, Cenozoic motion between east and west Antarctica: Nature, v. 404, no. 6774, p. 145-150.

Carter, S. P., Fricker, H. A., Blankenship, D. D., Johnson, J. V., Lipscomb, W. H., Price, S. F., and Young, D. A., 2011, Modeling 5 years of subglacial lake activity in the 
MacAyeal Ice Stream (Antarctica) catchment through assimilation of ICESat laser altimetry: Journal of Glaciology, v. 57, no. 206, p. 1098-1112.

Carter, S. P., Fricker, H. A., and Siegfried, M. R., 2013, Evidence of rapid subglacial water piracy under Whillans Ice Stream, West Antarctica: Journal of Glaciology, v. 59, no. 218, p. 1147-1162.

Childs, H., Brugger, E., Whitlock, B., Meredith, J., Ahern, S., Pugmire, D., Biagas, K., Miller, M., Harrison, C., Weber, G. H., Krishnan, H., Fogal, T., Sanderson, A., Garth, C., Bethel, E. W., Camp, D., Rubel, O., Durant, M., Favre, J. M., and Navratil, P., 2012, VisIt: An end-user tool for visualizing and analyzing very large data, High Performance Visualization--Enabling Extreme-Scale Scientific Insight.

Cornford, S. L., Martin, D., Payne, A., Ng, E., Le Brocq, A., Gladstone, R., Edwards, T. L., Shannon, S., Agosta, C., and Van Den Broeke, M., 2015, Century-scale simulations of the response of the West Antarctic Ice Sheet to a warming climate: Cryosphere (The), v. 9, p. 1579-1600.

Cornford, S. L., Martin, D. F., Graves, D. T., Ranken, D. F., Le Brocq, A. M., Gladstone, R. M., Payne, A. J., Ng, E. G., and Lipscomb, W. H., 2013, Adaptive mesh, finite volume modeling of marine ice sheets: Journal of Computational Physics, v. 232, no. 1, p. 529-549.

Creyts, T. T., and Schoof, C. G., 2009, Drainage through subglacial water sheets: Journal of Geophysical Research: Earth Surface, v. 114, no. F4.

Cuffey, K. M., and Paterson, W. S. B., 2010, The physics of glaciers, Academic Press, 693 p.:

Dalziel, I. W. D., and Lawver, L. A., 2001, The lithospheric setting of the West Antarctic ice sheet, The West Antarctic ice sheet: behavior and environment, Volume 77, American Geophysical Union, p. 29-44.

Dinniman, M. S., Klinck, J. M., and Hofmann, E. E., 2012, Sensitivity of Circumpolar Deep Water transport and ice shelf basal melt along the west Antarctic Peninsula to changes in the winds: Journal of Climate, v. 25 , no. 14, p. 4799-4816.

Dupont, T., and Alley, R., 2005, Assessment of the importance of ice-shelf buttressing to ice-sheet flow: Geophysical Research Letters, v. 32, no. 4.

Flowers, G. E., Modelling water flow under glaciers and ice sheets, in Proceedings Proc. R. Soc. A2015, Volume 471, The Royal Society, p. 20140907.

Flowers, G. E., and Clarke, G. K., 2002, A multicomponent coupled model of glacier hydrology 1. Theory and synthetic examples: Journal of Geophysical Research: Solid Earth, v. 107, no. B11.

Fretwell, P., Pritchard, H. D., Vaughan, D. G., Bamber, J. L., Barrand, N. E., Bell, R., Bianchi, C., Bingham, R. G., Blankenship, D. D., Casassa, G., Catania, G., Callens, D., Conway, H., Cook, A. J., Corr, H. F., Damaske, D., Damm, V., Ferraccioli, F., Forsberg, R., Fujita, S., Gim, Y., Gogineni, P., Griggs, J. A., Hindmarsh, R. C. A., Holmund, P., Holt, J. W., Jacobel, R. W., Jenkins, A., Jokat, W., Jordan, T., King, E. C., Kohler, J., Krabill, W., Riger-Kusk, M., Langley, K. A., Leitchenkov, G., Leuschen, C., Luyendyk, B. P., Matsuoka, K., Mouginot, J., Nitsche, F. O., Nogi, Y., Nost, O. A., Popov, S. V., Rignot, E., Rippin, D. M., Rivera, A., Roberts, J., Ross, N., Siegert, M. J., Smith, A. M., Steinhage, D., 
Studinger, M., Sun, B., Tinto, B. K., Welch, B. C., Wilson, D., Young, D. A., Xiangbin, C., and Zirrizzotti, A., 2013, Bedmap2: improved ice bed, surface and thickness datasets for Antarctica: The Cryosphere, v. 7, no. 1, p. 375-393.

Gille, S. T., 2014, Meridional displacement of the Antarctic Circumpolar Current: Philosophical Transactions of the Royal Society of London A: Mathematical, Physical and Engineering Sciences, v. 372, no. 2019, p. 20130273.

Goelzer, H., Huybrechts, P., Furst, J. J., Nick, F. M., Andersen, M. L., Edwards, T. L., Fettweis, X., Payne, A. J., and Shannon, S., 2013, Sensitivity of Greenland ice sheet projections to model formulations: Journal of Glaciology, v. 59, no. 216, p. 1.

Goff, J. A., Powell, E. M., Young, D. A., and Blankenship, D. D., 2014, Instruments and Methods--Conditional simulation of Thwaites Glacier (Antarctica) bed topography for flow models: incorporating inhomogeneous statistics and channelized morphology: Journal of Glaciology, v. 60, no. 222, p. 635.

Goldberg, D., Holland, D., and Schoof, C., 2009, Grounding line movement and ice shelf buttressing in marine ice sheets: Journal of Geophysical Research: Earth Surface, v. 114 , no. F4.

Golledge, N. R., Fogwill, C. J., Mackintosh, A. N., and Buckley, K. M., 2012, Dynamics of the last glacial maximum Antarctic ice-sheet and its response to ocean forcing: Proceedings of the National Academy of Sciences, v. 109, no. 40, p. 1605216056.

Golledge, N. R., Kowalewski, D. E., Naish, T. R., Levy, R. H., Fogwill, C. J., and Gasson, E. G. W., 2015, The multi-millennial Antarctic commitment to future sea-level rise: Nature, v. 526, no. 7573, p. 421-425.

Greve, R., and Blatter, H., 2009, Dynamics of ice sheets and glaciers, Springer Science \& Business Media, 287 p.:

Gudmundsson, G., Krug, J., Durand, G., Favier, L., and Gagliardini, O., 2012, The stability of grounding lines on retrograde slopes: The Cryosphere, v. 6, p. 14971505 .

Gudmundsson, G. H., 2003, Transmission of basal variability to a glacier surface: Journal of Geophysical Research: Solid Earth, v. 108, no. B5.

-, 2006, Fortnightly variations in the flow velocity of Rutford Ice Stream, West Antarctica: Nature, v. 444, no. 7122, p. 1063-1064.

Hiester, J., Sergienko, O., and Hulbe, C., 2016, Topographically mediated ice stream subglacial drainage networks: Journal of Geophysical Research: Earth Surface.

Hindmarsh, R., 1997, Deforming beds: viscous and plastic scales of deformation: Quaternary Science Reviews, v. 16, no. 9, p. 1039-1056.

Hindmarsh, R. C. A., 2004, A numerical comparison of approximations to the Stokes equations used in ice sheet and glacier modeling: Journal of Geophysical Research: Earth Surface (2003-2012), v. 109, no. F1.

Holt, J. W., Blankenship, D. D., Morse, D. L., Young, D. A., Peters, M. E., Kempf, S. D., Richter, T. G., Vaughan, D. G., and Corr, H. F. J., 2006, New boundary conditions for the West Antarctic Ice Sheet: Subglacial topography of the 
Thwaites and Smith glacier catchments: Geophysical Research Letters, v. 33, no. 9.

Hulbe, C. L., Wang, W., Joughin, I. R., and Siegert, M. J., 2003, The role of lateral and vertical shear in tributary flow toward a West Antarctic ice stream: Annals of Glaciology, v. 36, no. 1, p. 244-250.

Hutter, K., 1983, Theoretical glaciology: material science of ice and the mechanics of glaciers and ice sheets, Springer.

Iverson, N. R., Hooyer, T. S., and Baker, R. V., 1998, Ring-shear studies of till deformation: Coulomb-plastic behavior and distributed strain in glacier beds: Journal of Glaciology, v. 44, no. 148, p. 634-642.

Joughin, I., Smith, B. E., and Medley, B., 2014, Marine ice sheet collapse potentially under way for the Thwaites Glacier Basin, West Antarctica: Science, v. 344, no. 6185 , p. 735-738.

Joughin, I., and Tulaczyk, S., 2002, Positive mass balance of the Ross ice streams, West Antarctica: Science, v. 295, no. 5554, p. 476-480.

King, J. C., and Turner, J., 2007, Antarctic meteorology and climatology, Cambridge University Press, Cambridge Atmospheric and Space Science Series.

Llubes, M., Lanseau, C., and Rémy, F., 2006, Relations between basal condition, subglacial hydrological networks and geothermal flux in Antarctica: Earth and Planetary Science Letters, v. 241, no. 3, p. 655-662.

Lythe, M. B., Vaughan, D. G., and BEDMAP Consortium, 2001, BEDMAP: A new ice thickness and subglacial topographic model of Antarctica: Journal of Geophysical Research: Solid Earth (1978-2012), v. 106, no. B6, p. 11335-11351.

MacAyeal, D. R., 1989, Large-scale ice flow over a viscous basal sediment: Theory and application to ice stream B, Antarctica: Journal of Geophysical Research: Solid Earth (1978-2012), v. 94, no. B4, p. 4071-4087.

MacAyeal, D. R., 1993, A tutorial on the use of control methods in ice-sheet modeling: Journal of Glaciology, v. 39, no. 131.

Martin, D., 2014, Discussion of ice flow velocities on Thwaites Tongue, in Waibel, M. S., ed.

Mayewski, P. A., Meredith, M. P., Summerhayes, C. P., Turner, J., Worby, A., Barrett, P. J., Casassa, G., Bertler, N. A. N., Bracegirdle, T., Naveira Garabato, A. C., Bromwich, D., Campbell, H., Hamilton, G. S., Lyons, W. B., Maasch, K. A., Aoki, S., Xiao, C., and van Ommen, T., 2009, State of the Antarctic and Southern Ocean climate system: Reviews of Geophysics, v. 47, no. 1, p. RG1003.

Mercer, J. H., 1978, West Antarctic ice sheet and CO2 greenhouse effect: a threat of disaster: Nature, v. 27, p. 26.

Morland, L. W., 1984, Thermomechanical balances of ice sheet flows: Geophysical \& Astrophysical Fluid Dynamics, v. 29, no. 1-4, p. 237-266.

-, Unconfined ice shelf flow, in Proceedings Dynamics of the West Antarctic Ice Sheet, University of Utrecht, 1985, Reidel, p. 99-116.

Morlighem, M., Rignot, E., Seroussi, H., Larour, E., Ben Dhia, H., and Aubry, D., 2010, Spatial patterns of basal drag inferred using control methods from a full-Stokes 
and simpler models for Pine Island Glacier, West Antarctica: Geophysical Research Letters, v. 37, no. 14.

Mukasa, S. B., and Dalziel, I. W., 2000, Marie Byrd Land, West Antarctica: Evolution of Gondwana's Pacific margin constrained by zircon $\mathrm{U}-\mathrm{Pb}$ geochronology and feldspar common-Pb isotopic compositions: Geological Society of America Bulletin, v. 112, no. 4, p. 611-627.

Naish, T., Powell, R., Levy, R., Wilson, G., Scherer, R., Talarico, F., Krissek, L., Niessen, F., Pompilio, M., Wilson, T., Carter, L., DeConto, R., Huybers, P., McKay, R., Pollard, D., Ross, J., Winter, D., Barrett, P., Browne, G., Cody, R., Cowan, E., Crampton, J., Dunbar, G., Dunbar, N., Florindo, F., Gebhardt, C., Graham, I., Hannah, M., Hansaraj, D., Harwood, D., Helling, D., Henrys, S., Hinnov, L., Kuhn, G., Kyle, P., Laufer, A., Maffioli, P., Magens, D., Mandernack, K., McIntosh, W., Millan, C., Morin, R., Ohneiser, C., Paulsen, T., Persico, D., Raine, I., Reed, J., Riesselman, C., Sagnotti, L., Schmitt, D., Sjunneskog, C., Strong, P., Taviani, M., Vogel, S., Wilch, T., and Williams, T., 2009, Obliquitypaced Pliocene West Antarctic ice sheet oscillations: Nature, v. 458, no. 7236, p. 322-328.

Nitsche, F. O., Jacobs, S. S., Larter, R. D., and Gohl, K., 2007, Bathymetry of the Amundsen Sea continental shelf: implications for geology, oceanography, and glaciology: Geochemistry, Geophysics, Geosystems, v. 8, no. 10.

Nowicki, S., Bindschadler, R. A., Abe-Ouchi, A., Aschwanden, A., Bueler, E., Choi, H., Fastook, J., Granzow, G., Greve, R., and Gutowski, G., 2013, Insights into spatial sensitivities of ice mass response to environmental change from the SeaRISE ice sheet modeling project I: Antarctica: Journal of Geophysical Research: Earth Surface, p. 1-23.

Parizek, B. R., Christianson, K., Anandakrishnan, S., Alley, R. B., Walker, R. T., Edwards, R. A., Wolfe, D. S., Bertini, G. T., Rinehart, S. K., and Bindschadler, R. A., 2013, Dynamic (in) stability of Thwaites Glacier, West Antarctica: Journal of Geophysical Research: Earth Surface, v. 118, no. 2, p. 638-655.

Patankar, S., 1980, Numerical heat transfer and fluid flow, CRC press.

Pattyn, F., 2003, A new three-dimensional higher-order thermomechanical ice sheet model: Basic sensitivity, ice stream development, and ice flow across subglacial lakes: Journal of Geophysical Research: Solid Earth (1978-2012), v. 108, no. B8.

-, 2010, Antarctic subglacial conditions inferred from a hybrid ice sheet/ice stream model: Earth and Planetary Science Letters, v. 295, no. 3, p. 451-461.

Pattyn, F., Schoof, C., Perichon, L., Hindmarsh, R., Bueler, E., Fleurian, B. d., Durand, G., Gagliardini, O., Gladstone, R., and Goldberg, D., 2012, Results of the marine ice sheet model intercomparison project, MISMIP: The Cryosphere, v. 6, no. 3, p. 573-588.

Pollard, D., and DeConto, R. M., 2009, Modelling West Antarctic ice sheet growth and collapse through the past five million years: Nature, v. 458, no. 7236, p. 329-332.

Price, S., Waddington, E., and Conway, H., 2007, A full-stress, thermomechanical flow band model using the finite volume method: Journal of Geophysical Research: Earth Surface, v. 112, no. F3. 
Pritchard, H. D., Arthern, R. J., Vaughan, D. G., and Edwards, L. A., 2009, Extensive dynamic thinning on the margins of the Greenland and Antarctic ice sheets: Nature, v. 461, no. 7266, p. 971-975.

Rémy, F., and Legresy, B., 2004, Subglacial hydrological networks in Antarctica and their impact on ice flow: Annals of Glaciology, v. 39, no. 1, p. 67-72.

Rignot, E., 2001, Evidence for rapid retreat and mass loss of Thwaites Glacier, West Antarctica: Journal of Glaciology, v. 47, no. 157, p. 213-222.

-, 2008, Changes in West Antarctic ice stream dynamics observed with ALOS PALSAR data: Geophysical Research Letters, v. 35, no. 12.

Rignot, E., Mouginot, J., Morlighem, M., Seroussi, H., and Scheuchl, B., 2014, Widespread, rapid grounding line retreat of Pine Island, Thwaites, Smith, and Kohler glaciers, West Antarctica, from 1992 to 2011: Geophysical Research Letters, v. 41, no. 10, p. 3502-3509.

Rignot, E., Vaughan, D. G., Schmeltz, M., Dupont, T., and MacAyeal, D., 2002, Acceleration of pine island and thwaites glaciers, west antarctica: Annals of Glaciology, v. 34, no. 1, p. 189-194.

Ross, N., Bingham, R. G., Corr, H. F., Ferraccioli, F., Jordan, T. A., Le Brocq, A., Rippin, D. M., Young, D., Blankenship, D. D., and Siegert, M. J., 2012, Steep reverse bed slope at the grounding line of the Weddell Sea sector in West Antarctica: Nature Geoscience, v. 5, no. 6, p. 393-396.

Rydt, J. D., Gudmundsson, G. H., Corr, H., and Christoffersen, P., 2013, Surface undulations of Antarctic ice streams tightly controlled by bedrock topography: The Cryosphere, v. 7, no. 2, p. 407-417.

Schoof, C., 2002, Basal perturbations under ice streams: form drag and surface expression: Journal of Glaciology, v. 48, no. 162, p. 407-416.

-, 2007, Ice sheet grounding line dynamics: Steady states, stability, and hysteresis: Journal of Geophysical Research: Earth Surface, v. 112, no. F3.

Sergienko, O., 2013, Basal channels on ice shelves: Journal of Geophysical Research: Earth Surface, v. 118, no. 3, p. 1342-1355.

Sergienko, O., Creyts, T. T., and Hindmarsh, R., 2014, Similarity of organized patterns in driving and basal stresses of Antarctic and Greenland ice sheets beneath extensive areas of basal sliding: Geophysical Research Letters, v. 41, no. 11, p. 3925-3932.

Shepherd, A., Ivins, E. R., Geruo, A., Barletta, V. R., Bentley, M. J., Bettadpur, S., Briggs, K. H., Bromwich, D. H., Forsberg, R., and Galin, N., 2012, A reconciled estimate of ice-sheet mass balance: Science, v. 338, no. 6111, p. 1183-1189.

Shepherd, A., and Wingham, D., 2007, Recent sea-level contributions of the Antarctic and Greenland ice sheets: science, v. 315, no. 5818, p. 1529-1532.

Shepherd, A., Wingham, D., and Rignot, E., 2004, Warm ocean is eroding West Antarctic ice sheet: Geophysical Research Letters, v. 31, no. 23.

Shepherd, A., Wingham, D. J., and Mansley, J. A. D., 2002, Inland thinning of the Amundsen Sea sector, West Antarctica: Geophysical Research Letters, v. 29, no. 10, p. 2-1-2-4. 
Smith, R. C., Ainley, D., Baker, K., Domack, E., Emslie, S., Fraser, B., Kennett, J., Leventer, A., Mosley-Thompson, E., Sharon, S., and Vernet, M., 1999, Marine Ecosystem Sensitivity to Climate Change: BioScience, v. 49, no. 5, p. 393-404.

Sun, S., Cornford, S., Liu, Y., and Moore, J. C., 2014, Dynamic response of Antarctic ice shelves to bedrock uncertainty: The Cryosphere, v. 8, no. 4, p. 1561-1576.

Thoma, M., Jenkins, A., Holland, D., and Jacobs, S., 2008, Modelling circumpolar deep water intrusions on the Amundsen Sea continental shelf, Antarctica: Geophysical Research Letters, v. 35, no. 18.

Thomas, R., Rignot, E., Casassa, G., Kanagaratnam, P., Acuña, C., Akins, T., Brecher, H., Frederick, E., Gogineni, P., and Krabill, W., 2004, Accelerated sea-level rise from West Antarctica: Science, v. 306, no. 5694, p. 255-258.

Trathan, P. N., Forcada, J., and Murphy, E. J., 2007, Environmental forcing and Southern Ocean marine predator populations: effects of climate change and variability: Philosophical Transactions of the Royal Society B: Biological Sciences, v. 362, no. 1488 , p. 2351-2365.

Truffer, M., and Echelmeyer, K. A., 2003, Of isbrae and ice streams: Annals of Glaciology, v. 36, no. 1, p. 66-72.

Tulaczyk, S., 2006, Scale independence of till rheology: Journal of Glaciology, v. 52, no. 178, p. 377-380.

Versteeg, H. K., and Malalasekera, W., 2007, An introduction to computational fluid dynamics: the finite volume method, Pearson Education.

Vieli, A., and Payne, A., 2005, Assessing the ability of numerical ice sheet models to simulate grounding line migration: Journal of Geophysical Research: Earth Surface, v. 110, no. F1.

Wåhlin, A., Yuan, X., Björk, G., and Nohr, C., 2010, Inflow of Warm Circumpolar Deep Water in the Central Amundsen Shelf*: Journal of physical oceanography, v. 40, no. 6 , p. 1427-1434.

Weertman, J., 1974, Stability of the junction of an ice sheet and an ice shelf: Journal of Glaciology, v. 13, no. 67, p. 3-11. 


\section{Appendix A Experiment 1 Summary Table}

Driving stress and flux across the grounding line summarized for each co-located observation in experiment 1. Column 1 is the observation number. Column 2 is the transect (T) used to determine co-location for the given observation. Column 3 is the year of the B260 simulation that corresponds to the observation. Column 4 is the mean driving stress of the B260 simulation's ROI with units of kPa. Column 5 is the flux across the grounding line for the $B 260$ simulation in units of $\mathrm{km}^{3} \mathrm{a}^{-1}$. Columns 6 through 8 are the B270 simulation equivalents of columns 3 through 5 . Column 9 is the difference in driving stress calculated as B270 minus B260 with units of $\mathrm{kPa}$. Column 10 is the difference in flux across the grounding line in units of $\mathrm{km}^{3} \mathrm{a}^{-1}$ and calculated as B270 minus B260.

\begin{tabular}{|c|c|c|c|c|c|c|c|c|c|}
\hline obs & $\mathbf{T}$ & $\begin{array}{l}\text { B260 } \\
\text { year }\end{array}$ & $\begin{array}{c}\text { driving } \\
\text { stress } \\
(\mathrm{kPa})\end{array}$ & $\underset{\left(\mathbf{k m}^{3} \mathbf{a}^{-1}\right)}{\text { flux }}$ & $\begin{array}{l}\text { B270 } \\
\text { year }\end{array}$ & $\begin{array}{c}\text { driving } \\
\text { stress } \\
(\mathrm{kPa}) \\
\end{array}$ & $\underset{\left(\mathbf{k m}^{3} \mathbf{a}^{-1}\right)}{\text { flux }}$ & $\begin{array}{c}\Delta \text { driving } \\
\text { stress } \\
(\mathbf{k P a})\end{array}$ & $\underset{\left(\mathbf{k m}^{3} \mathbf{a}^{-1)}\right.}{\Delta \text { flux }}$ \\
\hline 1 & 3 & 422 & 96.86 & 127.82 & 271 & 90.89 & 224.79 & -5.97 & 96.97 \\
\hline 2 & 3 & 424 & 96.93 & 128.13 & 272 & 91.12 & 212.35 & -5.81 & 84.22 \\
\hline 3 & 3 & 425 & 96.97 & 128.86 & 273 & 91.25 & 205.06 & -5.72 & 76.19 \\
\hline 4 & 3 & 426 & 97.00 & 127.57 & 274 & 91.40 & 199.03 & -5.61 & 71.46 \\
\hline 5 & 3 & 427 & 97.06 & 128.84 & 275 & 91.53 & 189.93 & -5.52 & 61.09 \\
\hline 6 & 3 & 420 & 96.78 & 127.58 & 276 & 91.63 & 178.35 & -5.15 & 50.77 \\
\hline 7 & 3 & 414 & 96.58 & 126.03 & 277 & 91.75 & 174.87 & -4.83 & 48.84 \\
\hline 8 & 3 & 415 & 96.61 & 125.88 & 278 & 91.80 & 173.30 & -4.81 & 47.42 \\
\hline 9 & 3 & 416 & 96.64 & 125.44 & 279 & 91.84 & 169.50 & -4.80 & 44.06 \\
\hline 10 & 3 & 410 & 96.42 & 125.27 & 280 & 91.95 & 168.06 & -4.47 & 42.79 \\
\hline 11 & 3 & 411 & 96.46 & 127.37 & 281 & 92.06 & 167.90 & -4.40 & 40.53 \\
\hline 12 & 3 & 412 & 96.51 & 126.31 & 282 & 92.19 & 167.32 & -4.32 & 41.01 \\
\hline 13 & 3 & 413 & 96.53 & 126.39 & 283 & 92.28 & 166.78 & -4.26 & 40.39 \\
\hline 14 & 3 & 417 & 96.67 & 126.59 & 284 & 92.39 & 165.98 & -4.28 & 39.39 \\
\hline 15 & 3 & 418 & 96.71 & 126.21 & 285 & 92.46 & 164.24 & -4.24 & 38.03 \\
\hline 16 & 3 & 409 & 96.37 & 126.21 & 286 & 92.50 & 163.65 & -3.86 & 37.44 \\
\hline 17 & 3 & 407 & 96.27 & 124.85 & 287 & 92.62 & 162.55 & -3.65 & 37.70 \\
\hline 18 & 3 & 457 & 98.22 & 129.20 & 322 & 95.88 & 166.13 & -2.34 & 36.92 \\
\hline 19 & 3 & 458 & 98.27 & 130.69 & 323 & 96.00 & 165.28 & -2.27 & 34.58 \\
\hline 20 & 3 & 459 & 98.34 & 132.16 & 324 & 96.12 & 164.51 & -2.22 & 32.36 \\
\hline 21 & 3 & 460 & 98.39 & 130.74 & 325 & 96.17 & 164.69 & -2.22 & 33.95 \\
\hline 22 & 3 & 465 & 98.58 & 133.40 & 326 & 96.23 & 165.10 & -2.35 & 31.70 \\
\hline 23 & 3 & 461 & 98.41 & 129.99 & 327 & 96.37 & 163.61 & -2.04 & 33.63 \\
\hline
\end{tabular}




\begin{tabular}{|c|c|c|c|c|c|c|c|c|c|}
\hline obs & $\mathbf{T}$ & $\begin{array}{l}\text { B260 } \\
\text { year }\end{array}$ & $\begin{array}{l}\text { driving } \\
\text { stress } \\
(\mathbf{k P a})\end{array}$ & $\begin{array}{c}\text { flux } \\
\left(\mathrm{km}^{3} \mathbf{a}^{-1}\right)\end{array}$ & $\begin{array}{l}\text { B270 } \\
\text { year }\end{array}$ & $\begin{array}{c}\text { driving } \\
\text { stress } \\
(\mathbf{k P a})\end{array}$ & $\begin{array}{c}\text { flux } \\
\left(\mathbf{k m}^{3} \mathbf{a}^{-1}\right)\end{array}$ & $\begin{array}{c}\Delta \text { driving } \\
\text { stress } \\
(\mathbf{k P a})\end{array}$ & $\underset{\left(\mathbf{k m}^{3} \mathbf{a}^{-1)}\right.}{\Delta f l u x}$ \\
\hline 24 & 3 & 462 & 98.45 & 129.85 & 328 & 96.46 & 162.97 & -1.99 & 33.12 \\
\hline 25 & 3 & 463 & 98.50 & 129.04 & 329 & 96.58 & 162.30 & -1.92 & 33.26 \\
\hline 26 & 3 & 464 & 98.55 & 130.53 & 330 & 96.71 & 161.91 & -1.84 & 31.38 \\
\hline 27 & 3 & 478 & 99.22 & 130.69 & 335 & 97.09 & 159.78 & -2.13 & 29.09 \\
\hline 28 & 3 & 470 & 98.84 & 132.87 & 336 & 97.25 & 160.73 & -1.59 & 27.86 \\
\hline 29 & 3 & 471 & 98.89 & 133.55 & 337 & 97.34 & 161.42 & -1.55 & 27.87 \\
\hline 30 & 3 & 472 & 98.96 & 135.05 & 338 & 97.35 & 160.92 & -1.61 & 25.87 \\
\hline 31 & 3 & 473 & 99.01 & 133.63 & 339 & 97.47 & 160.37 & -1.54 & 26.74 \\
\hline 32 & 3 & 474 & 99.05 & 132.13 & 340 & 97.57 & 161.65 & -1.49 & 29.52 \\
\hline 33 & 3 & 477 & 99.17 & 129.64 & 341 & 97.65 & 160.87 & -1.52 & 31.22 \\
\hline 34 & 3 & 476 & 99.11 & 133.01 & 342 & 97.76 & 160.89 & -1.35 & 27.88 \\
\hline 35 & 3 & 479 & 99.27 & 132.44 & 343 & 97.82 & 160.84 & -1.44 & 28.40 \\
\hline 36 & 3 & 481 & 99.34 & 130.05 & 345 & 98.01 & 160.03 & -1.32 & 29.98 \\
\hline 37 & 3 & 486 & 99.49 & 130.47 & 347 & 98.13 & 160.70 & -1.36 & 30.23 \\
\hline 38 & 3 & 484 & 99.44 & 131.69 & 348 & 98.23 & 161.27 & -1.21 & 29.58 \\
\hline 39 & 3 & 489 & 99.65 & 130.64 & 349 & 98.35 & 160.59 & -1.30 & 29.95 \\
\hline 40 & 3 & 490 & 99.66 & 129.17 & 350 & 98.41 & 159.82 & -1.25 & 30.65 \\
\hline 41 & 3 & 497 & 99.99 & 128.84 & 351 & 98.46 & 160.09 & -1.53 & 31.25 \\
\hline 42 & 3 & 498 & 100.04 & 127.91 & 352 & 98.53 & 161.46 & -1.52 & 33.56 \\
\hline 43 & 3 & 500 & 100.10 & 128.41 & 353 & 98.62 & 159.95 & -1.48 & 31.54 \\
\hline 44 & 3 & 501 & 100.13 & 128.21 & 354 & 98.68 & 159.59 & -1.45 & 31.38 \\
\hline 45 & 3 & 502 & 100.17 & 128.07 & 355 & 98.77 & 160.03 & -1.39 & 31.96 \\
\hline 46 & 3 & 507 & 100.31 & 126.84 & 356 & 98.92 & 160.21 & -1.38 & 33.36 \\
\hline 47 & 3 & 510 & 100.43 & 128.19 & 357 & 99.00 & 160.81 & -1.43 & 32.62 \\
\hline 48 & 3 & 512 & 100.53 & 128.73 & 358 & 99.08 & 160.73 & -1.46 & 31.99 \\
\hline 49 & 3 & 513 & 100.57 & 128.30 & 359 & 99.17 & 160.30 & -1.41 & 32.00 \\
\hline 50 & 3 & 514 & 100.60 & 128.35 & 360 & 99.22 & 161.06 & -1.38 & 32.72 \\
\hline 51 & 3 & 515 & 100.65 & 129.23 & 361 & 99.27 & 159.34 & -1.38 & 30.11 \\
\hline 52 & 3 & 516 & 100.67 & 129.38 & 362 & 99.32 & 159.30 & -1.35 & 29.92 \\
\hline 53 & 3 & 517 & 100.71 & 129.96 & 363 & 99.41 & 159.59 & -1.30 & 29.63 \\
\hline 54 & 3 & 518 & 100.76 & 130.27 & 364 & 99.51 & 159.99 & -1.24 & 29.71 \\
\hline 55 & 3 & 519 & 100.79 & 129.95 & 365 & 99.60 & 158.28 & -1.19 & 28.33 \\
\hline 56 & 3 & 520 & 100.86 & 130.26 & 366 & 99.65 & 157.50 & -1.21 & 27.24 \\
\hline 57 & 3 & 521 & 100.92 & 130.40 & 367 & 99.76 & 159.02 & -1.16 & 28.62 \\
\hline 58 & 3 & 523 & 101.00 & 130.39 & 368 & 99.88 & 160.28 & -1.12 & 29.89 \\
\hline 59 & 3 & 525 & 101.08 & 130.14 & 369 & 99.98 & 161.47 & -1.10 & 31.32 \\
\hline 60 & 3 & 526 & 101.12 & 130.65 & 370 & 100.06 & 161.72 & -1.06 & 31.07 \\
\hline 61 & 3 & 529 & 101.23 & 130.41 & 371 & 100.11 & 162.70 & -1.12 & 32.29 \\
\hline 62 & 3 & 530 & 101.29 & 130.73 & 372 & 100.23 & 161.29 & -1.06 & 30.57 \\
\hline 63 & 3 & 531 & 101.32 & 129.95 & 373 & 100.31 & 162.55 & -1.01 & 32.61 \\
\hline
\end{tabular}




\begin{tabular}{|c|c|c|c|c|c|c|c|c|c|}
\hline obs & $\mathbf{T}$ & $\begin{array}{l}\text { B260 } \\
\text { year }\end{array}$ & $\begin{array}{l}\text { driving } \\
\text { stress } \\
(\mathbf{k P a})\end{array}$ & $\begin{array}{c}\text { flux } \\
\left(\mathrm{km}^{3} \mathbf{a}^{-1}\right)\end{array}$ & $\begin{array}{l}\text { B270 } \\
\text { year }\end{array}$ & $\begin{array}{c}\text { driving } \\
\text { stress } \\
(\mathbf{k P a})\end{array}$ & $\begin{array}{c}\text { flux } \\
\left(\mathbf{k m}^{3} \mathbf{a}^{-1}\right)\end{array}$ & $\begin{array}{c}\Delta \text { driving } \\
\text { stress } \\
(\mathbf{k P a})\end{array}$ & 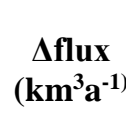 \\
\hline 64 & 3 & 534 & 101.44 & 129.72 & 374 & 100.42 & 164.90 & -1.02 & 35.18 \\
\hline 65 & 3 & 535 & 101.45 & 129.81 & 375 & 100.50 & 165.43 & -0.96 & 35.62 \\
\hline 66 & 3 & 537 & 101.54 & 130.41 & 376 & 100.58 & 167.01 & -0.96 & 36.60 \\
\hline 67 & 3 & 540 & 101.68 & 129.79 & 377 & 100.66 & 166.79 & -1.02 & 37.00 \\
\hline 68 & 3 & 541 & 101.72 & 129.11 & 378 & 100.78 & 166.66 & -0.93 & 37.55 \\
\hline 69 & 3 & 550 & 102.07 & 129.33 & 379 & 100.83 & 168.83 & -1.24 & 39.50 \\
\hline 70 & 3 & 552 & 102.10 & 129.86 & 380 & 100.96 & 170.66 & -1.14 & 40.80 \\
\hline 71 & 3 & 555 & 102.21 & 129.36 & 381 & 101.08 & 172.79 & -1.13 & 43.43 \\
\hline 72 & 3 & 558 & 102.33 & 130.00 & 382 & 101.23 & 173.66 & -1.10 & 43.66 \\
\hline 73 & 3 & 561 & 102.45 & 129.34 & 383 & 101.29 & 174.30 & -1.16 & 44.96 \\
\hline 74 & 3 & 567 & 102.67 & 130.52 & 384 & 101.37 & 174.80 & -1.30 & 44.29 \\
\hline 75 & 3 & 569 & 102.74 & 129.87 & 385 & 101.50 & 173.09 & -1.25 & 43.22 \\
\hline 76 & 3 & 571 & 102.80 & 130.76 & 386 & 101.56 & 175.16 & -1.24 & 44.40 \\
\hline 77 & 3 & 575 & 102.97 & 130.08 & 387 & 101.63 & 176.18 & -1.34 & 46.10 \\
\hline 78 & 3 & 577 & 103.06 & 131.89 & 388 & 101.78 & 175.93 & -1.28 & 44.04 \\
\hline 79 & 3 & 579 & 103.16 & 133.37 & 389 & 101.92 & 175.77 & -1.24 & 42.40 \\
\hline 80 & 3 & 580 & 103.20 & 133.21 & 390 & 102.00 & 175.29 & -1.20 & 42.09 \\
\hline 81 & 3 & 583 & 103.30 & 136.31 & 391 & 102.12 & 175.74 & -1.18 & 39.43 \\
\hline 82 & 3 & 584 & 103.39 & 138.72 & 392 & 102.25 & 178.40 & -1.14 & 39.68 \\
\hline 83 & 3 & 586 & 103.54 & 139.84 & 393 & 102.31 & 181.59 & -1.23 & 41.75 \\
\hline 84 & 3 & 587 & 103.60 & 140.31 & 394 & 102.46 & 183.60 & -1.14 & 43.29 \\
\hline 85 & 3 & 591 & 103.87 & 138.95 & 396 & 102.69 & 183.59 & -1.18 & 44.64 \\
\hline 86 & 3 & 593 & 103.98 & 140.36 & 397 & 102.79 & 182.78 & -1.19 & 42.42 \\
\hline 87 & 3 & 594 & 104.07 & 141.14 & 398 & 102.92 & 182.64 & -1.15 & 41.49 \\
\hline 88 & 3 & 595 & 104.13 & 140.59 & 399 & 103.04 & 181.43 & -1.09 & 40.84 \\
\hline 89 & 3 & 598 & 104.34 & 139.92 & 400 & 103.16 & 182.60 & -1.18 & 42.68 \\
\hline 90 & 3 & 600 & 104.40 & 138.65 & 401 & 103.24 & 181.84 & -1.17 & 43.19 \\
\hline 91 & 3 & 602 & 104.52 & 139.79 & 402 & 103.29 & 180.88 & -1.24 & 41.09 \\
\hline 92 & 3 & 605 & 104.65 & 138.24 & 403 & 103.41 & 180.84 & -1.24 & 42.60 \\
\hline 93 & 3 & 607 & 104.78 & 139.76 & 404 & 103.53 & 181.07 & -1.25 & 41.31 \\
\hline 94 & 3 & 608 & 104.83 & 139.89 & 405 & 103.64 & 179.55 & -1.19 & 39.66 \\
\hline 95 & 3 & 609 & 104.89 & 139.66 & 406 & 103.66 & 178.58 & -1.23 & 38.92 \\
\hline 96 & 3 & 610 & 104.95 & 139.79 & 407 & 103.78 & 177.68 & -1.17 & 37.90 \\
\hline 97 & 3 & 611 & 105.02 & 139.32 & 408 & 103.90 & 176.35 & -1.13 & 37.03 \\
\hline 98 & 3 & 612 & 105.10 & 137.85 & 409 & 104.04 & 177.01 & -1.07 & 39.17 \\
\hline 99 & 3 & 616 & 105.34 & 138.13 & 410 & 104.16 & 177.80 & -1.18 & 39.67 \\
\hline 100 & 3 & 617 & 105.42 & 138.34 & 411 & 104.23 & 179.97 & -1.20 & 41.62 \\
\hline 101 & 3 & 620 & 105.55 & 139.94 & 412 & 104.29 & 180.41 & -1.25 & 40.47 \\
\hline 102 & 3 & 621 & 105.61 & 140.84 & 413 & 104.40 & 178.75 & -1.21 & 37.91 \\
\hline 103 & 3 & 622 & 105.65 & 141.93 & 414 & 104.54 & 178.62 & -1.11 & 36.70 \\
\hline
\end{tabular}




\begin{tabular}{|c|c|c|c|c|c|c|c|c|c|}
\hline obs & $\mathbf{T}$ & $\begin{array}{l}\text { B260 } \\
\text { year }\end{array}$ & $\begin{array}{l}\text { driving } \\
\text { stress } \\
(\mathbf{k P a})\end{array}$ & $\begin{array}{c}\text { flux } \\
\left(\mathbf{k m}^{3} \mathbf{a}^{-1}\right)\end{array}$ & $\begin{array}{l}\text { B270 } \\
\text { year }\end{array}$ & $\begin{array}{l}\text { driving } \\
\text { stress } \\
(\mathbf{k P a})\end{array}$ & $\begin{array}{c}\text { flux } \\
\left(\mathbf{k m}^{3} \mathbf{a}^{-1}\right)\end{array}$ & $\begin{array}{c}\Delta \text { driving } \\
\text { stress } \\
(\mathbf{k P a})\end{array}$ & $\begin{array}{c}\Delta \text { flux } \\
\left(\mathbf{k m}^{3} \mathbf{a}^{-1)}\right.\end{array}$ \\
\hline 104 & 3 & 623 & 105.70 & 142.33 & 415 & 104.67 & 180.05 & -1.03 & 37.72 \\
\hline 105 & 3 & 625 & 105.86 & 143.24 & 416 & 104.79 & 178.33 & -1.08 & 35.09 \\
\hline 106 & 3 & 626 & 105.90 & 143.69 & 417 & 104.92 & 180.67 & -0.98 & 36.98 \\
\hline 107 & 3 & 627 & 105.98 & 144.48 & 418 & 105.01 & 181.01 & -0.98 & 36.53 \\
\hline 108 & 3 & 628 & 106.05 & 145.05 & 419 & 105.15 & 181.17 & -0.90 & 36.12 \\
\hline 109 & 3 & 629 & 106.13 & 146.55 & 420 & 105.25 & 181.09 & -0.89 & 34.54 \\
\hline 110 & 3 & 630 & 106.22 & 147.34 & 421 & 105.38 & 179.64 & -0.84 & 32.30 \\
\hline 111 & 3 & 635 & 106.68 & 149.14 & 426 & 106.06 & 181.56 & -0.62 & 32.42 \\
\hline 112 & 3 & 636 & 106.75 & 149.73 & 427 & 106.18 & 179.37 & -0.57 & 29.64 \\
\hline 113 & 3 & 643 & 107.35 & 150.47 & 434 & 106.95 & 182.69 & -0.40 & 32.22 \\
\hline 114 & 3 & 645 & 107.48 & 152.79 & 436 & 107.19 & 180.47 & -0.29 & 27.69 \\
\hline 115 & 3 & 646 & 107.60 & 151.89 & 437 & 107.31 & 182.27 & -0.28 & 30.38 \\
\hline 116 & 3 & 647 & 107.68 & 151.19 & 438 & 107.48 & 183.77 & -0.20 & 32.58 \\
\hline 117 & 3 & 648 & 107.80 & 152.47 & 439 & 107.58 & 184.18 & -0.22 & 31.71 \\
\hline 118 & 3 & 650 & 108.00 & 154.99 & 440 & 107.72 & 185.91 & -0.27 & 30.91 \\
\hline 119 & 3 & 651 & 108.10 & 154.26 & 441 & 107.89 & 184.23 & -0.22 & 29.97 \\
\hline 120 & 3 & 652 & 108.19 & 153.86 & 442 & 107.97 & 182.86 & -0.22 & 29.00 \\
\hline 121 & 3 & 653 & 108.30 & 152.89 & 443 & 108.15 & 183.42 & -0.15 & 30.53 \\
\hline 122 & 3 & 654 & 108.37 & 153.66 & 444 & 108.28 & 186.22 & -0.09 & 32.56 \\
\hline 123 & 3 & 655 & 108.47 & 154.94 & 445 & 108.44 & 187.72 & -0.03 & 32.78 \\
\hline 124 & 3 & 656 & 108.54 & 155.78 & 446 & 108.58 & 187.11 & 0.04 & 31.33 \\
\hline 125 & 3 & 657 & 108.63 & 155.89 & 447 & 108.68 & 186.69 & 0.05 & 30.80 \\
\hline 126 & 3 & 658 & 108.71 & 157.12 & 448 & 108.83 & 186.58 & 0.12 & 29.46 \\
\hline 127 & 3 & 660 & 108.89 & 155.27 & 449 & 108.96 & 186.63 & 0.07 & 31.36 \\
\hline 128 & 3 & 662 & 109.04 & 154.21 & 450 & 109.14 & 187.17 & 0.10 & 32.96 \\
\hline 129 & 3 & 663 & 109.08 & 154.67 & 451 & 109.29 & 187.00 & 0.21 & 32.33 \\
\hline 130 & 3 & 665 & 109.26 & 154.52 & 452 & 109.41 & 184.80 & 0.15 & 30.28 \\
\hline 131 & 3 & 666 & 109.35 & 152.92 & 453 & 109.54 & 183.56 & 0.19 & 30.64 \\
\hline 132 & 3 & 668 & 109.49 & 151.43 & 454 & 109.67 & 181.48 & 0.18 & 30.05 \\
\hline 133 & 3 & 669 & 109.59 & 150.69 & 455 & 109.78 & 181.07 & 0.19 & 30.38 \\
\hline 134 & 3 & 670 & 109.65 & 151.18 & 456 & 109.90 & 180.73 & 0.24 & 29.55 \\
\hline 135 & 3 & 671 & 109.71 & 150.57 & 457 & 109.92 & 181.39 & 0.21 & 30.82 \\
\hline 136 & 3 & 672 & 109.78 & 149.81 & 458 & 110.03 & 179.55 & 0.25 & 29.75 \\
\hline 137 & 3 & 673 & 109.87 & 150.14 & 459 & 110.13 & 179.75 & 0.27 & 29.60 \\
\hline 138 & 3 & 675 & 110.03 & 151.53 & 460 & 110.24 & 180.16 & 0.21 & 28.63 \\
\hline 139 & 3 & 676 & 110.06 & 149.79 & 461 & 110.33 & 180.81 & 0.27 & 31.02 \\
\hline 140 & 3 & 677 & 110.12 & 149.80 & 462 & 110.45 & 180.10 & 0.33 & 30.30 \\
\hline 141 & 3 & 678 & 110.19 & 149.66 & 463 & 110.55 & 179.09 & 0.36 & 29.43 \\
\hline 142 & 3 & 680 & 110.28 & 149.31 & 464 & 110.65 & 179.50 & 0.38 & 30.19 \\
\hline 143 & 3 & 681 & 110.35 & 149.65 & 465 & 110.77 & 179.87 & 0.43 & 30.22 \\
\hline
\end{tabular}




\begin{tabular}{|c|c|c|c|c|c|c|c|c|c|}
\hline obs & $\mathbf{T}$ & $\begin{array}{l}\text { B260 } \\
\text { year }\end{array}$ & $\begin{array}{l}\text { driving } \\
\text { stress } \\
(\mathbf{k P a})\end{array}$ & $\begin{array}{c}\text { flux } \\
\left(\mathbf{k m}^{3} \mathbf{a}^{-1}\right)\end{array}$ & $\begin{array}{l}\text { B270 } \\
\text { year }\end{array}$ & $\begin{array}{l}\text { driving } \\
\text { stress } \\
(\mathbf{k P a})\end{array}$ & $\begin{array}{c}\text { flux } \\
\left(\mathbf{k m}^{3} \mathbf{a}^{-1}\right)\end{array}$ & $\begin{array}{c}\Delta \text { driving } \\
\text { stress } \\
(\mathbf{k P a})\end{array}$ & $\begin{array}{c}\Delta \text { flux } \\
\left(\mathbf{k m}^{3} \mathbf{a}^{-1)}\right.\end{array}$ \\
\hline 144 & 3 & 682 & 110.39 & 149.76 & 466 & 110.84 & 181.42 & 0.46 & 31.66 \\
\hline 145 & 3 & 685 & 110.59 & 149.50 & 467 & 111.00 & 182.25 & 0.41 & 32.75 \\
\hline 146 & 3 & 687 & 110.73 & 151.10 & 468 & 111.15 & 181.01 & 0.42 & 29.91 \\
\hline 147 & 3 & 688 & 110.83 & 149.83 & 469 & 111.27 & 181.41 & 0.43 & 31.58 \\
\hline 148 & 3 & 689 & 110.89 & 150.59 & 470 & 111.34 & 181.73 & 0.45 & 31.14 \\
\hline 149 & 3 & 690 & 110.94 & 150.90 & 471 & 111.46 & 181.31 & 0.52 & 30.41 \\
\hline 150 & 3 & 691 & 111.01 & 151.60 & 472 & 111.56 & 180.55 & 0.55 & 28.95 \\
\hline 151 & 3 & 692 & 111.05 & 151.54 & 473 & 111.70 & 181.63 & 0.66 & 30.08 \\
\hline 152 & 3 & 695 & 111.30 & 150.62 & 474 & 111.86 & 182.29 & 0.56 & 31.67 \\
\hline 153 & 3 & 696 & 111.36 & 150.67 & 475 & 112.00 & 181.52 & 0.64 & 30.85 \\
\hline 154 & 3 & 698 & 111.48 & 149.66 & 476 & 112.16 & 181.56 & 0.68 & 31.90 \\
\hline 155 & 3 & 699 & 111.53 & 148.81 & 477 & 112.30 & 181.90 & 0.76 & 33.08 \\
\hline 156 & 3 & 700 & 111.60 & 149.22 & 478 & 112.39 & 181.83 & 0.80 & 32.61 \\
\hline 157 & 3 & 702 & 111.74 & 150.11 & 479 & 112.54 & 181.28 & 0.80 & 31.17 \\
\hline 158 & 3 & 703 & 111.79 & 149.05 & 480 & 112.68 & 181.17 & 0.89 & 32.12 \\
\hline 159 & 3 & 704 & 111.85 & 149.07 & 481 & 112.76 & 180.21 & 0.91 & 31.14 \\
\hline 160 & 3 & 706 & 111.99 & 148.96 & 482 & 112.91 & 179.96 & 0.92 & 31.00 \\
\hline 161 & 3 & 707 & 112.05 & 148.20 & 483 & 113.02 & 180.16 & 0.97 & 31.96 \\
\hline 162 & 3 & 708 & 112.10 & 147.95 & 484 & 113.17 & 180.35 & 1.07 & 32.40 \\
\hline 163 & 3 & 712 & 112.35 & 147.13 & 486 & 113.38 & 179.67 & 1.03 & 32.54 \\
\hline 164 & 3 & 713 & 112.44 & 146.78 & 487 & 113.50 & 179.22 & 1.06 & 32.44 \\
\hline 165 & 3 & 717 & 112.65 & 145.96 & 488 & 113.64 & 177.56 & 0.99 & 31.60 \\
\hline 166 & 3 & 711 & 112.30 & 147.41 & 489 & 113.73 & 177.61 & 1.43 & 30.21 \\
\hline 167 & 3 & 722 & 112.97 & 145.33 & 490 & 113.85 & 176.30 & 0.88 & 30.97 \\
\hline 168 & 3 & 719 & 112.74 & 145.32 & 491 & 113.92 & 175.87 & 1.18 & 30.55 \\
\hline 169 & 3 & 723 & 113.05 & 145.49 & 492 & 114.03 & 176.29 & 0.98 & 30.79 \\
\hline 170 & 3 & 724 & 113.10 & 145.80 & 493 & 114.20 & 177.99 & 1.10 & 32.19 \\
\hline 171 & 3 & 727 & 113.37 & 147.46 & 494 & 114.33 & 179.85 & 0.96 & 32.39 \\
\hline 172 & 3 & 728 & 113.43 & 148.36 & 495 & 114.50 & 182.58 & 1.07 & 34.22 \\
\hline 173 & 3 & 729 & 113.49 & 149.60 & 496 & 114.67 & 184.22 & 1.18 & 34.62 \\
\hline 174 & 3 & 731 & 113.65 & 150.46 & 497 & 114.81 & 186.02 & 1.16 & 35.56 \\
\hline 175 & 3 & 732 & 113.76 & 151.11 & 498 & 114.97 & 187.43 & 1.21 & 36.32 \\
\hline 176 & 3 & 733 & 113.83 & 151.43 & 499 & 115.08 & 187.66 & 1.25 & 36.23 \\
\hline 177 & 3 & 735 & 114.01 & 153.33 & 500 & 115.26 & 188.23 & 1.25 & 34.90 \\
\hline 178 & 3 & 737 & 114.20 & 155.59 & 501 & 115.42 & 189.01 & 1.21 & 33.42 \\
\hline 179 & 3 & 738 & 114.32 & 155.50 & 502 & 115.53 & 190.48 & 1.21 & 34.98 \\
\hline 180 & 3 & 739 & 114.43 & 155.26 & 503 & 115.68 & 191.11 & 1.25 & 35.85 \\
\hline 181 & 3 & 740 & 114.54 & 155.06 & 504 & 115.85 & 192.06 & 1.31 & 37.00 \\
\hline 182 & 3 & 744 & 114.87 & 155.07 & 505 & 115.98 & 192.30 & 1.11 & 37.23 \\
\hline 183 & 3 & 745 & 114.97 & 154.65 & 506 & 116.12 & 193.53 & 1.15 & 38.88 \\
\hline
\end{tabular}




\begin{tabular}{|c|c|c|c|c|c|c|c|c|c|}
\hline obs & $\mathbf{T}$ & $\begin{array}{l}\text { B260 } \\
\text { year }\end{array}$ & $\begin{array}{l}\text { driving } \\
\text { stress } \\
(\mathbf{k P a})\end{array}$ & $\begin{array}{c}\text { flux } \\
\left(\mathbf{k m}^{3} \mathbf{a}^{-1}\right)\end{array}$ & $\begin{array}{l}\text { B270 } \\
\text { year }\end{array}$ & $\begin{array}{l}\text { driving } \\
\text { stress } \\
(\mathbf{k P a})\end{array}$ & $\begin{array}{c}\text { flux } \\
\left(\mathbf{k m}^{3} \mathbf{a}^{-1}\right)\end{array}$ & $\begin{array}{c}\Delta \text { driving } \\
\text { stress } \\
(\mathbf{k P a})\end{array}$ & $\begin{array}{c}\Delta \text { flux } \\
\left(\mathbf{k m}^{3} \mathbf{a}^{-1)}\right.\end{array}$ \\
\hline 184 & 3 & 746 & 115.02 & 155.39 & 507 & 116.26 & 193.74 & 1.24 & 38.35 \\
\hline 185 & 3 & 748 & 115.29 & 156.23 & 508 & 116.39 & 194.10 & 1.10 & 37.87 \\
\hline 186 & 3 & 749 & 115.40 & 156.75 & 509 & 116.47 & 193.88 & 1.07 & 37.13 \\
\hline 187 & 3 & 750 & 115.52 & 156.47 & 510 & 116.64 & 193.49 & 1.12 & 37.02 \\
\hline 188 & 3 & 751 & 115.63 & 156.77 & 511 & 116.79 & 191.88 & 1.16 & 35.12 \\
\hline 189 & 3 & 752 & 115.70 & 156.56 & 512 & 116.90 & 191.48 & 1.21 & 34.92 \\
\hline 190 & 3 & 753 & 115.77 & 156.26 & 513 & 117.00 & 190.72 & 1.23 & 34.46 \\
\hline 191 & 3 & 754 & 115.86 & 156.31 & 514 & 117.13 & 190.11 & 1.27 & 33.81 \\
\hline 192 & 3 & 755 & 115.91 & 156.13 & 515 & 117.26 & 188.85 & 1.35 & 32.72 \\
\hline 193 & 3 & 756 & 115.99 & 156.60 & 516 & 117.40 & 188.16 & 1.41 & 31.56 \\
\hline 194 & 3 & 757 & 116.06 & 156.82 & 517 & 117.51 & 187.81 & 1.45 & 30.99 \\
\hline 195 & 3 & 758 & 116.14 & 157.02 & 518 & 117.63 & 187.49 & 1.49 & 30.47 \\
\hline 196 & 3 & 759 & 116.24 & 156.93 & 519 & 117.72 & 187.86 & 1.48 & 30.93 \\
\hline 197 & 3 & 761 & 116.41 & 157.08 & 521 & 117.90 & 187.69 & 1.49 & 30.61 \\
\hline 198 & 3 & 762 & 116.50 & 157.25 & 522 & 117.96 & 187.37 & 1.46 & 30.12 \\
\hline 199 & 3 & 763 & 116.57 & 156.50 & 523 & 118.12 & 187.12 & 1.55 & 30.63 \\
\hline 200 & 3 & 764 & 116.62 & 156.92 & 524 & 118.20 & 186.43 & 1.58 & 29.50 \\
\hline 201 & 3 & 765 & 116.74 & 157.13 & 525 & 118.31 & 186.35 & 1.57 & 29.21 \\
\hline 202 & 3 & 767 & 116.95 & 156.69 & 526 & 118.41 & 185.66 & 1.46 & 28.97 \\
\hline 203 & 3 & 768 & 116.99 & 156.48 & 527 & 118.49 & 185.88 & 1.50 & 29.40 \\
\hline 204 & 3 & 769 & 117.12 & 156.46 & 528 & 118.61 & 186.04 & 1.49 & 29.58 \\
\hline 205 & 3 & 770 & 117.19 & 156.28 & 529 & 118.75 & 185.90 & 1.55 & 29.62 \\
\hline 206 & 3 & 773 & 117.43 & 156.08 & 530 & 118.85 & 185.77 & 1.42 & 29.69 \\
\hline 207 & 3 & 774 & 117.46 & 156.03 & 531 & 119.01 & 185.23 & 1.55 & 29.20 \\
\hline 208 & 3 & 776 & 117.65 & 155.82 & 532 & 119.12 & 185.40 & 1.47 & 29.59 \\
\hline 209 & 3 & 777 & 117.73 & 155.08 & 533 & 119.23 & 185.25 & 1.50 & 30.17 \\
\hline 210 & 3 & 778 & 117.80 & 154.99 & 534 & 119.37 & 185.60 & 1.57 & 30.61 \\
\hline 211 & 3 & 779 & 117.87 & 154.89 & 535 & 119.48 & 185.65 & 1.61 & 30.76 \\
\hline 212 & 3 & 782 & 118.07 & 154.35 & 536 & 119.58 & 185.47 & 1.51 & 31.12 \\
\hline 213 & 3 & 783 & 118.13 & 154.78 & 537 & 119.70 & 185.40 & 1.57 & 30.62 \\
\hline 214 & 3 & 784 & 118.17 & 154.50 & 538 & 119.81 & 185.43 & 1.64 & 30.93 \\
\hline 215 & 3 & 785 & 118.23 & 154.16 & 539 & 119.90 & 185.05 & 1.67 & 30.89 \\
\hline 216 & 3 & 786 & 118.32 & 154.07 & 540 & 120.03 & 184.07 & 1.70 & 30.00 \\
\hline 217 & 3 & 787 & 118.37 & 153.67 & 541 & 120.11 & 183.23 & 1.74 & 29.56 \\
\hline 218 & 3 & 788 & 118.43 & 153.37 & 542 & 120.16 & 183.07 & 1.72 & 29.70 \\
\hline 219 & 3 & 789 & 118.49 & 152.65 & 543 & 120.26 & 182.94 & 1.77 & 30.29 \\
\hline 220 & 3 & 792 & 118.68 & 151.64 & 544 & 120.33 & 182.89 & 1.65 & 31.24 \\
\hline 221 & 3 & 793 & 118.73 & 151.41 & 545 & 120.46 & 182.98 & 1.73 & 31.56 \\
\hline 222 & 3 & 794 & 118.82 & 151.21 & 546 & 120.55 & 182.72 & 1.74 & 31.50 \\
\hline 223 & 3 & 796 & 118.99 & 150.96 & 547 & 120.64 & 182.68 & 1.65 & 31.72 \\
\hline
\end{tabular}




\begin{tabular}{|c|c|c|c|c|c|c|c|c|c|}
\hline obs & $\mathbf{T}$ & $\begin{array}{l}\text { B260 } \\
\text { year }\end{array}$ & $\begin{array}{l}\text { driving } \\
\text { stress } \\
(\mathrm{kPa})\end{array}$ & $\begin{array}{c}\text { flux } \\
\left(\mathbf{k m}^{3} \mathbf{a}^{-1}\right)\end{array}$ & $\begin{array}{l}\text { B270 } \\
\text { year }\end{array}$ & $\begin{array}{c}\text { driving } \\
\text { stress } \\
(\mathbf{k P a}) \\
\end{array}$ & $\underset{\left(\mathbf{k m}^{3} \mathbf{a}^{-1}\right)}{\text { flux }}$ & $\begin{array}{c}\Delta \text { driving } \\
\text { stress } \\
(\mathbf{k P a})\end{array}$ & $\underset{\left(\mathbf{k m}^{3} \mathbf{a}^{-1)}\right.}{\Delta \text { flux }}$ \\
\hline 224 & 3 & 797 & 119.05 & 150.98 & 548 & 120.65 & 182.87 & 1.60 & 31.89 \\
\hline 225 & 3 & 798 & 119.11 & 150.93 & 549 & 120.78 & 183.15 & 1.67 & 32.23 \\
\hline 226 & 3 & 801 & 119.30 & 150.37 & 550 & 120.90 & 183.07 & 1.60 & 32.70 \\
\hline 227 & 3 & 802 & 119.40 & 150.91 & 552 & 121.09 & 182.64 & 1.69 & 31.73 \\
\hline 228 & 3 & 804 & 119.55 & 150.63 & 553 & 121.19 & 182.38 & 1.64 & 31.76 \\
\hline 229 & 3 & 805 & 119.63 & 150.21 & 554 & 121.29 & 182.20 & 1.67 & 31.98 \\
\hline 230 & 3 & 807 & 119.74 & 149.57 & 555 & 121.41 & 182.01 & 1.66 & 32.44 \\
\hline 231 & 3 & 808 & 119.85 & 149.38 & 556 & 121.52 & 181.71 & 1.67 & 32.33 \\
\hline 232 & 3 & 809 & 119.91 & 149.11 & 557 & 121.60 & 181.88 & 1.70 & 32.77 \\
\hline 233 & 3 & 810 & 120.00 & 149.09 & 558 & 121.73 & 181.46 & 1.73 & 32.38 \\
\hline 234 & 3 & 811 & 120.04 & 148.80 & 559 & 121.83 & 181.19 & 1.78 & 32.38 \\
\hline 235 & 3 & 812 & 120.11 & 148.33 & 560 & 122.00 & 181.40 & 1.88 & 33.07 \\
\hline 236 & 3 & 813 & 120.17 & 148.06 & 561 & 122.10 & 180.96 & 1.93 & 32.90 \\
\hline 237 & 3 & 818 & 120.43 & 147.59 & 562 & 122.21 & 180.46 & 1.78 & 32.87 \\
\hline 238 & 3 & 819 & 120.46 & 147.59 & 563 & 122.26 & 180.49 & 1.80 & 32.90 \\
\hline 239 & 3 & 820 & 120.54 & 147.82 & 565 & 122.46 & 180.81 & 1.92 & 32.99 \\
\hline 240 & 3 & 821 & 120.61 & 147.90 & 566 & 122.56 & 180.50 & 1.95 & 32.60 \\
\hline 241 & 3 & 822 & 120.65 & 148.50 & 567 & 122.61 & 180.20 & 1.95 & 31.70 \\
\hline 242 & 3 & 824 & 120.79 & 149.14 & 568 & 122.76 & 180.93 & 1.97 & 31.79 \\
\hline 243 & 3 & 827 & 120.99 & 149.90 & 569 & 122.89 & 181.43 & 1.90 & 31.53 \\
\hline 244 & 3 & 825 & 120.85 & 149.18 & 570 & 122.98 & 181.89 & 2.13 & 32.71 \\
\hline 245 & 3 & 826 & 120.96 & 149.38 & 571 & 123.03 & 181.83 & 2.07 & 32.45 \\
\hline 246 & 3 & 828 & 121.07 & 150.32 & 572 & 123.15 & 181.82 & 2.08 & 31.50 \\
\hline 247 & 3 & 829 & 121.14 & 150.34 & 573 & 123.25 & 181.88 & 2.11 & 31.54 \\
\hline 248 & 3 & 830 & 121.19 & 150.74 & 574 & 123.34 & 181.76 & 2.16 & 31.02 \\
\hline 249 & 3 & 831 & 121.24 & 151.12 & 575 & 123.48 & 181.52 & 2.24 & 30.40 \\
\hline 250 & 3 & 836 & 121.56 & 153.17 & 576 & 123.50 & 181.60 & 1.94 & 28.44 \\
\hline 251 & 3 & 833 & 121.38 & 152.04 & 577 & 123.52 & 181.90 & 2.14 & 29.86 \\
\hline 252 & 3 & 834 & 121.42 & 152.48 & 578 & 123.59 & 181.55 & 2.17 & 29.07 \\
\hline 253 & 3 & 835 & 121.51 & 152.73 & 579 & 123.71 & 181.10 & 2.20 & 28.37 \\
\hline 254 & 3 & 837 & 121.65 & 153.42 & 580 & 123.77 & 180.94 & 2.12 & 27.53 \\
\hline 255 & 3 & 838 & 121.73 & 153.20 & 581 & 123.87 & 180.53 & 2.14 & 27.32 \\
\hline 256 & 3 & 839 & 121.81 & 152.91 & 582 & 123.98 & 180.03 & 2.17 & 27.12 \\
\hline 257 & 3 & 840 & 121.89 & 152.93 & 583 & 124.08 & 179.24 & 2.19 & 26.31 \\
\hline 258 & 3 & 841 & 121.97 & 152.73 & 584 & 124.18 & 178.50 & 2.21 & 25.77 \\
\hline 259 & 3 & 842 & 122.04 & 152.76 & 585 & 124.27 & 178.47 & 2.22 & 25.71 \\
\hline 260 & 3 & 823 & 120.71 & 148.89 & 586 & 124.33 & 178.54 & 3.63 & 29.65 \\
\hline 261 & 3 & 844 & 122.18 & 152.45 & 588 & 124.55 & 178.30 & 2.37 & 25.85 \\
\hline 262 & 3 & 845 & 122.21 & 152.72 & 589 & 124.65 & 177.61 & 2.44 & 24.89 \\
\hline 263 & 3 & 850 & 122.52 & 151.98 & 590 & 124.60 & 177.18 & 2.08 & 25.19 \\
\hline
\end{tabular}




\begin{tabular}{|c|c|c|c|c|c|c|c|c|c|}
\hline obs & $\mathbf{T}$ & $\begin{array}{l}\text { B260 } \\
\text { year }\end{array}$ & $\begin{array}{l}\text { driving } \\
\text { stress } \\
(\mathbf{k P a})\end{array}$ & $\begin{array}{c}\text { flux } \\
\left(\mathbf{k m}^{3} \mathbf{a}^{-1}\right)\end{array}$ & $\begin{array}{l}\text { B270 } \\
\text { year }\end{array}$ & $\begin{array}{c}\text { driving } \\
\text { stress } \\
(\mathbf{k P a})\end{array}$ & $\underset{\left(\mathbf{k m}^{3} \mathbf{a}^{-1}\right)}{\text { flux }}$ & $\begin{array}{c}\Delta \text { driving } \\
\text { stress } \\
(\mathbf{k P a})\end{array}$ & $\underset{\left(\mathbf{k m}^{3} \mathbf{a}^{-1)}\right.}{\Delta \text { flux }}$ \\
\hline 264 & 3 & 852 & 122.66 & 151.21 & 591 & 124.68 & 177.19 & 2.01 & 25.98 \\
\hline 265 & 3 & 853 & 122.77 & 151.12 & 592 & 124.80 & 176.96 & 2.03 & 25.83 \\
\hline 266 & 3 & 854 & 122.85 & 151.03 & 593 & 124.87 & 176.72 & 2.03 & 25.68 \\
\hline 267 & 3 & 855 & 122.91 & 151.06 & 594 & 125.00 & 176.57 & 2.08 & 25.51 \\
\hline 268 & 3 & 856 & 122.98 & 150.82 & 595 & 125.09 & 176.31 & 2.11 & 25.49 \\
\hline 269 & 3 & 857 & 123.00 & 150.65 & 596 & 125.11 & 176.03 & 2.12 & 25.38 \\
\hline 270 & 3 & 858 & 123.06 & 150.60 & 597 & 125.19 & 175.91 & 2.13 & 25.31 \\
\hline 271 & 3 & 859 & 123.11 & 150.50 & 598 & 125.28 & 175.67 & 2.18 & 25.18 \\
\hline 272 & 3 & 860 & 123.23 & 150.36 & 599 & 125.39 & 175.37 & 2.15 & 25.01 \\
\hline 273 & 3 & 861 & 123.32 & 150.38 & 600 & 125.50 & 175.49 & 2.18 & 25.11 \\
\hline 274 & 3 & 862 & 123.39 & 150.18 & 601 & 125.58 & 175.54 & 2.19 & 25.36 \\
\hline 275 & 3 & 865 & 123.58 & 149.49 & 602 & 125.68 & 175.27 & 2.10 & 25.78 \\
\hline 276 & 3 & 866 & 123.64 & 149.26 & 603 & 125.75 & 175.12 & 2.12 & 25.87 \\
\hline 277 & 3 & 867 & 123.65 & 149.47 & 604 & 125.86 & 174.76 & 2.21 & 25.28 \\
\hline 278 & 3 & 868 & 123.71 & 148.84 & 605 & 125.96 & 174.25 & 2.25 & 25.41 \\
\hline 279 & 3 & 870 & 123.83 & 148.04 & 606 & 126.07 & 173.71 & 2.24 & 25.67 \\
\hline 280 & 3 & 873 & 124.01 & 147.50 & 610 & 126.41 & 173.06 & 2.40 & 25.56 \\
\hline 281 & 3 & 875 & 124.10 & 146.95 & 611 & 126.48 & 173.17 & 2.38 & 26.22 \\
\hline 282 & 3 & 876 & 124.08 & 147.30 & 612 & 126.53 & 173.03 & 2.45 & 25.73 \\
\hline 283 & 3 & 877 & 124.14 & 146.82 & 613 & 126.58 & 172.80 & 2.44 & 25.98 \\
\hline 284 & 3 & 878 & 124.21 & 146.38 & 614 & 126.65 & 171.56 & 2.44 & 25.18 \\
\hline 285 & 3 & 879 & 124.33 & 146.32 & 615 & 126.70 & 171.44 & 2.37 & 25.12 \\
\hline 286 & 3 & 880 & 124.40 & 145.98 & 616 & 126.79 & 171.18 & 2.39 & 25.20 \\
\hline 287 & 3 & 882 & 124.53 & 146.35 & 617 & 126.93 & 171.14 & 2.40 & 24.78 \\
\hline 288 & 3 & 885 & 124.71 & 145.89 & 620 & 127.20 & 170.81 & 2.49 & 24.92 \\
\hline 289 & 3 & 886 & 124.75 & 145.26 & 621 & 127.34 & 170.81 & 2.59 & 25.56 \\
\hline 290 & 3 & 887 & 124.81 & 145.39 & 622 & 127.39 & 171.40 & 2.58 & 26.01 \\
\hline 291 & 3 & 888 & 124.84 & 144.87 & 623 & 127.44 & 170.98 & 2.60 & 26.10 \\
\hline 292 & 3 & 889 & 124.86 & 144.67 & 624 & 127.46 & 170.54 & 2.60 & 25.87 \\
\hline 293 & 3 & 890 & 124.83 & 144.14 & 625 & 127.54 & 169.99 & 2.70 & 25.84 \\
\hline 294 & 3 & 893 & 125.02 & 143.60 & 626 & 127.62 & 170.26 & 2.60 & 26.66 \\
\hline 295 & 3 & 894 & 125.04 & 143.75 & 628 & 127.77 & 170.11 & 2.73 & 26.37 \\
\hline 296 & 3 & 897 & 125.16 & 143.49 & 629 & 127.87 & 169.34 & 2.71 & 25.85 \\
\hline 297 & 3 & 898 & 125.23 & 143.14 & 630 & 127.94 & 168.97 & 2.72 & 25.83 \\
\hline 298 & 3 & 899 & 125.30 & 142.89 & 631 & 127.99 & 168.68 & 2.69 & 25.79 \\
\hline 299 & 3 & 901 & 125.37 & 143.19 & 632 & 128.05 & 168.46 & 2.68 & 25.28 \\
\hline 300 & 3 & 902 & 125.43 & 143.30 & 633 & 128.13 & 169.07 & 2.70 & 25.77 \\
\hline 301 & 3 & 903 & 125.48 & 142.98 & 634 & 128.18 & 169.28 & 2.70 & 26.30 \\
\hline 302 & 3 & 904 & 125.54 & 142.90 & 635 & 128.26 & 168.68 & 2.72 & 25.78 \\
\hline 303 & 3 & 906 & 125.65 & 142.99 & 636 & 128.26 & 168.64 & 2.61 & 25.66 \\
\hline
\end{tabular}




\begin{tabular}{|c|c|c|c|c|c|c|c|c|c|}
\hline obs & $\mathbf{T}$ & $\begin{array}{l}\text { B260 } \\
\text { year }\end{array}$ & $\begin{array}{l}\text { driving } \\
\text { stress } \\
(\mathbf{k P a})\end{array}$ & $\begin{array}{c}\text { flux } \\
\left(\mathbf{k m}^{3} \mathbf{a}^{-1}\right)\end{array}$ & $\begin{array}{l}\text { B270 } \\
\text { year }\end{array}$ & $\begin{array}{c}\text { driving } \\
\text { stress } \\
(\text { kPa) }\end{array}$ & $\underset{\left(\mathbf{k m}^{3} \mathbf{a}^{-1}\right)}{\text { flux }}$ & $\begin{array}{c}\Delta \text { driving } \\
\text { stress } \\
(\mathbf{k P a})\end{array}$ & $\underset{\left(\mathbf{k m}^{3} \mathbf{a}^{-1)}\right.}{\Delta \text { flux }}$ \\
\hline 304 & 3 & 907 & 125.71 & 143.38 & 637 & 128.35 & 168.26 & 2.64 & 24.88 \\
\hline 305 & 3 & 908 & 125.76 & 143.38 & 638 & 128.42 & 168.65 & 2.66 & 25.27 \\
\hline 306 & 3 & 909 & 125.82 & 143.16 & 639 & 128.50 & 169.27 & 2.68 & 26.11 \\
\hline 307 & 3 & 910 & 125.87 & 142.72 & 640 & 128.60 & 169.39 & 2.72 & 26.67 \\
\hline 308 & 3 & 912 & 126.03 & 142.99 & 641 & 128.68 & 170.43 & 2.65 & 27.43 \\
\hline 309 & 3 & 913 & 126.06 & 142.75 & 642 & 128.73 & 170.84 & 2.67 & 28.09 \\
\hline 310 & 3 & 914 & 126.12 & 142.75 & 643 & 128.82 & 170.24 & 2.70 & 27.49 \\
\hline 311 & 3 & 917 & 126.30 & 143.02 & 644 & 128.92 & 169.62 & 2.62 & 26.60 \\
\hline 312 & 3 & 918 & 126.36 & 143.41 & 645 & 129.01 & 170.11 & 2.65 & 26.70 \\
\hline 313 & 3 & 920 & 126.51 & 143.91 & 646 & 129.01 & 170.21 & 2.51 & 26.31 \\
\hline 314 & 3 & 921 & 126.57 & 143.94 & 647 & 129.11 & 170.16 & 2.54 & 26.23 \\
\hline 315 & 3 & 923 & 126.69 & 144.19 & 648 & 129.20 & 169.34 & 2.52 & 25.14 \\
\hline 316 & 3 & 925 & 126.76 & 144.41 & 649 & 129.32 & 168.71 & 2.56 & 24.30 \\
\hline 317 & 3 & 926 & 126.83 & 143.82 & 650 & 129.39 & 168.63 & 2.56 & 24.81 \\
\hline 318 & 3 & 927 & 126.90 & 144.22 & 651 & 129.47 & 169.15 & 2.57 & 24.93 \\
\hline 319 & 3 & 931 & 127.24 & 144.65 & 654 & 129.73 & 170.97 & 2.49 & 26.32 \\
\hline 320 & 3 & 933 & 127.34 & 145.32 & 655 & 129.82 & 171.31 & 2.48 & 25.99 \\
\hline 321 & 3 & 934 & 127.40 & 146.06 & 656 & 129.91 & 172.17 & 2.51 & 26.11 \\
\hline 322 & 3 & 935 & 127.47 & 144.80 & 657 & 129.94 & 170.90 & 2.48 & 26.10 \\
\hline 323 & 3 & 936 & 127.52 & 145.04 & 658 & 130.05 & 171.18 & 2.53 & 26.14 \\
\hline 324 & 3 & 937 & 127.62 & 145.22 & 659 & 130.12 & 171.13 & 2.49 & 25.91 \\
\hline 325 & 3 & 938 & 127.67 & 145.70 & 660 & 130.21 & 170.81 & 2.55 & 25.11 \\
\hline 326 & 3 & 939 & 127.73 & 146.19 & 661 & 130.32 & 171.00 & 2.58 & 24.81 \\
\hline 327 & 3 & 941 & 127.98 & 145.80 & 662 & 130.40 & 170.25 & 2.42 & 24.45 \\
\hline 328 & 3 & 942 & 128.05 & 145.89 & 663 & 130.50 & 170.01 & 2.45 & 24.12 \\
\hline 329 & 3 & 943 & 128.18 & 146.04 & 664 & 130.60 & 170.26 & 2.42 & 24.22 \\
\hline 330 & 3 & 944 & 128.17 & 145.88 & 665 & 130.71 & 169.93 & 2.54 & 24.05 \\
\hline 331 & 3 & 945 & 128.25 & 145.67 & 666 & 130.81 & 169.15 & 2.55 & 23.48 \\
\hline 332 & 3 & 946 & 128.38 & 145.62 & 667 & 130.86 & 169.80 & 2.49 & 24.18 \\
\hline 333 & 3 & 948 & 128.54 & 145.03 & 668 & 130.86 & 169.55 & 2.32 & 24.53 \\
\hline 334 & 3 & 949 & 128.62 & 144.81 & 669 & 130.96 & 169.84 & 2.34 & 25.03 \\
\hline 335 & 3 & 950 & 128.72 & 145.12 & 670 & 131.05 & 170.05 & 2.33 & 24.93 \\
\hline 336 & 3 & 951 & 128.78 & 144.95 & 671 & 131.11 & 169.90 & 2.32 & 24.95 \\
\hline 337 & 3 & 952 & 128.82 & 145.03 & 672 & 131.17 & 169.45 & 2.35 & 24.43 \\
\hline 338 & 3 & 953 & 128.87 & 145.23 & 673 & 131.21 & 168.99 & 2.34 & 23.76 \\
\hline 339 & 3 & 955 & 129.03 & 145.50 & 674 & 131.29 & 169.40 & 2.25 & 23.90 \\
\hline 340 & 3 & 956 & 129.10 & 145.94 & 675 & 131.39 & 169.90 & 2.28 & 23.96 \\
\hline 341 & 3 & 957 & 129.16 & 145.73 & 676 & 131.49 & 171.00 & 2.33 & 25.27 \\
\hline 342 & 3 & 958 & 129.23 & 145.28 & 677 & 131.59 & 170.88 & 2.35 & 25.60 \\
\hline 343 & 3 & 959 & 129.32 & 144.92 & 678 & 131.69 & 170.49 & 2.37 & 25.56 \\
\hline
\end{tabular}




\begin{tabular}{|c|c|c|c|c|c|c|c|c|c|}
\hline obs & $\mathbf{T}$ & $\begin{array}{l}\text { B260 } \\
\text { year }\end{array}$ & $\begin{array}{l}\text { driving } \\
\text { stress } \\
(\mathbf{k P a})\end{array}$ & $\begin{array}{c}\text { flux } \\
\left(\mathbf{k m}^{3} \mathbf{a}^{-1}\right)\end{array}$ & $\begin{array}{l}\text { B270 } \\
\text { year }\end{array}$ & $\begin{array}{l}\text { driving } \\
\text { stress } \\
(\mathbf{k P a})\end{array}$ & $\begin{array}{c}\text { flux } \\
\left(\mathbf{k m}^{3} \mathbf{a}^{-1}\right)\end{array}$ & $\begin{array}{c}\Delta \text { driving } \\
\text { stress } \\
(\mathbf{k P a})\end{array}$ & $\begin{array}{c}\Delta \text { flux } \\
\left(\mathbf{k m}^{3} \mathbf{a}^{-1)}\right.\end{array}$ \\
\hline 344 & 3 & 962 & 129.48 & 144.89 & 679 & 131.80 & 170.80 & 2.32 & 25.91 \\
\hline 345 & 3 & 963 & 129.55 & 145.02 & 680 & 131.88 & 170.59 & 2.33 & 25.57 \\
\hline 346 & 3 & 964 & 129.61 & 144.87 & 681 & 131.96 & 170.11 & 2.35 & 25.24 \\
\hline 347 & 3 & 965 & 129.67 & 144.60 & 682 & 131.99 & 169.74 & 2.32 & 25.14 \\
\hline 348 & 3 & 967 & 129.78 & 144.79 & 683 & 132.06 & 169.49 & 2.28 & 24.70 \\
\hline 349 & 3 & 968 & 129.85 & 144.58 & 684 & 132.16 & 169.52 & 2.31 & 24.94 \\
\hline 350 & 3 & 969 & 129.94 & 144.65 & 685 & 132.26 & 169.41 & 2.32 & 24.76 \\
\hline 351 & 3 & 971 & 130.06 & 145.08 & 687 & 132.42 & 170.39 & 2.36 & 25.31 \\
\hline 352 & 3 & 972 & 130.12 & 145.07 & 688 & 132.51 & 170.93 & 2.40 & 25.85 \\
\hline 353 & 3 & 974 & 130.24 & 144.15 & 689 & 132.60 & 170.46 & 2.36 & 26.31 \\
\hline 354 & 3 & 976 & 130.35 & 143.90 & 690 & 132.80 & 169.83 & 2.46 & 25.93 \\
\hline 355 & 3 & 977 & 130.41 & 144.20 & 691 & 132.92 & 169.48 & 2.51 & 25.28 \\
\hline 356 & 3 & 979 & 130.49 & 144.14 & 692 & 132.97 & 169.37 & 2.48 & 25.23 \\
\hline 357 & 3 & 980 & 130.49 & 143.86 & 693 & 133.10 & 168.63 & 2.61 & 24.77 \\
\hline 358 & 3 & 982 & 130.64 & 143.40 & 694 & 133.17 & 168.31 & 2.54 & 24.91 \\
\hline 359 & 3 & 983 & 130.68 & 143.37 & 695 & 133.25 & 168.28 & 2.57 & 24.91 \\
\hline 360 & 3 & 984 & 130.75 & 143.67 & 696 & 133.34 & 169.12 & 2.59 & 25.45 \\
\hline 361 & 3 & 987 & 130.96 & 143.76 & 697 & 133.46 & 169.33 & 2.50 & 25.57 \\
\hline 362 & 3 & 988 & 131.04 & 143.48 & 698 & 133.58 & 169.43 & 2.54 & 25.95 \\
\hline 363 & 3 & 989 & 131.10 & 143.21 & 699 & 133.66 & 169.15 & 2.56 & 25.95 \\
\hline 364 & 3 & 990 & 131.19 & 142.86 & 700 & 133.83 & 169.03 & 2.64 & 26.17 \\
\hline 365 & 3 & 991 & 131.26 & 143.03 & 701 & 133.92 & 169.26 & 2.66 & 26.22 \\
\hline 366 & 3 & 993 & 131.44 & 143.56 & 702 & 134.02 & 169.07 & 2.58 & 25.51 \\
\hline 367 & 3 & 994 & 131.53 & 143.22 & 703 & 134.12 & 168.67 & 2.59 & 25.45 \\
\hline 368 & 3 & 997 & 131.68 & 143.20 & 704 & 134.17 & 168.51 & 2.49 & 25.30 \\
\hline 369 & 3 & 998 & 131.74 & 143.44 & 705 & 134.27 & 168.54 & 2.53 & 25.10 \\
\hline 370 & 3 & 999 & 131.80 & 143.63 & 706 & 134.32 & 168.60 & 2.51 & 24.97 \\
\hline 371 & 3 & 1000 & 131.86 & 143.92 & 707 & 134.38 & 168.65 & 2.52 & 24.74 \\
\hline 372 & 3 & 1001 & 131.95 & 144.03 & 708 & 134.55 & 169.48 & 2.60 & 25.45 \\
\hline 373 & 3 & 1002 & 132.05 & 145.04 & 709 & 134.64 & 169.60 & 2.59 & 24.56 \\
\hline 374 & 3 & 1004 & 132.26 & 146.11 & 710 & 134.73 & 170.54 & 2.48 & 24.43 \\
\hline 375 & 3 & 1005 & 132.36 & 146.66 & 711 & 134.79 & 172.42 & 2.43 & 25.75 \\
\hline 376 & 3 & 1006 & 132.42 & 146.95 & 712 & 134.79 & 173.93 & 2.37 & 26.99 \\
\hline 377 & 3 & 1008 & 132.58 & 146.99 & 713 & 134.89 & 173.71 & 2.31 & 26.72 \\
\hline 378 & 3 & 1009 & 132.66 & 146.97 & 714 & 135.03 & 172.70 & 2.37 & 25.73 \\
\hline 379 & 3 & 1016 & 133.08 & 143.45 & 720 & 135.62 & 169.69 & 2.54 & 26.23 \\
\hline 380 & 3 & 1017 & 133.21 & 142.74 & 721 & 135.69 & 169.43 & 2.48 & 26.69 \\
\hline 381 & 3 & 1019 & 133.37 & 142.42 & 722 & 135.82 & 168.92 & 2.45 & 26.50 \\
\hline 382 & 3 & 1021 & 133.46 & 142.32 & 723 & 135.91 & 169.06 & 2.45 & 26.74 \\
\hline 383 & 3 & 1022 & 133.57 & 142.19 & 724 & 136.05 & 168.79 & 2.48 & 26.60 \\
\hline
\end{tabular}




\begin{tabular}{|c|c|c|c|c|c|c|c|c|c|}
\hline obs & $\mathbf{T}$ & $\begin{array}{l}\text { B260 } \\
\text { year }\end{array}$ & $\begin{array}{l}\text { driving } \\
\text { stress } \\
(\mathbf{k P a})\end{array}$ & $\begin{array}{c}\text { flux } \\
\left(\mathbf{k m}^{3} \mathbf{a}^{-1}\right)\end{array}$ & $\begin{array}{l}\text { B270 } \\
\text { year }\end{array}$ & $\begin{array}{l}\text { driving } \\
\text { stress } \\
(\mathbf{k P a})\end{array}$ & $\begin{array}{c}\text { flux } \\
\left(\mathbf{k m}^{\mathbf{3}} \mathbf{a}^{-1}\right)\end{array}$ & $\begin{array}{c}\Delta \text { driving } \\
\text { stress } \\
(\mathbf{k P a})\end{array}$ & 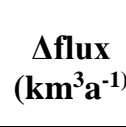 \\
\hline 384 & 3 & 1023 & 133.53 & 142.04 & 725 & 136.18 & 168.73 & 2.65 & 26.69 \\
\hline 385 & 3 & 1025 & 133.65 & 141.79 & 726 & 136.31 & 168.75 & 2.66 & 26.96 \\
\hline 386 & 3 & 1026 & 133.67 & 141.62 & 727 & 136.40 & 168.65 & 2.74 & 27.03 \\
\hline 387 & 3 & 1027 & 133.71 & 141.33 & 728 & 136.46 & 168.91 & 2.75 & 27.58 \\
\hline 388 & 3 & 1030 & 133.90 & 140.43 & 729 & 136.59 & 168.76 & 2.69 & 28.33 \\
\hline 389 & 3 & 1031 & 133.96 & 140.34 & 730 & 136.73 & 168.48 & 2.77 & 28.14 \\
\hline 390 & 3 & 1032 & 134.08 & 140.32 & 731 & 136.80 & 168.14 & 2.72 & 27.82 \\
\hline 391 & 3 & 1034 & 134.20 & 140.04 & 732 & 136.93 & 168.39 & 2.73 & 28.35 \\
\hline 392 & 3 & 1035 & 134.29 & 139.80 & 733 & 137.03 & 168.09 & 2.74 & 28.29 \\
\hline 393 & 3 & 1037 & 134.43 & 139.64 & 734 & 137.17 & 167.76 & 2.74 & 28.12 \\
\hline 394 & 3 & 1039 & 134.60 & 139.58 & 735 & 137.29 & 167.46 & 2.69 & 27.88 \\
\hline 395 & 3 & 1041 & 134.73 & 139.63 & 736 & 137.42 & 166.80 & 2.69 & 27.17 \\
\hline 396 & 3 & 1042 & 134.80 & 139.84 & 737 & 137.49 & 166.97 & 2.69 & 27.13 \\
\hline 397 & 3 & 1044 & 134.94 & 140.24 & 738 & 137.58 & 166.93 & 2.64 & 26.69 \\
\hline 398 & 3 & 1045 & 135.03 & 140.58 & 739 & 137.70 & 166.73 & 2.67 & 26.15 \\
\hline 399 & 3 & 1047 & 135.21 & 140.58 & 740 & 137.79 & 167.16 & 2.59 & 26.58 \\
\hline 400 & 3 & 1048 & 135.28 & 140.32 & 741 & 137.95 & 166.71 & 2.66 & 26.40 \\
\hline 401 & 3 & 1049 & 135.35 & 140.34 & 742 & 138.02 & 166.69 & 2.67 & 26.35 \\
\hline 402 & 3 & 1051 & 135.51 & 139.92 & 743 & 138.14 & 167.42 & 2.63 & 27.51 \\
\hline 403 & 3 & 1052 & 135.59 & 139.89 & 744 & 138.22 & 167.18 & 2.63 & 27.29 \\
\hline 404 & 3 & 1054 & 135.74 & 139.72 & 745 & 138.33 & 166.92 & 2.59 & 27.19 \\
\hline 405 & 3 & 1056 & 135.87 & 139.54 & 746 & 138.45 & 166.41 & 2.58 & 26.86 \\
\hline 406 & 3 & 1057 & 135.94 & 139.64 & 750 & 138.88 & 166.04 & 2.94 & 26.40 \\
\hline 407 & 3 & 1058 & 136.01 & 139.71 & 751 & 138.89 & 165.47 & 2.88 & 25.76 \\
\hline 408 & 3 & 1063 & 136.37 & 138.73 & 754 & 139.26 & 165.69 & 2.89 & 26.97 \\
\hline 409 & 3 & 1064 & 136.43 & 139.03 & 755 & 139.42 & 165.90 & 2.99 & 26.86 \\
\hline 410 & 3 & 1066 & 136.56 & 138.62 & 756 & 139.50 & 165.23 & 2.94 & 26.61 \\
\hline 411 & 3 & 1067 & 136.63 & 138.83 & 757 & 139.64 & 165.02 & 3.01 & 26.18 \\
\hline 412 & 3 & 1069 & 136.75 & 138.85 & 758 & 139.78 & 164.59 & 3.02 & 25.74 \\
\hline 413 & 3 & 1070 & 136.83 & 138.53 & 759 & 139.89 & 164.88 & 3.06 & 26.34 \\
\hline 414 & 3 & 1072 & 136.96 & 138.68 & 760 & 139.99 & 165.06 & 3.03 & 26.38 \\
\hline 415 & 3 & 1073 & 137.00 & 138.74 & 761 & 140.08 & 164.84 & 3.08 & 26.11 \\
\hline 416 & 3 & 1075 & 137.18 & 139.24 & 762 & 140.17 & 164.58 & 2.99 & 25.34 \\
\hline 417 & 3 & 1076 & 137.25 & 139.28 & 763 & 140.26 & 164.97 & 3.00 & 25.70 \\
\hline 418 & 3 & 1077 & 137.32 & 138.95 & 764 & 140.39 & 164.67 & 3.07 & 25.72 \\
\hline 419 & 3 & 1079 & 137.52 & 139.01 & 765 & 140.50 & 164.80 & 2.97 & 25.79 \\
\hline 420 & 3 & 1078 & 137.44 & 138.83 & 766 & 140.60 & 165.00 & 3.16 & 26.16 \\
\hline 421 & 3 & 1080 & 137.61 & 139.11 & 767 & 140.73 & 165.49 & 3.13 & 26.38 \\
\hline 422 & 3 & 1082 & 137.75 & 139.39 & 768 & 140.82 & 166.61 & 3.07 & 27.22 \\
\hline 423 & 3 & 1084 & 137.87 & 139.04 & 769 & 140.98 & 167.51 & 3.11 & 28.47 \\
\hline
\end{tabular}




\begin{tabular}{|c|c|c|c|c|c|c|c|c|c|}
\hline obs & $\mathbf{T}$ & $\begin{array}{l}\text { B260 } \\
\text { year }\end{array}$ & $\begin{array}{l}\text { driving } \\
\text { stress } \\
(\mathbf{k P a})\end{array}$ & $\underset{\left(\mathbf{k m}^{3} \mathbf{a}^{-1}\right)}{\text { flux }}$ & $\begin{array}{l}\text { B270 } \\
\text { year }\end{array}$ & $\begin{array}{l}\text { driving } \\
\text { stress } \\
(\mathbf{k P a})\end{array}$ & $\underset{\left(\mathbf{k m}^{3} \mathbf{a}^{-1}\right)}{\text { flux }}$ & $\begin{array}{c}\Delta \text { driving } \\
\text { stress } \\
(\mathbf{k P a})\end{array}$ & $\begin{array}{c}\Delta \text { flux } \\
\left(\mathbf{k m}^{3} \mathbf{a}^{-1)}\right.\end{array}$ \\
\hline 424 & 3 & 1085 & 137.95 & 139.27 & 770 & 141.08 & 167.67 & 3.13 & 28.40 \\
\hline 425 & 3 & 1086 & 138.09 & 139.50 & 771 & 141.18 & 168.49 & 3.09 & 28.99 \\
\hline 426 & 3 & 1088 & 138.20 & 139.96 & 772 & 141.35 & 169.03 & 3.15 & 29.07 \\
\hline 427 & 3 & 1089 & 138.27 & 140.01 & 773 & 141.45 & 169.49 & 3.18 & 29.48 \\
\hline 428 & 3 & 1090 & 138.34 & 140.36 & 774 & 141.60 & 170.70 & 3.25 & 30.34 \\
\hline 429 & 3 & 1094 & 138.69 & 143.14 & 775 & 141.83 & 171.19 & 3.14 & 28.04 \\
\hline 430 & 3 & 1095 & 138.81 & 142.86 & 776 & 141.99 & 171.34 & 3.18 & 28.48 \\
\hline 431 & 3 & 1096 & 138.89 & 142.81 & 777 & 142.11 & 171.42 & 3.22 & 28.61 \\
\hline 432 & 3 & 1099 & 139.09 & 143.17 & 778 & 142.22 & 171.05 & 3.13 & 27.88 \\
\hline 433 & 3 & 1100 & 139.20 & 142.95 & 779 & 142.35 & 171.06 & 3.15 & 28.12 \\
\hline 434 & 3 & 1101 & 139.34 & 142.91 & 780 & 142.51 & 170.77 & 3.17 & 27.86 \\
\hline 435 & 3 & 1104 & 139.62 & 143.00 & 781 & 142.63 & 170.58 & 3.01 & 27.58 \\
\hline 436 & 3 & 1105 & 139.73 & 143.19 & 782 & 142.66 & 170.14 & 2.93 & 26.95 \\
\hline 437 & 3 & 1106 & 139.86 & 143.21 & 783 & 142.81 & 170.42 & 2.95 & 27.21 \\
\hline 438 & 3 & 1107 & 139.88 & 143.36 & 784 & 142.94 & 171.09 & 3.06 & 27.73 \\
\hline 439 & 3 & 1110 & 140.23 & 143.21 & 785 & 143.09 & 170.89 & 2.86 & 27.67 \\
\hline 440 & 3 & 1111 & 140.28 & 143.22 & 786 & 143.26 & 171.00 & 2.98 & 27.78 \\
\hline 441 & 3 & 1112 & 140.34 & 142.99 & 787 & 143.38 & 170.64 & 3.04 & 27.65 \\
\hline 442 & 3 & 1114 & 140.52 & 143.03 & 788 & 143.53 & 170.42 & 3.01 & 27.39 \\
\hline 443 & 3 & 1115 & 140.63 & 143.02 & 789 & 143.63 & 170.30 & 3.01 & 27.27 \\
\hline 444 & 3 & 1116 & 140.73 & 142.81 & 790 & 143.75 & 170.79 & 3.02 & 27.97 \\
\hline 445 & 3 & 1117 & 140.83 & 142.67 & 791 & 143.94 & 170.76 & 3.11 & 28.09 \\
\hline 446 & 3 & 1119 & 141.02 & 142.55 & 792 & 144.06 & 170.74 & 3.04 & 28.19 \\
\hline 447 & 3 & 1120 & 141.13 & 142.27 & 793 & 144.17 & 171.18 & 3.05 & 28.91 \\
\hline 448 & 3 & 1121 & 141.20 & 142.30 & 794 & 144.25 & 171.25 & 3.04 & 28.94 \\
\hline 449 & 3 & 1125 & 141.54 & 142.76 & 795 & 144.44 & 171.20 & 2.90 & 28.44 \\
\hline 450 & 3 & 1126 & 141.65 & 143.15 & 796 & 144.48 & 171.65 & 2.82 & 28.50 \\
\hline 451 & 3 & 1127 & 141.74 & 143.37 & 797 & 144.63 & 171.59 & 2.89 & 28.22 \\
\hline 452 & 3 & 1129 & 141.91 & 143.20 & 798 & 144.78 & 171.73 & 2.87 & 28.53 \\
\hline 453 & 3 & 1130 & 142.01 & 143.09 & 799 & 144.90 & 171.73 & 2.90 & 28.64 \\
\hline 454 & 3 & 1131 & 142.07 & 142.83 & 800 & 144.98 & 171.41 & 2.91 & 28.59 \\
\hline 455 & 3 & 1132 & 142.15 & 142.68 & 801 & 145.11 & 170.87 & 2.96 & 28.20 \\
\hline 456 & 3 & 1133 & 142.23 & 142.27 & 802 & 145.18 & 170.48 & 2.95 & 28.21 \\
\hline 457 & 3 & 1134 & 142.30 & 142.10 & 803 & 145.31 & 169.75 & 3.01 & 27.66 \\
\hline 458 & 3 & 1137 & 142.57 & 141.45 & 804 & 145.49 & 169.74 & 2.92 & 28.29 \\
\hline 459 & 3 & 1138 & 142.70 & 141.31 & 805 & 145.58 & 169.80 & 2.87 & 28.50 \\
\hline 460 & 3 & 1139 & 142.73 & 140.76 & 806 & 145.82 & 169.53 & 3.08 & 28.77 \\
\hline 461 & 3 & 1141 & 142.87 & 140.24 & 807 & 145.84 & 168.82 & 2.98 & 28.58 \\
\hline 462 & 3 & 1142 & 142.93 & 140.16 & 808 & 145.96 & 168.02 & 3.04 & 27.86 \\
\hline 463 & 3 & 1143 & 143.04 & 139.94 & 809 & 146.07 & 167.46 & 3.03 & 27.52 \\
\hline
\end{tabular}




\begin{tabular}{|c|c|c|c|c|c|c|c|c|c|}
\hline obs & $\mathbf{T}$ & $\begin{array}{l}\text { B260 } \\
\text { year }\end{array}$ & $\begin{array}{l}\text { driving } \\
\text { stress } \\
(\mathbf{k P a})\end{array}$ & $\begin{array}{c}\text { flux } \\
\left(\mathbf{k m}^{3} \mathbf{a}^{-1}\right)\end{array}$ & $\begin{array}{l}\text { B270 } \\
\text { year }\end{array}$ & $\begin{array}{c}\text { driving } \\
\text { stress } \\
(\mathbf{k P a})\end{array}$ & $\underset{\left(\mathbf{k m}^{3} \mathbf{a}^{-1}\right)}{\text { flux }}$ & $\begin{array}{c}\Delta \text { driving } \\
\text { stress } \\
(\mathbf{k P a})\end{array}$ & $\underset{\left(\mathbf{k m}^{3} \mathbf{a}^{-1)}\right.}{\Delta \text { flux }}$ \\
\hline 464 & 3 & 1144 & 143.10 & 139.93 & 810 & 146.24 & 167.26 & 3.14 & 27.34 \\
\hline 465 & 3 & 1147 & 143.36 & 139.29 & 811 & 146.31 & 166.89 & 2.95 & 27.60 \\
\hline 466 & 3 & 1149 & 143.44 & 138.65 & 812 & 146.41 & 166.11 & 2.97 & 27.46 \\
\hline 467 & 3 & 1150 & 143.48 & 138.55 & 813 & 146.49 & 165.62 & 3.01 & 27.06 \\
\hline 468 & 3 & 1151 & 143.56 & 138.44 & 814 & 146.54 & 164.85 & 2.98 & 26.42 \\
\hline 469 & 3 & 1152 & 143.65 & 138.37 & 815 & 146.64 & 163.94 & 2.99 & 25.56 \\
\hline 470 & 3 & 1148 & 143.40 & 139.02 & 816 & 146.70 & 163.67 & 3.30 & 24.65 \\
\hline 471 & 3 & 1153 & 143.68 & 138.14 & 817 & 146.85 & 163.30 & 3.16 & 25.15 \\
\hline 472 & 3 & 1154 & 143.76 & 137.82 & 818 & 146.88 & 163.10 & 3.11 & 25.29 \\
\hline 473 & 3 & 1156 & 143.87 & 137.83 & 819 & 147.01 & 162.99 & 3.14 & 25.16 \\
\hline 474 & 3 & 1157 & 143.94 & 137.70 & 820 & 147.07 & 162.69 & 3.13 & 25.00 \\
\hline 475 & 3 & 1158 & 144.05 & 137.45 & 821 & 147.22 & 162.89 & 3.17 & 25.43 \\
\hline 476 & 3 & 1159 & 144.10 & 137.29 & 822 & 147.28 & 162.84 & 3.18 & 25.55 \\
\hline 477 & 3 & 1160 & 144.14 & 136.91 & 823 & 147.43 & 163.18 & 3.28 & 26.27 \\
\hline 478 & 3 & 1161 & 144.21 & 136.70 & 824 & 147.52 & 162.88 & 3.32 & 26.18 \\
\hline 479 & 3 & 1165 & 144.48 & 136.30 & 825 & 147.61 & 163.17 & 3.13 & 26.87 \\
\hline 480 & 3 & 1166 & 144.54 & 136.22 & 826 & 147.74 & 163.06 & 3.21 & 26.85 \\
\hline 481 & 3 & 1167 & 144.58 & 136.26 & 827 & 147.82 & 162.99 & 3.24 & 26.73 \\
\hline 482 & 3 & 1168 & 144.63 & 136.00 & 828 & 147.99 & 162.51 & 3.36 & 26.52 \\
\hline 483 & 3 & 1169 & 144.68 & 135.80 & 829 & 148.05 & 162.17 & 3.36 & 26.36 \\
\hline 484 & 3 & 1173 & 145.03 & 136.39 & 830 & 148.17 & 162.16 & 3.14 & 25.77 \\
\hline 485 & 3 & 1174 & 145.06 & 136.30 & 831 & 148.26 & 162.18 & 3.20 & 25.88 \\
\hline 486 & 3 & 1175 & 145.15 & 136.38 & 832 & 148.40 & 161.70 & 3.25 & 25.32 \\
\hline 487 & 3 & 1176 & 145.20 & 136.34 & 833 & 148.51 & 161.27 & 3.31 & 24.93 \\
\hline 488 & 3 & 1177 & 145.29 & 136.16 & 834 & 148.60 & 161.21 & 3.31 & 25.05 \\
\hline 489 & 3 & 1178 & 145.39 & 136.15 & 835 & 148.71 & 161.15 & 3.32 & 25.01 \\
\hline 490 & 3 & 1179 & 145.48 & 136.09 & 836 & 148.81 & 161.13 & 3.33 & 25.04 \\
\hline 491 & 3 & 1183 & 145.84 & 135.59 & 837 & 148.87 & 161.30 & 3.02 & 25.70 \\
\hline 492 & 3 & 1184 & 145.92 & 135.26 & 838 & 149.05 & 161.17 & 3.12 & 25.92 \\
\hline 493 & 3 & 1185 & 145.98 & 135.04 & 839 & 149.14 & 161.52 & 3.15 & 26.48 \\
\hline 494 & 3 & 1186 & 146.05 & 135.04 & 840 & 149.31 & 161.08 & 3.25 & 26.04 \\
\hline 495 & 3 & 1187 & 146.09 & 135.18 & 841 & 149.42 & 160.88 & 3.34 & 25.71 \\
\hline 496 & 3 & 1190 & 146.34 & 135.15 & 842 & 149.47 & 161.02 & 3.13 & 25.86 \\
\hline 497 & 1 & 1210 & 148.27 & 133.09 & 868 & 152.58 & 155.95 & 4.31 & 22.86 \\
\hline 498 & 1 & 1211 & 148.40 & 132.81 & 869 & 152.70 & 154.98 & 4.30 & 22.17 \\
\hline 499 & 1 & 1213 & 148.58 & 132.60 & 871 & 152.90 & 154.55 & 4.32 & 21.95 \\
\hline 500 & 1 & 1216 & 148.87 & 131.98 & 873 & 153.19 & 154.06 & 4.32 & 22.08 \\
\hline 501 & 1 & 1217 & 148.96 & 132.10 & 874 & 153.41 & 153.80 & 4.45 & 21.70 \\
\hline 502 & 1 & 1218 & 149.03 & 131.97 & 875 & 153.58 & 153.71 & 4.55 & 21.74 \\
\hline 503 & 1 & 1219 & 149.11 & 131.41 & 876 & 153.63 & 153.40 & 4.53 & 21.99 \\
\hline
\end{tabular}




\begin{tabular}{|c|c|c|c|c|c|c|c|c|c|}
\hline obs & $\mathbf{T}$ & $\begin{array}{l}\text { B260 } \\
\text { year }\end{array}$ & $\begin{array}{l}\text { driving } \\
\text { stress } \\
(\mathbf{k P a})\end{array}$ & $\begin{array}{c}\text { flux } \\
\left(\mathbf{k m}^{3} \mathbf{a}^{-1}\right)\end{array}$ & $\begin{array}{l}\text { B270 } \\
\text { year }\end{array}$ & $\begin{array}{l}\text { driving } \\
\text { stress } \\
(\mathbf{k P a})\end{array}$ & $\underset{\left(\mathbf{k m}^{3} \mathbf{a}^{-1}\right)}{\text { flux }}$ & $\begin{array}{c}\Delta \text { driving } \\
\text { stress } \\
(\mathbf{k P a})\end{array}$ & $\begin{array}{c}\Delta \text { flux } \\
\left(\mathbf{k m}^{3} \mathbf{a}^{-1)}\right.\end{array}$ \\
\hline 504 & 1 & 1221 & 149.29 & 130.55 & 877 & 153.74 & 153.04 & 4.44 & 22.50 \\
\hline 505 & 1 & 1222 & 149.36 & 130.61 & 878 & 153.85 & 152.67 & 4.50 & 22.06 \\
\hline 506 & 1 & 1223 & 149.43 & 130.63 & 879 & 153.97 & 152.57 & 4.54 & 21.94 \\
\hline 507 & 1 & 1225 & 149.60 & 130.21 & 880 & 154.10 & 152.61 & 4.50 & 22.40 \\
\hline 508 & 1 & 1226 & 149.75 & 129.94 & 881 & 154.18 & 152.31 & 4.43 & 22.37 \\
\hline 509 & 1 & 1228 & 149.88 & 130.49 & 882 & 154.33 & 152.36 & 4.46 & 21.87 \\
\hline 510 & 1 & 1229 & 149.94 & 130.00 & 883 & 154.50 & 151.88 & 4.56 & 21.88 \\
\hline 511 & 1 & 1230 & 150.04 & 129.87 & 884 & 154.53 & 151.79 & 4.49 & 21.92 \\
\hline 512 & 1 & 1231 & 150.14 & 129.80 & 885 & 154.61 & 152.14 & 4.47 & 22.34 \\
\hline 513 & 1 & 1232 & 150.20 & 129.81 & 886 & 154.74 & 152.05 & 4.54 & 22.24 \\
\hline 514 & 1 & 1233 & 150.26 & 129.75 & 887 & 154.87 & 151.62 & 4.61 & 21.87 \\
\hline 515 & 1 & 1235 & 150.43 & 129.66 & 888 & 155.04 & 151.13 & 4.61 & 21.46 \\
\hline 516 & 1 & 1236 & 150.47 & 129.85 & 889 & 155.16 & 151.53 & 4.69 & 21.68 \\
\hline 517 & 1 & 1238 & 150.67 & 129.40 & 891 & 155.36 & 150.93 & 4.69 & 21.53 \\
\hline 518 & 1 & 1239 & 150.72 & 129.21 & 892 & 155.49 & 150.83 & 4.77 & 21.62 \\
\hline 519 & 1 & 1241 & 150.87 & 128.95 & 893 & 155.55 & 151.07 & 4.68 & 22.12 \\
\hline 520 & 1 & 1242 & 150.95 & 128.94 & 894 & 155.71 & 150.76 & 4.77 & 21.82 \\
\hline 521 & 1 & 1243 & 151.07 & 129.06 & 895 & 155.80 & 150.74 & 4.74 & 21.68 \\
\hline 522 & 1 & 1245 & 151.23 & 129.23 & 896 & 155.97 & 150.76 & 4.74 & 21.53 \\
\hline 523 & 1 & 1247 & 151.38 & 129.15 & 898 & 156.13 & 151.06 & 4.75 & 21.92 \\
\hline 524 & 1 & 1249 & 151.60 & 129.19 & 899 & 156.30 & 151.54 & 4.70 & 22.35 \\
\hline 525 & 1 & 1251 & 151.76 & 129.38 & 901 & 156.59 & 151.09 & 4.84 & 21.71 \\
\hline 526 & 1 & 1252 & 151.85 & 129.13 & 902 & 156.74 & 150.90 & 4.89 & 21.78 \\
\hline 527 & 1 & 1254 & 152.00 & 129.14 & 903 & 156.76 & 151.01 & 4.76 & 21.86 \\
\hline 528 & 1 & 1255 & 152.07 & 129.16 & 904 & 156.92 & 150.79 & 4.84 & 21.63 \\
\hline 529 & 1 & 1256 & 152.15 & 129.35 & 905 & 157.11 & 150.14 & 4.96 & 20.79 \\
\hline 530 & 1 & 1258 & 152.37 & 129.53 & 906 & 157.24 & 150.66 & 4.87 & 21.13 \\
\hline 531 & 1 & 1259 & 152.48 & 129.56 & 907 & 157.40 & 150.57 & 4.92 & 21.01 \\
\hline 532 & 1 & 1261 & 152.61 & 129.53 & 909 & 157.61 & 150.90 & 5.00 & 21.36 \\
\hline 533 & 1 & 1263 & 152.76 & 129.08 & 910 & 157.75 & 150.87 & 4.99 & 21.79 \\
\hline 534 & 1 & 1264 & 152.85 & 129.22 & 911 & 157.85 & 149.98 & 5.00 & 20.76 \\
\hline 535 & 1 & 1265 & 152.93 & 129.18 & 912 & 157.90 & 150.09 & 4.97 & 20.91 \\
\hline 536 & 1 & 1266 & 153.00 & 129.02 & 913 & 157.95 & 150.12 & 4.95 & 21.10 \\
\hline 537 & 1 & 1267 & 153.06 & 129.09 & 914 & 158.14 & 149.57 & 5.08 & 20.48 \\
\hline 538 & 1 & 1268 & 153.16 & 128.87 & 915 & 158.32 & 149.19 & 5.16 & 20.32 \\
\hline 539 & 1 & 1272 & 153.51 & 127.51 & 916 & 158.44 & 148.95 & 4.93 & 21.44 \\
\hline 540 & 1 & 1273 & 153.60 & 127.38 & 917 & 158.50 & 148.15 & 4.90 & 20.77 \\
\hline 541 & 1 & 1274 & 153.66 & 126.95 & 918 & 158.58 & 147.94 & 4.93 & 20.99 \\
\hline 542 & 1 & 1275 & 153.72 & 126.98 & 919 & 158.72 & 147.74 & 5.00 & 20.76 \\
\hline 543 & 1 & 1276 & 153.86 & 126.75 & 920 & 158.84 & 147.53 & 4.99 & 20.78 \\
\hline
\end{tabular}




\begin{tabular}{|c|c|c|c|c|c|c|c|c|c|}
\hline obs & $\mathbf{T}$ & $\begin{array}{l}\text { B260 } \\
\text { year }\end{array}$ & $\begin{array}{l}\text { driving } \\
\text { stress } \\
(\mathbf{k P a})\end{array}$ & $\begin{array}{c}\text { flux } \\
\left(\mathbf{k m}^{3} \mathbf{a}^{-1}\right)\end{array}$ & $\begin{array}{l}\text { B270 } \\
\text { year }\end{array}$ & $\begin{array}{l}\text { driving } \\
\text { stress } \\
(\mathbf{k P a})\end{array}$ & $\underset{\left(\mathbf{k m}^{3} \mathbf{a}^{-1}\right)}{\text { flux }}$ & $\begin{array}{c}\Delta \text { driving } \\
\text { stress } \\
(\mathbf{k P a})\end{array}$ & 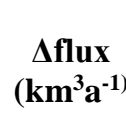 \\
\hline 544 & 1 & 1278 & 154.00 & 126.53 & 921 & 159.10 & 147.84 & 5.10 & 21.31 \\
\hline 545 & 1 & 1280 & 154.08 & 126.37 & 922 & 159.20 & 147.08 & 5.13 & 20.71 \\
\hline 546 & 1 & 1281 & 154.18 & 125.96 & 923 & 159.27 & 146.76 & 5.09 & 20.81 \\
\hline 547 & 1 & 1282 & 154.29 & 126.25 & 924 & 159.42 & 146.80 & 5.12 & 20.55 \\
\hline 548 & 1 & 1283 & 154.33 & 126.44 & 925 & 159.57 & 146.56 & 5.23 & 20.11 \\
\hline 549 & 1 & 1284 & 154.37 & 125.84 & 927 & 159.79 & 146.80 & 5.42 & 20.96 \\
\hline 550 & 1 & 1285 & 154.39 & 126.11 & 928 & 159.93 & 146.31 & 5.54 & 20.20 \\
\hline 551 & 1 & 1289 & 154.81 & 126.88 & 930 & 160.07 & 146.61 & 5.27 & 19.73 \\
\hline 552 & 1 & 1290 & 154.87 & 126.59 & 931 & 160.19 & 145.92 & 5.32 & 19.33 \\
\hline 553 & 1 & 1291 & 154.90 & 127.05 & 932 & 160.25 & 146.13 & 5.35 & 19.08 \\
\hline 554 & 1 & 1292 & 154.99 & 126.76 & 933 & 160.39 & 146.14 & 5.40 & 19.38 \\
\hline 555 & 1 & 1294 & 155.16 & 126.32 & 934 & 160.48 & 146.41 & 5.32 & 20.09 \\
\hline 556 & 1 & 1295 & 155.21 & 126.48 & 935 & 160.54 & 145.91 & 5.33 & 19.43 \\
\hline 557 & 1 & 1297 & 155.38 & 126.37 & 937 & 160.74 & 145.98 & 5.37 & 19.61 \\
\hline 558 & 1 & 1298 & 155.48 & 126.38 & 939 & 161.05 & 145.72 & 5.57 & 19.34 \\
\hline 559 & 1 & 1299 & 155.58 & 126.14 & 940 & 161.10 & 146.68 & 5.52 & 20.54 \\
\hline 560 & 1 & 1300 & 155.62 & 126.28 & 941 & 161.19 & 146.23 & 5.57 & 19.96 \\
\hline 561 & 1 & 1301 & 155.73 & 126.09 & 942 & 161.38 & 145.89 & 5.65 & 19.80 \\
\hline 562 & 1 & 1302 & 155.74 & 126.03 & 943 & 161.40 & 145.87 & 5.66 & 19.84 \\
\hline 563 & 1 & 1303 & 155.83 & 125.51 & 944 & 161.54 & 145.49 & 5.70 & 19.98 \\
\hline 564 & 1 & 1304 & 155.91 & 125.67 & 945 & 161.66 & 145.03 & 5.75 & 19.36 \\
\hline 565 & 1 & 1311 & 156.60 & 124.95 & 946 & 161.75 & 145.12 & 5.15 & 20.17 \\
\hline 566 & 1 & 1318 & 157.07 & 123.55 & 954 & 162.74 & 143.96 & 5.67 & 20.41 \\
\hline 567 & 1 & 1320 & 157.18 & 123.76 & 956 & 162.96 & 144.27 & 5.78 & 20.51 \\
\hline 568 & 1 & 1321 & 157.25 & 123.48 & 957 & 163.07 & 143.63 & 5.83 & 20.16 \\
\hline 569 & 1 & 1322 & 157.30 & 123.28 & 958 & 163.19 & 143.50 & 5.90 & 20.22 \\
\hline 570 & 1 & 1323 & 157.41 & 123.23 & 959 & 163.30 & 143.29 & 5.89 & 20.06 \\
\hline 571 & 1 & 1325 & 157.60 & 123.39 & 960 & 163.37 & 143.11 & 5.77 & 19.72 \\
\hline 572 & 1 & 1326 & 157.65 & 123.22 & 961 & 163.49 & 143.43 & 5.85 & 20.21 \\
\hline 573 & 1 & 1327 & 157.72 & 123.44 & 962 & 163.59 & 143.16 & 5.86 & 19.72 \\
\hline 574 & 1 & 1329 & 157.84 & 123.36 & 963 & 163.54 & 143.34 & 5.69 & 19.99 \\
\hline 575 & 1 & 1331 & 158.03 & 122.80 & 965 & 163.81 & 142.87 & 5.78 & 20.06 \\
\hline 576 & 1 & 1332 & 158.15 & 123.07 & 966 & 163.91 & 142.48 & 5.76 & 19.41 \\
\hline 577 & 1 & 1333 & 158.20 & 122.70 & 969 & 164.29 & 141.92 & 6.09 & 19.22 \\
\hline 578 & 1 & 1341 & 158.96 & 122.18 & 973 & 164.78 & 141.78 & 5.82 & 19.60 \\
\hline 579 & 1 & 1342 & 159.07 & 122.38 & 974 & 164.88 & 142.40 & 5.81 & 20.02 \\
\hline 580 & 1 & 1344 & 159.21 & 122.29 & 975 & 165.00 & 142.09 & 5.79 & 19.80 \\
\hline 581 & 1 & 1345 & 159.24 & 121.69 & 976 & 165.13 & 142.27 & 5.89 & 20.58 \\
\hline 582 & 1 & 1347 & 159.36 & 121.87 & 977 & 165.27 & 141.55 & 5.91 & 19.68 \\
\hline 583 & 1 & 1348 & 159.43 & 121.35 & 978 & 165.38 & 141.86 & 5.95 & 20.51 \\
\hline
\end{tabular}




\begin{tabular}{|c|c|c|c|c|c|c|c|c|c|}
\hline obs & $\mathbf{T}$ & $\begin{array}{l}\text { B260 } \\
\text { year }\end{array}$ & $\begin{array}{l}\text { driving } \\
\text { stress } \\
(\mathbf{k P a})\end{array}$ & $\begin{array}{c}\text { flux } \\
\left(\mathbf{k m}^{3} \mathbf{a}^{-1}\right)\end{array}$ & $\begin{array}{l}\text { B270 } \\
\text { year }\end{array}$ & $\begin{array}{l}\text { driving } \\
\text { stress } \\
(\mathbf{k P a})\end{array}$ & $\underset{\left(\mathbf{k m}^{3} \mathbf{a}^{-1}\right)}{\text { flux }}$ & $\begin{array}{c}\Delta \text { driving } \\
\text { stress } \\
(\mathbf{k P a})\end{array}$ & $\underset{\left(\mathbf{k m}^{3} \mathbf{a}^{-1)}\right.}{\Delta \text { flux }}$ \\
\hline 584 & 1 & 1350 & 159.59 & 121.22 & 979 & 165.54 & 140.90 & 5.95 & 19.68 \\
\hline 585 & 1 & 1351 & 159.69 & 120.88 & 980 & 165.59 & 141.30 & 5.91 & 20.41 \\
\hline 586 & 1 & 1356 & 160.15 & 121.33 & 984 & 166.09 & 141.54 & 5.94 & 20.20 \\
\hline 587 & 1 & 1357 & 160.20 & 121.21 & 985 & 166.21 & 141.39 & 6.01 & 20.18 \\
\hline 588 & 1 & 1359 & 160.35 & 121.40 & 986 & 166.29 & 141.40 & 5.94 & 19.99 \\
\hline 589 & 1 & 1360 & 160.43 & 120.92 & 987 & 166.44 & 141.86 & 6.02 & 20.93 \\
\hline 590 & 1 & 1362 & 160.58 & 121.78 & 988 & 166.58 & 141.39 & 6.00 & 19.61 \\
\hline 591 & 1 & 1363 & 160.66 & 121.85 & 989 & 166.69 & 141.84 & 6.03 & 19.99 \\
\hline 592 & 1 & 1364 & 160.74 & 122.12 & 990 & 166.82 & 141.31 & 6.08 & 19.19 \\
\hline 593 & 1 & 1365 & 160.88 & 122.05 & 991 & 166.96 & 141.25 & 6.07 & 19.20 \\
\hline 594 & 1 & 1367 & 161.04 & 122.36 & 992 & 167.06 & 141.19 & 6.02 & 18.83 \\
\hline 595 & 1 & 1369 & 161.19 & 122.38 & 994 & 167.24 & 141.10 & 6.06 & 18.72 \\
\hline 596 & 1 & 1370 & 161.28 & 122.25 & 995 & 167.36 & 141.16 & 6.08 & 18.90 \\
\hline 597 & 1 & 1375 & 161.89 & 122.25 & 996 & 167.41 & 140.56 & 5.53 & 18.31 \\
\hline 598 & 1 & 1376 & 162.02 & 121.80 & 997 & 167.51 & 140.60 & 5.48 & 18.79 \\
\hline 599 & 1 & 1372 & 161.50 & 122.49 & 999 & 167.75 & 140.19 & 6.25 & 17.70 \\
\hline 600 & 1 & 1373 & 161.61 & 122.00 & 1000 & 167.91 & 139.68 & 6.30 & 17.69 \\
\hline 601 & 1 & 1374 & 161.78 & 121.99 & 1001 & 168.03 & 139.53 & 6.25 & 17.54 \\
\hline 602 & 1 & 1378 & 162.25 & 121.96 & 1003 & 168.27 & 138.90 & 6.01 & 16.94 \\
\hline 603 & 1 & 1379 & 162.34 & 121.15 & 1004 & 168.34 & 138.29 & 6.00 & 17.13 \\
\hline 604 & 1 & 1380 & 162.42 & 120.79 & 1005 & 168.47 & 138.89 & 6.06 & 18.10 \\
\hline 605 & 1 & 1381 & 162.51 & 121.00 & 1006 & 168.61 & 138.35 & 6.10 & 17.35 \\
\hline 606 & 1 & 1382 & 162.58 & 120.65 & 1007 & 168.70 & 138.39 & 6.13 & 17.74 \\
\hline 607 & 1 & 1383 & 162.68 & 120.29 & 1008 & 168.77 & 138.20 & 6.10 & 17.92 \\
\hline 608 & 1 & 1385 & 162.87 & 119.97 & 1009 & 168.93 & 137.55 & 6.05 & 17.58 \\
\hline 609 & 1 & 1386 & 162.96 & 119.57 & 1010 & 169.05 & 137.37 & 6.09 & 17.79 \\
\hline 610 & 1 & 1388 & 163.14 & 119.35 & 1011 & 169.13 & 137.13 & 5.99 & 17.78 \\
\hline 611 & 1 & 1389 & 163.20 & 119.27 & 1012 & 169.23 & 137.21 & 6.03 & 17.94 \\
\hline 612 & 1 & 1390 & 163.28 & 119.22 & 1013 & 169.27 & 137.34 & 5.99 & 18.12 \\
\hline 613 & 1 & 1391 & 163.34 & 119.05 & 1014 & 169.36 & 137.09 & 6.01 & 18.04 \\
\hline 614 & 1 & 1393 & 163.51 & 118.53 & 1015 & 169.50 & 137.04 & 5.99 & 18.51 \\
\hline 615 & 1 & 1395 & 163.61 & 118.72 & 1016 & 169.58 & 136.27 & 5.97 & 17.54 \\
\hline 616 & 1 & 1396 & 163.69 & 118.50 & 1017 & 169.64 & 136.24 & 5.95 & 17.75 \\
\hline 617 & 1 & 1397 & 163.73 & 118.20 & 1018 & 169.79 & 135.45 & 6.05 & 17.24 \\
\hline 618 & 1 & 1399 & 163.93 & 118.29 & 1019 & 169.86 & 135.58 & 5.94 & 17.29 \\
\hline 619 & 1 & 1400 & 164.00 & 118.35 & 1020 & 169.93 & 135.58 & 5.92 & 17.23 \\
\hline 620 & 1 & 1401 & 164.05 & 118.28 & 1021 & 170.11 & 135.19 & 6.06 & 16.91 \\
\hline 621 & 1 & 1402 & 164.27 & 117.86 & 1022 & 170.16 & 135.60 & 5.88 & 17.75 \\
\hline 622 & 1 & 1404 & 164.38 & 117.73 & 1023 & 170.18 & 135.28 & 5.80 & 17.55 \\
\hline 623 & 1 & 1405 & 164.44 & 117.75 & 1024 & 170.19 & 135.09 & 5.75 & 17.33 \\
\hline
\end{tabular}




\begin{tabular}{|c|c|c|c|c|c|c|c|c|c|}
\hline obs & $\mathbf{T}$ & $\begin{array}{l}\text { B260 } \\
\text { year }\end{array}$ & $\begin{array}{l}\text { driving } \\
\text { stress } \\
(\mathbf{k P a})\end{array}$ & $\underset{\left(\mathbf{k m}^{3} \mathbf{a}^{-1}\right)}{\text { flux }}$ & $\begin{array}{l}\text { B270 } \\
\text { year }\end{array}$ & $\begin{array}{c}\text { driving } \\
\text { stress } \\
(\mathbf{k P a})\end{array}$ & $\underset{\left(\mathbf{k m}^{3} \mathbf{a}^{-1}\right)}{\text { flux }}$ & $\begin{array}{c}\Delta \text { driving } \\
\text { stress } \\
(\mathbf{k P a})\end{array}$ & $\underset{\left(\mathbf{k m}^{3} \mathbf{a}^{-1)}\right.}{\Delta \text { flux }}$ \\
\hline 624 & 1 & 1407 & 164.54 & 117.45 & 1025 & 170.28 & 135.28 & 5.74 & 17.83 \\
\hline 625 & 1 & 1406 & 164.45 & 117.54 & 1026 & 170.39 & 135.14 & 5.94 & 17.60 \\
\hline 626 & 1 & 1409 & 164.72 & 117.34 & 1027 & 170.57 & 135.49 & 5.85 & 18.14 \\
\hline 627 & 1 & 1411 & 164.91 & 117.06 & 1028 & 170.71 & 135.27 & 5.80 & 18.21 \\
\hline 628 & 1 & 1412 & 164.95 & 116.96 & 1029 & 170.80 & 134.74 & 5.85 & 17.78 \\
\hline 629 & 1 & 1413 & 164.99 & 117.03 & 1030 & 170.87 & 134.60 & 5.88 & 17.58 \\
\hline 630 & 1 & 1414 & 165.08 & 116.81 & 1031 & 171.01 & 134.86 & 5.93 & 18.05 \\
\hline 631 & 1 & 1416 & 165.22 & 116.70 & 1032 & 171.25 & 134.57 & 6.03 & 17.87 \\
\hline 632 & 1 & 1417 & 165.30 & 116.37 & 1033 & 171.34 & 134.52 & 6.05 & 18.15 \\
\hline 633 & 1 & 1418 & 165.38 & 116.03 & 1034 & 171.39 & 134.37 & 6.02 & 18.33 \\
\hline 634 & 1 & 1420 & 165.55 & 115.93 & 1035 & 171.55 & 134.26 & 6.00 & 18.34 \\
\hline 635 & 1 & 1422 & 165.73 & 115.64 & 1036 & 171.48 & 134.18 & 5.75 & 18.54 \\
\hline 636 & 1 & 1423 & 165.78 & 115.42 & 1037 & 171.57 & 133.69 & 5.79 & 18.27 \\
\hline 637 & 1 & 1424 & 165.87 & 115.48 & 1038 & 171.68 & 133.76 & 5.81 & 18.28 \\
\hline 638 & 1 & 1425 & 165.93 & 115.34 & 1039 & 171.80 & 133.88 & 5.86 & 18.53 \\
\hline 639 & 1 & 1427 & 166.01 & 115.28 & 1040 & 171.94 & 133.10 & 5.93 & 17.81 \\
\hline 640 & 1 & 1428 & 166.04 & 115.27 & 1041 & 172.05 & 133.34 & 6.01 & 18.06 \\
\hline 641 & 1 & 1429 & 166.06 & 115.16 & 1042 & 172.18 & 133.81 & 6.12 & 18.65 \\
\hline 642 & 1 & 1430 & 166.14 & 114.81 & 1043 & 172.26 & 133.25 & 6.12 & 18.44 \\
\hline 643 & 1 & 1432 & 166.22 & 114.74 & 1044 & 172.36 & 133.21 & 6.14 & 18.47 \\
\hline 644 & 1 & 1434 & 166.34 & 114.30 & 1045 & 172.58 & 132.73 & 6.24 & 18.42 \\
\hline 645 & 1 & 1435 & 166.40 & 114.06 & 1046 & 172.74 & 132.09 & 6.34 & 18.04 \\
\hline 646 & 1 & 1436 & 166.45 & 114.10 & 1047 & 172.85 & 131.83 & 6.41 & 17.73 \\
\hline 647 & 1 & 1437 & 166.56 & 114.34 & 1048 & 173.02 & 131.87 & 6.46 & 17.52 \\
\hline 648 & 1 & 1438 & 166.62 & 114.03 & 1049 & 173.16 & 131.38 & 6.55 & 17.35 \\
\hline 649 & 1 & 1439 & 166.64 & 113.94 & 1050 & 173.22 & 131.21 & 6.58 & 17.26 \\
\hline 650 & 1 & 1441 & 166.74 & 114.34 & 1051 & 173.43 & 131.13 & 6.68 & 16.79 \\
\hline 651 & 1 & 1442 & 166.77 & 114.19 & 1052 & 173.46 & 131.26 & 6.69 & 17.08 \\
\hline 652 & 1 & 1445 & 166.92 & 113.29 & 1053 & 173.53 & 131.38 & 6.61 & 18.10 \\
\hline 653 & 1 & 1447 & 167.02 & 113.30 & 1054 & 173.63 & 131.57 & 6.61 & 18.27 \\
\hline 654 & 1 & 1448 & 167.06 & 113.40 & 1055 & 173.71 & 131.20 & 6.65 & 17.81 \\
\hline 655 & 1 & 1449 & 167.21 & 113.27 & 1056 & 173.81 & 131.11 & 6.59 & 17.83 \\
\hline 656 & 1 & 1451 & 167.40 & 112.79 & 1057 & 173.89 & 131.24 & 6.49 & 18.45 \\
\hline 657 & 1 & 1452 & 167.49 & 112.96 & 1058 & 173.99 & 131.14 & 6.49 & 18.18 \\
\hline 658 & 1 & 1454 & 167.62 & 113.19 & 1059 & 174.10 & 130.86 & 6.47 & 17.67 \\
\hline 659 & 1 & 1455 & 167.66 & 113.19 & 1060 & 174.09 & 130.72 & 6.42 & 17.54 \\
\hline 660 & 1 & 1457 & 167.77 & 112.89 & 1061 & 174.27 & 130.19 & 6.49 & 17.30 \\
\hline 661 & 1 & 1458 & 167.87 & 112.83 & 1062 & 174.21 & 130.15 & 6.34 & 17.32 \\
\hline 662 & 1 & 1461 & 168.02 & 112.47 & 1063 & 174.21 & 130.03 & 6.20 & 17.57 \\
\hline 663 & 1 & 1462 & 168.05 & 112.35 & 1064 & 174.30 & 129.54 & 6.25 & 17.20 \\
\hline
\end{tabular}




\begin{tabular}{|c|c|c|c|c|c|c|c|c|c|}
\hline obs & $\mathbf{T}$ & $\begin{array}{l}\text { B260 } \\
\text { year }\end{array}$ & $\begin{array}{l}\text { driving } \\
\text { stress } \\
(\mathbf{k P a})\end{array}$ & $\begin{array}{c}\text { flux } \\
\left(\mathbf{k m}^{3} \mathbf{a}^{-1}\right)\end{array}$ & $\begin{array}{l}\text { B270 } \\
\text { year }\end{array}$ & $\begin{array}{c}\text { driving } \\
\text { stress } \\
(\mathbf{k P a})\end{array}$ & $\underset{\left(\mathbf{k m}^{3} \mathbf{a}^{-1}\right)}{\text { flux }}$ & $\begin{array}{c}\Delta \text { driving } \\
\text { stress } \\
(\mathbf{k P a})\end{array}$ & $\underset{\left(\mathbf{k m}^{3} \mathbf{a}^{-1)}\right.}{\Delta \text { flux }}$ \\
\hline 664 & 1 & 1463 & 168.08 & 111.93 & 1065 & 174.39 & 129.46 & 6.31 & 17.52 \\
\hline 665 & 1 & 1464 & 168.15 & 112.08 & 1066 & 174.53 & 129.36 & 6.38 & 17.28 \\
\hline 666 & 1 & 1465 & 168.25 & 112.02 & 1067 & 174.63 & 129.05 & 6.38 & 17.03 \\
\hline 667 & 1 & 1466 & 168.43 & 111.76 & 1068 & 174.71 & 128.77 & 6.28 & 17.01 \\
\hline 668 & 1 & 1467 & 168.46 & 111.69 & 1069 & 174.84 & 128.86 & 6.38 & 17.17 \\
\hline 669 & 1 & 1468 & 168.52 & 111.83 & 1070 & 174.83 & 128.75 & 6.31 & 16.92 \\
\hline 670 & 1 & 1469 & 168.58 & 111.97 & 1071 & 174.92 & 128.45 & 6.34 & 16.48 \\
\hline 671 & 1 & 1471 & 168.70 & 111.46 & 1072 & 174.94 & 128.21 & 6.24 & 16.76 \\
\hline 672 & 1 & 1472 & 168.82 & 111.71 & 1073 & 175.06 & 128.30 & 6.24 & 16.59 \\
\hline 673 & 1 & 1475 & 169.03 & 111.63 & 1074 & 175.20 & 128.53 & 6.17 & 16.90 \\
\hline 674 & 1 & 1476 & 169.21 & 111.60 & 1075 & 175.23 & 128.21 & 6.02 & 16.62 \\
\hline 675 & 1 & 1477 & 169.24 & 111.25 & 1076 & 175.31 & 128.11 & 6.07 & 16.86 \\
\hline 676 & 1 & 1478 & 169.27 & 111.21 & 1077 & 175.36 & 127.83 & 6.09 & 16.62 \\
\hline 677 & 1 & 1480 & 169.41 & 111.40 & 1078 & 175.46 & 128.35 & 6.05 & 16.94 \\
\hline 678 & 1 & 1481 & 169.45 & 111.16 & 1079 & 175.46 & 127.33 & 6.02 & 16.16 \\
\hline 679 & 1 & 1482 & 169.53 & 110.90 & 1080 & 175.51 & 127.65 & 5.98 & 16.75 \\
\hline 680 & 1 & 1485 & 169.77 & 110.56 & 1081 & 175.58 & 127.90 & 5.81 & 17.34 \\
\hline 681 & 1 & 1486 & 169.81 & 110.49 & 1082 & 175.66 & 127.46 & 5.84 & 16.97 \\
\hline 682 & 1 & 1487 & 169.81 & 110.49 & 1083 & 175.60 & 127.64 & 5.79 & 17.15 \\
\hline 683 & 1 & 1488 & 169.85 & 110.47 & 1084 & 175.69 & 127.43 & 5.84 & 16.97 \\
\hline 684 & 1 & 1492 & 169.95 & 110.93 & 1085 & 175.81 & 127.12 & 5.85 & 16.19 \\
\hline 685 & 1 & 1493 & 170.03 & 110.40 & 1086 & 175.83 & 127.10 & 5.80 & 16.69 \\
\hline 686 & 1 & 1490 & 169.87 & 110.59 & 1087 & 175.93 & 127.36 & 6.06 & 16.77 \\
\hline 687 & 1 & 1494 & 170.06 & 110.53 & 1088 & 175.94 & 127.07 & 5.88 & 16.54 \\
\hline 688 & 1 & 1495 & 170.15 & 110.73 & 1089 & 175.97 & 127.57 & 5.82 & 16.84 \\
\hline 689 & 1 & 1496 & 170.14 & 110.77 & 1090 & 176.08 & 127.45 & 5.94 & 16.68 \\
\hline 690 & 1 & 1497 & 170.13 & 110.97 & 1091 & 176.15 & 127.40 & 6.02 & 16.43 \\
\hline 691 & 1 & 1499 & 170.26 & 110.95 & 1092 & 176.26 & 127.37 & 6.00 & 16.42 \\
\hline 692 & 1 & 1501 & 170.41 & 111.05 & 1093 & 176.24 & 127.78 & 5.83 & 16.73 \\
\hline 693 & 1 & 1502 & 170.51 & 111.24 & 1094 & 176.36 & 128.09 & 5.85 & 16.84 \\
\hline 694 & 1 & 1505 & 170.65 & 111.01 & 1095 & 176.53 & 128.31 & 5.88 & 17.30 \\
\hline 695 & 1 & 1507 & 170.90 & 110.85 & 1096 & 176.62 & 128.51 & 5.72 & 17.66 \\
\hline 696 & 1 & 1508 & 170.96 & 110.52 & 1097 & 176.76 & 128.21 & 5.81 & 17.69 \\
\hline 697 & 1 & 1509 & 170.98 & 110.63 & 1098 & 176.85 & 128.28 & 5.87 & 17.65 \\
\hline 698 & 1 & 1510 & 171.08 & 110.59 & 1099 & 176.93 & 127.80 & 5.86 & 17.21 \\
\hline 699 & 1 & 1512 & 171.20 & 110.48 & 1100 & 176.99 & 128.46 & 5.79 & 17.97 \\
\hline 700 & 1 & 1513 & 171.27 & 110.43 & 1101 & 177.03 & 128.65 & 5.76 & 18.22 \\
\hline 701 & 1 & 1517 & 171.59 & 111.15 & 1102 & 177.23 & 128.57 & 5.64 & 17.42 \\
\hline 702 & 1 & 1519 & 171.79 & 111.35 & 1103 & 177.36 & 128.72 & 5.57 & 17.36 \\
\hline 703 & 1 & 1520 & 171.86 & 111.48 & 1104 & 177.46 & 129.06 & 5.60 & 17.58 \\
\hline
\end{tabular}




\begin{tabular}{|c|c|c|c|c|c|c|c|c|c|}
\hline obs & $\mathbf{T}$ & $\begin{array}{l}\text { B260 } \\
\text { year }\end{array}$ & $\begin{array}{l}\text { driving } \\
\text { stress } \\
(\mathbf{k P a})\end{array}$ & $\begin{array}{c}\text { flux } \\
\left(\mathbf{k m}^{3} \mathbf{a}^{-1}\right)\end{array}$ & $\begin{array}{l}\text { B270 } \\
\text { year }\end{array}$ & $\begin{array}{c}\text { driving } \\
\text { stress } \\
(\text { kPa) }\end{array}$ & $\underset{\left(\mathbf{k m}^{3} \mathbf{a}^{-1}\right)}{\text { flux }}$ & $\begin{array}{c}\Delta \text { driving } \\
\text { stress } \\
(\mathbf{k P a})\end{array}$ & $\underset{\left(\mathbf{k m}^{3} \mathbf{a}^{-1)}\right.}{\Delta \text { flux }}$ \\
\hline 704 & 1 & 1521 & 171.87 & 111.62 & 1105 & 177.52 & 129.33 & 5.65 & 17.72 \\
\hline 705 & 1 & 1522 & 171.97 & 111.79 & 1106 & 177.68 & 129.48 & 5.71 & 17.69 \\
\hline 706 & 1 & 1523 & 172.08 & 111.91 & 1107 & 177.77 & 129.47 & 5.69 & 17.55 \\
\hline 707 & 1 & 1524 & 172.17 & 112.28 & 1108 & 177.92 & 129.73 & 5.75 & 17.45 \\
\hline 708 & 1 & 1525 & 172.22 & 112.14 & 1109 & 177.99 & 129.77 & 5.77 & 17.63 \\
\hline 709 & 1 & 1526 & 172.34 & 112.24 & 1110 & 178.16 & 129.68 & 5.82 & 17.44 \\
\hline 710 & 1 & 1527 & 172.39 & 111.92 & 1111 & 178.31 & 129.74 & 5.92 & 17.81 \\
\hline 711 & 1 & 1531 & 172.80 & 111.51 & 1112 & 178.43 & 129.85 & 5.63 & 18.33 \\
\hline 712 & 1 & 1536 & 173.15 & 111.48 & 1113 & 178.62 & 129.93 & 5.47 & 18.45 \\
\hline 713 & 1 & 1537 & 173.20 & 111.62 & 1114 & 178.74 & 130.61 & 5.54 & 18.99 \\
\hline 714 & 1 & 1533 & 172.92 & 111.35 & 1115 & 178.91 & 130.78 & 5.99 & 19.43 \\
\hline 715 & 1 & 1534 & 172.97 & 111.43 & 1116 & 179.08 & 130.38 & 6.10 & 18.96 \\
\hline 716 & 1 & 1538 & 173.20 & 111.48 & 1117 & 179.26 & 130.11 & 6.06 & 18.63 \\
\hline 717 & 1 & 1539 & 173.27 & 111.51 & 1118 & 179.39 & 129.77 & 6.12 & 18.27 \\
\hline 718 & 1 & 1540 & 173.39 & 111.62 & 1119 & 179.49 & 129.49 & 6.09 & 17.87 \\
\hline 719 & 1 & 1542 & 173.57 & 111.70 & 1121 & 179.56 & 129.36 & 5.99 & 17.66 \\
\hline 720 & 1 & 1543 & 173.63 & 111.62 & 1122 & 179.68 & 129.31 & 6.04 & 17.69 \\
\hline 721 & 1 & 1544 & 173.75 & 111.67 & 1123 & 179.81 & 129.39 & 6.07 & 17.72 \\
\hline 722 & 1 & 1545 & 173.85 & 111.46 & 1124 & 179.85 & 129.29 & 6.00 & 17.83 \\
\hline 723 & 1 & 1547 & 173.95 & 111.24 & 1125 & 179.99 & 129.15 & 6.04 & 17.92 \\
\hline 724 & 1 & 1548 & 174.04 & 111.27 & 1126 & 180.04 & 128.64 & 6.00 & 17.38 \\
\hline 725 & 1 & 1549 & 174.15 & 111.28 & 1127 & 180.15 & 128.60 & 6.00 & 17.32 \\
\hline 726 & 1 & 1551 & 174.27 & 110.90 & 1128 & 180.32 & 128.68 & 6.05 & 17.79 \\
\hline 727 & 1 & 1550 & 174.25 & 111.07 & 1129 & 180.47 & 128.62 & 6.22 & 17.55 \\
\hline 728 & 1 & 1552 & 174.32 & 110.55 & 1130 & 180.54 & 129.43 & 6.21 & 18.88 \\
\hline 729 & 1 & 1557 & 174.64 & 110.05 & 1131 & 180.71 & 129.31 & 6.07 & 19.26 \\
\hline 730 & 1 & 1556 & 174.64 & 110.07 & 1132 & 180.81 & 129.06 & 6.17 & 18.99 \\
\hline 731 & 1 & 1560 & 174.82 & 109.72 & 1133 & 180.90 & 129.42 & 6.08 & 19.70 \\
\hline 732 & 1 & 1562 & 174.95 & 109.88 & 1134 & 180.97 & 129.23 & 6.02 & 19.35 \\
\hline 733 & 1 & 1563 & 175.09 & 110.09 & 1135 & 180.90 & 129.48 & 5.81 & 19.39 \\
\hline 734 & 1 & 1564 & 175.16 & 110.05 & 1136 & 180.93 & 129.32 & 5.77 & 19.27 \\
\hline 735 & 1 & 1566 & 175.26 & 110.47 & 1137 & 181.11 & 129.21 & 5.85 & 18.73 \\
\hline 736 & 1 & 1567 & 175.31 & 110.20 & 1138 & 181.22 & 129.08 & 5.90 & 18.88 \\
\hline 737 & 1 & 1570 & 175.55 & 110.35 & 1139 & 181.36 & 129.05 & 5.80 & 18.70 \\
\hline 738 & 1 & 1571 & 175.67 & 110.49 & 1140 & 181.46 & 128.94 & 5.79 & 18.45 \\
\hline 739 & 1 & 1572 & 175.77 & 110.06 & 1141 & 181.50 & 128.62 & 5.72 & 18.56 \\
\hline 740 & 1 & 1574 & 175.96 & 109.72 & 1142 & 181.68 & 128.96 & 5.71 & 19.25 \\
\hline 741 & 1 & 1576 & 176.03 & 109.62 & 1144 & 181.68 & 128.13 & 5.66 & 18.51 \\
\hline 742 & 3 & 1585 & 176.55 & 109.26 & 1145 & 181.77 & 128.26 & 5.22 & 19.00 \\
\hline 743 & 3 & 1588 & 176.69 & 109.28 & 1146 & 181.88 & 128.44 & 5.19 & 19.16 \\
\hline
\end{tabular}




\begin{tabular}{|c|c|c|c|c|c|c|c|c|c|}
\hline obs & $\mathbf{T}$ & $\begin{array}{l}\text { B260 } \\
\text { year }\end{array}$ & $\begin{array}{l}\text { driving } \\
\text { stress } \\
(\mathbf{k P a})\end{array}$ & $\begin{array}{c}\text { flux } \\
\left(\mathbf{k m}^{3} \mathbf{a}^{-1}\right)\end{array}$ & $\begin{array}{l}\text { B270 } \\
\text { year }\end{array}$ & $\begin{array}{l}\text { driving } \\
\text { stress } \\
(\mathbf{k P a})\end{array}$ & $\begin{array}{c}\text { flux } \\
\left(\mathbf{k m}^{3} \mathbf{a}^{-1}\right)\end{array}$ & $\begin{array}{c}\Delta \text { driving } \\
\text { stress } \\
(\mathbf{k P a})\end{array}$ & $\underset{\left(\mathbf{k m}^{3} \mathbf{a}^{-1)}\right.}{\Delta \text { flux }}$ \\
\hline 744 & 3 & 1589 & 176.68 & 109.21 & 1147 & 181.87 & 128.38 & 5.19 & 19.17 \\
\hline 745 & 3 & 1590 & 176.73 & 109.03 & 1148 & 181.90 & 128.06 & 5.17 & 19.02 \\
\hline 746 & 3 & 1591 & 176.88 & 109.03 & 1149 & 182.04 & 128.20 & 5.16 & 19.17 \\
\hline 747 & 3 & 1592 & 176.90 & 108.87 & 1150 & 182.12 & 128.25 & 5.22 & 19.38 \\
\hline 748 & 3 & 1593 & 176.95 & 108.89 & 1151 & 182.22 & 128.05 & 5.27 & 19.17 \\
\hline 749 & 3 & 1599 & 177.21 & 108.23 & 1154 & 182.50 & 127.58 & 5.29 & 19.35 \\
\hline 750 & 3 & 1597 & 177.14 & 108.78 & 1155 & 182.58 & 127.69 & 5.43 & 18.91 \\
\hline 751 & 3 & 1598 & 177.18 & 108.47 & 1156 & 182.72 & 127.43 & 5.54 & 18.97 \\
\hline 752 & 3 & 1600 & 177.27 & 108.82 & 1157 & 182.91 & 127.01 & 5.64 & 18.18 \\
\hline 753 & 3 & 1601 & 177.29 & 108.90 & 1158 & 183.02 & 127.19 & 5.73 & 18.29 \\
\hline 754 & 3 & 1602 & 177.36 & 108.51 & 1159 & 182.92 & 127.19 & 5.56 & 18.68 \\
\hline 755 & 3 & 1603 & 177.40 & 108.14 & 1160 & 183.01 & 127.06 & 5.61 & 18.92 \\
\hline 756 & 3 & 1604 & 177.47 & 108.14 & 1161 & 183.10 & 127.32 & 5.62 & 19.18 \\
\hline 757 & 3 & 1607 & 177.62 & 108.08 & 1162 & 183.08 & 127.34 & 5.46 & 19.27 \\
\hline 758 & 3 & 1608 & 177.66 & 107.98 & 1163 & 183.20 & 127.19 & 5.54 & 19.21 \\
\hline 759 & 3 & 1609 & 177.72 & 108.09 & 1164 & 183.28 & 127.40 & 5.56 & 19.31 \\
\hline 760 & 3 & 1610 & 177.77 & 108.02 & 1165 & 183.29 & 127.24 & 5.52 & 19.22 \\
\hline 761 & 3 & 1611 & 177.80 & 108.21 & 1166 & 183.35 & 126.93 & 5.55 & 18.72 \\
\hline 762 & 3 & 1614 & 177.96 & 107.66 & 1167 & 183.38 & 127.21 & 5.42 & 19.55 \\
\hline 763 & 3 & 1615 & 178.01 & 107.40 & 1168 & 183.34 & 127.45 & 5.33 & 20.05 \\
\hline 764 & 3 & 1616 & 178.03 & 107.31 & 1169 & 183.47 & 127.11 & 5.44 & 19.81 \\
\hline 765 & 3 & 1618 & 178.11 & 107.41 & 1170 & 183.53 & 126.69 & 5.42 & 19.28 \\
\hline 766 & 3 & 1619 & 178.17 & 107.16 & 1171 & 183.65 & 126.60 & 5.48 & 19.44 \\
\hline 767 & 3 & 1623 & 178.32 & 107.77 & 1172 & 183.70 & 127.02 & 5.38 & 19.24 \\
\hline 768 & 3 & 1624 & 178.36 & 106.97 & 1173 & 183.78 & 126.61 & 5.43 & 19.63 \\
\hline 769 & 3 & 1631 & 178.73 & 107.39 & 1174 & 183.85 & 126.38 & 5.12 & 18.98 \\
\hline 770 & 3 & 1632 & 178.74 & 107.10 & 1175 & 183.93 & 126.14 & 5.19 & 19.05 \\
\hline 771 & 3 & 1635 & 178.88 & 106.90 & 1178 & 184.17 & 125.26 & 5.29 & 18.36 \\
\hline 772 & 3 & 1636 & 178.95 & 106.74 & 1179 & 184.16 & 125.06 & 5.21 & 18.32 \\
\hline 773 & 3 & 1639 & 179.05 & 106.84 & 1182 & 184.35 & 125.53 & 5.30 & 18.70 \\
\hline 774 & 3 & 1640 & 179.13 & 106.83 & 1183 & 184.42 & 125.67 & 5.28 & 18.83 \\
\hline 775 & 3 & 1641 & 179.19 & 106.69 & 1184 & 184.46 & 125.42 & 5.27 & 18.73 \\
\hline 776 & 3 & 1642 & 179.20 & 107.24 & 1185 & 184.57 & 125.14 & 5.36 & 17.91 \\
\hline 777 & 3 & 1647 & 179.47 & 106.85 & 1186 & 184.62 & 125.55 & 5.15 & 18.70 \\
\hline 778 & 3 & 1648 & 179.56 & 106.84 & 1187 & 184.77 & 125.74 & 5.21 & 18.90 \\
\hline 779 & 3 & 1649 & 179.66 & 107.15 & 1188 & 184.82 & 125.84 & 5.16 & 18.69 \\
\hline 780 & 3 & 1650 & 179.74 & 107.54 & 1189 & 184.97 & 126.30 & 5.23 & 18.76 \\
\hline 781 & 3 & 1652 & 179.99 & 107.29 & 1192 & 185.34 & 125.96 & 5.35 & 18.67 \\
\hline 782 & 3 & 1653 & 180.03 & 107.21 & 1193 & 185.44 & 125.65 & 5.41 & 18.44 \\
\hline 783 & 3 & 1654 & 180.10 & 106.93 & 1194 & 185.53 & 125.83 & 5.42 & 18.90 \\
\hline
\end{tabular}




\begin{tabular}{|c|c|c|c|c|c|c|c|c|c|}
\hline obs & $\mathbf{T}$ & $\begin{array}{l}\text { B260 } \\
\text { year }\end{array}$ & $\begin{array}{l}\text { driving } \\
\text { stress } \\
(\mathbf{k P a})\end{array}$ & $\begin{array}{c}\text { flux } \\
\left(\mathbf{k m}^{3} \mathbf{a}^{-1}\right)\end{array}$ & $\begin{array}{l}\text { B270 } \\
\text { year }\end{array}$ & $\begin{array}{c}\text { driving } \\
\text { stress } \\
(\mathbf{k P a})\end{array}$ & $\underset{\left(\mathbf{k m}^{3} \mathbf{a}^{-1}\right)}{\text { flux }}$ & $\begin{array}{c}\Delta \text { driving } \\
\text { stress } \\
(\mathbf{k P a})\end{array}$ & $\underset{\left(\mathbf{k m}^{3} \mathbf{a}^{-1)}\right.}{\Delta \text { flux }}$ \\
\hline 784 & 3 & 1655 & 180.10 & 106.86 & 1195 & 185.74 & 126.29 & 5.64 & 19.43 \\
\hline 785 & 3 & 1656 & 180.14 & 106.93 & 1196 & 185.87 & 126.32 & 5.74 & 19.39 \\
\hline 786 & 3 & 1658 & 180.24 & 107.28 & 1197 & 185.96 & 125.87 & 5.72 & 18.58 \\
\hline 787 & 3 & 1660 & 180.44 & 107.30 & 1198 & 186.04 & 125.85 & 5.60 & 18.56 \\
\hline 788 & 3 & 1661 & 180.44 & 107.26 & 1199 & 186.06 & 125.69 & 5.62 & 18.43 \\
\hline 789 & 3 & 1664 & 180.61 & 107.28 & 1200 & 186.07 & 125.47 & 5.46 & 18.20 \\
\hline 790 & 3 & 1665 & 180.68 & 107.41 & 1201 & 186.14 & 125.72 & 5.46 & 18.31 \\
\hline 791 & 3 & 1666 & 180.75 & 107.71 & 1202 & 186.25 & 126.06 & 5.50 & 18.35 \\
\hline 792 & 3 & 1667 & 180.88 & 107.81 & 1203 & 186.39 & 125.76 & 5.51 & 17.95 \\
\hline 793 & 3 & 1669 & 180.99 & 107.84 & 1204 & 186.50 & 126.12 & 5.51 & 18.28 \\
\hline 794 & 3 & 1671 & 181.02 & 107.97 & 1205 & 186.55 & 126.29 & 5.53 & 18.33 \\
\hline 795 & 3 & 1672 & 181.12 & 108.36 & 1206 & 186.58 & 126.97 & 5.46 & 18.61 \\
\hline 796 & 3 & 1673 & 181.16 & 108.50 & 1207 & 186.68 & 126.72 & 5.53 & 18.21 \\
\hline 797 & 3 & 1674 & 181.24 & 108.42 & 1208 & 186.82 & 126.71 & 5.58 & 18.29 \\
\hline 798 & 3 & 1675 & 181.25 & 108.34 & 1209 & 186.90 & 126.80 & 5.65 & 18.46 \\
\hline 799 & 3 & 1678 & 181.37 & 108.89 & 1210 & 186.96 & 126.92 & 5.58 & 18.03 \\
\hline 800 & 3 & 1679 & 181.48 & 108.66 & 1211 & 187.02 & 126.58 & 5.54 & 17.93 \\
\hline 801 & 3 & 1680 & 181.56 & 107.94 & 1212 & 187.14 & 126.49 & 5.58 & 18.55 \\
\hline 802 & 3 & 1682 & 181.68 & 107.42 & 1213 & 187.27 & 126.04 & 5.60 & 18.62 \\
\hline 803 & 3 & 1683 & 181.73 & 107.28 & 1214 & 187.37 & 125.80 & 5.64 & 18.52 \\
\hline 804 & 3 & 1686 & 181.82 & 107.30 & 1215 & 187.53 & 125.74 & 5.71 & 18.43 \\
\hline 805 & 3 & 1687 & 181.89 & 107.13 & 1216 & 187.64 & 125.50 & 5.74 & 18.37 \\
\hline 806 & 3 & 1689 & 182.05 & 106.79 & 1217 & 187.72 & 125.32 & 5.67 & 18.53 \\
\hline 807 & 3 & 1690 & 182.13 & 106.97 & 1218 & 187.75 & 124.93 & 5.62 & 17.96 \\
\hline 808 & 3 & 1691 & 182.14 & 106.89 & 1219 & 187.85 & 125.11 & 5.71 & 18.22 \\
\hline 809 & 3 & 1693 & 182.27 & 107.03 & 1220 & 187.82 & 124.75 & 5.55 & 17.71 \\
\hline 810 & 3 & 1694 & 182.32 & 106.86 & 1221 & 187.91 & 124.66 & 5.58 & 17.80 \\
\hline 811 & 3 & 1696 & 182.45 & 106.22 & 1222 & 187.94 & 124.54 & 5.49 & 18.32 \\
\hline 812 & 3 & 1697 & 182.55 & 106.08 & 1223 & 188.08 & 124.00 & 5.53 & 17.92 \\
\hline 813 & 3 & 1698 & 182.62 & 106.13 & 1224 & 188.19 & 123.54 & 5.57 & 17.41 \\
\hline 814 & 3 & 1700 & 182.73 & 105.96 & 1225 & 188.20 & 123.53 & 5.47 & 17.57 \\
\hline 815 & 3 & 1701 & 182.81 & 105.76 & 1226 & 188.20 & 123.51 & 5.39 & 17.75 \\
\hline 816 & 3 & 1702 & 182.86 & 105.51 & 1227 & 188.28 & 123.34 & 5.42 & 17.83 \\
\hline 817 & 3 & 1703 & 182.92 & 105.42 & 1228 & 188.35 & 123.07 & 5.43 & 17.65 \\
\hline 818 & 3 & 1706 & 182.98 & 105.13 & 1229 & 188.40 & 123.10 & 5.42 & 17.97 \\
\hline 819 & 3 & 1707 & 183.02 & 105.11 & 1230 & 188.44 & 122.88 & 5.42 & 17.77 \\
\hline 820 & 3 & 1708 & 183.09 & 104.75 & 1231 & 188.48 & 122.30 & 5.39 & 17.55 \\
\hline 821 & 3 & 1709 & 183.09 & 104.52 & 1232 & 188.47 & 121.89 & 5.38 & 17.38 \\
\hline 822 & 3 & 1710 & 183.12 & 104.39 & 1233 & 188.49 & 121.69 & 5.37 & 17.30 \\
\hline 823 & 3 & 1711 & 183.16 & 104.40 & 1234 & 188.56 & 121.39 & 5.40 & 16.99 \\
\hline
\end{tabular}




\begin{tabular}{|c|c|c|c|c|c|c|c|c|c|}
\hline obs & $\mathbf{T}$ & $\begin{array}{l}\text { B260 } \\
\text { year }\end{array}$ & $\begin{array}{l}\text { driving } \\
\text { stress } \\
(\mathbf{k P a})\end{array}$ & $\begin{array}{c}\text { flux } \\
\left(\mathbf{k m}^{3} \mathbf{a}^{-1}\right)\end{array}$ & $\begin{array}{l}\text { B270 } \\
\text { year }\end{array}$ & $\begin{array}{c}\text { driving } \\
\text { stress } \\
(\mathbf{k P a})\end{array}$ & $\underset{\left(\mathbf{k m}^{3} \mathbf{a}^{-1}\right)}{\text { flux }}$ & $\begin{array}{c}\Delta \text { driving } \\
\text { stress } \\
(\mathbf{k P a})\end{array}$ & $\underset{\left(\mathbf{k m}^{3} \mathbf{a}^{-1)}\right.}{\Delta \text { flux }}$ \\
\hline 824 & 3 & 1712 & 183.17 & 104.07 & 1235 & 188.65 & 121.37 & 5.48 & 17.30 \\
\hline 825 & 3 & 1713 & 183.20 & 103.98 & 1236 & 188.72 & 121.04 & 5.51 & 17.06 \\
\hline 826 & 3 & 1714 & 183.20 & 103.91 & 1237 & 188.82 & 121.08 & 5.61 & 17.17 \\
\hline 827 & 3 & 1715 & 183.27 & 103.86 & 1238 & 188.85 & 120.56 & 5.58 & 16.71 \\
\hline 828 & 3 & 1716 & 183.29 & 103.82 & 1239 & 188.84 & 120.38 & 5.54 & 16.56 \\
\hline 829 & 3 & 1725 & 183.66 & 102.92 & 1240 & 188.93 & 120.30 & 5.27 & 17.38 \\
\hline 830 & 3 & 1726 & 183.66 & 102.95 & 1241 & 189.07 & 120.13 & 5.40 & 17.19 \\
\hline 831 & 3 & 1727 & 183.70 & 103.00 & 1242 & 189.13 & 120.63 & 5.43 & 17.63 \\
\hline 832 & 3 & 1728 & 183.76 & 102.95 & 1243 & 189.25 & 120.75 & 5.49 & 17.80 \\
\hline 833 & 3 & 1729 & 183.78 & 103.18 & 1244 & 189.28 & 120.06 & 5.50 & 16.88 \\
\hline 834 & 3 & 1730 & 183.73 & 103.25 & 1245 & 189.28 & 120.39 & 5.55 & 17.15 \\
\hline 835 & 3 & 1731 & 183.74 & 103.25 & 1246 & 189.32 & 120.35 & 5.58 & 17.10 \\
\hline 836 & 3 & 1732 & 183.79 & 102.99 & 1247 & 189.36 & 120.16 & 5.57 & 17.16 \\
\hline 837 & 3 & 1738 & 183.85 & 102.80 & 1248 & 189.43 & 120.28 & 5.58 & 17.48 \\
\hline 838 & 3 & 1739 & 183.90 & 102.65 & 1249 & 189.47 & 120.02 & 5.57 & 17.37 \\
\hline 839 & 3 & 1740 & 183.92 & 102.67 & 1250 & 189.50 & 120.11 & 5.58 & 17.43 \\
\hline 840 & 3 & 1741 & 183.95 & 102.29 & 1251 & 189.57 & 119.71 & 5.62 & 17.42 \\
\hline 841 & 3 & 1742 & 183.92 & 102.31 & 1252 & 189.61 & 119.45 & 5.69 & 17.14 \\
\hline 842 & 3 & 1743 & 183.99 & 102.36 & 1253 & 189.67 & 119.53 & 5.68 & 17.17 \\
\hline 843 & 3 & 1744 & 184.01 & 102.37 & 1254 & 189.73 & 119.68 & 5.72 & 17.31 \\
\hline 844 & 3 & 1745 & 183.97 & 102.45 & 1255 & 189.81 & 119.58 & 5.84 & 17.13 \\
\hline 845 & 3 & 1751 & 184.10 & 102.30 & 1256 & 189.82 & 119.63 & 5.73 & 17.33 \\
\hline 846 & 3 & 1752 & 184.14 & 102.68 & 1257 & 189.91 & 119.79 & 5.77 & 17.10 \\
\hline 847 & 3 & 1753 & 184.20 & 102.58 & 1258 & 189.98 & 119.92 & 5.78 & 17.34 \\
\hline 848 & 3 & 1755 & 184.34 & 102.61 & 1259 & 189.99 & 119.46 & 5.65 & 16.85 \\
\hline 849 & 3 & 1756 & 184.37 & 102.52 & 1260 & 190.03 & 119.69 & 5.65 & 17.18 \\
\hline 850 & 3 & 1758 & 184.41 & 102.47 & 1261 & 190.04 & 119.57 & 5.62 & 17.10 \\
\hline 851 & 3 & 1759 & 184.46 & 102.59 & 1262 & 190.09 & 119.68 & 5.63 & 17.09 \\
\hline 852 & 3 & 1760 & 184.38 & 102.26 & 1263 & 190.13 & 119.76 & 5.76 & 17.50 \\
\hline 853 & 3 & 1761 & 184.39 & 102.45 & 1264 & 190.21 & 119.72 & 5.82 & 17.28 \\
\hline 854 & 3 & 1764 & 184.58 & 102.45 & 1265 & 190.22 & 119.39 & 5.64 & 16.94 \\
\hline 855 & 3 & 1765 & 184.59 & 102.60 & 1266 & 190.31 & 119.58 & 5.71 & 16.98 \\
\hline 856 & 3 & 1766 & 184.63 & 102.47 & 1267 & 190.35 & 119.09 & 5.72 & 16.62 \\
\hline 857 & 3 & 1768 & 184.81 & 102.60 & 1268 & 190.42 & 118.74 & 5.61 & 16.14 \\
\hline 858 & 3 & 1769 & 184.82 & 102.39 & 1269 & 190.54 & 119.08 & 5.73 & 16.69 \\
\hline 859 & 3 & 1770 & 184.88 & 102.21 & 1270 & 190.59 & 118.96 & 5.70 & 16.75 \\
\hline 860 & 3 & 1771 & 184.90 & 102.03 & 1271 & 190.70 & 118.36 & 5.80 & 16.34 \\
\hline 861 & 3 & 1772 & 184.92 & 102.09 & 1272 & 190.61 & 118.60 & 5.70 & 16.52 \\
\hline 862 & 3 & 1773 & 184.95 & 101.89 & 1273 & 190.68 & 118.45 & 5.73 & 16.56 \\
\hline 863 & 3 & 1774 & 184.95 & 101.80 & 1274 & 190.72 & 118.68 & 5.77 & 16.89 \\
\hline
\end{tabular}




\begin{tabular}{|c|c|c|c|c|c|c|c|c|c|}
\hline obs & $\mathbf{T}$ & $\begin{array}{l}\text { B260 } \\
\text { year }\end{array}$ & $\begin{array}{l}\text { driving } \\
\text { stress } \\
(\mathbf{k P a})\end{array}$ & $\begin{array}{c}\text { flux } \\
\left(\mathbf{k m}^{3} \mathbf{a}^{-1}\right)\end{array}$ & $\begin{array}{l}\text { B270 } \\
\text { year }\end{array}$ & $\begin{array}{c}\text { driving } \\
\text { stress } \\
(\mathbf{k P a})\end{array}$ & $\underset{\left(\mathbf{k m}^{3} \mathbf{a}^{-1}\right)}{\text { flux }}$ & $\begin{array}{c}\Delta \text { driving } \\
\text { stress } \\
(\mathbf{k P a})\end{array}$ & $\underset{\left(\mathbf{k m}^{3} \mathbf{a}^{-1)}\right.}{\Delta \text { flux }}$ \\
\hline 864 & 3 & 1779 & 185.02 & 101.22 & 1275 & 190.74 & 118.36 & 5.72 & 17.14 \\
\hline 865 & 3 & 1780 & 184.98 & 101.43 & 1276 & 190.80 & 118.02 & 5.82 & 16.60 \\
\hline 866 & 3 & 1781 & 185.09 & 101.47 & 1277 & 190.79 & 117.76 & 5.70 & 16.29 \\
\hline 867 & 3 & 1782 & 185.10 & 101.51 & 1278 & 190.87 & 118.08 & 5.77 & 16.57 \\
\hline 868 & 3 & 1783 & 185.14 & 101.82 & 1279 & 190.93 & 118.36 & 5.79 & 16.54 \\
\hline 869 & 3 & 1784 & 185.17 & 101.68 & 1280 & 190.96 & 118.41 & 5.80 & 16.73 \\
\hline 870 & 3 & 1785 & 185.19 & 101.80 & 1281 & 191.00 & 118.55 & 5.82 & 16.76 \\
\hline 871 & 3 & 1786 & 185.31 & 101.88 & 1282 & 191.12 & 118.74 & 5.81 & 16.87 \\
\hline 872 & 3 & 1787 & 185.29 & 101.80 & 1283 & 191.18 & 118.92 & 5.88 & 17.12 \\
\hline 873 & 3 & 1788 & 185.35 & 101.88 & 1284 & 191.18 & 119.02 & 5.82 & 17.14 \\
\hline 874 & 3 & 1793 & 185.55 & 101.89 & 1285 & 191.21 & 119.23 & 5.65 & 17.34 \\
\hline 875 & 3 & 1794 & 185.56 & 102.07 & 1286 & 191.22 & 118.93 & 5.66 & 16.87 \\
\hline 876 & 3 & 1799 & 185.77 & 101.91 & 1287 & 191.35 & 119.30 & 5.58 & 17.39 \\
\hline 877 & 3 & 1800 & 185.78 & 101.75 & 1288 & 191.39 & 119.35 & 5.61 & 17.60 \\
\hline 878 & 3 & 1801 & 185.84 & 102.00 & 1289 & 191.48 & 119.07 & 5.64 & 17.07 \\
\hline 879 & 3 & 1802 & 185.90 & 102.04 & 1290 & 191.55 & 119.43 & 5.65 & 17.39 \\
\hline 880 & 3 & 1803 & 185.92 & 102.11 & 1291 & 191.67 & 119.43 & 5.76 & 17.31 \\
\hline 881 & 3 & 1804 & 185.93 & 101.84 & 1292 & 191.68 & 118.98 & 5.75 & 17.14 \\
\hline 882 & 3 & 1805 & 185.94 & 102.00 & 1293 & 191.66 & 118.95 & 5.72 & 16.95 \\
\hline 883 & 3 & 1806 & 185.97 & 101.71 & 1294 & 191.78 & 118.93 & 5.82 & 17.23 \\
\hline 884 & 3 & 1807 & 186.06 & 101.83 & 1295 & 191.89 & 118.70 & 5.83 & 16.87 \\
\hline 885 & 3 & 1811 & 186.27 & 102.03 & 1296 & 191.96 & 118.92 & 5.69 & 16.89 \\
\hline 886 & 3 & 1812 & 186.25 & 102.08 & 1297 & 191.88 & 119.18 & 5.62 & 17.11 \\
\hline 887 & 3 & 1813 & 186.26 & 102.49 & 1298 & 191.99 & 119.08 & 5.73 & 16.58 \\
\hline 888 & 3 & 1814 & 186.27 & 102.09 & 1299 & 191.96 & 119.19 & 5.69 & 17.10 \\
\hline 889 & 3 & 1815 & 186.36 & 102.14 & 1300 & 191.99 & 119.39 & 5.63 & 17.24 \\
\hline 890 & 3 & 1816 & 186.38 & 101.61 & 1301 & 192.00 & 119.12 & 5.62 & 17.52 \\
\hline 891 & 3 & 1817 & 186.42 & 101.38 & 1302 & 192.06 & 119.34 & 5.63 & 17.96 \\
\hline 892 & 3 & 1818 & 186.50 & 101.39 & 1303 & 192.01 & 119.20 & 5.51 & 17.82 \\
\hline 893 & 3 & 1821 & 186.61 & 101.47 & 1304 & 192.10 & 118.93 & 5.50 & 17.46 \\
\hline 894 & 3 & 1822 & 186.60 & 101.35 & 1305 & 192.19 & 118.22 & 5.59 & 16.87 \\
\hline 895 & 3 & 1839 & 187.06 & 101.21 & 1306 & 192.30 & 118.39 & 5.24 & 17.17 \\
\hline 896 & 3 & 1823 & 186.59 & 101.54 & 1307 & 192.35 & 118.49 & 5.76 & 16.95 \\
\hline 897 & 3 & 1824 & 186.61 & 101.38 & 1308 & 192.39 & 118.34 & 5.78 & 16.96 \\
\hline 898 & 3 & 1840 & 187.10 & 101.28 & 1309 & 192.46 & 118.58 & 5.36 & 17.30 \\
\hline 899 & 3 & 1841 & 187.14 & 101.42 & 1310 & 192.55 & 118.38 & 5.42 & 16.95 \\
\hline 900 & 3 & 1842 & 187.10 & 101.26 & 1311 & 192.64 & 118.31 & 5.53 & 17.05 \\
\hline 901 & 3 & 1843 & 187.14 & 101.43 & 1312 & 192.68 & 118.51 & 5.54 & 17.08 \\
\hline 902 & 3 & 1844 & 187.16 & 101.73 & 1313 & 192.72 & 118.02 & 5.56 & 16.29 \\
\hline 903 & 3 & 1845 & 187.24 & 101.60 & 1314 & 192.68 & 118.19 & 5.44 & 16.59 \\
\hline
\end{tabular}




\begin{tabular}{|c|c|c|c|c|c|c|c|c|c|}
\hline obs & $\mathbf{T}$ & $\begin{array}{l}\text { B260 } \\
\text { year }\end{array}$ & $\begin{array}{l}\text { driving } \\
\text { stress } \\
(\mathbf{k P a})\end{array}$ & $\begin{array}{c}\text { flux } \\
\left(\mathbf{k m}^{\mathbf{3}} \mathbf{a}^{-1}\right)\end{array}$ & $\begin{array}{l}\text { B270 } \\
\text { year }\end{array}$ & $\begin{array}{c}\text { driving } \\
\text { stress } \\
(\mathbf{k P a})\end{array}$ & $\underset{\left(\mathbf{k m}^{3} \mathbf{a}^{-1}\right)}{\text { flux }}$ & $\begin{array}{c}\Delta \text { driving } \\
\text { stress } \\
(\mathbf{k P a})\end{array}$ & $\underset{\left(\mathbf{k m}^{3} \mathbf{a}^{-1)}\right.}{\Delta \text { flux }}$ \\
\hline 904 & 3 & 1846 & 187.32 & 101.17 & 1315 & 192.74 & 117.96 & 5.42 & 16.79 \\
\hline 905 & 3 & 1847 & 187.32 & 101.27 & 1316 & 192.82 & 118.16 & 5.50 & 16.89 \\
\hline 906 & 3 & 1848 & 187.40 & 101.01 & 1317 & 192.88 & 118.14 & 5.48 & 17.13 \\
\hline 907 & 3 & 1859 & 187.83 & 101.83 & 1318 & 192.94 & 118.14 & 5.11 & 16.30 \\
\hline 908 & 3 & 1860 & 187.92 & 101.74 & 1319 & 192.97 & 118.30 & 5.04 & 16.56 \\
\hline 909 & 3 & 1861 & 187.99 & 101.64 & 1320 & 193.01 & 118.54 & 5.02 & 16.90 \\
\hline 910 & 3 & 1862 & 188.05 & 101.33 & 1321 & 193.09 & 118.28 & 5.04 & 16.94 \\
\hline 911 & 3 & 1863 & 188.06 & 101.64 & 1322 & 193.20 & 117.95 & 5.14 & 16.31 \\
\hline 912 & 3 & 1864 & 188.13 & 101.21 & 1323 & 193.24 & 118.31 & 5.10 & 17.11 \\
\hline 913 & 3 & 1865 & 188.12 & 101.14 & 1324 & 193.30 & 118.29 & 5.18 & 17.15 \\
\hline 914 & 3 & 1849 & 187.46 & 101.18 & 1325 & 193.38 & 117.97 & 5.93 & 16.79 \\
\hline 915 & 3 & 1850 & 187.56 & 101.02 & 1326 & 193.41 & 117.79 & 5.84 & 16.77 \\
\hline 916 & 3 & 1851 & 187.60 & 101.00 & 1327 & 193.49 & 117.96 & 5.88 & 16.96 \\
\hline 917 & 3 & 1852 & 187.61 & 101.15 & 1328 & 193.51 & 118.18 & 5.90 & 17.03 \\
\hline 918 & 3 & 1853 & 187.62 & 101.11 & 1329 & 193.53 & 118.30 & 5.91 & 17.19 \\
\hline 919 & 3 & 1866 & 188.14 & 101.05 & 1330 & 193.63 & 118.86 & 5.49 & 17.81 \\
\hline 920 & 3 & 1867 & 188.21 & 100.85 & 1331 & 193.68 & 118.11 & 5.47 & 17.26 \\
\hline 921 & 1 & 1869 & 188.26 & 100.54 & 1340 & 194.10 & 116.91 & 5.84 & 16.37 \\
\hline 922 & 1 & 1871 & 188.28 & 100.62 & 1341 & 194.18 & 116.65 & 5.90 & 16.03 \\
\hline 923 & 1 & 1872 & 188.31 & 100.42 & 1342 & 194.20 & 116.27 & 5.89 & 15.86 \\
\hline 924 & 1 & 1873 & 188.27 & 100.67 & 1343 & 194.32 & 116.02 & 6.04 & 15.35 \\
\hline 925 & 1 & 1874 & 188.23 & 100.73 & 1344 & 194.39 & 115.89 & 6.16 & 15.16 \\
\hline 926 & 1 & 1876 & 188.26 & 100.44 & 1345 & 194.39 & 115.84 & 6.13 & 15.40 \\
\hline 927 & 1 & 1877 & 188.34 & 99.97 & 1346 & 194.53 & 115.68 & 6.19 & 15.72 \\
\hline 928 & 1 & 1879 & 188.43 & 99.92 & 1347 & 194.53 & 115.24 & 6.10 & 15.32 \\
\hline 929 & 1 & 1880 & 188.51 & 100.11 & 1348 & 194.59 & 115.01 & 6.09 & 14.90 \\
\hline 930 & 1 & 1882 & 188.56 & 99.81 & 1349 & 194.68 & 115.20 & 6.12 & 15.39 \\
\hline 931 & 1 & 1883 & 188.56 & 99.66 & 1350 & 194.72 & 115.22 & 6.16 & 15.56 \\
\hline 932 & 1 & 1885 & 188.57 & 99.54 & 1351 & 194.77 & 114.90 & 6.20 & 15.36 \\
\hline 933 & 1 & 1886 & 188.57 & 99.44 & 1352 & 194.76 & 115.12 & 6.19 & 15.69 \\
\hline 934 & 1 & 1887 & 188.55 & 99.36 & 1353 & 194.68 & 114.82 & 6.13 & 15.46 \\
\hline 935 & 1 & 1888 & 188.59 & 99.31 & 1354 & 194.71 & 114.67 & 6.12 & 15.35 \\
\hline 936 & 1 & 1889 & 188.64 & 99.61 & 1355 & 194.73 & 114.50 & 6.09 & 14.89 \\
\hline 937 & 1 & 1890 & 188.65 & 99.42 & 1356 & 194.83 & 114.57 & 6.18 & 15.15 \\
\hline 938 & 1 & 1892 & 188.79 & 99.14 & 1357 & 194.82 & 114.57 & 6.03 & 15.43 \\
\hline 939 & 1 & 1893 & 188.77 & 98.91 & 1358 & 194.90 & 114.64 & 6.12 & 15.73 \\
\hline 940 & 1 & 1894 & 188.72 & 98.91 & 1359 & 194.93 & 114.62 & 6.21 & 15.71 \\
\hline 941 & 1 & 1897 & 188.83 & 98.92 & 1360 & 194.94 & 114.56 & 6.11 & 15.64 \\
\hline 942 & 1 & 1898 & 188.83 & 98.86 & 1361 & 194.97 & 114.37 & 6.14 & 15.51 \\
\hline 943 & 1 & 1900 & 188.94 & 98.31 & 1362 & 195.02 & 114.42 & 6.07 & 16.10 \\
\hline
\end{tabular}




\begin{tabular}{|c|c|c|c|c|c|c|c|c|c|}
\hline obs & $\mathbf{T}$ & $\begin{array}{l}\text { B260 } \\
\text { year }\end{array}$ & $\begin{array}{l}\text { driving } \\
\text { stress } \\
(\mathbf{k P a})\end{array}$ & $\begin{array}{c}\text { flux } \\
\left(\mathbf{k m}^{3} \mathbf{a}^{-1}\right)\end{array}$ & $\begin{array}{l}\text { B270 } \\
\text { year }\end{array}$ & $\begin{array}{c}\text { driving } \\
\text { stress } \\
(\mathbf{k P a})\end{array}$ & $\begin{array}{c}\text { flux } \\
\left(\mathbf{k m}^{3} \mathbf{a}^{-1}\right)\end{array}$ & $\begin{array}{c}\Delta \text { driving } \\
\text { stress } \\
(\mathbf{k P a})\end{array}$ & $\underset{\left(\mathbf{k m}^{3} \mathbf{a}^{-1)}\right.}{\Delta \text { flux }}$ \\
\hline 944 & 1 & 1902 & 189.07 & 97.86 & 1363 & 195.04 & 114.14 & 5.97 & 16.28 \\
\hline 945 & 1 & 1903 & 189.07 & 98.45 & 1364 & 195.07 & 114.04 & 5.99 & 15.59 \\
\hline 946 & 1 & 1906 & 189.20 & 99.23 & 1365 & 195.09 & 113.85 & 5.89 & 14.61 \\
\hline 947 & 1 & 1907 & 189.19 & 98.91 & 1366 & 195.10 & 113.91 & 5.91 & 14.99 \\
\hline 948 & 1 & 1908 & 189.30 & 99.02 & 1367 & 195.14 & 113.84 & 5.83 & 14.81 \\
\hline 949 & 1 & 1909 & 189.32 & 99.12 & 1368 & 195.19 & 113.90 & 5.87 & 14.78 \\
\hline 950 & 1 & 1910 & 189.39 & 98.97 & 1369 & 195.25 & 113.65 & 5.86 & 14.68 \\
\hline 951 & 1 & 1911 & 189.45 & 99.11 & 1370 & 195.28 & 113.49 & 5.83 & 14.38 \\
\hline 952 & 1 & 1912 & 189.42 & 99.18 & 1371 & 195.22 & 113.81 & 5.80 & 14.63 \\
\hline 953 & 1 & 1915 & 189.59 & 98.76 & 1372 & 195.24 & 113.98 & 5.65 & 15.23 \\
\hline 954 & 1 & 1916 & 189.69 & 98.78 & 1373 & 195.31 & 114.01 & 5.62 & 15.23 \\
\hline 955 & 1 & 1918 & 189.76 & 98.61 & 1374 & 195.37 & 113.78 & 5.61 & 15.17 \\
\hline 956 & 1 & 1919 & 189.93 & 98.59 & 1375 & 195.40 & 113.97 & 5.48 & 15.38 \\
\hline 957 & 1 & 1923 & 189.86 & 98.10 & 1376 & 195.38 & 113.97 & 5.52 & 15.87 \\
\hline 958 & 1 & 1924 & 189.83 & 98.19 & 1377 & 195.28 & 114.08 & 5.45 & 15.89 \\
\hline 959 & 1 & 1925 & 189.86 & 98.37 & 1378 & 195.38 & 113.96 & 5.51 & 15.59 \\
\hline 960 & 1 & 1928 & 189.97 & 98.49 & 1380 & 195.49 & 113.77 & 5.52 & 15.28 \\
\hline 961 & 1 & 1927 & 189.92 & 98.79 & 1382 & 195.56 & 113.60 & 5.64 & 14.81 \\
\hline 962 & 1 & 1929 & 190.02 & 98.62 & 1383 & 195.67 & 113.58 & 5.65 & 14.96 \\
\hline 963 & 1 & 1930 & 190.01 & 98.51 & 1384 & 195.69 & 113.34 & 5.68 & 14.83 \\
\hline 964 & 1 & 1933 & 190.08 & 98.41 & 1385 & 195.74 & 113.28 & 5.65 & 14.87 \\
\hline 965 & 1 & 1934 & 190.09 & 98.33 & 1386 & 195.78 & 113.15 & 5.69 & 14.82 \\
\hline 966 & 1 & 1937 & 190.09 & 98.13 & 1387 & 195.87 & 113.05 & 5.78 & 14.92 \\
\hline 967 & 1 & 1938 & 190.14 & 98.13 & 1388 & 195.89 & 112.99 & 5.75 & 14.87 \\
\hline 968 & 1 & 1939 & 190.20 & 97.99 & 1389 & 195.94 & 112.99 & 5.74 & 15.00 \\
\hline 969 & 1 & 1940 & 190.22 & 97.79 & 1390 & 196.04 & 112.83 & 5.82 & 15.04 \\
\hline 970 & 1 & 1941 & 190.23 & 97.62 & 1391 & 196.07 & 112.25 & 5.84 & 14.62 \\
\hline 971 & 1 & 1942 & 190.25 & 97.47 & 1392 & 196.15 & 112.37 & 5.90 & 14.90 \\
\hline 972 & 1 & 1945 & 190.31 & 97.58 & 1393 & 196.16 & 112.27 & 5.85 & 14.69 \\
\hline 973 & 1 & 1947 & 190.38 & 97.37 & 1394 & 196.18 & 112.88 & 5.79 & 15.50 \\
\hline 974 & 1 & 1948 & 190.39 & 97.63 & 1395 & 196.29 & 112.33 & 5.90 & 14.70 \\
\hline 975 & 1 & 1950 & 190.45 & 97.50 & 1396 & 196.32 & 112.52 & 5.87 & 15.01 \\
\hline 976 & 1 & 1953 & 190.61 & 97.66 & 1397 & 196.43 & 112.32 & 5.82 & 14.66 \\
\hline 977 & 1 & 1954 & 190.60 & 97.76 & 1398 & 196.45 & 112.25 & 5.85 & 14.49 \\
\hline 978 & 1 & 1955 & 190.59 & 97.81 & 1399 & 196.39 & 112.11 & 5.80 & 14.30 \\
\hline 979 & 1 & 1956 & 190.60 & 97.88 & 1400 & 196.43 & 112.17 & 5.82 & 14.29 \\
\hline 980 & 1 & 1957 & 190.61 & 97.74 & 1401 & 196.51 & 112.13 & 5.90 & 14.40 \\
\hline 981 & 1 & 1958 & 190.63 & 97.78 & 1402 & 196.50 & 112.53 & 5.88 & 14.75 \\
\hline 982 & 1 & 1959 & 190.61 & 97.83 & 1403 & 196.53 & 112.20 & 5.92 & 14.37 \\
\hline 983 & 1 & 1960 & 190.68 & 97.76 & 1404 & 196.60 & 112.28 & 5.92 & 14.52 \\
\hline
\end{tabular}




\begin{tabular}{|c|c|c|c|c|c|c|c|c|c|}
\hline obs & $\mathbf{T}$ & $\begin{array}{l}\text { B260 } \\
\text { year }\end{array}$ & $\begin{array}{c}\text { driving } \\
\text { stress } \\
(\mathbf{k P a})\end{array}$ & $\underset{\left(\mathbf{k m}^{3} \mathbf{a}^{-1}\right)}{\text { flux }}$ & $\begin{array}{l}\text { B270 } \\
\text { year }\end{array}$ & $\begin{array}{c}\text { driving } \\
\text { stress } \\
(\mathbf{k P a})\end{array}$ & $\underset{\left(\mathbf{k m}^{3} \mathbf{a}^{-1}\right)}{\text { flux }}$ & $\begin{array}{c}\Delta \text { driving } \\
\text { stress } \\
(\mathbf{k P a})\end{array}$ & $\underset{\left(\mathbf{k m}^{3} \mathbf{a}^{-1)}\right.}{\Delta f l u x}$ \\
\hline 984 & 1 & 1961 & 190.65 & 98.08 & 1405 & 196.66 & 112.14 & 6.01 & 14.06 \\
\hline 985 & 1 & 1962 & 190.77 & 98.24 & 1406 & 196.78 & 112.73 & 6.01 & 14.49 \\
\hline 986 & 1 & 1967 & 191.06 & 97.42 & 1407 & 196.74 & 112.77 & 5.68 & 15.35 \\
\hline 987 & 1 & 1969 & 191.01 & 97.39 & 1408 & 196.78 & 112.73 & 5.77 & 15.34 \\
\hline 988 & 1 & 1970 & 191.06 & 97.66 & 1409 & 196.85 & 112.73 & 5.79 & 15.07 \\
\hline 989 & 1 & 1971 & 191.10 & 97.69 & 1410 & 196.91 & 112.80 & 5.81 & 15.12 \\
\hline 990 & 1 & 1972 & 191.08 & 97.51 & 1411 & 196.94 & 112.84 & 5.85 & 15.33 \\
\hline 991 & 1 & 1973 & 191.13 & 97.77 & 1412 & 196.96 & 112.58 & 5.84 & 14.81 \\
\hline 992 & 1 & 1974 & 191.20 & 98.00 & 1413 & 197.00 & 112.63 & 5.79 & 14.64 \\
\hline 993 & 1 & 1976 & 191.28 & 97.53 & 1414 & 197.08 & 112.68 & 5.80 & 15.15 \\
\hline 994 & 1 & 1975 & 191.25 & 97.79 & 1415 & 197.18 & 112.72 & 5.93 & 14.93 \\
\hline 995 & 1 & 1977 & 191.35 & 97.49 & 1416 & 197.18 & 113.08 & 5.83 & 15.60 \\
\hline 996 & 1 & 1978 & 191.38 & 97.95 & 1417 & 197.20 & 113.17 & 5.82 & 15.22 \\
\hline 997 & 1 & 1980 & 191.41 & 97.47 & 1418 & 197.22 & 112.97 & 5.81 & 15.51 \\
\hline 998 & 1 & 1981 & 191.43 & 97.73 & 1419 & 197.29 & 112.75 & 5.86 & 15.02 \\
\hline 999 & 1 & 1982 & 191.49 & 97.74 & 1420 & 197.41 & 112.96 & 5.92 & 15.23 \\
\hline 1000 & 1 & 1983 & 191.50 & 97.64 & 1421 & 197.38 & 112.89 & 5.88 & 15.25 \\
\hline 1001 & 1 & 1984 & 191.57 & 97.64 & 1422 & 197.45 & 112.85 & 5.88 & 15.21 \\
\hline 1002 & 1 & 1985 & 191.61 & 97.61 & 1423 & 197.55 & 112.91 & 5.95 & 15.30 \\
\hline 1003 & 1 & 1986 & 191.63 & 97.43 & 1424 & 197.60 & 112.68 & 5.98 & 15.25 \\
\hline 1004 & 1 & 1987 & 191.67 & 97.51 & 1425 & 197.67 & 112.63 & 6.01 & 15.12 \\
\hline 1005 & 1 & 1996 & 191.98 & 97.31 & 1426 & 197.77 & 112.78 & 5.79 & 15.46 \\
\hline 1006 & 1 & 1997 & 191.99 & 97.40 & 1427 & 197.80 & 113.28 & 5.81 & 15.88 \\
\hline 1007 & 1 & 1999 & 192.15 & 98.02 & 1428 & 197.84 & 113.36 & 5.69 & 15.33 \\
\hline 1008 & 1 & 2000 & 192.10 & 98.07 & 1429 & 197.88 & 113.60 & 5.78 & 15.53 \\
\hline 1009 & 1 & 2001 & 192.18 & 97.78 & 1430 & 197.92 & 113.13 & 5.75 & 15.35 \\
\hline 1010 & 1 & 2002 & 192.20 & 98.08 & 1431 & 197.95 & 114.09 & 5.75 & 16.01 \\
\hline 1011 & 1 & 2003 & 192.20 & 98.20 & 1432 & 197.96 & 114.18 & 5.76 & 15.98 \\
\hline 1012 & 1 & 2004 & 192.20 & 98.45 & 1433 & 198.03 & 114.32 & 5.83 & 15.87 \\
\hline 1013 & 1 & 2005 & 192.26 & 98.58 & 1434 & 198.13 & 114.56 & 5.87 & 15.98 \\
\hline 1014 & 1 & 2007 & 192.32 & 98.89 & 1435 & 198.27 & 114.90 & 5.95 & 16.01 \\
\hline 1015 & 1 & 2008 & 192.29 & 99.05 & 1436 & 198.21 & 115.16 & 5.93 & 16.11 \\
\hline 1016 & 1 & 2010 & 192.38 & 99.11 & 1437 & 198.27 & 115.73 & 5.90 & 16.62 \\
\hline 1017 & 1 & 2011 & 192.42 & 98.99 & 1438 & 198.42 & 115.89 & 6.00 & 16.91 \\
\hline 1018 & 1 & 2012 & 192.46 & 99.45 & 1439 & 198.43 & 115.99 & 5.97 & 16.54 \\
\hline 1019 & 1 & 2013 & 192.39 & 99.32 & 1440 & 198.49 & 116.07 & 6.10 & 16.75 \\
\hline 1020 & 1 & 2015 & 192.46 & 99.69 & 1441 & 198.53 & 116.06 & 6.07 & 16.37 \\
\hline 1021 & 1 & 2016 & 192.38 & 100.01 & 1442 & 198.55 & 116.27 & 6.17 & 16.27 \\
\hline 1022 & 1 & 2017 & 192.40 & 100.02 & 1443 & 198.63 & 116.68 & 6.24 & 16.65 \\
\hline 1023 & 1 & 2018 & 192.48 & 100.30 & 1444 & 198.77 & 116.69 & 6.29 & 16.39 \\
\hline
\end{tabular}




\begin{tabular}{|c|c|c|c|c|c|c|c|c|c|}
\hline obs & $\mathbf{T}$ & $\begin{array}{l}\text { B260 } \\
\text { year }\end{array}$ & $\begin{array}{c}\text { driving } \\
\text { stress } \\
(\mathbf{k P a})\end{array}$ & $\underset{\left(\mathbf{k m}^{3} \mathbf{a}^{-1}\right)}{\text { flux }}$ & $\begin{array}{l}\text { B270 } \\
\text { year }\end{array}$ & $\begin{array}{l}\text { driving } \\
\text { stress } \\
(\mathbf{k P a})\end{array}$ & $\underset{\left(\mathbf{k m}^{3} \mathbf{a}^{-1}\right)}{\text { flux }}$ & $\begin{array}{c}\Delta \text { driving } \\
\text { stress } \\
(\mathbf{k P a})\end{array}$ & $\underset{\left(\mathbf{k m}^{3} \mathbf{a}^{-1)}\right.}{\Delta f^{1} \mathbf{u x}}$ \\
\hline 1024 & 1 & 2020 & 192.66 & 100.44 & 1445 & 198.84 & 117.13 & 6.18 & 16.69 \\
\hline 1025 & 1 & 2022 & 192.81 & 100.51 & 1446 & 198.95 & 117.17 & 6.14 & 16.66 \\
\hline 1026 & 1 & 2023 & 192.87 & 100.66 & 1447 & 199.00 & 117.52 & 6.13 & 16.86 \\
\hline 1027 & 1 & 2024 & 192.86 & 100.28 & 1448 & 198.94 & 117.49 & 6.08 & 17.21 \\
\hline 1028 & 1 & 2027 & 192.94 & 100.08 & 1449 & 198.99 & 116.96 & 6.06 & 16.88 \\
\hline 1029 & 1 & 2030 & 193.05 & 99.40 & 1450 & 199.20 & 115.66 & 6.15 & 16.26 \\
\hline 1030 & 1 & 2031 & 193.07 & 99.48 & 1451 & 199.26 & 115.54 & 6.19 & 16.06 \\
\hline 1031 & 1 & 2029 & 193.00 & 99.59 & 1452 & 199.27 & 115.69 & 6.27 & 16.10 \\
\hline 1032 & 1 & 2033 & 193.16 & 99.04 & 1453 & 199.25 & 115.38 & 6.09 & 16.33 \\
\hline 1033 & 1 & 2035 & 193.29 & 99.50 & 1454 & 199.38 & 115.93 & 6.09 & 16.43 \\
\hline 1034 & 1 & 2036 & 193.28 & 99.72 & 1455 & 199.40 & 116.29 & 6.13 & 16.58 \\
\hline 1035 & 1 & 2037 & 193.30 & 99.86 & 1456 & 199.52 & 115.57 & 6.22 & 15.71 \\
\hline 1036 & 1 & 2038 & 193.37 & 99.16 & 1457 & 199.47 & 115.74 & 6.10 & 16.57 \\
\hline 1037 & 1 & 2040 & 193.47 & 99.18 & 1458 & 199.64 & 115.89 & 6.17 & 16.71 \\
\hline 1038 & 1 & 2041 & 193.53 & 98.71 & 1459 & 199.73 & 115.11 & 6.20 & 16.40 \\
\hline 1039 & 1 & 2042 & 193.52 & 98.50 & 1460 & 199.70 & 115.35 & 6.18 & 16.86 \\
\hline 1040 & 1 & 2044 & 193.66 & 98.80 & 1461 & 199.81 & 115.34 & 6.15 & 16.53 \\
\hline 1041 & 1 & 2046 & 193.78 & 98.84 & 1462 & 199.93 & 115.15 & 6.15 & 16.31 \\
\hline 1042 & 1 & 2047 & 193.89 & 98.40 & 1463 & 200.04 & 115.89 & 6.15 & 17.49 \\
\hline 1043 & 1 & 2049 & 194.01 & 99.35 & 1464 & 200.14 & 115.96 & 6.13 & 16.61 \\
\hline 1044 & 1 & 2050 & 194.04 & 98.33 & 1465 & 200.22 & 115.98 & 6.18 & 17.65 \\
\hline 1045 & 1 & 2053 & 194.18 & 98.05 & 1466 & 200.28 & 116.45 & 6.10 & 18.40 \\
\hline 1046 & 1 & 2054 & 194.24 & 98.81 & 1467 & 200.32 & 116.24 & 6.08 & 17.43 \\
\hline 1047 & 1 & 2057 & 194.36 & 98.74 & 1468 & 200.38 & 117.39 & 6.02 & 18.65 \\
\hline 1048 & 1 & 2059 & 194.46 & 98.22 & 1469 & 200.46 & 117.22 & 6.00 & 19.00 \\
\hline 1049 & 1 & 2062 & 194.59 & 99.29 & 1470 & 200.64 & 117.09 & 6.04 & 17.80 \\
\hline 1050 & 1 & 2064 & 194.70 & 99.67 & 1471 & 200.78 & 116.90 & 6.08 & 17.23 \\
\hline 1051 & 1 & 2065 & 194.73 & 99.69 & 1472 & 200.91 & 116.74 & 6.19 & 17.05 \\
\hline 1052 & 1 & 2067 & 194.81 & 99.12 & 1473 & 200.91 & 117.84 & 6.10 & 18.72 \\
\hline 1053 & 1 & 2070 & 194.94 & 99.16 & 1474 & 201.05 & 117.36 & 6.11 & 18.20 \\
\hline 1054 & 1 & 2068 & 194.81 & 99.48 & 1475 & 200.97 & 117.30 & 6.16 & 17.82 \\
\hline 1055 & 1 & 2071 & 195.04 & 98.98 & 1476 & 201.01 & 117.37 & 5.97 & 18.39 \\
\hline 1056 & 1 & 2074 & 195.15 & 100.11 & 1477 & 201.15 & 117.91 & 6.00 & 17.80 \\
\hline 1057 & 1 & 2075 & 195.11 & 99.63 & 1478 & 201.35 & 118.16 & 6.24 & 18.53 \\
\hline 1058 & 1 & 2077 & 195.22 & 99.70 & 1479 & 201.47 & 118.04 & 6.25 & 18.34 \\
\hline 1059 & 1 & 2079 & 195.36 & 99.43 & 1480 & 201.55 & 118.34 & 6.19 & 18.90 \\
\hline 1060 & 1 & 2080 & 195.35 & 99.85 & 1481 & 201.68 & 118.32 & 6.33 & 18.47 \\
\hline 1061 & 1 & 2083 & 195.50 & 99.99 & 1482 & 201.89 & 118.36 & 6.39 & 18.37 \\
\hline 1062 & 1 & 2084 & 195.54 & 99.92 & 1483 & 202.05 & 118.30 & 6.51 & 18.38 \\
\hline 1063 & 1 & 2085 & 195.56 & 100.14 & 1484 & 202.14 & 118.54 & 6.58 & 18.40 \\
\hline
\end{tabular}




\begin{tabular}{|c|c|c|c|c|c|c|c|c|c|}
\hline obs & $\mathbf{T}$ & $\begin{array}{l}\text { B260 } \\
\text { year }\end{array}$ & $\begin{array}{c}\text { driving } \\
\text { stress } \\
(\mathbf{k P a})\end{array}$ & $\underset{\left(\mathbf{k m}^{3} \mathbf{a}^{-1}\right)}{\text { flux }}$ & $\begin{array}{l}\text { B270 } \\
\text { year }\end{array}$ & $\begin{array}{l}\text { driving } \\
\text { stress } \\
(\mathbf{k P a})\end{array}$ & $\underset{\left(\mathbf{k m}^{3} \mathbf{a}^{-1}\right)}{\text { flux }}$ & $\begin{array}{c}\Delta \text { driving } \\
\text { stress } \\
(\mathbf{k P a})\end{array}$ & $\underset{\left(\mathbf{k m}^{3} \mathbf{a}^{-1)}\right.}{\Delta f^{1} \mathbf{u x}}$ \\
\hline 1064 & 1 & 2087 & 195.60 & 100.33 & 1485 & 202.29 & 118.72 & 6.69 & 18.40 \\
\hline 1065 & 1 & 2088 & 195.65 & 100.22 & 1486 & 202.35 & 118.96 & 6.70 & 18.74 \\
\hline 1066 & 1 & 2091 & 195.74 & 99.97 & 1487 & 202.47 & 119.16 & 6.74 & 19.19 \\
\hline 1067 & 1 & 2092 & 195.73 & 100.10 & 1488 & 202.60 & 119.41 & 6.86 & 19.31 \\
\hline 1068 & 1 & 2093 & 195.73 & 100.33 & 1489 & 202.72 & 119.26 & 6.99 & 18.93 \\
\hline 1069 & 1 & 2095 & 195.92 & 100.21 & 1490 & 202.85 & 119.74 & 6.93 & 19.53 \\
\hline 1070 & 1 & 2096 & 195.76 & 100.45 & 1491 & 203.02 & 119.20 & 7.26 & 18.75 \\
\hline 1071 & 1 & 2098 & 195.82 & 100.19 & 1492 & 203.14 & 119.02 & 7.32 & 18.83 \\
\hline 1072 & 1 & 2100 & 195.97 & 99.83 & 1493 & 203.26 & 118.15 & 7.29 & 18.33 \\
\hline 1073 & 1 & 2101 & 196.06 & 99.82 & 1494 & 203.32 & 118.62 & 7.26 & 18.80 \\
\hline 1074 & 1 & 2104 & 196.25 & 99.76 & 1495 & 203.38 & 118.22 & 7.13 & 18.47 \\
\hline 1075 & 1 & 2105 & 196.19 & 100.10 & 1496 & 203.49 & 119.00 & 7.30 & 18.90 \\
\hline 1076 & 1 & 2106 & 196.29 & 100.14 & 1497 & 203.57 & 119.32 & 7.28 & 19.18 \\
\hline 1077 & 1 & 2110 & 196.46 & 99.97 & 1498 & 203.62 & 119.41 & 7.15 & 19.44 \\
\hline 1078 & 1 & 2112 & 196.45 & 99.71 & 1499 & 203.71 & 119.73 & 7.26 & 20.02 \\
\hline 1079 & 1 & 2113 & 196.42 & 99.72 & 1500 & 203.88 & 119.54 & 7.46 & 19.82 \\
\hline 1080 & 1 & 2114 & 196.40 & 99.78 & 1501 & 203.97 & 119.36 & 7.57 & 19.57 \\
\hline 1081 & 1 & 2117 & 196.60 & 99.82 & 1502 & 204.13 & 119.65 & 7.53 & 19.84 \\
\hline 1082 & 1 & 2118 & 196.63 & 99.84 & 1503 & 204.15 & 119.79 & 7.52 & 19.95 \\
\hline 1083 & 1 & 2119 & 196.63 & 99.78 & 1504 & 204.14 & 119.82 & 7.52 & 20.04 \\
\hline 1084 & 1 & 2123 & 196.95 & & 1505 & 204.27 & 119.97 & 7.33 & 20.00 \\
\hline 1085 & 1 & 2124 & 197.01 & 99.91 & 1506 & 204.34 & 119.91 & 7.33 & 20.00 \\
\hline 1086 & 1 & 2126 & 197.09 & 100.39 & 1507 & 204.45 & 119.99 & 7.36 & 19.60 \\
\hline 1087 & 1 & 2128 & 197.13 & 100.75 & 1508 & 204.56 & 120.24 & 7.43 & 19.49 \\
\hline 1088 & 1 & 2130 & 197.30 & 100.85 & 1509 & 204.63 & 120.05 & 7.33 & 19.20 \\
\hline 1089 & 1 & 2131 & 197.45 & 100.90 & 1510 & 204.80 & 120.60 & 7.35 & 19.69 \\
\hline 1090 & 1 & 2134 & 197.65 & 101.11 & 1511 & 205.01 & 120.44 & 7.36 & 19.33 \\
\hline 1091 & 1 & 2135 & 197.61 & 101.21 & 1512 & 205.04 & 120.71 & 7.43 & 19.50 \\
\hline 1092 & 1 & 2136 & 197.74 & 101.25 & 1513 & 205.11 & 120.90 & 7.37 & 19.65 \\
\hline 1093 & 1 & 2139 & 197.97 & 101.42 & 1514 & 205.18 & 120.55 & 7.22 & 19.13 \\
\hline 1094 & 1 & 2140 & 198.01 & 101.36 & 1515 & 205.26 & 120.67 & 7.25 & 19.31 \\
\hline 1095 & 1 & 2142 & 198.08 & 101.80 & 1516 & 205.30 & 120.55 & 7.21 & 18.75 \\
\hline 1096 & 1 & 2146 & 198.30 & 101.60 & 1517 & 205.38 & 120.23 & 7.08 & 18.63 \\
\hline 1097 & 1 & 2144 & 198.26 & 101.79 & 1518 & 205.57 & 120.82 & 7.31 & 19.03 \\
\hline 1098 & 1 & 2148 & 198.41 & 101.57 & 1519 & 205.30 & 121.22 & 6.88 & 19.65 \\
\hline 1099 & 1 & 2151 & 198.59 & 101.79 & 1520 & 205.40 & 121.42 & 6.80 & 19.62 \\
\hline 1100 & 1 & 2152 & 198.54 & 101.76 & 1521 & 205.70 & 121.23 & 7.16 & 19.46 \\
\hline 1101 & 1 & 2154 & 198.64 & 102.07 & 1522 & 205.71 & 121.58 & 7.07 & 19.51 \\
\hline 1102 & 1 & 2155 & 198.71 & 102.18 & 1523 & 205.84 & 122.23 & 7.13 & 20.05 \\
\hline 1103 & 1 & 2156 & 198.81 & 102.24 & 1524 & 206.04 & 122.48 & 7.23 & 20.24 \\
\hline
\end{tabular}




\begin{tabular}{|c|c|c|c|c|c|c|c|c|c|}
\hline obs & $\mathbf{T}$ & $\begin{array}{l}\text { B260 } \\
\text { year }\end{array}$ & $\begin{array}{c}\text { driving } \\
\text { stress } \\
(\mathbf{k P a})\end{array}$ & $\underset{\left(\mathbf{k m}^{3} \mathbf{a}^{-1}\right)}{\text { flux }}$ & $\begin{array}{l}\text { B270 } \\
\text { year }\end{array}$ & $\begin{array}{l}\text { driving } \\
\text { stress } \\
(\mathbf{k P a})\end{array}$ & $\underset{\left(\mathbf{k m}^{3} \mathbf{a}^{-1}\right)}{\text { flux }}$ & $\begin{array}{c}\Delta \text { driving } \\
\text { stress } \\
(\mathbf{k P a})\end{array}$ & $\underset{\left(\mathbf{k m}^{3} \mathbf{a}^{-1)}\right.}{\Delta f^{1} \mathbf{u x}}$ \\
\hline 1104 & 1 & 2160 & 198.99 & 102.27 & 1525 & 206.27 & 122.51 & 7.28 & 20.24 \\
\hline 1105 & 1 & 2161 & 199.05 & 102.17 & 1526 & 206.48 & 122.52 & 7.43 & 20.35 \\
\hline 1106 & 1 & 2164 & 199.18 & 102.73 & 1527 & 206.45 & 122.30 & 7.28 & 19.57 \\
\hline 1107 & 1 & 2166 & 199.26 & 103.18 & 1528 & 206.53 & 122.45 & 7.27 & 19.26 \\
\hline 1108 & 1 & 2167 & 199.32 & 103.29 & 1529 & 206.67 & 122.58 & 7.35 & 19.29 \\
\hline 1109 & 1 & 2168 & 199.36 & 103.24 & 1530 & 206.71 & 122.64 & 7.34 & 19.40 \\
\hline 1110 & 1 & 2170 & 199.60 & 103.06 & 1531 & 206.93 & 122.40 & 7.32 & 19.33 \\
\hline 1111 & 1 & 2171 & 199.60 & 103.19 & 1532 & 206.96 & 123.39 & 7.36 & 20.20 \\
\hline 1112 & 1 & 2174 & 199.91 & 103.33 & 1533 & 207.18 & 122.53 & 7.27 & 19.20 \\
\hline 1113 & 1 & 2175 & 200.00 & 103.46 & 1534 & 207.35 & 122.66 & 7.34 & 19.20 \\
\hline 1114 & 1 & 2176 & 200.14 & 103.49 & 1535 & 207.44 & 122.57 & 7.31 & 19.09 \\
\hline 1115 & 1 & 2178 & 200.19 & 103.51 & 1536 & 207.60 & 122.77 & 7.41 & 19.26 \\
\hline 1116 & 1 & 2180 & 200.30 & 103.77 & 1537 & 207.61 & 122.43 & 7.32 & 18.67 \\
\hline 1117 & 1 & 2181 & 200.25 & 103.79 & 1538 & 207.67 & 122.47 & 7.42 & 18.68 \\
\hline 1118 & 1 & 2183 & 200.41 & 103.60 & 1539 & 207.77 & 122.70 & 7.36 & 19.10 \\
\hline 1119 & 1 & 2185 & 200.55 & 103.67 & 1540 & 207.94 & 123.35 & 7.40 & 19.68 \\
\hline 1120 & 1 & 2187 & 200.68 & 103.25 & 1541 & 208.05 & 123.30 & 7.37 & 20.05 \\
\hline 1121 & 1 & 2188 & 200.67 & 103.30 & 1542 & 208.04 & 122.66 & 7.37 & 19.36 \\
\hline 1122 & 1 & 2190 & 200.89 & 103.52 & 1543 & 208.15 & 123.14 & 7.26 & 19.63 \\
\hline 1123 & 1 & 2191 & 200.88 & 103.41 & 1544 & 208.33 & 122.25 & 7.45 & 18.84 \\
\hline 1124 & 1 & 2192 & 200.96 & 103.49 & 1545 & 208.51 & 121.88 & 7.55 & 18.39 \\
\hline 1125 & 1 & 2193 & 200.93 & 103.64 & 1546 & 208.53 & 121.97 & 7.59 & 18.33 \\
\hline 1126 & 1 & 2194 & 201.03 & 103.90 & 1547 & 208.67 & 121.91 & 7.64 & 18.01 \\
\hline 1127 & 1 & 2196 & 201.08 & 103.57 & 1548 & 208.53 & 122.28 & 7.45 & 18.71 \\
\hline 1128 & 1 & 2200 & 201.15 & 103.92 & 1549 & 208.67 & 122.62 & 7.52 & 18.70 \\
\hline 1129 & 1 & 2201 & 201.19 & 104.09 & 1550 & 208.77 & 122.83 & 7.58 & 18.74 \\
\hline 1130 & 1 & 2202 & 201.27 & 104.14 & 1551 & 208.66 & 122.64 & 7.39 & 18.50 \\
\hline 1131 & 1 & 2204 & 201.49 & 104.04 & 1552 & 208.77 & 122.43 & 7.28 & 18.39 \\
\hline 1132 & 1 & 2205 & 201.53 & 103.96 & 1553 & 208.78 & 122.15 & 7.25 & 18.19 \\
\hline 1133 & 1 & 2206 & 201.65 & 103.99 & 1554 & 208.93 & 122.88 & 7.28 & 18.88 \\
\hline 1134 & 1 & 2208 & 201.71 & 104.01 & 1555 & 209.01 & 122.33 & 7.30 & 18.31 \\
\hline 1135 & 1 & 2209 & 201.73 & 104.21 & 1556 & 209.16 & 122.32 & 7.43 & 18.11 \\
\hline 1136 & 1 & 2211 & 201.82 & 104.53 & 1558 & 209.26 & 121.99 & 7.45 & 17.47 \\
\hline 1137 & 1 & 2212 & 201.93 & 104.54 & 1559 & 209.36 & 122.63 & 7.44 & 18.09 \\
\hline 1138 & 1 & 2213 & 201.92 & 104.38 & 1560 & 209.41 & 122.65 & 7.50 & 18.27 \\
\hline 1139 & 1 & 2216 & 202.18 & 104.95 & 1561 & 209.56 & 123.34 & 7.38 & 18.39 \\
\hline 1140 & 1 & 2217 & 202.26 & 104.99 & 1562 & 209.71 & 122.78 & 7.44 & 17.79 \\
\hline 1141 & 1 & 2220 & 202.45 & 105.26 & 1563 & 209.69 & 122.86 & 7.23 & 17.60 \\
\hline 1142 & 1 & 2221 & 202.52 & 105.44 & 1564 & 209.52 & 123.32 & 7.00 & 17.89 \\
\hline 1143 & 1 & 2223 & 202.59 & 105.69 & 1565 & 209.79 & 123.20 & 7.20 & 17.52 \\
\hline
\end{tabular}




\begin{tabular}{|c|c|c|c|c|c|c|c|c|c|}
\hline obs & $\mathbf{T}$ & $\begin{array}{l}\text { B260 } \\
\text { year }\end{array}$ & $\begin{array}{c}\text { driving } \\
\text { stress } \\
(\mathbf{k P a})\end{array}$ & $\underset{\left(\mathbf{k m}^{3} \mathbf{a}^{-1}\right)}{\text { flux }}$ & $\begin{array}{l}\text { B270 } \\
\text { year }\end{array}$ & $\begin{array}{c}\text { driving } \\
\text { stress } \\
(\mathbf{k P a})\end{array}$ & $\underset{\left(\mathbf{k m}^{3} \mathbf{a}^{-1}\right)}{\text { flux }}$ & $\begin{array}{c}\Delta \text { driving } \\
\text { stress } \\
\text { (kPa) }\end{array}$ & $\underset{\left(\mathbf{k m}^{3} \mathbf{a}^{-1)}\right.}{\Delta \text { flux }}$ \\
\hline 1144 & 1 & 2224 & 202.53 & 105.33 & 1566 & 209.67 & 123.06 & 7.14 & 17.73 \\
\hline 1145 & 1 & 2225 & 202.64 & 105.73 & 1567 & 209.80 & 122.84 & 7.16 & 17.11 \\
\hline 1146 & 1 & 2226 & 202.66 & 105.30 & 1568 & 209.93 & 122.64 & 7.27 & 17.34 \\
\hline 1147 & 1 & 2228 & 202.88 & 105.34 & 1569 & 210.08 & 123.02 & 7.19 & 17.67 \\
\hline 1148 & 1 & 2229 & 202.86 & 105.00 & 1570 & 210.31 & 122.99 & 7.46 & 17.98 \\
\hline 1149 & 1 & 2230 & 202.91 & 105.02 & 1571 & 210.46 & 123.01 & 7.55 & 17.99 \\
\hline 1150 & 1 & 2231 & 203.05 & 104.85 & 1572 & 210.43 & 122.79 & 7.38 & 17.93 \\
\hline 1151 & 1 & 2233 & 203.10 & 105.27 & 1573 & 210.42 & 122.80 & 7.31 & 17.53 \\
\hline 1152 & 1 & 2234 & 203.14 & 105.35 & 1574 & 210.48 & 122.66 & 7.34 & 17.31 \\
\hline 1153 & 1 & 2237 & 203.25 & 105.57 & 1575 & 210.68 & 123.03 & 7.43 & 17.46 \\
\hline 1154 & 1 & 2238 & 203.35 & 105.13 & 1576 & 210.80 & 123.34 & 7.45 & 18.21 \\
\hline 1155 & 1 & 2242 & 203.54 & 105.20 & 1578 & 211.01 & 123.03 & 7.47 & 17.83 \\
\hline 1156 & 1 & 2244 & 203.71 & 105.05 & 1580 & 211.15 & 122.85 & 7.44 & 17.80 \\
\hline 1157 & 1 & 2246 & 203.60 & 105.42 & 1581 & 211.06 & 122.59 & 7.46 & 17.17 \\
\hline 1158 & 1 & 2248 & 203.69 & 105.28 & 1582 & 211.23 & 122.60 & 7.54 & 17.32 \\
\hline 1159 & 1 & 2249 & 203.78 & 105.37 & 1583 & 211.33 & 122.63 & 7.55 & 17.25 \\
\hline 1160 & 1 & 2250 & 203.86 & 105.52 & 1584 & 211.38 & 122.67 & 7.52 & 17.15 \\
\hline 1161 & 1 & 2251 & 203.95 & 105.27 & 1585 & 211.47 & 122.39 & 7.52 & 17.12 \\
\hline 1162 & 1 & 2252 & 204.03 & 105.70 & 1586 & 211.65 & 122.22 & 7.62 & 16.52 \\
\hline 1163 & 1 & 2254 & 204.17 & 105.20 & 1587 & 211.70 & 122.32 & 7.54 & 17.12 \\
\hline 1164 & 1 & 2256 & 204.40 & 104.76 & 1588 & 211.83 & 121.95 & 7.43 & 17.19 \\
\hline 1165 & 1 & 2257 & 204.39 & 104.65 & 1589 & 211.82 & 121.54 & 7.43 & 16.89 \\
\hline 1166 & 1 & 2259 & 204.56 & 104.77 & 1590 & 211.91 & 121.57 & 7.35 & 16.80 \\
\hline 1167 & 1 & 2260 & 204.52 & 104.85 & 1591 & 211.83 & 121.10 & 7.31 & 16.25 \\
\hline 1168 & 1 & 2261 & 204.47 & 104.74 & 1592 & 211.88 & 121.35 & 7.41 & 16.61 \\
\hline 1169 & 1 & 2262 & 204.59 & 104.80 & 1593 & 211.98 & 121.83 & 7.39 & 17.03 \\
\hline 1170 & 1 & 2266 & 204.76 & 105.13 & 1594 & 212.04 & 121.37 & 7.28 & 16.24 \\
\hline 1171 & 1 & 2267 & 204.82 & 104.99 & 1595 & 212.03 & 121.47 & 7.21 & 16.48 \\
\hline 1172 & 1 & 2270 & 204.91 & 104.46 & 1596 & 212.04 & 121.26 & 7.13 & 16.80 \\
\hline 1173 & 1 & 2271 & 205.04 & 104.16 & 1597 & 212.16 & 121.13 & 7.13 & 16.97 \\
\hline 1174 & 1 & 2272 & 205.07 & 104.39 & 1598 & 212.24 & 121.07 & 7.17 & 16.68 \\
\hline 1175 & 1 & 2273 & 205.15 & 104.28 & 1599 & 212.34 & 120.95 & 7.19 & 16.67 \\
\hline 1176 & 1 & 2277 & 205.24 & 103.79 & 1600 & 212.35 & 121.00 & 7.11 & 17.20 \\
\hline 1177 & 1 & 2278 & 205.20 & 103.61 & 1601 & 212.36 & 120.76 & 7.16 & 17.15 \\
\hline 1178 & 1 & 2279 & 205.16 & 103.51 & 1602 & 212.37 & 120.67 & 7.21 & 17.16 \\
\hline 1179 & 1 & 2280 & 205.20 & 103.68 & 1603 & 212.36 & 120.76 & 7.15 & 17.09 \\
\hline 1180 & 1 & 2282 & 205.36 & 103.96 & 1604 & 212.37 & 120.65 & 7.00 & 16.69 \\
\hline 1181 & 1 & 2284 & 205.36 & 104.06 & 1605 & 212.44 & 120.47 & 7.08 & 16.41 \\
\hline 1182 & 1 & 2285 & 205.36 & 104.18 & 1606 & 212.46 & 120.52 & 7.11 & 16.35 \\
\hline 1183 & 1 & 2286 & 205.36 & 103.70 & 1607 & 212.60 & 120.64 & 7.23 & 16.94 \\
\hline
\end{tabular}




\begin{tabular}{|c|c|c|c|c|c|c|c|c|c|}
\hline obs & $\mathbf{T}$ & $\begin{array}{l}\text { B260 } \\
\text { year }\end{array}$ & $\begin{array}{c}\text { driving } \\
\text { stress } \\
(\mathbf{k P a})\end{array}$ & $\underset{\left(\mathbf{k m}^{3} \mathbf{a}^{-1}\right)}{\text { flux }}$ & $\begin{array}{l}\text { B270 } \\
\text { year }\end{array}$ & $\begin{array}{l}\text { driving } \\
\text { stress } \\
(\mathbf{k P a})\end{array}$ & $\underset{\left(\mathbf{k m}^{3} \mathbf{a}^{-1}\right)}{\text { flux }}$ & $\begin{array}{c}\Delta \text { driving } \\
\text { stress } \\
(\mathbf{k P a})\end{array}$ & $\underset{\left(\mathbf{k m}^{3} \mathbf{a}^{-1)}\right.}{\Delta f^{1} \mathbf{u x}}$ \\
\hline 1184 & 1 & 2289 & 205.51 & 104.09 & 1608 & 212.54 & 120.51 & 7.03 & 16.42 \\
\hline 1185 & 1 & 2291 & 205.59 & 103.70 & 1609 & 212.56 & 120.78 & 6.97 & 17.08 \\
\hline 1186 & 1 & 2294 & 205.63 & 104.01 & 1610 & 212.59 & 121.01 & 6.95 & 17.00 \\
\hline 1187 & 1 & 2295 & 205.62 & 103.94 & 1611 & 212.64 & 120.63 & 7.02 & 16.69 \\
\hline 1188 & 1 & 2296 & 205.53 & 103.88 & 1612 & 212.68 & 120.33 & 7.16 & 16.45 \\
\hline 1189 & 1 & 2297 & 205.74 & 103.50 & 1613 & 212.76 & 120.40 & 7.02 & 16.91 \\
\hline 1190 & 1 & 2298 & 205.78 & 103.45 & 1614 & 212.95 & 120.68 & 7.18 & 17.22 \\
\hline 1191 & 1 & 2302 & 205.99 & 103.57 & 1615 & 212.96 & 120.30 & 6.97 & 16.73 \\
\hline 1192 & 1 & 2303 & 206.03 & 103.34 & 1616 & 213.09 & 120.63 & 7.05 & 17.29 \\
\hline 1193 & 1 & 2304 & 206.08 & 103.15 & 1617 & 213.08 & 120.17 & 7.01 & 17.02 \\
\hline 1194 & 1 & 2305 & 206.09 & 103.46 & 1618 & 213.08 & 120.22 & 7.00 & 16.76 \\
\hline 1195 & 1 & 2308 & 206.14 & 103.03 & 1619 & 213.21 & 119.74 & 7.07 & 16.71 \\
\hline 1196 & 1 & 2309 & 206.25 & 103.05 & 1620 & 213.23 & 119.74 & 6.99 & 16.69 \\
\hline 1197 & 1 & 2311 & 206.38 & 103.21 & 1621 & 213.30 & 119.43 & 6.92 & 16.23 \\
\hline 1198 & 1 & 2312 & 206.44 & 103.33 & 1622 & 213.37 & 119.45 & 6.93 & 16.12 \\
\hline 1199 & 1 & 2313 & 206.53 & 102.63 & 1623 & 213.44 & & 6.91 & 16.89 \\
\hline 1200 & 1 & 2314 & 206.53 & 102.89 & 1624 & 213.49 & 119.25 & 6.96 & 16.36 \\
\hline 1201 & 1 & 2315 & 206.48 & 102.56 & 1625 & 213.55 & 119.82 & 7.07 & 17.26 \\
\hline 1202 & 1 & 2319 & 206.60 & 102.39 & 1626 & 213.79 & 119.41 & 7.19 & 17.02 \\
\hline 1203 & 1 & 2321 & 206.76 & 102.09 & 1627 & 213.88 & 119.53 & 7.12 & 17.45 \\
\hline 1204 & 1 & 2323 & 206.82 & 102.88 & 1628 & 213.97 & 119.53 & 7.15 & 16.65 \\
\hline 1205 & 1 & 2324 & 206.82 & 102.46 & 1629 & 214.06 & 119.32 & 7.24 & 16.86 \\
\hline 1206 & 1 & 2326 & 206.99 & 102.81 & 1630 & 214.12 & 119.44 & 7.13 & 16.62 \\
\hline 1207 & 1 & 2327 & 207.04 & 102.42 & 1631 & 214.25 & 119.47 & 7.22 & 17.05 \\
\hline 1208 & 1 & 2328 & 207.04 & 102.43 & 1632 & 214.37 & 119.08 & 7.33 & 16.65 \\
\hline 1209 & 1 & 2332 & 207.19 & 102.77 & 1633 & 214.45 & 119.12 & 7.26 & 16.35 \\
\hline 1210 & 1 & 2333 & 207.24 & 103.17 & 1634 & 214.42 & 119.07 & 7.19 & 15.90 \\
\hline 1211 & 1 & 2335 & 207.31 & 102.74 & 1635 & 214.53 & 119.10 & 7.22 & 16.36 \\
\hline 1212 & 1 & 2336 & 207.46 & 102.46 & 1636 & 214.49 & 119.43 & 7.03 & 16.97 \\
\hline 1213 & 1 & 2337 & 207.41 & 102.56 & 1637 & 214.49 & 119.36 & 7.08 & 16.80 \\
\hline 1214 & 1 & 2338 & 207.47 & 102.48 & 1638 & 214.45 & 118.91 & 6.98 & 16.43 \\
\hline 1215 & 1 & 2341 & 207.66 & 102.72 & 1639 & 214.57 & 118.71 & 6.91 & 15.99 \\
\hline 1216 & 1 & 2342 & 207.67 & 102.48 & 1640 & 214.69 & 118.74 & 7.01 & 16.27 \\
\hline 1217 & 1 & 2343 & 207.67 & 103.08 & 1641 & 214.62 & 118.89 & 6.95 & 15.81 \\
\hline 1218 & 1 & 2344 & 207.65 & 102.86 & 1642 & 214.64 & 118.92 & 7.00 & 16.06 \\
\hline 1219 & 1 & 2349 & 208.01 & 102.35 & 1643 & 214.65 & 118.95 & 6.64 & 16.59 \\
\hline 1220 & 1 & 2350 & 208.03 & 102.26 & 1644 & 214.86 & 118.27 & 6.83 & 16.01 \\
\hline 1221 & 1 & 2351 & 208.01 & 102.09 & 1645 & 214.91 & 118.54 & 6.91 & 16.45 \\
\hline 1222 & 1 & 2352 & 208.10 & 101.86 & 1646 & 214.90 & 117.85 & 6.79 & 15.99 \\
\hline 1223 & 1 & 2353 & 208.11 & 101.97 & 1647 & 214.94 & 118.12 & 6.83 & 16.15 \\
\hline
\end{tabular}




\begin{tabular}{|c|c|c|c|c|c|c|c|c|c|}
\hline obs & $\mathbf{T}$ & $\begin{array}{l}\text { B260 } \\
\text { year }\end{array}$ & $\begin{array}{c}\text { driving } \\
\text { stress } \\
(\mathbf{k P a})\end{array}$ & $\underset{\left(\mathbf{k m}^{3} \mathbf{a}^{-1}\right)}{\text { flux }}$ & $\begin{array}{l}\text { B270 } \\
\text { year }\end{array}$ & $\begin{array}{c}\text { driving } \\
\text { stress } \\
(\mathbf{k P a})\end{array}$ & $\underset{\left(\mathbf{k m}^{3} \mathbf{a}^{-1}\right)}{\text { flux }}$ & $\begin{array}{c}\Delta \text { driving } \\
\text { stress } \\
\text { (kPa) }\end{array}$ & $\underset{\left(\mathbf{k m}^{3} \mathbf{a}^{-1)}\right.}{\Delta \text { flux }}$ \\
\hline 1224 & 1 & 2354 & 208.09 & 101.79 & 1648 & 215.10 & 117.87 & 7.01 & 16.08 \\
\hline 1225 & 1 & 2355 & 208.15 & 101.74 & 1649 & 214.91 & 118.11 & 6.76 & 16.37 \\
\hline 1226 & 1 & 2360 & 208.20 & 101.23 & 1650 & 214.81 & 118.00 & 6.62 & 16.77 \\
\hline 1227 & 1 & 2361 & 208.21 & 101.03 & 1651 & 215.02 & 118.16 & 6.82 & 17.13 \\
\hline 1228 & 1 & 2362 & 208.25 & 101.08 & 1652 & 214.99 & 117.90 & 6.75 & 16.82 \\
\hline 1229 & 1 & 2363 & 208.22 & 100.99 & 1653 & 214.92 & 117.92 & 6.70 & 16.93 \\
\hline 1230 & 1 & 2370 & 208.16 & 101.46 & 1654 & 214.99 & 117.99 & 6.84 & 16.54 \\
\hline 1231 & 1 & 2371 & 208.25 & 101.77 & 1655 & 214.99 & 117.96 & 6.74 & 16.20 \\
\hline 1232 & 1 & 2372 & 208.30 & 101.53 & 1656 & 214.97 & 118.04 & 6.67 & 16.50 \\
\hline 1233 & 1 & 2373 & 208.43 & 101.63 & 1657 & 215.07 & 118.48 & 6.64 & 16.85 \\
\hline 1234 & 1 & 2374 & 208.51 & 101.53 & 1658 & 215.19 & 117.69 & 6.68 & 16.17 \\
\hline 1235 & 1 & 2375 & 208.49 & 101.11 & 1659 & 215.31 & 117.26 & 6.82 & 16.15 \\
\hline 1236 & 1 & 2376 & 208.50 & 101.77 & 1660 & 215.33 & 117.71 & 6.83 & 15.94 \\
\hline 1237 & 1 & 2377 & 208.53 & 101.54 & 1661 & 215.46 & 117.50 & 6.93 & 15.96 \\
\hline 1238 & 1 & 2378 & 208.48 & 101.99 & 1662 & 215.55 & 117.84 & 7.07 & 15.85 \\
\hline 1239 & 1 & 2379 & 208.50 & 101.83 & 1663 & 215.52 & 117.88 & 7.02 & 16.04 \\
\hline 1240 & 1 & 2380 & 208.49 & 101.43 & 1664 & 215.35 & 117.69 & 6.86 & 16.26 \\
\hline 1241 & 1 & 2381 & 208.53 & 101.89 & 1665 & 215.39 & 117.45 & 6.86 & 15.56 \\
\hline 1242 & 1 & 2383 & 208.64 & 102.02 & 1666 & 215.50 & 117.63 & 6.85 & 15.60 \\
\hline 1243 & 1 & 2384 & 208.79 & 101.68 & 1667 & 215.42 & 117.50 & 6.64 & 15.82 \\
\hline 1244 & 1 & 2385 & 208.75 & 101.54 & 1668 & 215.41 & 118.00 & 6.66 & 16.47 \\
\hline 1245 & 1 & 2387 & 208.89 & 101.25 & 1669 & 215.44 & 117.96 & 6.55 & 16.71 \\
\hline 1246 & 1 & 2388 & 208.90 & 101.45 & 1670 & 215.41 & 117.52 & 6.50 & 16.07 \\
\hline 1247 & 1 & 2392 & 208.88 & 101.25 & 1671 & 215.48 & 117.87 & 6.60 & 16.62 \\
\hline 1248 & 1 & 2393 & 209.05 & 101.12 & 1672 & 215.53 & 117.56 & 6.48 & 16.44 \\
\hline 1249 & 1 & 2394 & 209.07 & 101.31 & 1673 & 215.68 & 117.06 & 6.61 & 15.75 \\
\hline 1250 & 1 & 2395 & 208.93 & 101.06 & 1674 & 215.75 & 116.50 & 6.82 & 15.44 \\
\hline 1251 & 1 & 2396 & 209.08 & 100.78 & 1675 & 215.74 & 116.65 & 6.66 & 15.86 \\
\hline 1252 & 1 & 2397 & 208.94 & 100.77 & 1676 & 215.93 & 116.83 & 6.99 & 16.06 \\
\hline 1253 & 1 & 2401 & 209.14 & 100.38 & 1677 & 215.85 & 116.70 & 6.72 & 16.32 \\
\hline 1254 & 1 & 2402 & 209.06 & 100.73 & 1678 & 215.95 & 116.89 & 6.89 & 16.16 \\
\hline 1255 & 1 & 2403 & 209.22 & 100.80 & 1679 & 216.07 & 116.73 & 6.85 & 15.93 \\
\hline 1256 & 1 & 2404 & 209.06 & 100.77 & 1680 & 216.13 & 116.88 & 7.07 & 16.11 \\
\hline 1257 & 1 & 2398 & 209.07 & 100.83 & 1681 & 216.16 & 116.89 & 7.09 & 16.05 \\
\hline 1258 & 1 & 2405 & 209.19 & 100.72 & 1682 & 216.05 & 116.41 & 6.86 & 15.69 \\
\hline 1259 & 1 & 2409 & 209.23 & 100.96 & 1683 & 216.13 & 115.90 & 6.90 & 14.95 \\
\hline 1260 & 1 & 2410 & 209.20 & 101.00 & 1684 & 216.22 & 116.18 & 7.02 & 15.18 \\
\hline 1261 & 1 & 2415 & 209.07 & 100.32 & 1685 & 216.27 & 116.16 & 7.20 & 15.84 \\
\hline 1262 & 1 & 2416 & 209.11 & 100.35 & 1686 & 216.25 & 116.50 & 7.14 & 16.15 \\
\hline 1263 & 1 & 2417 & 209.10 & 100.95 & 1687 & 216.22 & 116.16 & 7.12 & 15.21 \\
\hline
\end{tabular}




\begin{tabular}{|c|c|c|c|c|c|c|c|c|c|}
\hline obs & $\mathbf{T}$ & $\begin{array}{l}\text { B260 } \\
\text { year }\end{array}$ & $\begin{array}{c}\text { driving } \\
\text { stress } \\
\text { (kPa) }\end{array}$ & $\underset{\left(\mathbf{k m}^{3} \mathbf{a}^{-1}\right)}{\text { flux }}$ & $\begin{array}{l}\text { B270 } \\
\text { year }\end{array}$ & $\begin{array}{c}\text { driving } \\
\text { stress } \\
(\mathbf{k P a})\end{array}$ & $\underset{\left(\mathbf{k m}^{3} \mathbf{a}^{-1}\right)}{\text { flux }}$ & $\begin{array}{c}\Delta \text { driving } \\
\text { stress } \\
\text { (kPa) }\end{array}$ & $\underset{\left(\mathbf{k m}^{3} \mathbf{a}^{-1)}\right.}{\Delta \text { flux }}$ \\
\hline 1264 & 1 & 2418 & 209.12 & 100.72 & 1688 & 216.20 & 116.43 & 7.08 & 15.71 \\
\hline 1265 & 1 & 2419 & 209.35 & 100.68 & 1689 & 216.32 & 115.93 & 6.97 & 15.25 \\
\hline 1266 & 1 & 2420 & 209.22 & 100.54 & 1690 & 216.38 & 115.82 & 7.15 & 15.28 \\
\hline 1267 & 1 & 2421 & 209.21 & 100.62 & 1691 & 216.18 & 115.96 & 6.96 & 15.34 \\
\hline 1268 & 1 & 2422 & 209.27 & 100.57 & 1692 & 216.27 & 115.81 & 7.00 & 15.23 \\
\hline 1269 & 1 & 2423 & 209.26 & 100.54 & 1693 & 216.33 & 115.56 & 7.08 & 15.02 \\
\hline 1270 & 1 & 2429 & 209.30 & 101.25 & 1694 & 216.39 & 115.53 & 7.09 & 14.28 \\
\hline 1271 & 1 & 2430 & 209.26 & 100.90 & 1695 & 216.47 & 115.55 & 7.21 & 14.64 \\
\hline 1272 & 1 & 2431 & 209.33 & 101.10 & 1696 & 216.53 & 115.69 & 7.20 & 14.60 \\
\hline 1273 & 1 & 2432 & 209.42 & 100.99 & 1697 & 216.63 & 115.64 & 7.21 & 14.65 \\
\hline 1274 & 1 & 2433 & 209.49 & 101.00 & 1698 & 216.67 & 115.68 & 7.17 & 14.68 \\
\hline 1275 & 1 & 2434 & 209.44 & 100.86 & 1699 & 216.66 & 115.40 & 7.22 & 14.54 \\
\hline 1276 & 1 & 2435 & 209.49 & 100.94 & 1700 & 216.72 & 115.08 & 7.23 & 14.14 \\
\hline 1277 & 1 & 2436 & 209.59 & 100.59 & 1701 & 216.72 & 115.21 & 7.13 & 14.62 \\
\hline 1278 & 1 & 2437 & 209.58 & 100.47 & 1702 & 216.76 & 115.07 & 7.18 & 14.59 \\
\hline 1279 & 1 & 2438 & 209.60 & 100.12 & 1703 & 216.91 & 114.83 & 7.31 & 14.71 \\
\hline 1280 & 1 & 2439 & 209.62 & 100.16 & 1704 & 216.89 & 114.64 & 7.27 & 14.48 \\
\hline 1281 & 1 & 2440 & 209.62 & 100.22 & 1705 & 216.86 & 114.78 & 7.24 & 14.57 \\
\hline 1282 & 1 & 2442 & 209.68 & 100.43 & 1706 & 217.09 & 114.65 & 7.40 & 14.22 \\
\hline 1283 & 1 & 2443 & 209.63 & 100.53 & 1707 & 217.02 & 114.52 & 7.39 & 13.98 \\
\hline 1284 & 1 & 2444 & 209.69 & 100.43 & 1708 & 216.94 & 114.41 & 7.25 & 13.98 \\
\hline 1285 & 1 & 2445 & 209.74 & 100.30 & 1709 & 216.96 & 114.67 & 7.22 & 14.37 \\
\hline 1286 & 1 & 2446 & 209.77 & 100.18 & 1710 & 217.07 & 114.72 & 7.30 & 14.54 \\
\hline 1287 & 1 & 2447 & 209.82 & 100.14 & 1711 & 217.09 & 114.61 & 7.27 & 14.47 \\
\hline 1288 & 1 & 2448 & 209.82 & 100.12 & 1712 & 217.16 & 114.77 & 7.33 & 14.66 \\
\hline 1289 & 1 & 2454 & 209.83 & 99.80 & 1713 & 217.23 & 114.57 & 7.39 & 14.76 \\
\hline 1290 & 1 & 2455 & 209.83 & 100.13 & 1714 & 217.18 & 114.78 & 7.35 & 14.64 \\
\hline 1291 & 1 & 2456 & 209.88 & 100.00 & 1715 & 217.22 & 114.53 & 7.34 & 14.53 \\
\hline 1292 & 1 & 2458 & 209.90 & 99.51 & 1716 & 217.15 & 114.93 & 7.25 & 15.41 \\
\hline 1293 & 1 & 2459 & 209.93 & 99.21 & 1717 & 217.28 & 115.03 & 7.35 & 15.82 \\
\hline 1294 & 1 & 2460 & 209.89 & 99.80 & 1718 & 217.13 & 115.03 & 7.24 & 15.23 \\
\hline 1295 & 1 & 2461 & 209.92 & 99.70 & 1719 & 217.17 & 114.29 & 7.26 & 14.59 \\
\hline 1296 & 1 & 2462 & 209.98 & 99.59 & 1720 & 217.28 & 114.38 & 7.31 & 14.79 \\
\hline 1297 & 1 & 2463 & 209.95 & 99.64 & 1721 & 217.31 & 114.55 & 7.35 & 14.91 \\
\hline 1298 & 1 & 2464 & 209.95 & 99.68 & 1722 & 217.31 & 114.41 & 7.37 & 14.73 \\
\hline 1299 & 1 & 2465 & 209.86 & 99.72 & 1723 & 217.35 & 114.05 & 7.49 & 14.33 \\
\hline 1300 & 1 & 2471 & 209.99 & 99.31 & 1724 & 217.37 & 113.71 & 7.38 & 14.40 \\
\hline 1301 & 1 & 2466 & 209.87 & 100.07 & 1725 & 217.55 & 113.62 & 7.68 & 13.55 \\
\hline 1302 & 1 & 2472 & 210.08 & 99.53 & 1726 & 217.33 & 113.56 & 7.25 & 14.03 \\
\hline 1303 & 1 & 2476 & 210.12 & 98.93 & 1727 & 217.37 & 113.88 & 7.24 & 14.95 \\
\hline
\end{tabular}




\begin{tabular}{|c|c|c|c|c|c|c|c|c|c|}
\hline obs & $\mathbf{T}$ & $\begin{array}{l}\text { B260 } \\
\text { year }\end{array}$ & $\begin{array}{c}\text { driving } \\
\text { stress } \\
(\mathbf{k P a})\end{array}$ & $\underset{\left(\mathbf{k m}^{3} \mathbf{a}^{-1}\right)}{\text { flux }}$ & $\begin{array}{l}\text { B270 } \\
\text { year }\end{array}$ & $\begin{array}{l}\text { driving } \\
\text { stress } \\
(\mathbf{k P a})\end{array}$ & $\underset{\left(\mathbf{k m}^{3} \mathbf{a}^{-1}\right)}{\text { flux }}$ & $\begin{array}{c}\Delta \text { driving } \\
\text { stress } \\
(\mathbf{k P a})\end{array}$ & $\underset{\left(\mathbf{k m}^{3} \mathbf{a}^{-1)}\right.}{\Delta f^{1} \mathbf{u x}}$ \\
\hline 1304 & 1 & 2477 & 210.20 & 98.90 & 1728 & 217.50 & 114.86 & 7.29 & 15.95 \\
\hline 1305 & 1 & 2483 & 210.01 & 98.74 & 1729 & 217.56 & 114.20 & 7.56 & 15.46 \\
\hline 1306 & 1 & 2484 & 209.95 & 98.80 & 1730 & 217.59 & 114.27 & 7.64 & 15.46 \\
\hline 1307 & 1 & 2485 & 209.95 & 98.43 & 1731 & 217.61 & 113.88 & 7.66 & 15.46 \\
\hline 1308 & 1 & 2486 & 210.10 & 98.23 & 1732 & 217.62 & 113.46 & 7.52 & 15.24 \\
\hline 1309 & 1 & 2487 & 209.96 & 98.39 & 1733 & 217.68 & 113.73 & 7.72 & 15.34 \\
\hline 1310 & 1 & 2488 & 209.90 & 98.49 & 1734 & 217.64 & 113.70 & 7.74 & 15.21 \\
\hline 1311 & 1 & 2492 & 210.00 & 98.52 & 1735 & 217.59 & 113.62 & 7.58 & 15.10 \\
\hline 1312 & 1 & 2493 & 209.99 & 98.07 & 1736 & 217.71 & 113.79 & 7.72 & 15.73 \\
\hline 1313 & 1 & 2494 & 209.98 & 98.05 & 1737 & 217.63 & 114.26 & 7.65 & 16.21 \\
\hline 1314 & 1 & 2495 & 209.97 & 98.21 & 1738 & 217.67 & 114.24 & 7.71 & 16.03 \\
\hline 1315 & 1 & 2502 & 210.05 & 98.84 & 1739 & 217.69 & 113.86 & 7.64 & 15.02 \\
\hline 1316 & 1 & 2503 & 210.12 & 98.80 & 1740 & 217.69 & 113.76 & 7.57 & 14.96 \\
\hline 1317 & 1 & 2504 & 210.20 & 98.65 & 1741 & 217.72 & 113.35 & 7.52 & 14.70 \\
\hline 1318 & 1 & 2505 & 210.06 & 98.53 & 1742 & 217.79 & 113.10 & 7.74 & 14.57 \\
\hline 1319 & 1 & 2506 & 210.15 & 98.63 & 1743 & 217.83 & 113.19 & 7.68 & 14.56 \\
\hline 1320 & 1 & 2507 & 210.16 & 98.16 & 1744 & 217.85 & 113.00 & 7.68 & 14.85 \\
\hline 1321 & 1 & 2508 & 210.10 & 98.14 & 1745 & 217.84 & 112.69 & 7.74 & 14.55 \\
\hline 1322 & 1 & 2509 & 210.05 & 98.25 & 1746 & 217.95 & 113.03 & 7.90 & 14.78 \\
\hline 1323 & 1 & 2510 & 210.10 & 98.11 & 1747 & 217.95 & 113.49 & 7.85 & 15.38 \\
\hline 1324 & 1 & 2512 & 210.10 & 98.11 & 1748 & 218.05 & 113.90 & 7.94 & 15.78 \\
\hline 1325 & 1 & 2513 & 210.13 & 97.97 & 1749 & 218.01 & 113.84 & 7.88 & 15.86 \\
\hline 1326 & 1 & 2514 & 210.17 & 98.00 & 1750 & 218.06 & 113.89 & 7.89 & 15.89 \\
\hline 1327 & 1 & 2515 & 210.23 & 97.77 & 1751 & 218.18 & 113.26 & 7.95 & 15.49 \\
\hline 1328 & 1 & 2516 & 210.17 & 98.13 & 1752 & 218.02 & 113.04 & 7.85 & 14.91 \\
\hline 1329 & 1 & 2517 & 210.25 & 97.90 & 1753 & 218.02 & 112.97 & 7.77 & 15.07 \\
\hline 1330 & 1 & 2518 & 210.27 & 97.94 & 1754 & 218.14 & 112.18 & 7.87 & 14.24 \\
\hline 1331 & 1 & 2522 & 210.32 & 97.94 & 1755 & 218.04 & 112.66 & 7.71 & 14.73 \\
\hline 1332 & 1 & 2523 & 210.17 & 98.06 & 1756 & 218.07 & 112.76 & 7.89 & 14.71 \\
\hline 1333 & 1 & 2524 & 210.08 & 97.86 & 1757 & 218.11 & 112.91 & 8.03 & 15.06 \\
\hline 1334 & 1 & 2525 & 210.06 & 98.00 & 1758 & 218.23 & 113.24 & 8.17 & 15.24 \\
\hline 1335 & 1 & 2526 & 210.11 & 97.86 & 1759 & 218.24 & 113.21 & 8.13 & 15.35 \\
\hline 1336 & 1 & 2533 & 210.18 & 97.55 & 1760 & 218.13 & 112.99 & 7.95 & 15.43 \\
\hline 1337 & 1 & 2534 & 210.21 & 97.68 & 1761 & 218.20 & 112.70 & 7.99 & 15.02 \\
\hline 1338 & 1 & 2535 & 210.28 & 97.60 & 1762 & 218.13 & 112.52 & 7.85 & 14.92 \\
\hline 1339 & 1 & 2536 & 210.25 & 97.39 & 1763 & 218.29 & 112.30 & 8.04 & 14.91 \\
\hline 1340 & 1 & 2537 & 210.27 & 97.24 & 1764 & 218.34 & 112.26 & 8.07 & 15.01 \\
\hline 1341 & 1 & 2538 & 210.20 & 97.49 & 1765 & 218.38 & 112.35 & 8.17 & 14.86 \\
\hline 1342 & 1 & 2539 & 210.23 & 97.73 & 1766 & 218.35 & 112.62 & 8.12 & 14.88 \\
\hline 1343 & 1 & 2544 & 210.38 & 97.31 & 1767 & 218.17 & 112.26 & 7.79 & 14.95 \\
\hline
\end{tabular}




\begin{tabular}{|c|c|c|c|c|c|c|c|c|c|}
\hline obs & $\mathbf{T}$ & $\begin{array}{l}\text { B260 } \\
\text { year }\end{array}$ & $\begin{array}{c}\text { driving } \\
\text { stress } \\
(\mathbf{k P a}) \\
\end{array}$ & $\underset{\left(\mathbf{k m}^{3} \mathbf{a}^{-1}\right)}{\text { flux }}$ & $\begin{array}{l}\text { B270 } \\
\text { year }\end{array}$ & $\begin{array}{l}\text { driving } \\
\text { stress } \\
(\mathbf{k P a})\end{array}$ & $\underset{\left(\mathbf{k m}^{3} \mathbf{a}^{-1}\right)}{\text { flux }}$ & $\begin{array}{c}\Delta \text { driving } \\
\text { stress } \\
(\mathbf{k P a}) \\
\end{array}$ & $\underset{\left(\mathbf{k m}^{3} \mathbf{a}^{-1)}\right.}{\Delta \text { flux }}$ \\
\hline 1344 & 1 & 2545 & 210.43 & 97.50 & 1768 & 218.12 & 112.56 & 7.69 & 15.06 \\
\hline 1345 & 1 & 2546 & 210.37 & 96.97 & 1769 & 218.30 & 111.97 & 7.93 & 14.99 \\
\hline 1346 & 1 & 2547 & 210.41 & 96.99 & 1770 & 218.37 & 112.17 & 7.95 & 15.18 \\
\hline 1347 & 1 & 2548 & 210.44 & 96.89 & 1771 & 218.42 & 111.96 & 7.98 & 15.07 \\
\hline 1348 & 1 & 2549 & 210.42 & 96.86 & 1772 & 218.36 & 112.15 & 7.94 & 15.29 \\
\hline 1349 & 1 & 2550 & 210.44 & 97.05 & 1773 & 218.44 & 112.27 & 7.99 & 15.22 \\
\hline 1350 & 1 & 2551 & 210.44 & 96.81 & 1774 & 218.47 & 112.14 & 8.03 & 15.33 \\
\hline 1351 & 1 & 2552 & 210.43 & 97.23 & 1775 & 218.53 & 112.15 & 8.10 & 14.93 \\
\hline 1352 & 1 & 2540 & 210.33 & 97.35 & 1776 & 218.45 & 111.92 & 8.12 & 14.57 \\
\hline 1353 & 1 & 2553 & 210.48 & 97.25 & 1777 & 218.31 & 112.07 & 7.82 & 14.82 \\
\hline 1354 & 1 & 2554 & 210.62 & 97.08 & 1778 & 218.29 & 111.91 & 7.67 & 14.84 \\
\hline 1355 & 1 & 2555 & 210.52 & 97.06 & 1779 & 218.35 & 111.46 & 7.83 & 14.40 \\
\hline 1356 & 1 & 2556 & 210.55 & 97.13 & 1780 & 218.40 & 111.59 & 7.85 & 14.46 \\
\hline 1357 & 1 & 2557 & 210.47 & 97.17 & 1781 & 217.93 & 112.08 & 7.46 & 14.91 \\
\hline 1358 & 1 & 2558 & 210.51 & 97.18 & 1782 & 218.00 & 111.86 & 7.49 & 14.67 \\
\hline 1359 & 1 & 2559 & 210.55 & 97.13 & 1783 & 217.90 & 112.09 & 7.35 & 14.96 \\
\hline 1360 & 1 & 2563 & 210.20 & 97.46 & 1784 & 217.84 & 112.14 & 7.63 & 14.68 \\
\hline 1361 & 1 & 2564 & 210.07 & 97.25 & 1785 & 217.97 & 111.75 & 7.89 & 14.50 \\
\hline 1362 & 1 & 2565 & 210.11 & 96.93 & 1786 & 218.02 & 111.67 & 7.91 & 14.74 \\
\hline 1363 & 1 & 2566 & 210.06 & 97.02 & 1787 & 217.96 & 111.67 & 7.91 & 14.65 \\
\hline 1364 & 1 & 2567 & 209.98 & 96.82 & 1788 & 217.97 & 111.23 & 7.99 & 14.41 \\
\hline 1365 & 1 & 2568 & 210.09 & 96.87 & 1789 & 217.86 & 111.37 & 7.77 & 14.50 \\
\hline 1366 & 1 & 2569 & 209.91 & 97.12 & 1790 & 217.67 & 111.13 & 7.76 & 14.00 \\
\hline 1367 & 1 & 2570 & 209.93 & 96.73 & 1791 & 217.76 & 111.54 & 7.83 & 14.81 \\
\hline 1368 & 1 & 2573 & 209.87 & 97.49 & 1792 & 217.70 & 111.83 & 7.83 & 14.34 \\
\hline 1369 & 1 & 2574 & 209.91 & 97.28 & 1793 & 217.71 & 112.24 & 7.80 & 14.96 \\
\hline 1370 & 1 & 2575 & 209.96 & 97.31 & 1794 & 217.74 & 111.80 & 7.78 & 14.50 \\
\hline 1371 & 1 & 2576 & 209.96 & 97.17 & 1795 & 217.82 & 111.71 & 7.85 & 14.54 \\
\hline 1372 & 1 & 2577 & 210.01 & 97.08 & 1796 & 217.83 & 111.88 & 7.82 & 14.81 \\
\hline 1373 & 1 & 2578 & 210.00 & 97.42 & 1797 & 217.96 & 111.72 & 7.97 & 14.31 \\
\hline 1374 & 1 & 2579 & 209.99 & 97.43 & 1798 & 217.94 & 111.52 & 7.95 & 14.09 \\
\hline 1375 & 1 & 2580 & 210.08 & 97.47 & 1799 & 217.89 & 111.34 & 7.81 & 13.87 \\
\hline 1376 & 1 & 2581 & 209.99 & 97.68 & 1800 & 217.87 & 111.87 & 7.89 & 14.19 \\
\hline 1377 & 1 & 2585 & 209.85 & 97.18 & 1801 & 217.80 & 111.71 & 7.95 & 14.53 \\
\hline 1378 & 1 & 2586 & 210.06 & 97.04 & 1802 & 217.89 & 111.27 & 7.83 & 14.23 \\
\hline 1379 & 1 & 2587 & 209.96 & 97.11 & 1803 & 217.89 & 111.45 & 7.93 & 14.35 \\
\hline 1380 & 1 & 2588 & 209.99 & 97.05 & 1804 & 217.92 & 111.16 & 7.92 & 14.11 \\
\hline 1381 & 1 & 2589 & 209.98 & 97.34 & 1805 & 217.95 & 110.98 & 7.97 & 13.63 \\
\hline 1382 & 1 & 2590 & 210.07 & 97.24 & 1806 & 218.01 & 110.87 & 7.94 & 13.63 \\
\hline 1383 & 1 & 2591 & 210.07 & 97.00 & 1807 & 218.03 & 111.16 & 7.96 & 14.16 \\
\hline
\end{tabular}




\begin{tabular}{|c|c|c|c|c|c|c|c|c|c|}
\hline obs & $\mathbf{T}$ & $\begin{array}{l}\text { B260 } \\
\text { year }\end{array}$ & $\begin{array}{c}\text { driving } \\
\text { stress } \\
(\mathbf{k P a})\end{array}$ & $\underset{\left(\mathbf{k m}^{3} \mathbf{a}^{-1}\right)}{\text { flux }}$ & $\begin{array}{l}\text { B270 } \\
\text { year }\end{array}$ & $\begin{array}{l}\text { driving } \\
\text { stress } \\
(\mathbf{k P a})\end{array}$ & $\underset{\left(\mathbf{k m}^{3} \mathbf{a}^{-1}\right)}{\text { flux }}$ & $\begin{array}{c}\Delta \text { driving } \\
\text { stress } \\
(\mathbf{k P a})\end{array}$ & $\underset{\left(\mathbf{k m}^{3} \mathbf{a}^{-1)}\right.}{\Delta f^{1} \mathbf{u x}}$ \\
\hline 1384 & 1 & 2592 & 210.12 & 97.11 & 1808 & 217.88 & 111.57 & 7.76 & 14.46 \\
\hline 1385 & 1 & 2599 & 210.06 & 97.04 & 1809 & 217.97 & 111.15 & 7.91 & 14.11 \\
\hline 1386 & 1 & 2600 & 210.05 & 96.97 & 1810 & 218.12 & 111.19 & 8.06 & 14.21 \\
\hline 1387 & 1 & 2601 & 210.04 & 96.61 & 1811 & 218.03 & 111.27 & 7.99 & 14.66 \\
\hline 1388 & 1 & 2602 & 210.00 & 96.94 & 1812 & 218.03 & 110.75 & 8.03 & 13.81 \\
\hline 1389 & 1 & 2603 & 210.13 & 96.84 & 1813 & 218.22 & 110.75 & 8.09 & 13.90 \\
\hline 1390 & 1 & 2604 & 210.17 & 96.79 & 1814 & 218.25 & 111.04 & 8.08 & 14.25 \\
\hline 1391 & 1 & 2605 & 210.12 & 96.71 & 1815 & 218.17 & 110.88 & 8.04 & 14.17 \\
\hline 1392 & 1 & 2606 & 209.98 & 97.32 & 1816 & 218.25 & 110.64 & 8.27 & 13.32 \\
\hline 1393 & 1 & 2607 & 210.05 & 97.07 & 1817 & 218.28 & 110.84 & 8.24 & 13.77 \\
\hline 1394 & 1 & 2612 & 209.93 & 96.84 & 1818 & 218.31 & 110.55 & 8.38 & 13.71 \\
\hline 1395 & 1 & 2613 & 210.01 & 96.96 & 1819 & 218.38 & 110.68 & 8.37 & 13.72 \\
\hline 1396 & 1 & 2614 & 210.01 & 97.01 & 1820 & 218.42 & 110.59 & 8.42 & 13.59 \\
\hline 1397 & 1 & 2615 & 209.91 & 97.03 & 1821 & 218.42 & 110.38 & 8.51 & 13.35 \\
\hline 1398 & 1 & 2616 & 209.98 & 97.00 & 1822 & 218.47 & 110.24 & 8.49 & 13.24 \\
\hline 1399 & 1 & 2617 & 209.97 & 96.91 & 1823 & 218.37 & 110.26 & 8.40 & 13.35 \\
\hline 1400 & 1 & 2618 & 210.02 & 96.81 & 1824 & 218.25 & 110.73 & 8.24 & 13.91 \\
\hline 1401 & 1 & 2619 & 210.04 & 96.67 & 1825 & 218.27 & 110.89 & 8.23 & 14.21 \\
\hline 1402 & 1 & 2625 & 210.12 & 97.13 & 1826 & 218.32 & 110.38 & 8.20 & 13.24 \\
\hline 1403 & 1 & 2626 & 210.16 & 96.61 & 1827 & 218.33 & 110.32 & 8.17 & 13.71 \\
\hline 1404 & 1 & 2627 & 210.16 & 96.61 & 1828 & 218.37 & 110.01 & 8.21 & 13.40 \\
\hline 1405 & 1 & 2628 & 210.08 & 96.50 & 1829 & 218.34 & 110.09 & 8.26 & 13.58 \\
\hline 1406 & 1 & 2629 & 210.17 & 96.42 & 1830 & 218.34 & 109.92 & 8.18 & 13.49 \\
\hline 1407 & 3 & 2631 & 210.14 & 96.86 & 1855 & 218.59 & 109.67 & 8.45 & 12.81 \\
\hline 1408 & 3 & 2632 & 210.16 & 97.07 & 1856 & 218.60 & 109.52 & 8.44 & 12.45 \\
\hline 1409 & 3 & 2633 & 210.19 & 96.80 & 1857 & 218.66 & 109.17 & 8.47 & 12.37 \\
\hline 1410 & 3 & 2635 & 210.14 & 96.86 & 1858 & 218.72 & 109.02 & 8.58 & 12.16 \\
\hline 1411 & 3 & 2636 & 210.10 & 96.80 & 1859 & 218.67 & 109.02 & 8.57 & 12.22 \\
\hline 1412 & 3 & 2637 & 210.13 & 96.48 & 1860 & 218.69 & 109.46 & 8.56 & 12.98 \\
\hline 1413 & 3 & 2638 & 209.89 & 96.88 & 1861 & 218.68 & 109.80 & 8.79 & 12.92 \\
\hline 1414 & 3 & 2639 & 209.89 & 96.75 & 1862 & 218.65 & 110.16 & 8.76 & 13.41 \\
\hline 1415 & 3 & 2640 & 209.95 & 97.11 & 1863 & 218.75 & 110.07 & 8.80 & 12.97 \\
\hline 1416 & 3 & 2643 & 210.19 & 96.58 & 1864 & 218.72 & 110.23 & 8.53 & 13.65 \\
\hline 1417 & 3 & 2644 & 210.26 & 96.41 & 1865 & 218.82 & 109.79 & 8.56 & 13.38 \\
\hline 1418 & 3 & 2645 & 210.30 & 96.36 & 1866 & 218.62 & 109.60 & 8.32 & 13.24 \\
\hline 1419 & 3 & 2646 & 210.24 & 96.28 & 1867 & 218.71 & 109.72 & 8.47 & 13.44 \\
\hline 1420 & 3 & 2647 & 210.41 & 96.22 & 1868 & 218.48 & 110.10 & 8.07 & 13.88 \\
\hline 1421 & 3 & 2648 & 210.10 & 96.74 & 1869 & 218.58 & 109.87 & 8.48 & 13.13 \\
\hline 1422 & 3 & 2653 & 210.24 & 96.34 & 1870 & 218.65 & 109.66 & 8.41 & 13.32 \\
\hline 1423 & 3 & 2654 & 210.21 & 96.59 & 1871 & 218.66 & 109.46 & 8.45 & 12.87 \\
\hline
\end{tabular}




\begin{tabular}{|c|c|c|c|c|c|c|c|c|c|}
\hline obs & $\mathbf{T}$ & $\begin{array}{l}\text { B260 } \\
\text { year }\end{array}$ & $\begin{array}{c}\text { driving } \\
\text { stress } \\
(\mathbf{k P a})\end{array}$ & $\underset{\left(\mathbf{k m}^{3} \mathbf{a}^{-1}\right)}{\text { flux }}$ & $\begin{array}{l}\text { B270 } \\
\text { year }\end{array}$ & $\begin{array}{l}\text { driving } \\
\text { stress } \\
(\mathbf{k P a})\end{array}$ & $\underset{\left(\mathbf{k m}^{3} \mathbf{a}^{-1}\right)}{\text { flux }}$ & $\begin{array}{c}\Delta \text { driving } \\
\text { stress } \\
(\mathbf{k P a})\end{array}$ & $\underset{\left(\mathbf{k m}^{3} \mathbf{a}^{-1)}\right.}{\Delta f^{1} \mathbf{u x}}$ \\
\hline 1424 & 3 & 2655 & 210.25 & 96.40 & 1872 & 218.69 & 109.45 & 8.45 & 13.06 \\
\hline 1425 & 3 & 2656 & 210.32 & 96.41 & 1873 & 218.75 & 109.41 & 8.43 & 13.00 \\
\hline 1426 & 3 & 2657 & 210.23 & 96.50 & 1874 & 218.77 & 109.36 & 8.53 & 12.86 \\
\hline 1427 & 3 & 2658 & 210.07 & 96.56 & 1875 & 218.73 & 109.45 & 8.66 & 12.89 \\
\hline 1428 & 3 & 2664 & 210.35 & 96.14 & 1876 & 218.73 & 109.37 & 8.38 & 13.23 \\
\hline 1429 & 3 & 2665 & 210.26 & 96.20 & 1877 & 218.94 & 109.43 & 8.68 & 13.24 \\
\hline 1430 & 3 & 2666 & 210.16 & 96.19 & 1878 & 218.95 & 109.69 & 8.79 & 13.49 \\
\hline 1431 & 3 & 2667 & 210.20 & 96.21 & 1879 & 218.96 & 109.84 & 8.76 & 13.63 \\
\hline 1432 & 3 & 2668 & 210.22 & 96.44 & 1880 & 219.07 & 109.86 & 8.85 & 13.42 \\
\hline 1433 & 3 & 2669 & 210.13 & 96.49 & 1881 & 219.01 & 110.08 & 8.89 & 13.58 \\
\hline 1434 & 3 & 2670 & 210.14 & 96.36 & 1882 & 218.83 & 109.84 & 8.69 & 13.48 \\
\hline 1435 & 3 & 2671 & 210.19 & 96.14 & 1883 & 218.75 & 109.70 & 8.56 & 13.56 \\
\hline 1436 & 3 & 2672 & 210.11 & 95.83 & 1884 & 218.71 & 109.66 & 8.60 & 13.83 \\
\hline 1437 & 3 & 2684 & 210.41 & 95.78 & 1885 & 218.79 & 109.56 & 8.39 & 13.78 \\
\hline 1438 & 3 & 2685 & 210.39 & 96.09 & 1886 & 218.71 & 109.63 & 8.31 & 13.55 \\
\hline 1439 & 3 & 2686 & 210.46 & 95.52 & 1887 & 218.71 & 109.68 & 8.25 & 14.15 \\
\hline 1440 & 3 & 2687 & 210.49 & 95.83 & 1888 & 218.88 & 109.71 & 8.39 & 13.88 \\
\hline 1441 & 3 & 2688 & 210.30 & 96.21 & 1889 & 219.10 & 109.68 & 8.80 & 13.47 \\
\hline 1442 & 3 & 2689 & 210.38 & 96.31 & 1890 & 218.97 & 109.65 & 8.59 & 13.34 \\
\hline 1443 & 3 & 2690 & 210.36 & 95.79 & 1891 & 219.08 & 108.95 & 8.73 & 13.16 \\
\hline 1444 & 3 & 2691 & 210.40 & 95.98 & 1892 & 219.04 & 108.98 & 8.63 & 13.00 \\
\hline 1445 & 3 & 2692 & 210.36 & 95.89 & 1893 & 219.16 & 108.23 & 8.80 & 12.35 \\
\hline 1446 & 3 & 2693 & 210.43 & 95.97 & 1894 & 219.00 & 108.68 & 8.57 & 12.71 \\
\hline 1447 & 3 & 2704 & 210.56 & 95.29 & 1895 & 219.03 & 108.64 & 8.47 & 13.34 \\
\hline 1448 & 3 & 2705 & 210.52 & 95.51 & 1896 & 218.96 & 108.66 & 8.44 & 13.14 \\
\hline 1449 & 3 & 2706 & 210.59 & 95.73 & 1897 & 219.04 & 108.55 & 8.45 & 12.83 \\
\hline 1450 & 3 & 2707 & 210.69 & 95.48 & 1898 & 219.05 & 108.40 & 8.36 & 12.92 \\
\hline 1451 & 3 & 2708 & 210.68 & 95.48 & 1899 & 218.95 & 108.66 & 8.28 & 13.17 \\
\hline 1452 & 3 & 2709 & 210.65 & 95.34 & 1900 & 218.96 & 108.95 & 8.30 & 13.60 \\
\hline 1453 & 3 & 2710 & 210.50 & 95.47 & 1901 & 219.05 & 108.66 & 8.55 & 13.19 \\
\hline 1454 & 3 & 2711 & 210.49 & 95.34 & 1902 & 219.01 & 108.30 & 8.52 & 12.95 \\
\hline 1455 & 3 & 2712 & 210.62 & 95.25 & 1903 & 219.11 & 108.61 & 8.50 & 13.36 \\
\hline 1456 & 3 & 2713 & 210.55 & 95.44 & 1904 & 219.16 & 108.56 & 8.61 & 13.12 \\
\hline 1457 & 3 & 2714 & 210.57 & 95.27 & 1905 & 219.02 & 108.45 & 8.45 & 13.18 \\
\hline 1458 & 3 & 2715 & 210.54 & 95.28 & 1906 & 219.16 & 108.22 & 8.62 & 12.94 \\
\hline 1459 & 3 & 2716 & 210.50 & 95.93 & 1907 & 218.86 & 108.32 & 8.36 & 12.40 \\
\hline 1460 & 3 & 2717 & 210.51 & 95.87 & 1908 & 218.95 & 108.49 & 8.44 & 12.61 \\
\hline 1461 & 3 & 2718 & 210.67 & 96.14 & 1909 & 219.08 & 108.36 & 8.41 & 12.22 \\
\hline 1462 & 3 & 2719 & 210.61 & 96.04 & 1910 & 219.05 & 108.69 & 8.45 & 12.65 \\
\hline 1463 & 3 & 2720 & 210.57 & 96.14 & 1911 & 219.09 & 109.02 & 8.52 & 12.88 \\
\hline
\end{tabular}




\begin{tabular}{|c|c|c|c|c|c|c|c|c|c|}
\hline obs & $\mathbf{T}$ & $\begin{array}{l}\text { B260 } \\
\text { year }\end{array}$ & $\begin{array}{c}\text { driving } \\
\text { stress } \\
(\mathbf{k P a})\end{array}$ & $\underset{\left(\mathbf{k m}^{3} \mathbf{a}^{-1}\right)}{\text { flux }}$ & $\begin{array}{l}\text { B270 } \\
\text { year }\end{array}$ & $\begin{array}{c}\text { driving } \\
\text { stress } \\
(\mathbf{k P a})\end{array}$ & $\underset{\left(\mathbf{k m}^{3} \mathbf{a}^{-1}\right)}{\text { flux }}$ & $\begin{array}{c}\Delta \text { driving } \\
\text { stress } \\
\text { (kPa) }\end{array}$ & $\underset{\left(\mathbf{k m}^{3} \mathbf{a}^{-1)}\right.}{\Delta \text { flux }}$ \\
\hline 1464 & 3 & 2721 & 210.58 & 95.88 & 1912 & 218.83 & 108.08 & 8.25 & 12.19 \\
\hline 1465 & 3 & 2730 & 210.78 & 95.99 & 1913 & 218.80 & 108.31 & 8.03 & 12.32 \\
\hline 1466 & 3 & 2739 & 210.77 & 95.23 & 1914 & 218.69 & 108.69 & 7.92 & 13.46 \\
\hline 1467 & 3 & 2738 & 210.81 & 95.74 & 1917 & 218.86 & 108.47 & 8.05 & 12.73 \\
\hline 1468 & 3 & 2733 & 210.90 & 95.84 & 1918 & 218.83 & 108.50 & 7.93 & 12.66 \\
\hline 1469 & 3 & 2734 & 210.75 & 96.05 & 1919 & 218.84 & 108.38 & 8.09 & 12.34 \\
\hline 1470 & 3 & 2735 & 210.86 & 95.97 & 1920 & 218.93 & 108.32 & 8.07 & 12.35 \\
\hline 1471 & 3 & 2742 & 210.93 & 95.28 & 1921 & 218.88 & 108.71 & 7.95 & 13.42 \\
\hline 1472 & 3 & 2743 & 210.93 & 95.19 & 1922 & 218.87 & 108.28 & 7.94 & 13.08 \\
\hline 1473 & 3 & 2746 & 210.96 & 95.59 & 1923 & 218.77 & 108.75 & 7.81 & 13.16 \\
\hline 1474 & 3 & 2747 & 210.99 & 95.65 & 1924 & 218.90 & 108.64 & 7.91 & 12.99 \\
\hline 1475 & 3 & 2748 & 211.00 & 95.67 & 1925 & 218.96 & 108.76 & 7.96 & 13.10 \\
\hline 1476 & 3 & 2749 & 211.03 & 95.66 & 1926 & 218.91 & 108.59 & 7.88 & 12.93 \\
\hline 1477 & 3 & 2750 & 211.04 & 95.68 & 1927 & 219.05 & 108.10 & 8.01 & 12.42 \\
\hline 1478 & 3 & 2751 & 210.95 & 95.91 & 1928 & 219.04 & 108.26 & 8.09 & 12.35 \\
\hline 1479 & 3 & 2757 & 211.07 & 95.43 & 1929 & 218.90 & 108.66 & 7.83 & 13.23 \\
\hline 1480 & 3 & 2759 & 210.96 & 95.53 & 1930 & 218.88 & 108.42 & 7.92 & 12.90 \\
\hline 1481 & 3 & 2762 & 210.81 & 95.62 & 1936 & 218.77 & 108.70 & 7.96 & 13.08 \\
\hline 1482 & 3 & 2770 & 210.92 & 95.23 & 1937 & 218.88 & 108.76 & 7.97 & 13.52 \\
\hline 1483 & 3 & 2771 & 210.94 & 95.32 & 1938 & 218.79 & 108.01 & 7.84 & 12.69 \\
\hline 1484 & 3 & 2772 & 210.93 & 95.65 & 1939 & 219.02 & 108.62 & 8.09 & 12.97 \\
\hline 1485 & 3 & 2773 & 211.02 & 95.40 & 1940 & 218.97 & 108.79 & 7.95 & 13.39 \\
\hline 1486 & 3 & 2778 & 211.14 & 95.69 & 1941 & 218.85 & 108.82 & 7.71 & 13.13 \\
\hline 1487 & 3 & 2779 & 210.90 & 95.59 & 1942 & 218.91 & 108.94 & 8.01 & 13.35 \\
\hline 1488 & 3 & 2780 & 210.87 & 95.65 & 1943 & 218.95 & 108.65 & 8.08 & 13.00 \\
\hline 1489 & 3 & 2781 & 211.07 & 95.27 & 1944 & 218.87 & 108.81 & 7.80 & 13.54 \\
\hline 1490 & 3 & 2782 & 211.08 & 95.31 & 1945 & 218.95 & 108.94 & 7.87 & 13.63 \\
\hline 1491 & 3 & 2783 & 211.05 & 95.17 & 1946 & 218.92 & 109.09 & 7.88 & 13.92 \\
\hline 1492 & 3 & 2784 & 211.14 & 95.09 & 1947 & 218.99 & 109.40 & 7.85 & 14.31 \\
\hline 1493 & 3 & 2785 & 211.07 & 95.29 & 1948 & 219.01 & 109.37 & 7.94 & 14.09 \\
\hline 1494 & 3 & 2793 & 210.90 & 94.93 & 1949 & 218.95 & 109.62 & 8.05 & 14.69 \\
\hline 1495 & 3 & 2794 & 211.05 & 94.70 & 1950 & 218.97 & 108.98 & 7.92 & 14.28 \\
\hline 1496 & 3 & 2795 & 210.98 & 95.15 & 1951 & 218.99 & 109.04 & 8.01 & 13.89 \\
\hline 1497 & 3 & 2796 & 210.86 & 95.06 & 1952 & 218.89 & 108.73 & 8.04 & 13.67 \\
\hline 1498 & 3 & 2797 & 210.89 & 95.22 & 1953 & 219.00 & 109.14 & 8.11 & 13.92 \\
\hline 1499 & 3 & 2798 & 210.85 & 94.99 & 1954 & 219.03 & 109.47 & 8.18 & 14.48 \\
\hline 1500 & 3 & 2799 & 210.64 & 94.91 & 1955 & 219.14 & 109.18 & 8.50 & 14.26 \\
\hline 1501 & 3 & 2800 & 210.75 & 94.84 & 1956 & 219.07 & 109.50 & 8.32 & 14.66 \\
\hline 1502 & 3 & 2810 & 210.80 & 94.67 & 1957 & 219.17 & 109.46 & 8.36 & 14.79 \\
\hline 1503 & 3 & 2811 & 210.88 & 94.50 & 1958 & 219.22 & 109.26 & 8.35 & 14.75 \\
\hline
\end{tabular}




\begin{tabular}{|c|c|c|c|c|c|c|c|c|c|}
\hline obs & $\mathbf{T}$ & $\begin{array}{l}\text { B260 } \\
\text { year }\end{array}$ & $\begin{array}{c}\text { driving } \\
\text { stress } \\
(\mathbf{k P a})\end{array}$ & $\underset{\left(\mathbf{k m}^{3} \mathbf{a}^{-1}\right)}{\text { flux }}$ & $\begin{array}{l}\text { B270 } \\
\text { year }\end{array}$ & $\begin{array}{l}\text { driving } \\
\text { stress } \\
(\mathbf{k P a})\end{array}$ & $\underset{\left(\mathbf{k m}^{3} \mathbf{a}^{-1}\right)}{\text { flux }}$ & $\begin{array}{c}\Delta \text { driving } \\
\text { stress } \\
(\mathbf{k P a})\end{array}$ & $\underset{\left(\mathbf{k m}^{3} \mathbf{a}^{-1)}\right.}{\Delta f^{1} \mathbf{u x}}$ \\
\hline 1504 & 3 & 2812 & 210.91 & 94.61 & 1959 & 219.19 & 109.54 & 8.28 & 14.93 \\
\hline 1505 & 3 & 2813 & 210.84 & 94.53 & 1960 & 219.21 & 109.27 & 8.37 & 14.74 \\
\hline 1506 & 3 & 2814 & 210.84 & 94.36 & 1961 & 219.38 & 108.98 & 8.55 & 14.62 \\
\hline 1507 & 3 & 2815 & 210.96 & 94.24 & 1962 & 219.35 & 108.96 & 8.39 & 14.73 \\
\hline 1508 & 3 & 2816 & 210.87 & 94.62 & 1963 & 219.28 & 109.18 & 8.41 & 14.56 \\
\hline 1509 & 3 & 2817 & 210.83 & 94.70 & 1964 & 219.36 & 109.14 & 8.53 & 14.44 \\
\hline 1510 & 3 & 2818 & 210.91 & 94.22 & 1965 & 219.37 & 109.19 & 8.45 & 14.97 \\
\hline 1511 & 3 & 2819 & 210.99 & 94.40 & 1966 & 219.44 & 108.80 & 8.44 & 14.40 \\
\hline 1512 & 3 & 2833 & 210.68 & 94.00 & 1967 & 219.44 & 109.07 & 8.76 & 15.07 \\
\hline 1513 & 3 & 2834 & 210.62 & 94.32 & 1968 & 219.43 & 109.17 & 8.81 & 14.85 \\
\hline 1514 & 3 & 2835 & 210.83 & 93.83 & 1969 & 219.46 & 108.88 & 8.63 & 15.05 \\
\hline 1515 & 3 & 2836 & 210.72 & 94.21 & 1970 & 219.46 & 108.70 & 8.74 & 14.50 \\
\hline 1516 & 3 & 2837 & 210.71 & 94.34 & 1971 & 219.46 & 108.83 & 8.75 & 14.49 \\
\hline 1517 & 3 & 2838 & 210.70 & 94.00 & 1972 & 219.49 & 108.52 & 8.79 & 14.52 \\
\hline 1518 & 3 & 2839 & 210.65 & 93.93 & 1973 & 219.53 & 108.50 & 8.88 & 14.57 \\
\hline 1519 & 3 & 2840 & 210.66 & 94.18 & 1974 & 219.33 & 108.72 & 8.68 & 14.54 \\
\hline 1520 & 3 & 2841 & 210.56 & 93.83 & 1975 & 219.38 & 109.05 & 8.82 & 15.22 \\
\hline 1521 & 3 & 2842 & 210.53 & 93.82 & 1976 & 219.32 & 108.87 & 8.78 & 15.06 \\
\hline 1522 & 3 & 2850 & 210.46 & 93.80 & 1977 & 219.48 & 108.96 & 9.02 & 15.16 \\
\hline 1523 & 3 & 2851 & 210.47 & 94.05 & 1978 & 219.54 & 108.59 & 9.06 & 14.54 \\
\hline 1524 & 3 & 2852 & 210.48 & 94.39 & 1979 & 219.54 & 108.06 & 9.06 & 13.68 \\
\hline 1525 & 3 & 2853 & 210.54 & 94.06 & 1980 & 219.52 & 107.99 & 8.99 & 13.92 \\
\hline 1526 & 3 & 2854 & 210.51 & 94.04 & 1981 & 219.62 & 108.53 & 9.11 & 14.50 \\
\hline 1527 & 3 & 2855 & 210.50 & 94.08 & 1982 & 219.56 & 108.71 & 9.06 & 14.63 \\
\hline 1528 & 3 & 2861 & 210.55 & 94.26 & 1983 & 219.37 & 108.22 & 8.82 & 13.96 \\
\hline 1529 & 3 & 2862 & 210.56 & 93.59 & 1984 & 219.22 & 108.50 & 8.66 & 14.90 \\
\hline 1530 & 3 & 2863 & 210.53 & 93.58 & 1985 & 219.38 & 108.50 & 8.85 & 14.92 \\
\hline 1531 & 3 & 2864 & 210.53 & 93.76 & 1986 & 219.40 & 108.10 & 8.86 & 14.33 \\
\hline 1532 & 3 & 2865 & 210.64 & 94.01 & 1987 & 219.48 & 107.84 & 8.84 & 13.82 \\
\hline 1533 & 3 & 2866 & 210.64 & 93.98 & 1988 & 219.51 & 107.76 & 8.87 & 13.78 \\
\hline 1534 & 3 & 2870 & 210.60 & 93.85 & 1989 & 219.58 & 107.64 & 8.98 & 13.79 \\
\hline 1535 & 3 & 2871 & 210.65 & 94.13 & 1990 & 219.52 & 108.11 & 8.87 & 13.98 \\
\hline 1536 & 3 & 2872 & 210.61 & 94.20 & 1991 & 219.50 & 107.99 & 8.90 & 13.79 \\
\hline 1537 & 3 & 2873 & 210.63 & 94.34 & 1992 & 219.48 & 107.92 & 8.85 & 13.59 \\
\hline 1538 & 3 & 2874 & 210.72 & 94.54 & 1993 & 219.71 & 107.32 & 8.99 & 12.78 \\
\hline 1539 & 3 & 2875 & 210.65 & 94.67 & 1994 & 219.64 & 107.36 & 8.99 & 12.69 \\
\hline 1540 & 3 & 2876 & 210.76 & 94.73 & 1995 & 219.77 & 107.30 & 9.01 & 12.57 \\
\hline 1541 & 3 & 2877 & 210.76 & 94.51 & 1996 & 219.57 & 107.09 & 8.81 & 12.58 \\
\hline 1542 & 3 & 2878 & 210.73 & 94.36 & 1997 & 219.65 & 107.00 & 8.92 & 12.64 \\
\hline 1543 & 3 & 2879 & 210.68 & 94.45 & 1998 & 219.73 & 106.77 & 9.05 & 12.32 \\
\hline
\end{tabular}




\begin{tabular}{|c|c|c|c|c|c|c|c|c|c|}
\hline obs & $\mathbf{T}$ & $\begin{array}{l}\text { B260 } \\
\text { year }\end{array}$ & $\begin{array}{c}\text { driving } \\
\text { stress } \\
(\mathbf{k P a})\end{array}$ & $\underset{\left(\mathbf{k m}^{3} \mathbf{a}^{-1}\right)}{\text { flux }}$ & $\begin{array}{l}\text { B270 } \\
\text { year }\end{array}$ & $\begin{array}{l}\text { driving } \\
\text { stress } \\
(\mathbf{k P a})\end{array}$ & $\underset{\left(\mathbf{k m}^{3} \mathbf{a}^{-1}\right)}{\text { flux }}$ & $\begin{array}{c}\Delta \text { driving } \\
\text { stress } \\
(\mathbf{k P a})\end{array}$ & $\underset{\left(\mathbf{k m}^{3} \mathbf{a}^{-1)}\right.}{\Delta f^{1} \mathbf{u x}}$ \\
\hline 1544 & 3 & 2880 & 210.73 & 93.98 & 1999 & 219.66 & 106.61 & 8.93 & 12.63 \\
\hline 1545 & 3 & 2881 & 210.82 & 94.38 & 2000 & 219.63 & 106.71 & 8.81 & 12.33 \\
\hline 1546 & 3 & 2882 & 210.85 & 94.32 & 2001 & 219.61 & 107.02 & 8.77 & 12.71 \\
\hline 1547 & 3 & 2897 & 210.78 & 93.86 & 2002 & 219.58 & 106.86 & 8.80 & 13.01 \\
\hline 1548 & 3 & 2898 & 210.72 & 93.44 & 2003 & 219.72 & 106.91 & 9.00 & 13.47 \\
\hline 1549 & 3 & 2899 & 210.81 & 93.31 & 2004 & 219.65 & 106.46 & 8.84 & 13.15 \\
\hline 1550 & 3 & 2900 & 210.71 & 93.94 & 2005 & 219.69 & 106.55 & 8.97 & 12.61 \\
\hline 1551 & 3 & 2901 & 210.77 & 93.54 & 2006 & 219.73 & 106.76 & 8.96 & 13.22 \\
\hline 1552 & 3 & 2902 & 210.86 & 93.46 & 2007 & 219.73 & 106.92 & 8.86 & 13.47 \\
\hline 1553 & 3 & 2903 & 210.81 & 93.45 & 2008 & 219.68 & 106.62 & 8.87 & 13.16 \\
\hline 1554 & 3 & 2904 & 210.74 & 93.59 & 2009 & 219.73 & 106.55 & 8.99 & 12.96 \\
\hline 1555 & 3 & 2905 & 210.71 & 93.34 & 2010 & 219.67 & 106.59 & 8.96 & 13.25 \\
\hline 1556 & 3 & 2906 & 210.74 & 93.37 & 2011 & 219.67 & 106.79 & 8.93 & 13.42 \\
\hline 1557 & 3 & 2907 & 210.81 & 93.61 & 2012 & 219.67 & 106.53 & 8.86 & 12.92 \\
\hline 1558 & 3 & 2923 & 210.63 & 93.32 & 2013 & 219.70 & 106.39 & 9.07 & 13.07 \\
\hline 1559 & 3 & 2927 & 210.45 & 93.24 & 2014 & 219.69 & 106.40 & 9.24 & 13.16 \\
\hline 1560 & 3 & 2928 & 210.64 & 93.08 & 2015 & 219.65 & 106.61 & 9.01 & 13.54 \\
\hline 1561 & 3 & 2929 & 210.37 & 93.19 & 2016 & 219.69 & 106.63 & 9.32 & 13.45 \\
\hline 1562 & 3 & 2930 & 210.36 & 93.20 & 2017 & 219.70 & 106.14 & 9.34 & 12.94 \\
\hline 1563 & 3 & 2931 & 210.55 & 93.39 & 2018 & 219.73 & 106.62 & 9.18 & 13.22 \\
\hline 1564 & 3 & 2932 & 210.35 & 93.41 & 2019 & 219.73 & 105.92 & 9.38 & 12.51 \\
\hline 1565 & 3 & 2933 & 210.36 & 92.62 & 2020 & 219.56 & 105.87 & 9.20 & 13.26 \\
\hline 1566 & 3 & 2934 & 210.53 & 92.94 & 2021 & 219.59 & 106.57 & 9.06 & 13.62 \\
\hline 1567 & 3 & 2935 & 210.36 & 92.66 & 2022 & 219.63 & 106.30 & 9.27 & 13.64 \\
\hline 1568 & 3 & 2936 & 210.26 & 92.49 & 2023 & 219.60 & 105.84 & 9.35 & 13.35 \\
\hline 1569 & 3 & 2937 & 210.52 & 92.81 & 2024 & 219.41 & 106.01 & 8.89 & 13.20 \\
\hline 1570 & 3 & 2946 & 210.38 & 92.40 & 2025 & 219.60 & 105.77 & 9.21 & 13.37 \\
\hline 1571 & 3 & 2947 & 210.31 & 92.82 & 2026 & 219.55 & 105.64 & 9.24 & 12.83 \\
\hline 1572 & 3 & 2948 & 210.57 & 92.50 & 2027 & 219.55 & 105.48 & 8.98 & 12.98 \\
\hline 1573 & 3 & 2949 & 210.64 & 92.58 & 2028 & 219.60 & 105.44 & 8.96 & 12.86 \\
\hline 1574 & 3 & 2950 & 210.40 & 92.88 & 2029 & 219.46 & 105.45 & 9.06 & 12.57 \\
\hline 1575 & 3 & 2951 & 210.52 & 93.10 & 2030 & 219.58 & 105.82 & 9.06 & 12.72 \\
\hline 1576 & 3 & 2952 & 210.40 & 92.88 & 2031 & 219.64 & 105.95 & 9.24 & 13.07 \\
\hline 1577 & 3 & 2953 & 210.25 & 92.56 & 2032 & 219.53 & 105.94 & 9.28 & 13.39 \\
\hline 1578 & 3 & 2956 & 210.31 & 92.35 & 2033 & 219.73 & 106.29 & 9.41 & 13.94 \\
\hline 1579 & 3 & 2957 & 210.49 & 92.51 & 2034 & 219.67 & 105.89 & 9.18 & 13.38 \\
\hline 1580 & 3 & 2958 & 210.35 & 92.48 & 2035 & 219.70 & 105.96 & 9.35 & 13.48 \\
\hline 1581 & 3 & 2959 & 210.42 & 92.63 & 2036 & 219.53 & 105.39 & 9.12 & 12.75 \\
\hline 1582 & 3 & 2960 & 210.30 & 92.58 & 2037 & 219.44 & 105.91 & 9.14 & 13.33 \\
\hline 1583 & 3 & 2962 & 210.20 & 93.08 & 2038 & 219.43 & 106.35 & 9.23 & 13.27 \\
\hline
\end{tabular}




\begin{tabular}{|c|c|c|c|c|c|c|c|c|c|}
\hline obs & $\mathbf{T}$ & $\begin{array}{l}\text { B260 } \\
\text { year }\end{array}$ & $\begin{array}{c}\text { driving } \\
\text { stress } \\
(\mathbf{k P a}) \\
\end{array}$ & $\begin{array}{c}\text { flux } \\
\left(\mathbf{k m}^{\mathbf{3}} \mathbf{a}^{-1}\right)\end{array}$ & $\begin{array}{l}\text { B270 } \\
\text { year }\end{array}$ & $\begin{array}{l}\text { driving } \\
\text { stress } \\
(\mathbf{k P a})\end{array}$ & $\begin{array}{c}\text { flux } \\
\left(\mathbf{k m}^{\mathbf{3}} \mathbf{a}^{-1}\right)\end{array}$ & $\begin{array}{c}\Delta \text { driving } \\
\text { stress } \\
(\mathbf{k P a}) \\
\end{array}$ & $\begin{array}{c}\Delta \text { flux } \\
\left(\mathbf{k m}^{3} \mathbf{a}^{-1)}\right.\end{array}$ \\
\hline 1584 & 3 & 2963 & 210.32 & 92.80 & 2039 & 219.22 & 106.21 & 8.90 & 13.41 \\
\hline 1585 & 3 & 2964 & 210.18 & 92.92 & 2040 & 219.35 & 105.76 & 9.17 & 12.85 \\
\hline 1586 & 3 & 2966 & 210.25 & 92.64 & 2041 & 219.22 & 106.07 & 8.97 & 13.43 \\
\hline 1587 & 3 & 2968 & 210.37 & 92.80 & 2042 & 219.34 & 105.82 & 8.97 & 13.02 \\
\hline 1588 & 3 & 2969 & 210.29 & 93.02 & 2043 & 219.28 & 105.65 & 8.99 & 12.63 \\
\hline 1589 & 3 & 2972 & 210.37 & 93.49 & 2045 & 219.33 & 106.12 & 8.96 & 12.63 \\
\hline 1590 & 3 & 2973 & 210.35 & 92.74 & 2046 & 219.33 & 106.20 & 8.98 & 13.45 \\
\hline 1591 & 3 & 2971 & 210.26 & 93.31 & 2047 & 219.34 & 105.97 & 9.07 & 12.66 \\
\hline 1592 & 3 & 2976 & 210.22 & 92.78 & 2048 & 219.35 & 105.90 & 9.12 & 13.12 \\
\hline 1593 & 3 & 2977 & 210.21 & 92.87 & 2049 & 219.36 & 105.85 & 9.15 & 12.98 \\
\hline 1594 & 3 & 2979 & 210.25 & 92.79 & 2050 & 219.28 & 105.84 & 9.03 & 13.05 \\
\hline 1595 & 3 & 2980 & 210.25 & 92.86 & 2051 & 219.25 & 105.81 & 8.99 & 12.95 \\
\hline 1596 & 3 & 2982 & 210.17 & 92.49 & 2052 & 219.33 & 105.91 & 9.15 & 13.42 \\
\hline 1597 & 3 & 2983 & 210.16 & 92.71 & 2053 & 219.33 & 106.01 & 9.17 & 13.30 \\
\hline 1598 & 3 & 2984 & 210.27 & 92.91 & 2054 & 219.28 & 105.97 & 9.01 & 13.07 \\
\hline 1599 & 3 & 2987 & 210.24 & 93.20 & 2055 & 219.44 & 106.02 & 9.20 & 12.82 \\
\hline 1600 & 3 & 2988 & 210.24 & 93.04 & 2056 & 219.38 & 105.63 & 9.13 & 12.60 \\
\hline 1601 & 3 & 2989 & 210.28 & 93.16 & 2057 & 219.44 & 106.09 & 9.16 & 12.93 \\
\hline 1602 & 3 & 2990 & 210.28 & 93.19 & 2058 & 219.43 & 105.97 & 9.15 & 12.78 \\
\hline 1603 & 3 & 2991 & 210.29 & 93.22 & 2059 & 219.47 & 105.73 & 9.18 & 12.52 \\
\hline 1604 & 3 & 2992 & 210.21 & 93.19 & 2060 & 219.46 & 105.77 & 9.25 & 12.58 \\
\hline 1605 & 3 & 2993 & 210.36 & 93.17 & 2061 & 219.42 & 105.36 & 9.06 & 12.19 \\
\hline 1606 & 3 & 2994 & 210.31 & 93.13 & 2062 & 219.47 & 105.79 & 9.16 & 12.66 \\
\hline 1607 & 3 & 2996 & 210.27 & 92.97 & 2063 & 219.42 & 106.11 & 9.16 & 13.15 \\
\hline 1608 & 3 & 2997 & 210.27 & 92.98 & 2064 & 219.45 & 106.00 & 9.18 & 13.02 \\
\hline 1609 & 3 & 2995 & 210.32 & 93.09 & 2065 & 219.38 & 105.73 & 9.06 & 12.64 \\
\hline 1610 & 3 & 2999 & 210.31 & 92.69 & 2066 & 219.42 & 105.83 & 9.11 & 13.14 \\
\hline 1611 & 3 & 3001 & 210.36 & 93.12 & 2067 & 219.34 & 105.78 & 8.98 & 12.67 \\
\hline 1612 & 3 & 3003 & 210.30 & 92.60 & 2068 & 219.32 & 105.69 & 9.02 & 13.09 \\
\hline 1613 & 3 & 3004 & 210.20 & 92.75 & 2069 & 219.25 & 105.99 & 9.04 & 13.23 \\
\hline 1614 & 3 & 3006 & 210.26 & 92.94 & 2070 & 219.24 & 105.80 & 8.99 & 12.86 \\
\hline 1615 & 3 & 3008 & 210.08 & 92.98 & 2071 & 219.36 & 105.96 & 9.28 & 12.98 \\
\hline 1616 & 3 & 3009 & 210.01 & 92.67 & 2072 & 219.41 & 105.93 & 9.40 & 13.27 \\
\hline 1617 & 3 & 3010 & 210.04 & 92.70 & 2073 & 219.33 & 105.40 & 9.30 & 12.70 \\
\hline 1618 & 3 & 3011 & 210.06 & 92.95 & 2074 & 219.39 & 105.40 & 9.33 & 12.45 \\
\hline 1619 & 3 & 3014 & 210.09 & 93.02 & 2075 & 219.50 & 105.59 & 9.40 & 12.57 \\
\hline 1620 & 3 & 3015 & 210.07 & 92.78 & 2076 & 219.36 & 105.16 & 9.29 & 12.38 \\
\hline 1621 & 3 & 3016 & 210.13 & 92.68 & 2077 & 219.43 & 105.64 & 9.30 & 12.96 \\
\hline 1622 & 3 & 3018 & 210.04 & 92.85 & 2078 & 219.36 & 105.61 & 9.33 & 12.76 \\
\hline 1623 & 3 & 3020 & 210.13 & 92.76 & 2079 & 219.39 & 105.68 & 9.26 & 12.92 \\
\hline
\end{tabular}




\begin{tabular}{|c|c|c|c|c|c|c|c|c|c|}
\hline obs & $\mathbf{T}$ & $\begin{array}{l}\text { B260 } \\
\text { year }\end{array}$ & $\begin{array}{c}\text { driving } \\
\text { stress } \\
(\mathbf{k P a}) \\
\end{array}$ & $\begin{array}{c}\text { flux } \\
\left(\mathbf{k m}^{\mathbf{3}} \mathbf{a}^{-1}\right)\end{array}$ & $\begin{array}{l}\text { B270 } \\
\text { year }\end{array}$ & $\begin{array}{l}\text { driving } \\
\text { stress } \\
(\mathbf{k P a})\end{array}$ & $\begin{array}{c}\text { flux } \\
\left(\mathbf{k m}^{3} \mathbf{a}^{-1}\right)\end{array}$ & $\begin{array}{c}\Delta \text { driving } \\
\text { stress } \\
(\mathbf{k P a}) \\
\end{array}$ & $\begin{array}{c}\Delta \text { flux } \\
\left(\mathbf{k m}^{3} \mathbf{a}^{-1)}\right.\end{array}$ \\
\hline 1624 & 3 & 3021 & 210.13 & 92.50 & 2080 & 219.41 & 105.31 & 9.28 & 12.81 \\
\hline 1625 & 3 & 3017 & 210.07 & 92.88 & 2081 & 219.40 & 105.14 & 9.33 & 12.25 \\
\hline 1626 & 3 & 3025 & 210.16 & 92.26 & 2082 & 219.27 & 105.11 & 9.11 & 12.85 \\
\hline 1627 & 3 & 3026 & 210.12 & 92.04 & 2083 & 219.32 & 105.26 & 9.20 & 13.22 \\
\hline 1628 & 3 & 3027 & 210.14 & 91.80 & 2084 & 219.27 & 104.93 & 9.12 & 13.12 \\
\hline 1629 & 3 & 3028 & 210.18 & 91.78 & 2085 & 219.30 & 104.68 & 9.11 & 12.90 \\
\hline 1630 & 3 & 3032 & 210.06 & 91.92 & 2087 & 219.23 & 104.66 & 9.17 & 12.73 \\
\hline 1631 & 3 & 3033 & 210.11 & 91.90 & 2088 & 219.28 & 104.56 & 9.17 & 12.66 \\
\hline 1632 & 3 & 3037 & 209.85 & 92.08 & 2091 & 219.33 & 104.06 & 9.47 & 11.97 \\
\hline 1633 & 3 & 3038 & 209.86 & 91.81 & 2092 & 219.31 & 104.03 & 9.45 & 12.22 \\
\hline 1634 & 3 & 3040 & 209.83 & 91.82 & 2093 & 219.33 & 104.56 & 9.50 & 12.75 \\
\hline 1635 & 3 & 3041 & 209.93 & 91.87 & 2094 & 219.35 & 104.36 & 9.42 & 12.49 \\
\hline 1636 & 3 & 3045 & 210.01 & 92.20 & 2096 & 219.30 & 104.31 & 9.29 & 12.11 \\
\hline 1637 & 3 & 3047 & 209.98 & 92.33 & 2097 & 219.31 & 104.58 & 9.33 & 12.25 \\
\hline 1638 & 3 & 3049 & 210.06 & 92.19 & 2098 & 219.37 & 104.56 & 9.30 & 12.37 \\
\hline 1639 & 3 & 3050 & 210.04 & 91.82 & 2099 & 219.30 & 104.66 & 9.26 & 12.84 \\
\hline 1640 & 3 & 3051 & 209.94 & 92.09 & 2100 & 219.29 & 104.60 & 9.35 & 12.50 \\
\hline 1641 & 3 & 3054 & 209.95 & 91.84 & 2101 & 219.34 & 104.32 & 9.39 & 12.49 \\
\hline 1642 & 3 & 3055 & 209.89 & 91.97 & 2102 & 219.26 & 104.37 & 9.37 & 12.41 \\
\hline 1643 & 3 & 3057 & 209.80 & 91.88 & 2103 & 219.24 & 104.25 & 9.43 & 12.38 \\
\hline 1644 & 3 & 3062 & 209.75 & 91.57 & 2105 & 219.13 & 104.45 & 9.38 & 12.88 \\
\hline 1645 & 3 & 3060 & 209.75 & 91.75 & 2106 & 219.28 & 104.75 & 9.53 & 13.00 \\
\hline 1646 & 3 & 3061 & 209.76 & 91.47 & 2107 & 219.19 & 104.43 & 9.42 & 12.97 \\
\hline 1647 & 3 & 3065 & 209.78 & 91.26 & 2109 & 219.25 & 104.38 & 9.47 & 13.12 \\
\hline 1648 & 3 & 3066 & 209.83 & 91.60 & 2110 & 219.22 & 104.43 & 9.38 & 12.83 \\
\hline 1649 & 3 & 3069 & 209.85 & 91.53 & 2111 & 219.25 & 104.27 & 9.39 & 12.74 \\
\hline 1650 & 3 & 3073 & 209.90 & 91.04 & 2112 & 219.34 & 104.58 & 9.45 & 13.54 \\
\hline 1651 & 3 & 3074 & 209.91 & 91.22 & 2113 & 219.22 & 104.39 & 9.31 & 13.17 \\
\hline 1652 & 3 & 3080 & 209.89 & 91.34 & 2114 & 219.18 & 104.45 & 9.29 & 13.10 \\
\hline 1653 & 3 & 3075 & 209.92 & 91.52 & 2115 & 219.14 & 104.44 & 9.22 & 12.92 \\
\hline 1654 & 3 & 3076 & 209.95 & 91.71 & 2116 & 219.17 & 104.16 & 9.22 & 12.45 \\
\hline 1655 & 3 & 3077 & 209.93 & 91.60 & 2117 & 219.12 & 103.99 & 9.18 & 12.39 \\
\hline 1656 & 3 & 3078 & 209.95 & 91.35 & 2118 & 219.19 & 103.96 & 9.24 & 12.61 \\
\hline 1657 & 3 & 3081 & 209.89 & 91.15 & 2119 & 218.99 & 103.93 & 9.11 & 12.78 \\
\hline 1658 & 3 & 3082 & 209.87 & 91.18 & 2120 & 218.97 & 104.22 & 9.11 & 13.05 \\
\hline 1659 & 3 & 3085 & 209.94 & 91.29 & 2121 & 218.96 & 104.09 & 9.02 & 12.80 \\
\hline 1660 & 3 & 3086 & 209.88 & 91.35 & 2123 & 218.89 & 104.13 & 9.01 & 12.78 \\
\hline 1661 & 3 & 3087 & 209.77 & 91.41 & 2124 & 219.03 & 104.04 & 9.26 & 12.62 \\
\hline 1662 & 3 & 3092 & 209.73 & 91.24 & 2125 & 219.17 & 103.95 & 9.44 & 12.70 \\
\hline 1663 & 3 & 3093 & 209.71 & 91.13 & 2126 & 219.10 & 104.25 & 9.39 & 13.12 \\
\hline
\end{tabular}




\begin{tabular}{|c|c|c|c|c|c|c|c|c|c|}
\hline obs & $\mathbf{T}$ & $\begin{array}{l}\text { B260 } \\
\text { year }\end{array}$ & $\begin{array}{c}\text { driving } \\
\text { stress } \\
(\mathbf{k P a}) \\
\end{array}$ & $\begin{array}{c}\text { flux } \\
\left(\mathbf{k m}^{\mathbf{3}} \mathbf{a}^{-1}\right)\end{array}$ & $\begin{array}{l}\text { B270 } \\
\text { year }\end{array}$ & $\begin{array}{l}\text { driving } \\
\text { stress } \\
(\mathbf{k P a})\end{array}$ & $\begin{array}{c}\text { flux } \\
\left(\mathbf{k m}^{3} \mathbf{a}^{-1}\right)\end{array}$ & $\begin{array}{c}\Delta \text { driving } \\
\text { stress } \\
(\mathbf{k P a}) \\
\end{array}$ & $\underset{\left(\mathbf{k m}^{3} \mathbf{a}^{-1)}\right.}{\Delta \text { flux }}$ \\
\hline 1664 & 3 & 3094 & 209.74 & 91.12 & 2127 & 219.26 & 104.35 & 9.52 & 13.23 \\
\hline 1665 & 3 & 3096 & 209.65 & 90.84 & 2128 & 219.06 & 104.64 & 9.40 & 13.81 \\
\hline 1666 & 3 & 3097 & 209.67 & 90.95 & 2129 & 219.09 & 104.41 & 9.42 & 13.46 \\
\hline 1667 & 3 & 3098 & 209.64 & 90.84 & 2130 & 219.01 & 104.51 & 9.37 & 13.66 \\
\hline 1668 & 3 & 3099 & 209.65 & 90.71 & 2131 & 219.06 & 104.21 & 9.41 & 13.50 \\
\hline 1669 & 3 & 3100 & 209.65 & 90.65 & 2132 & 219.05 & 103.83 & 9.40 & 13.19 \\
\hline 1670 & 3 & 3101 & 209.54 & 90.43 & 2133 & 219.05 & 103.77 & 9.52 & 13.34 \\
\hline 1671 & 3 & 3102 & 209.58 & 90.43 & 2134 & 219.10 & 103.80 & 9.53 & 13.37 \\
\hline 1672 & 3 & 3108 & 209.59 & 90.10 & 2135 & 218.84 & 103.70 & 9.25 & 13.61 \\
\hline 1673 & 3 & 3109 & 209.56 & 90.21 & 2136 & 218.76 & 103.28 & 9.20 & 13.07 \\
\hline 1674 & 3 & 3110 & 209.55 & 90.30 & 2137 & 218.77 & 103.32 & 9.22 & 13.02 \\
\hline 1675 & 3 & 3111 & 209.57 & 90.17 & 2138 & 219.04 & 103.39 & 9.48 & 13.22 \\
\hline 1676 & 3 & 3112 & 209.56 & 90.27 & 2139 & 218.98 & 103.50 & 9.42 & 13.24 \\
\hline 1677 & 3 & 3122 & 209.46 & 90.07 & 2143 & 218.91 & 103.60 & 9.44 & 13.53 \\
\hline 1678 & 3 & 3125 & 209.49 & 90.22 & 2144 & 218.80 & 103.49 & 9.31 & 13.28 \\
\hline 1679 & 3 & 3126 & 209.51 & 89.99 & 2145 & 218.75 & 104.12 & 9.24 & 14.13 \\
\hline 1680 & 3 & 3127 & 209.50 & 89.88 & 2146 & 218.75 & 103.77 & 9.25 & 13.89 \\
\hline 1681 & 3 & 3128 & 209.49 & 89.97 & 2147 & 218.79 & 103.77 & 9.30 & 13.79 \\
\hline 1682 & 3 & 3132 & 209.55 & 90.19 & 2148 & 218.61 & 103.95 & 9.07 & 13.76 \\
\hline 1683 & 3 & 3135 & 209.48 & 90.66 & 2150 & 218.55 & 103.97 & 9.08 & 13.31 \\
\hline 1684 & 3 & 3152 & 209.11 & 90.56 & 2151 & 218.57 & 103.94 & 9.46 & 13.38 \\
\hline 1685 & 3 & 3153 & 209.18 & 90.53 & 2152 & 218.56 & 103.79 & 9.38 & 13.26 \\
\hline 1686 & 3 & 3154 & 209.20 & 90.43 & 2153 & 218.51 & 103.96 & 9.31 & 13.53 \\
\hline 1687 & 3 & 3155 & 209.16 & 90.50 & 2154 & 218.64 & 103.88 & 9.48 & 13.37 \\
\hline 1688 & 3 & 3141 & 209.44 & 90.50 & 2155 & 218.54 & 104.08 & 9.10 & 13.58 \\
\hline 1689 & 3 & 3148 & 209.15 & 91.03 & 2156 & 218.52 & 103.60 & 9.37 & 12.56 \\
\hline 1690 & 3 & 3149 & 209.33 & 90.44 & 2157 & 218.62 & 103.91 & 9.28 & 13.47 \\
\hline 1691 & 3 & 3150 & 209.27 & 90.30 & 2158 & 218.55 & 103.52 & 9.29 & 13.22 \\
\hline 1692 & 3 & 3151 & 209.17 & 90.54 & 2159 & 218.57 & 103.62 & 9.40 & 13.08 \\
\hline 1693 & 3 & 3156 & 209.16 & 90.20 & 2165 & 218.54 & 103.57 & 9.38 & 13.37 \\
\hline 1694 & 3 & 3157 & 209.13 & 90.28 & 2166 & 218.57 & 103.65 & 9.44 & 13.37 \\
\hline 1695 & 3 & 3158 & 209.14 & 90.39 & 2167 & 218.53 & 103.67 & 9.39 & 13.28 \\
\hline 1696 & 3 & 3161 & 209.09 & 90.67 & 2170 & 218.49 & 103.91 & 9.40 & 13.24 \\
\hline 1697 & 3 & 3162 & 209.18 & 90.58 & 2171 & 218.54 & 103.44 & 9.36 & 12.86 \\
\hline 1698 & 3 & 3181 & 208.94 & 90.16 & 2172 & 218.47 & 103.53 & 9.53 & 13.36 \\
\hline 1699 & 3 & 3166 & 209.15 & 90.75 & 2174 & 218.31 & 103.31 & 9.16 & 12.56 \\
\hline 1700 & 3 & 3167 & 209.03 & 90.64 & 2175 & 218.44 & 103.26 & 9.41 & 12.62 \\
\hline 1701 & 3 & 3168 & 209.13 & 90.90 & 2176 & 218.54 & 102.95 & 9.41 & 12.04 \\
\hline 1702 & 3 & 3171 & 208.84 & 90.39 & 2177 & 218.36 & 103.01 & 9.52 & 12.62 \\
\hline 1703 & 3 & 3180 & 208.89 & 90.43 & 2180 & 218.34 & 103.20 & 9.45 & 12.77 \\
\hline
\end{tabular}




\begin{tabular}{|c|c|c|c|c|c|c|c|c|c|}
\hline obs & $\mathbf{T}$ & $\begin{array}{l}\text { B260 } \\
\text { year }\end{array}$ & $\begin{array}{c}\text { driving } \\
\text { stress } \\
(\mathbf{k P a})\end{array}$ & $\underset{\left(\mathbf{k m}^{3} \mathbf{a}^{-1}\right)}{\text { flux }}$ & $\begin{array}{l}\text { B270 } \\
\text { year }\end{array}$ & $\begin{array}{l}\text { driving } \\
\text { stress } \\
(\mathbf{k P a})\end{array}$ & $\underset{\left(\mathbf{k m}^{3} \mathbf{a}^{-1}\right)}{\text { flux }}$ & $\begin{array}{c}\Delta \text { driving } \\
\text { stress } \\
(\mathbf{k P a})\end{array}$ & $\begin{array}{c}\Delta \mathbf{f l u x}^{3} \\
\left(\mathbf{k m}^{3} \mathbf{a}^{-1)}\right.\end{array}$ \\
\hline 1704 & 3 & 3186 & 208.87 & 89.76 & 2181 & 218.31 & 102.94 & 9.44 & 13.18 \\
\hline 1705 & 3 & 3177 & 208.84 & 90.66 & 2182 & 218.18 & 102.77 & 9.34 & 12.11 \\
\hline 1706 & 3 & 3178 & 208.88 & 90.17 & 2183 & 218.33 & 102.67 & 9.45 & 12.50 \\
\hline 1707 & 3 & 3187 & 208.89 & 89.40 & 2184 & 218.34 & 102.47 & 9.45 & 13.07 \\
\hline 1708 & 3 & 3188 & 208.80 & 89.44 & 2185 & 218.29 & 102.74 & 9.49 & 13.30 \\
\hline 1709 & 3 & 3189 & 208.80 & 89.45 & 2186 & 218.27 & 102.64 & 9.48 & 13.18 \\
\hline 1710 & 3 & 3163 & 209.14 & 90.84 & 2187 & 218.26 & 102.60 & 9.12 & 11.76 \\
\hline 1711 & 3 & 3205 & 208.79 & 89.61 & 2188 & 218.27 & 102.21 & 9.47 & 12.60 \\
\hline 1712 & 3 & 3182 & 208.94 & 90.18 & 2189 & 218.27 & 102.31 & 9.33 & 12.13 \\
\hline 1713 & 3 & 3172 & 208.83 & 90.48 & 2190 & 218.21 & 102.09 & 9.39 & 11.61 \\
\hline 1714 & 3 & 3173 & 208.84 & 90.50 & 2191 & 218.19 & 102.39 & 9.35 & 11.90 \\
\hline 1715 & 3 & 3174 & 208.81 & 90.35 & 2192 & 218.19 & 102.63 & 9.38 & 12.28 \\
\hline 1716 & 3 & 3175 & 208.83 & 90.53 & 2193 & 218.10 & 102.73 & 9.27 & 12.20 \\
\hline 1717 & 3 & 3137 & 209.50 & 90.60 & 2194 & 218.03 & 102.42 & 8.52 & 11.82 \\
\hline
\end{tabular}




\section{Appendix B Experiment 2 Summary Table}

Driving stress and flux across the grounding line summarized for each co-located observation in experiment 2. Column1 is the observation number. Column 2 is the transect (T) used to determine co-location for the given observation. Column 3 is the year of the B270 simulation that corresponds to the observation. Column 4 is the mean driving stress of the B270 simulation's ROI with units of $\mathrm{kPa}$. Column 5 is the flux across the grounding line for the B270 simulation in units of $\mathrm{km}^{3} \mathrm{a}^{-1}$. Columns 6 through 8 are the G425 simulation equivalents of columns 3 through 5. Column 9 is the difference in driving stress calculated as $\mathbf{G 4 2 5}$ minus B270 with units of $\mathrm{kPa}$. Column 10 is the difference in flux across the grounding line in units of $\mathbf{k m}^{3} \mathrm{a}^{-1}$ and calculated as G425 minus G425.

\begin{tabular}{cc|ccc|ccc|cc} 
obs & T & $\begin{array}{c}\text { B270 } \\
\text { year }\end{array}$ & $\begin{array}{c}\text { driving } \\
\text { stress } \\
(\mathbf{k P a})\end{array}$ & $\begin{array}{c}\text { flux } \\
\left(\mathbf{k m}^{3} \mathbf{a}^{-1}\right)\end{array}$ & $\begin{array}{c}\text { G425 } \\
\text { year }\end{array}$ & $\begin{array}{c}\text { driving } \\
\text { stress } \\
(\mathbf{k P a})\end{array}$ & $\begin{array}{c}\text { flux } \\
\left(\mathbf{k m}^{3} \mathbf{a}^{-1}\right)\end{array}$ & $\begin{array}{c}\Delta \text { driving } \\
\text { stress } \\
(\mathbf{k P a})\end{array}$ & $\begin{array}{c}\Delta \mathbf{\Delta f l u x} \\
\left(\mathbf{k m}^{3} \mathbf{a}^{-1}\right)\end{array}$ \\
\hline 1 & 4 & 659 & 130.12 & 171.13 & 426 & 131.01 & 408.85 & 0.89 & 237.72 \\
2 & 1 & 665 & 130.71 & 169.93 & 428 & 132.29 & 399.66 & 1.58 & 229.73 \\
3 & 1 & 668 & 130.86 & 169.55 & 429 & 132.71 & 394.86 & 1.86 & 225.31 \\
4 & 1 & 673 & 131.21 & 168.99 & 430 & 133.35 & 384.42 & 2.14 & 215.43 \\
5 & 1 & 706 & 134.32 & 168.6 & 443 & 138.61 & 314.54 & 4.29 & 145.94 \\
6 & 1 & 708 & 134.55 & 169.48 & 444 & 138.93 & 307.39 & 4.38 & 137.92 \\
7 & 1 & 741 & 137.95 & 166.71 & 490 & 147.08 & 241.04 & 9.14 & 74.33 \\
8 & 1 & 743 & 138.14 & 167.42 & 491 & 147.36 & 241.5 & 9.22 & 74.08 \\
9 & 1 & 744 & 138.22 & 167.18 & 492 & 147.5 & 241.78 & 9.27 & 74.59 \\
10 & 1 & 745 & 138.33 & 166.92 & 493 & 147.6 & 241.15 & 9.28 & 74.24 \\
11 & 1 & 746 & 138.45 & 166.41 & 494 & 147.62 & 240.44 & 9.17 & 74.03 \\
12 & 1 & 756 & 139.5 & 165.23 & 495 & 147.72 & 240.19 & 8.22 & 74.96 \\
13 & 1 & 778 & 142.22 & 171.05 & 510 & 150.76 & 234.59 & 8.53 & 63.54 \\
14 & 1 & 779 & 142.35 & 171.06 & 511 & 150.71 & 233.64 & 8.36 & 62.58 \\
15 & 1 & 780 & 142.51 & 170.77 & 512 & 150.97 & 233.9 & 8.46 & 63.13 \\
16 & 1 & 781 & 142.63 & 170.58 & 513 & 151.17 & 232.35 & 8.54 & 61.77 \\
17 & 1 & 787 & 143.38 & 170.64 & 519 & 152.31 & 228.28 & 8.93 & 57.64 \\
18 & 1 & 788 & 143.53 & 170.42 & 520 & 152.53 & 227.63 & 9.01 & 57.21 \\
19 & 1 & 789 & 143.63 & 170.3 & 521 & 152.46 & 227.55 & 8.83 & 57.25 \\
20 & 1 & 790 & 143.75 & 170.79 & 523 & 152.73 & 225.07 & 8.99 & 54.29 \\
21 & 1 & 791 & 143.94 & 170.76 & 524 & 152.99 & 224.3 & 9.05 & 53.53 \\
22 & 2 & 804 & 145.49 & 169.74 & 525 & 153.07 & 224.72 & 7.58 & 54.98 \\
23 & 4 & 820 & 147.07 & 162.69 & 527 & 153.29 & 223.9 & 6.22 & 61.21 \\
& & & & & & & & &
\end{tabular}




\begin{tabular}{|c|c|c|c|c|c|c|c|c|c|}
\hline obs & $\mathbf{T}$ & $\begin{array}{l}\text { B270 } \\
\text { year }\end{array}$ & $\begin{array}{l}\text { driving } \\
\text { stress } \\
(\mathbf{k P a})\end{array}$ & $\underset{\left(\mathbf{k m}^{3} \mathbf{a}^{-1}\right)}{\text { flux }}$ & $\begin{array}{l}\text { G425 } \\
\text { year }\end{array}$ & $\begin{array}{l}\text { driving } \\
\text { stress } \\
(\mathbf{k P a})\end{array}$ & $\underset{\left(\mathbf{k m}^{3} \mathbf{a}^{-1}\right)}{\text { flux }}$ & $\begin{array}{c}\Delta \text { driving } \\
\text { stress } \\
(\mathbf{k P a})\end{array}$ & $\underset{\left(\mathbf{k m}^{3} \mathbf{a}^{-1}\right)}{\Delta \text { flux }}$ \\
\hline 24 & 4 & 823 & 147.43 & 163.18 & 530 & 153.75 & 220.46 & 6.33 & 57.28 \\
\hline 25 & 2 & 827 & 147.82 & 162.99 & 538 & 154.57 & 215.64 & 6.75 & 52.65 \\
\hline 26 & 2 & 828 & 147.99 & 162.51 & 539 & 154.73 & 216.89 & 6.74 & 54.37 \\
\hline 27 & 2 & 829 & 148.05 & 162.17 & 540 & 154.87 & 215.92 & 6.83 & 53.75 \\
\hline 28 & 2 & 831 & 148.26 & 162.18 & 543 & 155.4 & 215.94 & 7.14 & 53.77 \\
\hline 29 & 2 & 832 & 148.4 & 161.7 & 544 & 155.5 & 215.36 & 7.1 & 53.66 \\
\hline 30 & 2 & 833 & 148.51 & 161.27 & 545 & 155.6 & 214.14 & 7.1 & 52.87 \\
\hline 31 & 2 & 837 & 148.87 & 161.3 & 549 & 156.06 & 212.64 & 7.19 & 51.34 \\
\hline 32 & 2 & 854 & 150.58 & 157.21 & 564 & 158.49 & 203.72 & 7.9 & 46.51 \\
\hline 33 & 2 & 855 & 150.74 & 156.92 & 565 & 158.76 & 202.46 & 8.03 & 45.55 \\
\hline 34 & 2 & 858 & 151.13 & 157.6 & 569 & 159.37 & 200.18 & 8.24 & 42.58 \\
\hline 35 & 2 & 859 & 151.26 & 157.31 & 572 & 159.72 & 196.84 & 8.47 & 39.53 \\
\hline 36 & 2 & 860 & 151.34 & 157.11 & 573 & 159.84 & 196.34 & 8.5 & 39.24 \\
\hline 37 & 2 & 861 & 151.48 & 156.55 & 574 & 159.94 & 196.12 & 8.46 & 39.57 \\
\hline 38 & 2 & 877 & 153.74 & 153.04 & 575 & 160.05 & 195.32 & 6.32 & 42.27 \\
\hline 39 & 2 & 878 & 153.85 & 152.67 & 577 & 160.2 & 194.24 & 6.35 & 41.57 \\
\hline 40 & 2 & 879 & 153.97 & 152.57 & 578 & 160.25 & 193.71 & 6.28 & 41.14 \\
\hline 41 & 2 & 880 & 154.1 & 152.61 & 579 & 160.35 & 192.95 & 6.25 & 40.34 \\
\hline 42 & 2 & 881 & 154.18 & 152.31 & 580 & 160.52 & 193.28 & 6.34 & 40.97 \\
\hline 43 & 2 & 882 & 154.33 & 152.36 & 581 & 160.71 & 192.71 & 6.38 & 40.34 \\
\hline 44 & 2 & 1097 & 176.76 & 128.21 & 747 & 185.47 & 167.6 & 8.7 & 39.39 \\
\hline 45 & 2 & 1130 & 180.54 & 129.43 & 760 & 188.1 & 166.77 & 7.57 & 37.33 \\
\hline 46 & 2 & 1142 & 181.68 & 128.96 & 770 & 189.98 & 164.16 & 8.3 & 35.19 \\
\hline 47 & 2 & 1143 & 181.75 & 128.8 & 771 & 190.19 & 164.3 & 8.44 & 35.5 \\
\hline 48 & 2 & 1152 & 182.31 & 127.82 & 780 & 191.69 & 162.68 & 9.37 & 34.86 \\
\hline 49 & 2 & 1153 & 182.43 & 127.63 & 781 & 191.9 & 162.63 & 9.47 & 35 \\
\hline 50 & 2 & 1157 & 182.91 & 127.01 & 787 & 192.74 & 159.85 & 9.83 & 32.85 \\
\hline 51 & 2 & 1158 & 183.02 & 127.19 & 788 & 192.94 & 159.81 & 9.92 & 32.62 \\
\hline 52 & 2 & 1179 & 184.16 & 125.06 & 800 & 194.53 & 158.1 & 10.36 & 33.05 \\
\hline 53 & 1 & 1179 & 184.16 & 125.06 & 819 & 197.5 & 158.85 & 13.34 & 33.8 \\
\hline 54 & 1 & 1180 & 184.21 & 125.3 & 820 & 197.7 & 158.69 & 13.49 & 33.4 \\
\hline 55 & 1 & 1181 & 184.25 & 125.36 & 821 & 197.73 & 158.42 & 13.48 & 33.06 \\
\hline 56 & 1 & 1186 & 184.62 & 125.55 & 823 & 198.09 & 158.26 & 13.47 & 32.71 \\
\hline 57 & 1 & 1187 & 184.77 & 125.74 & 824 & 198.22 & 158.31 & 13.45 & 32.57 \\
\hline 58 & 1 & 1188 & 184.82 & 125.84 & 826 & 198.58 & 158.3 & 13.76 & 32.47 \\
\hline 59 & 1 & 1189 & 184.97 & 126.3 & 827 & 198.75 & 158.19 & 13.78 & 31.88 \\
\hline 60 & 1 & 1191 & 185.22 & 126 & 828 & 198.98 & 158.24 & 13.76 & 32.23 \\
\hline 61 & 2 & 1226 & 188.2 & 123.51 & 829 & 199.16 & 158.1 & 10.96 & 34.59 \\
\hline 62 & 1 & 1231 & 188.48 & 122.3 & 846 & 202.26 & 158.25 & 13.79 & 35.95 \\
\hline 63 & 1 & 1241 & 189.07 & 120.13 & 847 & 202.28 & 158.86 & 13.22 & 38.73 \\
\hline
\end{tabular}




\begin{tabular}{|c|c|c|c|c|c|c|c|c|c|}
\hline obs & $\mathbf{T}$ & $\begin{array}{l}\text { B270 } \\
\text { year }\end{array}$ & $\begin{array}{l}\text { driving } \\
\text { stress } \\
(\mathbf{k P a})\end{array}$ & $\begin{array}{c}\text { flux } \\
\left(\mathbf{k m}^{3} \mathbf{a}^{-1}\right)\end{array}$ & $\begin{array}{l}\text { G425 } \\
\text { year }\end{array}$ & $\begin{array}{l}\text { driving } \\
\text { stress } \\
(\mathbf{k P a})\end{array}$ & $\underset{\left(\mathbf{k m}^{3} \mathbf{a}^{-1}\right)}{\text { flux }}$ & $\begin{array}{c}\Delta \text { driving } \\
\text { stress } \\
(\mathbf{k P a})\end{array}$ & $\underset{\left(\mathbf{k m}^{3} \mathbf{a}^{-1}\right)}{\Delta f l u x}$ \\
\hline 64 & 1 & 1242 & 189.13 & 120.63 & 848 & 202.44 & 158.46 & 13.31 & 37.83 \\
\hline 65 & 1 & 1263 & 190.13 & 119.76 & 849 & 202.56 & 158.1 & 12.43 & 38.34 \\
\hline 66 & 1 & 1264 & 190.21 & 119.72 & 850 & 202.61 & 158.15 & 12.4 & 38.43 \\
\hline 67 & 1 & 1266 & 190.31 & 119.58 & 852 & 203.01 & 159.25 & 12.7 & 39.67 \\
\hline 68 & 1 & 1284 & 191.18 & 119.02 & 853 & 203.24 & 159.27 & 12.06 & 40.25 \\
\hline 69 & 1 & 1292 & 191.68 & 118.98 & 854 & 203.35 & 158.92 & 11.67 & 39.94 \\
\hline 70 & 1 & 1293 & 191.66 & 118.95 & 855 & 203.69 & 158.2 & 12.03 & 39.25 \\
\hline 71 & 1 & 1294 & 191.78 & 118.93 & 856 & 203.78 & 157.63 & 12 & 38.7 \\
\hline 72 & 1 & 1295 & 191.89 & 118.7 & 857 & 204.05 & 157.52 & 12.16 & 38.83 \\
\hline 73 & 1 & 1296 & 191.96 & 118.92 & 858 & 204.25 & 156.8 & 12.29 & 37.88 \\
\hline 74 & 1 & 1297 & 191.88 & 119.18 & 859 & 204.46 & 156.59 & 12.59 & 37.4 \\
\hline 75 & 1 & 1302 & 192.06 & 119.34 & 860 & 204.7 & 156.87 & 12.64 & 37.54 \\
\hline 76 & 1 & 1303 & 192.01 & 119.2 & 861 & 204.65 & 155.53 & 12.64 & 36.32 \\
\hline 77 & 1 & 1304 & 192.1 & 118.93 & 862 & 204.79 & 154.71 & 12.68 & 35.78 \\
\hline 78 & 1 & 1305 & 192.19 & 118.22 & 863 & 204.85 & 155.68 & 12.67 & 37.46 \\
\hline 79 & 2 & 1306 & 192.3 & 118.39 & 891 & 207.82 & 151.52 & 15.52 & 33.13 \\
\hline 80 & 2 & 1308 & 192.39 & 118.34 & 892 & 208.05 & 151.59 & 15.66 & 33.24 \\
\hline 81 & 2 & 1309 & 192.46 & 118.58 & 893 & 208.13 & 151.68 & 15.67 & 33.1 \\
\hline 82 & 2 & 1310 & 192.55 & 118.38 & 895 & 208.44 & 152.01 & 15.89 & 33.64 \\
\hline 83 & 2 & 1311 & 192.64 & 118.31 & 896 & 208.52 & 151.98 & 15.88 & 33.67 \\
\hline 84 & 2 & 1312 & 192.68 & 118.51 & 897 & 208.75 & 152.39 & 16.06 & 33.88 \\
\hline 85 & 2 & 1313 & 192.72 & 118.02 & 898 & 208.83 & 152.15 & 16.11 & 34.13 \\
\hline 86 & 1 & 1357 & 194.82 & 114.57 & 919 & 211.42 & 149.08 & 16.6 & 34.51 \\
\hline 87 & 1 & 1358 & 194.9 & 114.64 & 920 & 211.55 & 149.04 & 16.66 & 34.39 \\
\hline 88 & 1 & 1359 & 194.93 & 114.62 & 921 & 211.73 & 149.06 & 16.79 & 34.44 \\
\hline 89 & 1 & 1387 & 195.87 & 113.05 & 925 & 212.23 & 149.8 & 16.37 & 36.75 \\
\hline 90 & 2 & 1388 & 195.89 & 112.99 & 929 & 213.01 & 149.14 & 17.12 & 36.15 \\
\hline 91 & 2 & 1389 & 195.94 & 112.99 & 930 & 213.1 & 149.48 & 17.16 & 36.49 \\
\hline 92 & 2 & 1390 & 196.04 & 112.83 & 931 & 213.2 & 149.66 & 17.16 & 36.83 \\
\hline 93 & 2 & 1391 & 196.07 & 112.25 & 932 & 213.17 & 149.8 & 17.1 & 37.55 \\
\hline 94 & 1 & 1412 & 196.96 & 112.58 & 935 & 213.75 & 148.85 & 16.79 & 36.27 \\
\hline 95 & 1 & 1415 & 197.18 & 112.72 & 936 & 213.9 & 148.97 & 16.72 & 36.25 \\
\hline 96 & 1 & 1418 & 197.22 & 112.97 & 937 & 213.97 & 148.94 & 16.74 & 35.97 \\
\hline 97 & 1 & 1420 & 197.41 & 112.96 & 938 & 214.24 & 149.03 & 16.83 & 36.07 \\
\hline 98 & 2 & 1425 & 197.67 & 112.63 & 940 & 214.57 & 149.74 & 16.9 & 37.11 \\
\hline 99 & 2 & 1438 & 198.42 & 115.89 & 942 & 214.85 & 149.72 & 16.44 & 33.83 \\
\hline 100 & 4 & 1444 & 198.77 & 116.69 & 945 & 215.09 & 149.06 & 16.32 & 32.37 \\
\hline 101 & 4 & 1477 & 201.15 & 117.91 & 965 & 217.87 & 148.36 & 16.72 & 30.45 \\
\hline 102 & 4 & 1479 & 201.47 & 118.04 & 966 & 217.85 & 149.14 & 16.38 & 31.11 \\
\hline 103 & 4 & 1490 & 202.85 & 119.74 & 987 & 221.02 & 145.12 & 18.17 & 25.38 \\
\hline
\end{tabular}




\begin{tabular}{|c|c|c|c|c|c|c|c|c|c|}
\hline obs & $\mathbf{T}$ & $\begin{array}{l}\text { B270 } \\
\text { year }\end{array}$ & $\begin{array}{l}\text { driving } \\
\text { stress } \\
(\mathbf{k P a})\end{array}$ & $\begin{array}{c}\text { flux } \\
\left(\mathbf{k m}^{3} \mathbf{a}^{-1}\right)\end{array}$ & $\begin{array}{l}\text { G425 } \\
\text { year }\end{array}$ & $\begin{array}{l}\text { driving } \\
\text { stress } \\
(\mathbf{k P a})\end{array}$ & $\underset{\left(\mathbf{k m}^{3} \mathbf{a}^{-1}\right)}{\text { flux }}$ & $\begin{array}{c}\Delta \text { driving } \\
\text { stress } \\
(\mathbf{k P a})\end{array}$ & $\underset{\left(\mathbf{k m}^{3} \mathbf{a}^{-1}\right)}{\Delta \text { flux }}$ \\
\hline 104 & 4 & 1497 & 203.57 & 119.32 & 989 & 221.06 & 144.98 & 17.49 & 25.66 \\
\hline 105 & 4 & 1498 & 203.62 & 119.41 & 992 & 221.66 & 145.21 & 18.04 & 25.8 \\
\hline 106 & 1 & 1498 & 203.62 & 119.41 & 997 & 222.03 & 146.26 & 18.41 & 26.86 \\
\hline 107 & 1 & 1500 & 203.88 & 119.54 & 998 & 222.24 & 145.91 & 18.37 & 26.37 \\
\hline 108 & 1 & 1505 & 204.27 & 119.97 & 999 & 222.39 & 146.12 & 18.12 & 26.15 \\
\hline 109 & 1 & 1508 & 204.56 & 120.24 & 1000 & 222.28 & 146.26 & 17.72 & 26.01 \\
\hline 110 & 1 & 1510 & 204.8 & 120.6 & 1001 & 222.52 & 146.23 & 17.73 & 25.63 \\
\hline 111 & 1 & 1511 & 205.01 & 120.44 & 1002 & 222.75 & 146.02 & 17.73 & 25.58 \\
\hline 112 & 1 & 1515 & 205.26 & 120.67 & 1003 & 222.91 & 146.18 & 17.66 & 25.51 \\
\hline 113 & 1 & 1517 & 205.38 & 120.23 & 1004 & 223.09 & 146.7 & 17.71 & 26.47 \\
\hline 114 & 1 & 1519 & 205.3 & 121.22 & 1005 & 223.26 & 146.74 & 17.96 & 25.52 \\
\hline 115 & 1 & 1521 & 205.7 & 121.23 & 1006 & 223.33 & 146.47 & 17.63 & 25.25 \\
\hline 116 & 1 & 1522 & 205.71 & 121.58 & 1007 & 223.36 & 145.95 & 17.65 & 24.38 \\
\hline 117 & 1 & 1523 & 205.84 & 122.23 & 1008 & 223.52 & 145.78 & 17.68 & 23.55 \\
\hline 118 & 1 & 1525 & 206.27 & 122.51 & 1009 & 223.62 & 145.11 & 17.36 & 22.6 \\
\hline 119 & 1 & 1527 & 206.45 & 122.3 & 1010 & 223.73 & 144.84 & 17.28 & 22.55 \\
\hline 120 & 1 & 1528 & 206.53 & 122.45 & 1011 & 223.89 & 144.82 & 17.36 & 22.37 \\
\hline 121 & 1 & 1529 & 206.67 & 122.58 & 1012 & 223.93 & 144.59 & 17.26 & 22.01 \\
\hline 122 & 1 & 1530 & 206.71 & 122.64 & 1013 & 224.18 & 144.41 & 17.48 & 21.77 \\
\hline 123 & 1 & 1531 & 206.93 & 122.4 & 1014 & 224.2 & 143.8 & 17.28 & 21.41 \\
\hline 124 & 1 & 1532 & 206.96 & 123.39 & 1015 & 224.52 & 143.52 & 17.56 & 20.13 \\
\hline 125 & 1 & 1538 & 207.67 & 122.47 & 1021 & 224.75 & 142.32 & 17.07 & 19.85 \\
\hline 126 & 1 & 1539 & 207.77 & 122.7 & 1022 & 224.74 & 142.7 & 16.97 & 20 \\
\hline 127 & 1 & 1541 & 208.05 & 123.3 & 1024 & 225.17 & 142.42 & 17.12 & 19.12 \\
\hline 128 & 1 & 1545 & 208.51 & 121.88 & 1027 & 225.51 & 141.81 & 17.01 & 19.93 \\
\hline 129 & 1 & 1547 & 208.67 & 121.91 & 1028 & 225.72 & 141.84 & 17.05 & 19.93 \\
\hline 130 & 1 & 1548 & 208.53 & 122.28 & 1029 & 225.87 & 142.5 & 17.34 & 20.22 \\
\hline 131 & 1 & 1549 & 208.67 & 122.62 & 1030 & 225.92 & 142.47 & 17.25 & 19.85 \\
\hline 132 & 1 & 1552 & 208.77 & 122.43 & 1031 & 225.98 & 142.17 & 17.22 & 19.73 \\
\hline 133 & 1 & 1553 & 208.78 & 122.15 & 1033 & 225.96 & 141.9 & 17.18 & 19.75 \\
\hline 134 & 1 & 1554 & 208.93 & 122.88 & 1034 & 226.13 & 141.7 & 17.2 & 18.83 \\
\hline 135 & 1 & 1555 & 209.01 & 122.33 & 1035 & 226.25 & 141.92 & 17.24 & 19.59 \\
\hline 136 & 1 & 1556 & 209.16 & 122.32 & 1036 & 226.36 & 141.82 & 17.2 & 19.5 \\
\hline 137 & 1 & 1558 & 209.26 & 121.99 & 1037 & 226.46 & 141.51 & 17.2 & 19.52 \\
\hline 138 & 1 & 1559 & 209.36 & 122.63 & 1038 & 226.65 & 141.52 & 17.29 & 18.89 \\
\hline 139 & 1 & 1560 & 209.41 & 122.65 & 1039 & 226.64 & 141.77 & 17.23 & 19.13 \\
\hline 140 & 1 & 1561 & 209.56 & 123.34 & 1040 & 226.76 & 141.89 & 17.2 & 18.54 \\
\hline 141 & 1 & 1562 & 209.71 & 122.78 & 1041 & 226.84 & 141.47 & 17.13 & 18.69 \\
\hline 142 & 1 & 1563 & 209.69 & 122.86 & 1042 & 227.07 & 141.76 & 17.38 & 18.9 \\
\hline 143 & 1 & 1564 & 209.52 & 123.32 & 1043 & 227.06 & 142.16 & 17.54 & 18.84 \\
\hline
\end{tabular}




\begin{tabular}{|c|c|c|c|c|c|c|c|c|c|}
\hline obs & $\mathbf{T}$ & $\begin{array}{l}\text { B270 } \\
\text { year }\end{array}$ & $\begin{array}{l}\text { driving } \\
\text { stress } \\
(\mathbf{k P a})\end{array}$ & $\begin{array}{c}\text { flux } \\
\left(\mathbf{k m}^{3} \mathbf{a}^{-1}\right)\end{array}$ & $\begin{array}{l}\text { G425 } \\
\text { year }\end{array}$ & $\begin{array}{l}\text { driving } \\
\text { stress } \\
(\mathbf{k P a})\end{array}$ & $\underset{\left(\mathbf{k m}^{3} \mathbf{a}^{-1}\right)}{\text { flux }}$ & $\begin{array}{c}\Delta \text { driving } \\
\text { stress } \\
(\mathbf{k P a})\end{array}$ & $\underset{\left(\mathbf{k m}^{3} \mathbf{a}^{-1}\right)}{\Delta f l u x}$ \\
\hline 144 & 1 & 1565 & 209.79 & 123.2 & 1044 & 227.05 & 141.91 & 17.25 & 18.71 \\
\hline 145 & 1 & 1568 & 209.93 & 122.64 & 1045 & 227.06 & 141.39 & 17.13 & 18.76 \\
\hline 146 & 1 & 1569 & 210.08 & 123.02 & 1046 & 227.08 & 141.23 & 17 & 18.21 \\
\hline 147 & 1 & 1570 & 210.31 & 122.99 & 1047 & 227.02 & 141.2 & 16.7 & 18.22 \\
\hline 148 & 4 & 1597 & 212.16 & 121.13 & 1049 & 226.98 & 140.79 & 14.82 & 19.66 \\
\hline 149 & 1 & 1597 & 212.16 & 121.13 & 1071 & 228.51 & 138.1 & 16.34 & 16.97 \\
\hline 150 & 1 & 1598 & 212.24 & 121.07 & 1072 & 228.47 & 137.84 & 16.22 & 16.78 \\
\hline 151 & 1 & 1600 & 212.35 & 121 & 1073 & 228.39 & 137.54 & 16.04 & 16.54 \\
\hline 152 & 1 & 1601 & 212.36 & 120.76 & 1074 & 228.7 & 138.37 & 16.34 & 17.61 \\
\hline 153 & 1 & 1602 & 212.37 & 120.67 & 1075 & 228.51 & 138.29 & 16.14 & 17.62 \\
\hline 154 & 1 & 1603 & 212.36 & 120.76 & 1076 & 228.54 & 139.01 & 16.19 & 18.25 \\
\hline 155 & 1 & 1605 & 212.44 & 120.47 & 1077 & 228.57 & 138.77 & 16.13 & 18.3 \\
\hline 156 & 1 & 1608 & 212.54 & 120.51 & 1078 & 228.73 & 138.35 & 16.18 & 17.85 \\
\hline 157 & 1 & 1609 & 212.56 & 120.78 & 1079 & 228.85 & 138.38 & 16.29 & 17.6 \\
\hline 158 & 1 & 1610 & 212.59 & 121.01 & 1080 & 228.82 & 138.03 & 16.24 & 17.02 \\
\hline 159 & 1 & 1614 & 212.95 & 120.68 & 1081 & 228.87 & 137.74 & 15.92 & 17.07 \\
\hline 160 & 1 & 1615 & 212.96 & 120.3 & 1082 & 228.91 & 137.46 & 15.95 & 17.15 \\
\hline 161 & 1 & 1616 & 213.09 & 120.63 & 1083 & 228.84 & 137.22 & 15.75 & 16.59 \\
\hline 162 & 1 & 1619 & 213.21 & 119.74 & 1084 & 228.86 & 137.61 & 15.65 & 17.87 \\
\hline 163 & 1 & 1620 & 213.23 & 119.74 & 1085 & 228.9 & 137.58 & 15.67 & 17.84 \\
\hline 164 & 1 & 1621 & 213.3 & 119.43 & 1086 & 229.17 & 137.53 & 15.87 & 18.09 \\
\hline 165 & 1 & 1622 & 213.37 & 119.45 & 1087 & 228.76 & 137.21 & 15.39 & 17.76 \\
\hline 166 & 1 & 1623 & 213.44 & 119.52 & 1088 & 229.06 & 137.71 & 15.62 & 18.2 \\
\hline 167 & 1 & 1626 & 213.79 & 119.41 & 1089 & 228.95 & 137.15 & 15.15 & 17.75 \\
\hline 168 & 1 & 1627 & 213.88 & 119.53 & 1090 & 229.18 & 136.69 & 15.3 & 17.15 \\
\hline 169 & 1 & 1628 & 213.97 & 119.53 & 1091 & 229.38 & 136.95 & 15.41 & 17.41 \\
\hline 170 & 1 & 1629 & 214.06 & 119.32 & 1092 & 229.52 & 136.73 & 15.46 & 17.41 \\
\hline 171 & 1 & 1630 & 214.12 & 119.44 & 1093 & 229.48 & 137.38 & 15.36 & 17.94 \\
\hline 172 & 1 & 1631 & 214.25 & 119.47 & 1094 & 229.53 & 136.84 & 15.27 & 17.37 \\
\hline 173 & 1 & 1633 & 214.45 & 119.12 & 1095 & 229.59 & 136.32 & 15.14 & 17.2 \\
\hline 174 & 1 & 1635 & 214.53 & 119.1 & 1096 & 229.61 & 135.7 & 15.08 & 16.61 \\
\hline 175 & 1 & 1636 & 214.49 & 119.43 & 1097 & 229.72 & 135.95 & 15.22 & 16.51 \\
\hline 176 & 1 & 1637 & 214.49 & 119.36 & 1098 & 229.62 & 135.44 & 15.14 & 16.08 \\
\hline 177 & 1 & 1638 & 214.45 & 118.91 & 1099 & 229.58 & 135.85 & 15.13 & 16.94 \\
\hline 178 & 1 & 1639 & 214.57 & 118.71 & 1100 & 229.73 & 135.99 & 15.15 & 17.28 \\
\hline 179 & 1 & 1640 & 214.69 & 118.74 & 1101 & 229.77 & 136.07 & 15.08 & 17.32 \\
\hline 180 & 1 & 1643 & 214.65 & 118.95 & 1102 & 229.96 & 135.89 & 15.32 & 16.95 \\
\hline 181 & 1 & 1644 & 214.86 & 118.27 & 1103 & 230 & 136.35 & 15.14 & 18.08 \\
\hline 182 & 1 & 1645 & 214.91 & 118.54 & 1104 & 229.97 & 136.12 & 15.05 & 17.58 \\
\hline 183 & 1 & 1646 & 214.9 & 117.85 & 1105 & 230.15 & 135.4 & 15.25 & 17.56 \\
\hline
\end{tabular}




\begin{tabular}{|c|c|c|c|c|c|c|c|c|c|}
\hline obs & $\mathbf{T}$ & $\begin{array}{l}\text { B270 } \\
\text { year }\end{array}$ & $\begin{array}{l}\text { driving } \\
\text { stress } \\
(\mathbf{k P a})\end{array}$ & $\underset{\left(\mathbf{k m}^{3} \mathbf{a}^{-1}\right)}{\text { flux }}$ & $\begin{array}{l}\text { G425 } \\
\text { year }\end{array}$ & $\begin{array}{l}\text { driving } \\
\text { stress } \\
(\mathbf{k P a})\end{array}$ & $\underset{\left(\mathbf{k m}^{3} \mathbf{a}^{-1}\right)}{\text { flux }}$ & $\begin{array}{c}\Delta \text { driving } \\
\text { stress } \\
(\mathbf{k P a})\end{array}$ & $\underset{\left(\mathbf{k m}^{3} \mathbf{a}^{-1}\right)}{\Delta \text { flux }}$ \\
\hline 184 & 1 & 1647 & 214.94 & 118.12 & 1106 & 230.16 & 135.06 & 15.22 & 16.94 \\
\hline 185 & 1 & 1650 & 214.81 & 118 & 1107 & 230.16 & 135.1 & 15.34 & 17.1 \\
\hline 186 & 1 & 1651 & 215.02 & 118.16 & 1108 & 230.07 & 134.87 & 15.04 & 16.71 \\
\hline 187 & 1 & 1652 & 214.99 & 117.9 & 1109 & 230.27 & 134.49 & 15.28 & 16.6 \\
\hline 188 & 1 & 1653 & 214.92 & 117.92 & 1110 & 230.14 & 134.99 & 15.22 & 17.07 \\
\hline 189 & 1 & 1654 & 214.99 & 117.99 & 1111 & 230.48 & 135.23 & 15.49 & 17.23 \\
\hline 190 & 1 & 1655 & 214.99 & 117.96 & 1112 & 230.4 & 135.71 & 15.41 & 17.74 \\
\hline 191 & 1 & 1658 & 215.19 & 117.69 & 1113 & 230.42 & 135.22 & 15.23 & 17.52 \\
\hline 192 & 1 & 1659 & 215.31 & 117.26 & 1114 & 230.52 & 135.79 & 15.21 & 18.53 \\
\hline 193 & 1 & 1661 & 215.46 & 117.5 & 1115 & 230.12 & 135.51 & 14.66 & 18.01 \\
\hline 194 & 1 & 1664 & 215.35 & 117.69 & 1116 & 230.59 & 135.54 & 15.24 & 17.85 \\
\hline 195 & 1 & 1665 & 215.39 & 117.45 & 1117 & 230.46 & 135.66 & 15.06 & 18.21 \\
\hline 196 & 1 & 1666 & 215.5 & 117.63 & 1118 & 230.66 & 135.43 & 15.17 & 17.8 \\
\hline 197 & 1 & 1667 & 215.42 & 117.5 & 1119 & 230.77 & 134.9 & 15.35 & 17.4 \\
\hline 198 & 1 & 1668 & 215.41 & 118 & 1120 & 230.86 & 134.51 & 15.45 & 16.5 \\
\hline 199 & 1 & 1669 & 215.44 & 117.96 & 1121 & 230.82 & 134.29 & 15.38 & 16.33 \\
\hline 200 & 1 & 1670 & 215.41 & 117.52 & 1122 & 230.68 & 134.34 & 15.27 & 16.82 \\
\hline 201 & 1 & 1671 & 215.48 & 117.87 & 1123 & 230.62 & 134.93 & 15.14 & 17.07 \\
\hline 202 & 1 & 1672 & 215.53 & 117.56 & 1124 & 230.56 & 135.3 & 15.03 & 17.74 \\
\hline 203 & 1 & 1673 & 215.68 & 117.06 & 1125 & 230.73 & 135.07 & 15.04 & 18.01 \\
\hline 204 & 1 & 1682 & 216.05 & 116.41 & 1126 & 230.82 & 134.9 & 14.77 & 18.49 \\
\hline 205 & 1 & 1683 & 216.13 & 115.9 & 1130 & 231.07 & 134.16 & 14.94 & 18.26 \\
\hline 206 & 1 & 1684 & 216.22 & 116.18 & 1131 & 231.03 & 134.15 & 14.81 & 17.97 \\
\hline 207 & 1 & 1686 & 216.25 & 116.5 & 1132 & 230.86 & 134.36 & 14.61 & 17.86 \\
\hline 208 & 1 & 1688 & 216.2 & 116.43 & 1134 & 230.98 & 134.06 & 14.78 & 17.63 \\
\hline 209 & 1 & 1689 & 216.32 & 115.93 & 1135 & 230.9 & 133.9 & 14.57 & 17.97 \\
\hline 210 & 1 & 1690 & 216.38 & 115.82 & 1136 & 231.02 & 134.38 & 14.65 & 18.56 \\
\hline 211 & 1 & 1691 & 216.18 & 115.96 & 1137 & 231.16 & 134.21 & 14.98 & 18.26 \\
\hline 212 & 1 & 1692 & 216.27 & 115.81 & 1138 & 231.18 & 134.03 & 14.91 & 18.23 \\
\hline 213 & 1 & 1693 & 216.33 & 115.56 & 1139 & 231.3 & 133.92 & 14.96 & 18.36 \\
\hline 214 & 1 & 1694 & 216.39 & 115.53 & 1140 & 231.33 & 133.71 & 14.94 & 18.18 \\
\hline 215 & 1 & 1697 & 216.63 & 115.64 & 1141 & 231.1 & 133.59 & 14.47 & 17.95 \\
\hline 216 & 1 & 1698 & 216.67 & 115.68 & 1142 & 231.3 & 133.52 & 14.63 & 17.83 \\
\hline 217 & 1 & 1706 & 217.09 & 114.65 & 1143 & 231.34 & 132.99 & 14.26 & 18.34 \\
\hline 218 & 1 & 1707 & 217.02 & 114.52 & 1144 & 231.34 & 132.7 & 14.33 & 18.18 \\
\hline 219 & 1 & 1708 & 216.94 & 114.41 & 1145 & 231.46 & 132.39 & 14.52 & 17.98 \\
\hline 220 & 1 & 1709 & 216.96 & 114.67 & 1146 & 231.46 & 132.01 & 14.5 & 17.34 \\
\hline 221 & 1 & 1710 & 217.07 & 114.72 & 1147 & 231.54 & 131.97 & 14.47 & 17.25 \\
\hline 222 & 1 & 1711 & 217.09 & 114.61 & 1148 & 231.67 & 131.75 & 14.58 & 17.14 \\
\hline 223 & 1 & 1712 & 217.16 & 114.77 & 1149 & 231.73 & 131.96 & 14.58 & 17.18 \\
\hline
\end{tabular}




\begin{tabular}{|c|c|c|c|c|c|c|c|c|c|}
\hline obs & $\mathbf{T}$ & $\begin{array}{l}\text { B270 } \\
\text { year }\end{array}$ & $\begin{array}{l}\text { driving } \\
\text { stress } \\
(\mathbf{k P a})\end{array}$ & $\begin{array}{c}\text { flux } \\
\left(\mathbf{k m}^{3} \mathbf{a}^{-1}\right)\end{array}$ & $\begin{array}{l}\text { G425 } \\
\text { year }\end{array}$ & $\begin{array}{l}\text { driving } \\
\text { stress } \\
(\mathbf{k P a})\end{array}$ & $\underset{\left(\mathbf{k m}^{3} \mathbf{a}^{-1}\right)}{\mathbf{f l u x}}$ & $\begin{array}{c}\Delta \text { driving } \\
\text { stress } \\
(\mathbf{k P a})\end{array}$ & $\underset{\left(\mathbf{k m}^{3} \mathbf{a}^{-1}\right)}{\Delta \text { flux }}$ \\
\hline 224 & 1 & 1713 & 217.23 & 114.57 & 1150 & 231.91 & 131.69 & 14.68 & 17.12 \\
\hline 225 & 1 & 1714 & 217.18 & 114.78 & 1151 & 231.91 & 131.61 & 14.73 & 16.84 \\
\hline 226 & 1 & 1716 & 217.15 & 114.93 & 1152 & 231.67 & 131.04 & 14.52 & 16.12 \\
\hline 227 & 1 & 1717 & 217.28 & 115.03 & 1153 & 231.71 & 130.9 & 14.43 & 15.87 \\
\hline 228 & 1 & 1718 & 217.13 & 115.03 & 1154 & 231.71 & 130.86 & 14.58 & 15.83 \\
\hline 229 & 1 & 1719 & 217.17 & 114.29 & 1155 & 231.82 & 130.5 & 14.64 & 16.21 \\
\hline 230 & 1 & 1720 & 217.28 & 114.38 & 1156 & 231.71 & 130.84 & 14.43 & 16.46 \\
\hline 231 & 1 & 1721 & 217.31 & 114.55 & 1157 & 231.68 & 130.73 & 14.37 & 16.18 \\
\hline 232 & 1 & 1722 & 217.31 & 114.41 & 1158 & 231.79 & 131.02 & 14.48 & 16.61 \\
\hline 233 & 1 & 1724 & 217.37 & 113.71 & 1159 & 231.69 & 131.32 & 14.32 & 17.61 \\
\hline 234 & 1 & 1726 & 217.33 & 113.56 & 1160 & 231.85 & 130.86 & 14.52 & 17.31 \\
\hline 235 & 1 & 1727 & 217.37 & 113.88 & 1161 & 231.91 & 130.9 & 14.54 & 17.02 \\
\hline 236 & 1 & 1729 & 217.56 & 114.2 & 1162 & 231.91 & 130.66 & 14.34 & 16.46 \\
\hline 237 & 1 & 1730 & 217.59 & 114.27 & 1163 & 231.99 & 130.52 & 14.4 & 16.26 \\
\hline 238 & 1 & 1731 & 217.61 & 113.88 & 1164 & 232.03 & 130.66 & 14.42 & 16.77 \\
\hline 239 & 1 & 1732 & 217.62 & 113.46 & 1165 & 232.12 & 130.65 & 14.5 & 17.18 \\
\hline 240 & 1 & 1733 & 217.68 & 113.73 & 1166 & 231.89 & 130.97 & 14.2 & 17.23 \\
\hline 241 & 1 & 1734 & 217.64 & 113.7 & 1167 & 231.91 & 130.96 & 14.27 & 17.26 \\
\hline 242 & 1 & 1735 & 217.59 & 113.62 & 1168 & 232.03 & 131.31 & 14.45 & 17.69 \\
\hline 243 & 1 & 1739 & 217.69 & 113.86 & 1169 & 231.99 & 131.31 & 14.3 & 17.45 \\
\hline 244 & 1 & 1740 & 217.69 & 113.76 & 1170 & 232.22 & 131.04 & 14.52 & 17.29 \\
\hline 245 & 1 & 1741 & 217.72 & 113.35 & 1171 & 232.22 & 131.26 & 14.5 & 17.91 \\
\hline 246 & 1 & 1742 & 217.79 & 113.1 & 1172 & 232.34 & 131 & 14.54 & 17.9 \\
\hline 247 & 1 & 1743 & 217.83 & 113.19 & 1173 & 232.49 & 130.9 & 14.66 & 17.71 \\
\hline 248 & 1 & 1748 & 218.05 & 113.9 & 1174 & 232.44 & 131.22 & 14.39 & 17.32 \\
\hline 249 & 1 & 1749 & 218.01 & 113.84 & 1175 & 232.49 & 130.94 & 14.48 & 17.1 \\
\hline 250 & 1 & 1755 & 218.04 & 112.66 & 1176 & 232.52 & 130.19 & 14.49 & 17.53 \\
\hline 251 & 1 & 1756 & 218.07 & 112.76 & 1177 & 232.62 & 130.36 & 14.55 & 17.59 \\
\hline 252 & 1 & 1757 & 218.11 & 112.91 & 1178 & 232.7 & 130.03 & 14.59 & 17.11 \\
\hline 253 & 1 & 1758 & 218.23 & 113.24 & 1179 & 232.67 & 130.2 & 14.44 & 16.96 \\
\hline 254 & 1 & 1759 & 218.24 & 113.21 & 1180 & 232.79 & 130.26 & 14.55 & 17.05 \\
\hline 255 & 1 & 1760 & 218.13 & 112.99 & 1181 & 232.58 & 130.45 & 14.45 & 17.46 \\
\hline 256 & 1 & 1761 & 218.2 & 112.7 & 1182 & 232.68 & 130.4 & 14.48 & 17.7 \\
\hline 257 & 1 & 1762 & 218.13 & 112.52 & 1183 & 232.68 & 130.45 & 14.55 & 17.93 \\
\hline 258 & 1 & 1763 & 218.29 & 112.3 & 1184 & 232.55 & 130.23 & 14.26 & 17.93 \\
\hline 259 & 1 & 1764 & 218.34 & 112.26 & 1185 & 232.64 & 129.93 & 14.31 & 17.67 \\
\hline 260 & 1 & 1767 & 218.17 & 112.26 & 1186 & 232.5 & 130.12 & 14.33 & 17.86 \\
\hline 261 & 1 & 1768 & 218.12 & 112.56 & 1187 & 232.55 & 130.01 & 14.43 & 17.45 \\
\hline 262 & 1 & 1769 & 218.3 & 111.97 & 1188 & 232.62 & 129.77 & 14.31 & 17.8 \\
\hline 263 & 1 & 1770 & 218.37 & 112.17 & 1189 & 232.61 & 129.64 & 14.24 & 17.47 \\
\hline
\end{tabular}




\begin{tabular}{|c|c|c|c|c|c|c|c|c|c|}
\hline obs & $\mathbf{T}$ & $\begin{array}{l}\text { B270 } \\
\text { year }\end{array}$ & $\begin{array}{l}\text { driving } \\
\text { stress } \\
(\mathbf{k P a})\end{array}$ & $\underset{\left(\mathbf{k m}^{3} \mathbf{a}^{-1}\right)}{\text { flux }}$ & $\begin{array}{l}\text { G425 } \\
\text { year }\end{array}$ & $\begin{array}{l}\text { driving } \\
\text { stress } \\
(\mathbf{k P a})\end{array}$ & $\begin{array}{c}\text { flux } \\
\left(\mathbf{k m}^{\mathbf{3}} \mathbf{a}^{-1}\right)\end{array}$ & $\begin{array}{c}\Delta \text { driving } \\
\text { stress } \\
(\mathbf{k P a})\end{array}$ & $\underset{\left(\mathbf{k m}^{3} \mathbf{a}^{-1}\right)}{\Delta \text { flux }}$ \\
\hline 264 & 1 & 1771 & 218.42 & 111.96 & 1190 & 232.83 & 129.91 & 14.41 & 17.95 \\
\hline 265 & 1 & 1777 & 218.31 & 112.07 & 1191 & 232.88 & 129.74 & 14.57 & 17.67 \\
\hline 266 & 1 & 1778 & 218.29 & 111.91 & 1192 & 232.87 & 129.1 & 14.58 & 17.19 \\
\hline 267 & 1 & 1779 & 218.35 & 111.46 & 1193 & 232.74 & 129.36 & 14.38 & 17.9 \\
\hline 268 & 1 & 1780 & 218.4 & 111.59 & 1194 & 232.94 & 128.84 & 14.54 & 17.25 \\
\hline 269 & 1 & 1781 & 217.93 & 112.08 & 1195 & 232.75 & 128.6 & 14.81 & 16.52 \\
\hline 270 & 1 & 1782 & 218 & 111.86 & 1196 & 232.97 & 128.57 & 14.97 & 16.71 \\
\hline 271 & 1 & 1783 & 217.9 & 112.09 & 1197 & 232.78 & 129.58 & 14.88 & 17.49 \\
\hline 272 & 1 & 1784 & 217.84 & 112.14 & 1198 & 232.83 & 129.05 & 15 & 16.91 \\
\hline 273 & 1 & 1785 & 217.97 & 111.75 & 1199 & 232.6 & 128.65 & 14.64 & 16.9 \\
\hline 274 & 1 & 1786 & 218.02 & 111.67 & 1200 & 232.56 & 128.22 & 14.54 & 16.55 \\
\hline 275 & 1 & 1787 & 217.96 & 111.67 & 1201 & 232.72 & 128.11 & 14.75 & 16.45 \\
\hline 276 & 1 & 1788 & 217.97 & 111.23 & 1202 & 232.74 & 128 & 14.77 & 16.77 \\
\hline 277 & 1 & 1792 & 217.7 & 111.83 & 1203 & 232.63 & 127.44 & 14.93 & 15.61 \\
\hline 278 & 1 & 1793 & 217.71 & 112.24 & 1204 & 232.73 & 127.66 & 15.02 & 15.42 \\
\hline 279 & 1 & 1794 & 217.74 & 111.8 & 1205 & 232.72 & 127.45 & 14.98 & 15.64 \\
\hline 280 & 1 & 1795 & 217.82 & 111.71 & 1206 & 232.84 & 127.41 & 15.02 & 15.7 \\
\hline 281 & 1 & 1796 & 217.83 & 111.88 & 1207 & 232.79 & 127.19 & 14.96 & 15.31 \\
\hline 282 & 1 & 1797 & 217.96 & 111.72 & 1208 & 232.62 & 126.94 & 14.65 & 15.22 \\
\hline 283 & 1 & 1798 & 217.94 & 111.52 & 1209 & 232.81 & 126.65 & 14.87 & 15.13 \\
\hline 284 & 1 & 1801 & 217.8 & 111.71 & 1210 & 232.8 & 126.77 & 15 & 15.06 \\
\hline 285 & 1 & 1802 & 217.89 & 111.27 & 1211 & 232.59 & 126.45 & 14.71 & 15.18 \\
\hline 286 & 1 & 1803 & 217.89 & 111.45 & 1212 & 232.3 & 127.38 & 14.42 & 15.93 \\
\hline 287 & 1 & 1804 & 217.92 & 111.16 & 1213 & 232.21 & 127.08 & 14.3 & 15.92 \\
\hline 288 & 1 & 1805 & 217.95 & 110.98 & 1214 & 232.4 & 126.71 & 14.45 & 15.74 \\
\hline 289 & 1 & 1806 & 218.01 & 110.87 & 1215 & 232.49 & 126.32 & 14.48 & 15.46 \\
\hline 290 & 1 & 1809 & 217.97 & 111.15 & 1216 & 232.5 & 126.27 & 14.53 & 15.12 \\
\hline 291 & 1 & 1810 & 218.12 & 111.19 & 1217 & 232.49 & 126.9 & 14.38 & 15.71 \\
\hline 292 & 1 & 1811 & 218.03 & 111.27 & 1218 & 232.32 & 127.5 & 14.29 & 16.23 \\
\hline 293 & 1 & 1812 & 218.03 & 110.75 & 1219 & 232.21 & 127.46 & 14.18 & 16.72 \\
\hline 294 & 1 & 1813 & 218.22 & 110.75 & 1220 & 232.67 & 126.96 & 14.45 & 16.22 \\
\hline 295 & 1 & 1814 & 218.25 & 111.04 & 1221 & 232.42 & 126.75 & 14.17 & 15.71 \\
\hline 296 & 1 & 1815 & 218.17 & 110.88 & 1222 & 232.4 & 126.81 & 14.24 & 15.93 \\
\hline 297 & 1 & 1816 & 218.25 & 110.64 & 1223 & 232.33 & 126.48 & 14.08 & 15.85 \\
\hline 298 & 1 & 1817 & 218.28 & 110.84 & 1224 & 232.4 & 126.55 & 14.12 & 15.71 \\
\hline 299 & 1 & 1818 & 218.31 & 110.55 & 1225 & 232.17 & 126.03 & 13.86 & 15.48 \\
\hline 300 & 1 & 1819 & 218.38 & 110.68 & 1226 & 232.34 & 126.63 & 13.96 & 15.94 \\
\hline 301 & 1 & 1820 & 218.42 & 110.59 & 1227 & 232.34 & 126.54 & 13.92 & 15.94 \\
\hline 302 & 1 & 1821 & 218.42 & 110.38 & 1228 & 232.46 & 125.83 & 14.05 & 15.44 \\
\hline 303 & 1 & 1822 & 218.47 & 110.24 & 1229 & 232.46 & 125.05 & 13.99 & 14.81 \\
\hline
\end{tabular}




\begin{tabular}{|c|c|c|c|c|c|c|c|c|c|}
\hline obs & $\mathbf{T}$ & $\begin{array}{l}\text { B270 } \\
\text { year }\end{array}$ & $\begin{array}{l}\text { driving } \\
\text { stress } \\
(\mathbf{k P a})\end{array}$ & $\begin{array}{c}\text { flux } \\
\left(\mathbf{k m}^{3} \mathbf{a}^{-1}\right)\end{array}$ & $\begin{array}{l}\text { G425 } \\
\text { year }\end{array}$ & $\begin{array}{l}\text { driving } \\
\text { stress } \\
(\mathbf{k P a})\end{array}$ & $\underset{\left(\mathbf{k m}^{3} \mathbf{a}^{-1}\right)}{\text { flux }}$ & $\begin{array}{c}\Delta \text { driving } \\
\text { stress } \\
(\mathbf{k P a})\end{array}$ & $\underset{\left(\mathbf{k m}^{3} \mathbf{a}^{-1}\right)}{\Delta \text { flux }}$ \\
\hline 304 & 1 & 1823 & 218.37 & 110.26 & 1230 & 232.51 & 125.73 & 14.14 & 15.47 \\
\hline 305 & 1 & 1824 & 218.25 & 110.73 & 1231 & 232.51 & 124.9 & 14.26 & 14.17 \\
\hline 306 & 1 & 1825 & 218.27 & 110.89 & 1232 & 232.42 & 124.96 & 14.15 & 14.07 \\
\hline 307 & 1 & 1826 & 218.32 & 110.38 & 1233 & 232.77 & 126.09 & 14.45 & 15.72 \\
\hline 308 & 1 & 1827 & 218.33 & 110.32 & 1234 & 232.5 & 125.97 & 14.17 & 15.65 \\
\hline 309 & 1 & 1828 & 218.37 & 110.01 & 1235 & 232.66 & 125.66 & 14.3 & 15.64 \\
\hline 310 & 1 & 1829 & 218.34 & 110.09 & 1236 & 232.62 & 125.78 & 14.29 & 15.69 \\
\hline 311 & 1 & 1830 & 218.34 & 109.92 & 1237 & 232.6 & 125.47 & 14.25 & 15.55 \\
\hline 312 & 1 & 1831 & 218.34 & 110.02 & 1238 & 232.54 & 125.32 & 14.2 & 15.3 \\
\hline 313 & 1 & 1832 & 218.41 & 110.38 & 1239 & 232.39 & 125.65 & 13.98 & 15.27 \\
\hline 314 & 1 & 1833 & 218.44 & 110.35 & 1240 & 232.54 & 126.53 & 14.1 & 16.18 \\
\hline 315 & 1 & 1838 & 218.51 & 110.16 & 1241 & 232.41 & 126.36 & 13.89 & 16.2 \\
\hline 316 & 1 & 1839 & 218.38 & 110.71 & 1242 & 232.48 & 126.69 & 14.1 & 15.98 \\
\hline 317 & 1 & 1840 & 218.42 & 110.88 & 1243 & 232.59 & 126.28 & 14.17 & 15.41 \\
\hline 318 & 1 & 1841 & 218.46 & 110.23 & 1244 & 232.66 & 126.23 & 14.2 & 16.01 \\
\hline 319 & 1 & 1842 & 218.48 & 110.04 & 1245 & 232.65 & 126.42 & 14.17 & 16.38 \\
\hline 320 & 1 & 1843 & 218.51 & 110.11 & 1246 & 232.63 & 126.36 & 14.11 & 16.25 \\
\hline 321 & 1 & 1844 & 218.54 & 109.86 & 1247 & 232.72 & 126.76 & 14.18 & 16.9 \\
\hline 322 & 1 & 1857 & 218.66 & 109.17 & 1260 & 232.68 & 126.03 & 14.02 & 16.86 \\
\hline 323 & 1 & 1862 & 218.65 & 110.16 & 1265 & 233.01 & 125.55 & 14.36 & 15.38 \\
\hline 324 & 1 & 1878 & 218.95 & 109.69 & 1279 & 233.36 & 125 & 14.41 & 15.32 \\
\hline 325 & 1 & 1879 & 218.96 & 109.84 & 1280 & 233.3 & 125.06 & 14.34 & 15.22 \\
\hline 326 & 1 & 1880 & 219.07 & 109.86 & 1281 & 233.17 & 124.6 & 14.11 & 14.73 \\
\hline 327 & 1 & 1881 & 219.01 & 110.08 & 1282 & 233.18 & 124.62 & 14.17 & 14.55 \\
\hline 328 & 1 & 1882 & 218.83 & 109.84 & 1283 & 233.27 & 124.61 & 14.44 & 14.77 \\
\hline 329 & 1 & 1883 & 218.75 & 109.7 & 1284 & 233.15 & 124.61 & 14.4 & 14.92 \\
\hline 330 & 1 & 1884 & 218.71 & 109.66 & 1285 & 233.18 & 124.71 & 14.47 & 15.05 \\
\hline 331 & 1 & 1890 & 218.97 & 109.65 & 1286 & 233.34 & 125.02 & 14.37 & 15.37 \\
\hline 332 & 1 & 1891 & 219.08 & 108.95 & 1287 & 233.18 & 124.58 & 14.1 & 15.63 \\
\hline 333 & 1 & 1892 & 219.04 & 108.98 & 1288 & 233.34 & 124.87 & 14.3 & 15.89 \\
\hline 334 & 1 & 1893 & 219.16 & 108.23 & 1289 & 233.35 & 124.49 & 14.19 & 16.25 \\
\hline 335 & 1 & 1894 & 219 & 108.68 & 1290 & 233.42 & 124.65 & 14.42 & 15.97 \\
\hline 336 & 1 & 1895 & 219.03 & 108.64 & 1291 & 233.54 & 124.76 & 14.51 & 16.12 \\
\hline 337 & 1 & 1896 & 218.96 & 108.66 & 1292 & 233.31 & 124.35 & 14.35 & 15.69 \\
\hline 338 & 1 & 1897 & 219.04 & 108.55 & 1293 & 233.28 & 124.1 & 14.24 & 15.55 \\
\hline 339 & 1 & 1898 & 219.05 & 108.4 & 1294 & 233.37 & 123.97 & 14.32 & 15.58 \\
\hline 340 & 1 & 1899 & 218.95 & 108.66 & 1295 & 233.49 & 123.67 & 14.54 & 15.01 \\
\hline 341 & 4 & 1901 & 219.05 & 108.66 & 1312 & 232.93 & 122.9 & 13.89 & 14.24 \\
\hline 342 & 4 & 1902 & 219.01 & 108.3 & 1313 & 233.01 & 122.68 & 14 & 14.38 \\
\hline 343 & 1 & 1920 & 218.93 & 108.32 & 1314 & 233.11 & 122.4 & 14.18 & 14.08 \\
\hline
\end{tabular}




\begin{tabular}{|c|c|c|c|c|c|c|c|c|c|}
\hline obs & $\mathbf{T}$ & $\begin{array}{l}\text { B270 } \\
\text { year }\end{array}$ & $\begin{array}{l}\text { driving } \\
\text { stress } \\
(\mathbf{k P a})\end{array}$ & $\begin{array}{c}\text { flux } \\
\left(\mathbf{k m}^{3} \mathbf{a}^{-1}\right)\end{array}$ & $\begin{array}{l}\text { G425 } \\
\text { year }\end{array}$ & $\begin{array}{l}\text { driving } \\
\text { stress } \\
(\mathbf{k P a})\end{array}$ & $\underset{\left(\mathbf{k m}^{3} \mathbf{a}^{-1}\right)}{\mathbf{f l u x}}$ & $\begin{array}{c}\Delta \text { driving } \\
\text { stress } \\
(\mathbf{k P a})\end{array}$ & $\underset{\left(\mathbf{k m}^{3} \mathbf{a}^{-1}\right)}{\Delta \text { flux }}$ \\
\hline 344 & 1 & 1932 & 218.91 & 108.43 & 1328 & 233.27 & 121.14 & 14.36 & 12.71 \\
\hline 345 & 1 & 1940 & 218.97 & 108.79 & 1336 & 233.08 & 121.08 & 14.11 & 12.29 \\
\hline 346 & 4 & 1940 & 218.97 & 108.79 & 1341 & 232.94 & 120.68 & 13.96 & 11.89 \\
\hline 347 & 4 & 1941 & 218.85 & 108.82 & 1342 & 232.98 & 120.63 & 14.14 & 11.82 \\
\hline 348 & 4 & 1942 & 218.91 & 108.94 & 1343 & 233.12 & 120.3 & 14.21 & 11.36 \\
\hline 349 & 4 & 1945 & 218.95 & 108.94 & 1346 & 233.12 & 120.26 & 14.17 & 11.33 \\
\hline 350 & 4 & 1946 & 218.92 & 109.09 & 1347 & 233.01 & 119.96 & 14.09 & 10.87 \\
\hline 351 & 4 & 1947 & 218.99 & 109.4 & 1348 & 233.01 & 120.14 & 14.03 & 10.75 \\
\hline 352 & 4 & 1948 & 219.01 & 109.37 & 1349 & 233.19 & 120.82 & 14.18 & 11.45 \\
\hline 353 & 4 & 1949 & 218.95 & 109.62 & 1350 & 233.03 & 120.58 & 14.08 & 10.96 \\
\hline 354 & 4 & 1950 & 218.97 & 108.98 & 1351 & 233.04 & 120.31 & 14.07 & 11.33 \\
\hline 355 & 4 & 1952 & 218.89 & 108.73 & 1352 & 233.16 & 120.3 & 14.27 & 11.57 \\
\hline 356 & 4 & 1953 & 219 & 109.14 & 1353 & 233.16 & 120.07 & 14.15 & 10.93 \\
\hline 357 & 4 & 1961 & 219.38 & 108.98 & 1354 & 233.16 & 119.56 & 13.78 & 10.58 \\
\hline 358 & 4 & 1962 & 219.35 & 108.96 & 1355 & 233.18 & 119.47 & 13.83 & 10.5 \\
\hline 359 & 4 & 1963 & 219.28 & 109.18 & 1356 & 233.17 & 119.6 & 13.89 & 10.42 \\
\hline 360 & 4 & 1966 & 219.44 & 108.8 & 1357 & 233.17 & 119.41 & 13.73 & 10.61 \\
\hline 361 & 4 & 1967 & 219.44 & 109.07 & 1358 & 233.26 & 119.11 & 13.82 & 10.04 \\
\hline 362 & 4 & 1968 & 219.43 & 109.17 & 1359 & 233.24 & 119.62 & 13.81 & 10.46 \\
\hline 363 & 4 & 1969 & 219.46 & 108.88 & 1360 & 233.2 & 119.59 & 13.73 & 10.71 \\
\hline 364 & 1 & 1973 & 219.53 & 108.5 & 1361 & 233.25 & 119.4 & 13.72 & 10.91 \\
\hline 365 & 1 & 1975 & 219.38 & 109.05 & 1363 & 232.99 & 118.94 & 13.61 & 9.89 \\
\hline 366 & 1 & 1976 & 219.32 & 108.87 & 1364 & 233.07 & 118.9 & 13.75 & 10.03 \\
\hline 367 & 1 & 1977 & 219.48 & 108.96 & 1365 & 233.17 & 118.63 & 13.68 & 9.67 \\
\hline 368 & 1 & 1978 & 219.54 & 108.59 & 1366 & 233.2 & 118.72 & 13.66 & 10.13 \\
\hline 369 & 4 & 1981 & 219.62 & 108.53 & 1367 & 233.24 & 118.79 & 13.62 & 10.26 \\
\hline 370 & 1 & 1983 & 219.37 & 108.22 & 1369 & 233.17 & 119.05 & 13.8 & 10.84 \\
\hline 371 & 1 & 1984 & 219.22 & 108.5 & 1370 & 233.1 & 118.66 & 13.88 & 10.16 \\
\hline 372 & 1 & 1985 & 219.38 & 108.5 & 1371 & 232.98 & 118.73 & 13.6 & 10.23 \\
\hline 373 & 1 & 1986 & 219.4 & 108.1 & 1372 & 233.03 & 118.73 & 13.63 & 10.64 \\
\hline 374 & 1 & 1987 & 219.48 & 107.84 & 1373 & 233.01 & 118.5 & 13.53 & 10.67 \\
\hline 375 & 1 & 1988 & 219.51 & 107.76 & 1374 & 233.11 & 119.53 & 13.6 & 11.77 \\
\hline 376 & 1 & 1989 & 219.58 & 107.64 & 1375 & 233.2 & 119.78 & 13.62 & 12.14 \\
\hline 377 & 1 & 1990 & 219.52 & 108.11 & 1376 & 233.15 & 119.55 & 13.63 & 11.44 \\
\hline 378 & 1 & 1991 & 219.5 & 107.99 & 1377 & 233.14 & 119.04 & 13.63 & 11.05 \\
\hline 379 & 1 & 1992 & 219.48 & 107.92 & 1378 & 233.15 & 119.18 & 13.68 & 11.26 \\
\hline 380 & 1 & 1993 & 219.71 & 107.32 & 1379 & 233.14 & 119.14 & 13.43 & 11.82 \\
\hline 381 & 1 & 1994 & 219.64 & 107.36 & 1380 & 233.19 & 118.96 & 13.55 & 11.6 \\
\hline 382 & 1 & 1995 & 219.77 & 107.3 & 1381 & 233.15 & 118.37 & 13.38 & 11.07 \\
\hline 383 & 1 & 2003 & 219.72 & 106.91 & 1382 & 233.15 & 118.38 & 13.43 & 11.47 \\
\hline
\end{tabular}




\begin{tabular}{|c|c|c|c|c|c|c|c|c|c|}
\hline obs & $\mathbf{T}$ & $\begin{array}{l}\text { B270 } \\
\text { year }\end{array}$ & $\begin{array}{l}\text { driving } \\
\text { stress } \\
(\mathbf{k P a})\end{array}$ & $\begin{array}{c}\text { flux } \\
\left(\mathbf{k m}^{3} \mathbf{a}^{-1}\right)\end{array}$ & $\begin{array}{l}\text { G425 } \\
\text { year }\end{array}$ & $\begin{array}{l}\text { driving } \\
\text { stress } \\
(\mathbf{k P a})\end{array}$ & $\underset{\left(\mathbf{k m}^{3} \mathbf{a}^{-1}\right)}{\text { flux }}$ & $\begin{array}{c}\Delta \text { driving } \\
\text { stress } \\
(\mathbf{k P a})\end{array}$ & $\underset{\left(\mathbf{k m}^{3} \mathbf{a}^{-1}\right)}{\Delta \text { flux }}$ \\
\hline 384 & 1 & 2004 & 219.65 & 106.46 & 1383 & 233.27 & 118.35 & 13.62 & 11.9 \\
\hline 385 & 1 & 2005 & 219.69 & 106.55 & 1384 & 233.11 & 118.37 & 13.43 & 11.82 \\
\hline 386 & 1 & 2006 & 219.73 & 106.76 & 1385 & 233.21 & 118.05 & 13.49 & 11.3 \\
\hline 387 & 1 & 2007 & 219.73 & 106.92 & 1386 & 233.1 & 118.34 & 13.37 & 11.41 \\
\hline 388 & 1 & 2008 & 219.68 & 106.62 & 1387 & 233.17 & 118.2 & 13.5 & 11.58 \\
\hline 389 & 1 & 2009 & 219.73 & 106.55 & 1388 & 233.15 & 118.07 & 13.42 & 11.52 \\
\hline 390 & 1 & 2010 & 219.67 & 106.59 & 1389 & 233.16 & 118.2 & 13.49 & 11.62 \\
\hline 391 & 1 & 2011 & 219.67 & 106.79 & 1390 & 233.08 & 118.21 & 13.41 & 11.42 \\
\hline 392 & 1 & 2012 & 219.67 & 106.53 & 1391 & 233.16 & 118.21 & 13.49 & 11.69 \\
\hline 393 & 1 & 2013 & 219.7 & 106.39 & 1392 & 233.09 & 117.91 & 13.39 & 11.52 \\
\hline 394 & 1 & 2014 & 219.69 & 106.4 & 1393 & 233 & 117.97 & 13.31 & 11.57 \\
\hline 395 & 1 & 2015 & 219.65 & 106.61 & 1394 & 232.99 & 117.78 & 13.34 & 11.17 \\
\hline 396 & 1 & 2016 & 219.69 & 106.63 & 1395 & 233.01 & 117.79 & 13.32 & 11.15 \\
\hline 397 & 1 & 2019 & 219.73 & 105.92 & 1396 & 233.17 & 116.92 & 13.44 & 11 \\
\hline 398 & 1 & 2020 & 219.56 & 105.87 & 1397 & 233.13 & 117.27 & 13.57 & 11.4 \\
\hline 399 & 1 & 2021 & 219.59 & 106.57 & 1398 & 233.12 & 117.35 & 13.53 & 10.78 \\
\hline 400 & 1 & 2022 & 219.63 & 106.3 & 1399 & 233.03 & 117.56 & 13.4 & 11.26 \\
\hline 401 & 1 & 2023 & 219.6 & 105.84 & 1400 & 233.12 & 117.26 & 13.52 & 11.42 \\
\hline 402 & 1 & 2024 & 219.41 & 106.01 & 1401 & 232.96 & 117.11 & 13.55 & 11.1 \\
\hline 403 & 1 & 2025 & 219.6 & 105.77 & 1402 & 233.1 & 117.23 & 13.5 & 11.47 \\
\hline 404 & 1 & 2026 & 219.55 & 105.64 & 1403 & 233.19 & 117.27 & 13.64 & 11.62 \\
\hline 405 & 1 & 2027 & 219.55 & 105.48 & 1404 & 233.24 & 117.18 & 13.69 & 11.71 \\
\hline 406 & 1 & 2028 & 219.6 & 105.44 & 1405 & 233 & 117.14 & 13.4 & 11.71 \\
\hline 407 & 1 & 2029 & 219.46 & 105.45 & 1406 & 233.18 & 117.77 & 13.72 & 12.32 \\
\hline 408 & 1 & 2030 & 219.58 & 105.82 & 1407 & 233.1 & 117.73 & 13.52 & 11.9 \\
\hline 409 & 1 & 2031 & 219.64 & 105.95 & 1408 & 232.91 & 117.51 & 13.27 & 11.55 \\
\hline 410 & 1 & 2032 & 219.53 & 105.94 & 1409 & 232.84 & 116.96 & 13.31 & 11.02 \\
\hline 411 & 1 & 2033 & 219.73 & 106.29 & 1410 & 232.95 & 116.93 & 13.22 & 10.65 \\
\hline 412 & 4 & 2034 & 219.67 & 105.89 & 1411 & 232.84 & 117.16 & 13.17 & 11.27 \\
\hline 413 & 4 & 2035 & 219.7 & 105.96 & 1412 & 232.77 & 117.02 & 13.07 & 11.05 \\
\hline 414 & 4 & 2036 & 219.53 & 105.39 & 1413 & 232.93 & 117.43 & 13.39 & 12.04 \\
\hline 415 & 4 & 2037 & 219.44 & 105.91 & 1414 & 232.93 & 117.28 & 13.49 & 11.38 \\
\hline 416 & 4 & 2038 & 219.43 & 106.35 & 1415 & 232.76 & 117.32 & 13.33 & 10.97 \\
\hline 417 & 4 & 2039 & 219.22 & 106.21 & 1416 & 232.67 & 116.94 & 13.45 & 10.72 \\
\hline 418 & 1 & 2043 & 219.28 & 105.65 & 1417 & 232.75 & 116.66 & 13.47 & 11.02 \\
\hline 419 & 1 & 2044 & 219.31 & 106.04 & 1418 & 232.76 & 116.62 & 13.45 & 10.58 \\
\hline 420 & 1 & 2045 & 219.33 & 106.12 & 1419 & 232.4 & 116.66 & 13.07 & 10.54 \\
\hline 421 & 1 & 2046 & 219.33 & 106.2 & 1420 & 232.51 & 117.24 & 13.18 & 11.04 \\
\hline 422 & 1 & 2047 & 219.34 & 105.97 & 1421 & 232.52 & 116.55 & 13.18 & 10.59 \\
\hline 423 & 1 & 2048 & 219.35 & 105.9 & 1422 & 232.56 & 116.4 & 13.21 & 10.5 \\
\hline
\end{tabular}




\begin{tabular}{|c|c|c|c|c|c|c|c|c|c|}
\hline obs & $\mathbf{T}$ & $\begin{array}{l}\text { B270 } \\
\text { year }\end{array}$ & $\begin{array}{l}\text { driving } \\
\text { stress } \\
(\mathbf{k P a})\end{array}$ & $\begin{array}{c}\text { flux } \\
\left(\mathbf{k m}^{3} \mathbf{a}^{-1}\right)\end{array}$ & $\begin{array}{l}\text { G425 } \\
\text { year }\end{array}$ & $\begin{array}{l}\text { driving } \\
\text { stress } \\
(\mathbf{k P a})\end{array}$ & $\underset{\left(\mathbf{k m}^{3} \mathbf{a}^{-1}\right)}{\text { flux }}$ & $\begin{array}{c}\Delta \text { driving } \\
\text { stress } \\
(\mathbf{k P a})\end{array}$ & $\underset{\left(\mathbf{k m}^{3} \mathbf{a}^{-1}\right)}{\Delta \text { flux }}$ \\
\hline 424 & 1 & 2049 & 219.36 & 105.85 & 1423 & 232.58 & 116.77 & 13.22 & 10.92 \\
\hline 425 & 1 & 2050 & 219.28 & 105.84 & 1424 & 232.56 & 116.39 & 13.28 & 10.55 \\
\hline 426 & 1 & 2051 & 219.25 & 105.81 & 1425 & 232.54 & 116.73 & 13.29 & 10.91 \\
\hline 427 & 1 & 2052 & 219.33 & 105.91 & 1426 & 232.7 & 116.51 & 13.37 & 10.6 \\
\hline 428 & 1 & 2069 & 219.25 & 105.99 & 1427 & 232.6 & 116.78 & 13.36 & 10.8 \\
\hline 429 & 1 & 2070 & 219.24 & 105.8 & 1428 & 232.66 & 116.65 & 13.41 & 10.84 \\
\hline 430 & 1 & 2071 & 219.36 & 105.96 & 1429 & 232.68 & 116.89 & 13.32 & 10.93 \\
\hline 431 & 1 & 2072 & 219.41 & 105.93 & 1430 & 232.85 & 116.96 & 13.43 & 11.03 \\
\hline 432 & 1 & 2073 & 219.33 & 105.4 & 1431 & 232.63 & 116.71 & 13.3 & 11.31 \\
\hline 433 & 1 & 2074 & 219.39 & 105.4 & 1432 & 232.87 & 116.86 & 13.48 & 11.46 \\
\hline 434 & 1 & 2075 & 219.5 & 105.59 & 1433 & 232.8 & 116.26 & 13.31 & 10.66 \\
\hline 435 & 1 & 2076 & 219.36 & 105.16 & 1434 & 232.57 & 116.34 & 13.2 & 11.18 \\
\hline 436 & 1 & 2077 & 219.43 & 105.64 & 1435 & 232.58 & 115.91 & 13.14 & 10.27 \\
\hline 437 & 1 & 2078 & 219.36 & 105.61 & 1436 & 232.54 & 116.63 & 13.17 & 11.02 \\
\hline 438 & 1 & 2099 & 219.3 & 104.66 & 1437 & 232.63 & 117.53 & 13.33 & 12.87 \\
\hline 439 & 1 & 2100 & 219.29 & 104.6 & 1438 & 232.62 & 117.36 & 13.33 & 12.76 \\
\hline 440 & 1 & 2101 & 219.34 & 104.32 & 1439 & 232.68 & 116.74 & 13.34 & 12.42 \\
\hline 441 & 1 & 2102 & 219.26 & 104.37 & 1440 & 232.86 & 117.04 & 13.6 & 12.66 \\
\hline 442 & 1 & 2103 & 219.24 & 104.25 & 1441 & 232.43 & 116.98 & 13.2 & 12.73 \\
\hline 443 & 1 & 2125 & 219.17 & 103.95 & 1451 & 232.42 & 116.88 & 13.25 & 12.93 \\
\hline 444 & 1 & 2126 & 219.1 & 104.25 & 1452 & 232.46 & 116.47 & 13.36 & 12.22 \\
\hline 445 & 1 & 2127 & 219.26 & 104.35 & 1453 & 232.4 & 116.54 & 13.14 & 12.19 \\
\hline 446 & 1 & 2128 & 219.06 & 104.64 & 1454 & 232.36 & 116.59 & 13.3 & 11.94 \\
\hline 447 & 1 & 2129 & 219.09 & 104.41 & 1455 & 232.41 & 116.41 & 13.32 & 12.01 \\
\hline 448 & 1 & 2130 & 219.01 & 104.51 & 1456 & 232.35 & 116.38 & 13.33 & 11.88 \\
\hline 449 & 1 & 2131 & 219.06 & 104.21 & 1457 & 232.36 & 115.96 & 13.3 & 11.75 \\
\hline 450 & 1 & 2132 & 219.05 & 103.83 & 1458 & 232.31 & 115.49 & 13.26 & 11.66 \\
\hline 451 & 1 & 2133 & 219.05 & 103.77 & 1459 & 232.24 & 115.85 & 13.18 & 12.08 \\
\hline 452 & 1 & 2134 & 219.1 & 103.8 & 1460 & 232.19 & 116.18 & 13.09 & 12.39 \\
\hline 453 & 1 & 2135 & 218.84 & 103.7 & 1461 & 232.19 & 115.8 & 13.36 & 12.1 \\
\hline 454 & 1 & 2136 & 218.76 & 103.28 & 1462 & 232.3 & 116.1 & 13.54 & 12.82 \\
\hline 455 & 1 & 2137 & 218.77 & 103.32 & 1463 & 232.35 & 115.78 & 13.58 & 12.46 \\
\hline 456 & 1 & 2138 & 219.04 & 103.39 & 1464 & 232.2 & 116.37 & 13.16 & 12.98 \\
\hline 457 & 1 & 2139 & 218.98 & 103.5 & 1465 & 232.25 & 116.75 & 13.27 & 13.25 \\
\hline 458 & 1 & 2140 & 218.93 & 103.44 & 1466 & 232.18 & 116.25 & 13.25 & 12.82 \\
\hline 459 & 1 & 2152 & 218.56 & 103.79 & 1467 & 232.09 & 116.05 & 13.53 & 12.26 \\
\hline 460 & 1 & 2153 & 218.51 & 103.96 & 1468 & 232 & 116.36 & 13.49 & 12.4 \\
\hline 461 & 1 & 2154 & 218.64 & 103.88 & 1469 & 231.9 & 115.95 & 13.26 & 12.07 \\
\hline 462 & 1 & 2155 & 218.54 & 104.08 & 1470 & 231.82 & 115.88 & 13.28 & 11.79 \\
\hline 463 & 1 & 2156 & 218.52 & 103.6 & 1471 & 231.76 & 115.64 & 13.24 & 12.04 \\
\hline
\end{tabular}




\begin{tabular}{|c|c|c|c|c|c|c|c|c|c|}
\hline obs & $\mathbf{T}$ & $\begin{array}{l}\text { B270 } \\
\text { year }\end{array}$ & $\begin{array}{c}\text { driving } \\
\text { stress } \\
(\mathbf{k P a})\end{array}$ & $\begin{array}{c}\text { flux } \\
\left(\mathrm{km}^{3} \mathbf{a}^{-1}\right)\end{array}$ & $\begin{array}{l}\text { G425 } \\
\text { year }\end{array}$ & $\begin{array}{l}\text { driving } \\
\text { stress } \\
(\mathbf{k P a})\end{array}$ & $\underset{\left(\mathbf{k m}^{3} \mathbf{a}^{-1}\right)}{\text { flux }}$ & $\begin{array}{c}\Delta \text { driving } \\
\text { stress } \\
(\mathbf{k P a})\end{array}$ & $\begin{array}{c}\Delta \text { flux } \\
\left(\mathbf{k m}^{3} \mathbf{a}^{-1}\right)\end{array}$ \\
\hline 464 & 1 & 2157 & 218.62 & 103.91 & 1472 & 231.86 & 116.01 & 13.24 & 12.1 \\
\hline 465 & 1 & 2158 & 218.55 & 103.52 & 1473 & 231.9 & 116.19 & 13.34 & 12.67 \\
\hline 466 & 1 & 2159 & 218.57 & 103.62 & 1474 & 231.87 & 115.59 & 13.3 & 11.97 \\
\hline 467 & 1 & 2160 & 218.61 & 103.59 & 1475 & 231.9 & 115.46 & 13.29 & 11.87 \\
\hline 468 & 1 & 2161 & 218.57 & 103.21 & 1476 & 231.88 & 115.51 & 13.31 & 12.31 \\
\hline 469 & 1 & 2162 & 218.6 & 103.28 & 1477 & 231.94 & 115.28 & 13.33 & 12.01 \\
\hline 470 & 1 & 2163 & 218.61 & 103.63 & 1478 & 231.92 & 115.12 & 13.31 & 11.49 \\
\hline 471 & 1 & 2164 & 218.52 & 103.59 & 1479 & 232.06 & 115.44 & 13.53 & 11.85 \\
\hline 472 & 1 & 2165 & 218.54 & 103.57 & 1480 & 231.98 & 115.15 & 13.43 & 11.58 \\
\hline 473 & 1 & 2166 & 218.57 & 103.65 & 1481 & 231.93 & 115.14 & 13.36 & 11.49 \\
\hline 474 & 1 & 2167 & 218.53 & 103.67 & 1482 & 231.99 & 115.52 & 13.46 & 11.85 \\
\hline 475 & 1 & 2177 & 218.36 & 103.01 & 1483 & 231.82 & 115.46 & 13.46 & 12.44 \\
\hline 476 & 1 & 2178 & 218.44 & 102.99 & 1484 & 231.78 & 115.83 & 13.34 & 12.84 \\
\hline 477 & 1 & 2180 & 218.34 & 103.2 & 1485 & 231.72 & 115.82 & 13.37 & 12.62 \\
\hline 478 & 1 & 2194 & 218.03 & 102.42 & 1487 & 231.57 & 115.85 & 13.54 & 13.43 \\
\hline
\end{tabular}




\section{APPENDIX C Grounding Line Retreat Over Beds}

Animations showing grounding line retreat over the beds for each simulation. A gray transparency indicates the locations of floating ice and the grounding line is located generally on the landward side between the floating and grounded ice. Each frame is one year and animations show 40 frames per second. Resolution is variable from $4 \mathrm{~km}$ to $250 \mathrm{~m}$.

\begin{tabular}{ccc} 
file name & file type & size \\
\hline B260_FloatBed_40fps.avi & AVI & $55.8 \mathrm{MB}$ \\
B270_FloatBed_40fps.avi & AVI & $37.3 \mathrm{MB}$ \\
G425_FloatBed_40fps.avi & AVI & $27.8 \mathrm{MB}$
\end{tabular}

in supplemental files 


\section{APPENDIX D Ice Thickness Evolution}

Animations showing temporal evolution of the thickness field from the last year of forced retreat until the end of the simulations. The grounding line positions and Thwaites domain boundary are contoured in black. Each frame is one year and animations show 40 frames per second. Resolution is variable from $4 \mathrm{~km}$ to $250 \mathrm{~m}$ with all grounded ice being at least $2 \mathrm{~km}$ resolution.

\begin{tabular}{ccr} 
file name & file type & \multicolumn{1}{c}{ size } \\
\hline B260_Thk_40fps.avi & AVI & $81 \mathrm{MB}$ \\
B270_Thk_40fps.avi & AVI & $58.2 \mathrm{MB}$ \\
G425_Thk_40fps.avi & AVI & $44.2 \mathrm{MB}$
\end{tabular}

in supplemental files 


\section{APPENDIX E Ice Velocity}

Animations showing temporal evolution of the velocity field from the last year of forced retreat until the end of the simulations. The grounding line positions and Thwaites domain boundary are contoured in black. Each frame is one year and animations show 40 frames per second. Resolution is variable from $4 \mathrm{~km}$ to $250 \mathrm{~m}$ with velocities of grounded ice being at least $2 \mathrm{~km}$ resolution.

\begin{tabular}{ccr} 
file name & file type & \multicolumn{1}{c}{ size } \\
\hline B260_Vel_40fps.avi & AVI & $102.5 \mathrm{MB}$ \\
B270_Vel_40fps.avi & AVI & $74 \mathrm{MB}$ \\
G425_Vel_40fps.avi & AVI & $49 \mathrm{MB}$
\end{tabular}

in supplemental files 


\section{APPENDIX F Effective Strain Rate}

Animations showing temporal evolution of the effective strain rate field (second invariant of strain tensor) from the last year of forced retreat until the end of the simulations. The Thwaites domain boundary is contoured in white. Each frame is one year and animations show 40 frames per second. Resolution is variable from 4 $\mathbf{k m}$ to $250 \mathrm{~m}$ with the effective strain rate of grounded ice being at least $2 \mathbf{~ k m}$ resolution.

\begin{tabular}{ccr} 
file name & file type & \multicolumn{1}{c}{ size } \\
\hline B260_EffStr_40fps.avi & AVI & $133.4 \mathrm{MB}$ \\
B270_EffStr_40fps.avi & AVI & $89 \mathrm{MB}$ \\
G425_EffStr_40fps.avi & AVI & $102.4 \mathrm{MB}$
\end{tabular}

in supplemental files 


\section{APPENDIX G Transect 1}

Vertical profile animations of unforced grounding line retreat and surface deflation along T1 (uppermost transect). Each frame is one year and animations display 25 frames per second.

\begin{tabular}{ccc} 
file name & file type & size \\
\hline IceProfileT1_B260_25fps.avi & AVI & $28 \mathrm{MB}$ \\
IceProfileT1_B270_25fps.avi & AVI & $14 \mathrm{MB}$ \\
IceProfileT1_G425_25fps.avi & AVI & $12 \mathrm{MB}$
\end{tabular}

in supplemental files 


\section{APPENDIX H Transect 2}

Vertical profile animations of unforced grounding line retreat and surface deflation along T2. Each frame is one year and animations display 25 frames per second.

\begin{tabular}{ccc} 
file name & file type & size \\
\hline IceProfileT2_B260_25fps.avi & AVI & $14 \mathrm{MB}$ \\
IceProfileT2_B270_25fps.avi & AVI & $14 \mathrm{MB}$ \\
IceProfileT2_G425_25fps.avi & AVI & $11 \mathrm{MB}$
\end{tabular}

in supplemental files 


\section{APPENDIX I Transect 3}

Vertical profile animations of unforced grounding line retreat and surface deflation along T3 (approximate geographic centerline). Each frame is one year and animations display 25 frames per second.

\begin{tabular}{ccc} 
file name & file type & size \\
\hline IceProfileT3_B260_25fps.avi & AVI & $14 \mathrm{MB}$ \\
IceProfileT3_B270_25fps.avi & AVI & $14 \mathrm{MB}$ \\
IceProfileT3_G425_25fps.avi & AVI & $11 \mathrm{MB}$
\end{tabular}

in supplemental files 


\section{APPENDIX J Transect 4}

Vertical profile animations of unforced grounding line retreat and surface deflation along T4. Each frame is one year and animations display 25 frames per second.

\begin{tabular}{ccr} 
file name & file type & \multicolumn{1}{c}{ size } \\
\hline IceProfileT4_B260_25fps.avi & AVI & $15 \mathrm{MB}$ \\
IceProfileT4_B270_25fps.avi & AVI & $15 \mathrm{MB}$ \\
IceProfileT4_G425_25fps.avi & AVI & $12.5 \mathrm{MB}$
\end{tabular}

in supplemental files 


\section{APPENDIX K Transect 5}

Vertical profile animations of unforced grounding line retreat and surface deflation along T5 (lowest transect). Each frame is one year and animations display 25 frames per second.

\begin{tabular}{ccc} 
file name & file type & size \\
\hline IceProfileT5_B260_25fps.avi & AVI & $13 \mathrm{MB}$ \\
IceProfileT5_B270_25fps.avi & AVI & $13 \mathrm{MB}$ \\
IceProfileT5_G425_25fps.avi & AVI & $11 \mathrm{MB}$
\end{tabular}

in supplemental files 


\title{
APPENDIX L Experiment 1 Co-location
}

Field differences at co-located grounding line positions for experiment 1 . The scalar fields include differences in thickness $(\mathrm{m})$, differences in surface gradient, and differences in driving stress $(\mathbf{k P a})$.

\begin{abstract}
Also included is an animation showing how the ROIs differ for the simulations in experiment 1. For this animation, a value of 1 indicated the B260 ROI area, a value of 2 indicates the B270 ROI, and a value of 3 indicates their union (overlapping area).
\end{abstract}

The resolution is $\mathbf{4} \mathbf{~ k m}$ for these files.

\begin{tabular}{lcc}
\multicolumn{1}{c}{ file name } & file type & size \\
\hline Experiment1_Thkdiff_40fps.avi & AVI & $26 \mathrm{MB}$ \\
Experiment1_GradSdiff_40fps.avi & AVI & $26 \mathrm{MB}$ \\
Experiment1_Dsdiff_40fps.avi & AVI & $26 \mathrm{MB}$ \\
Experiment1_AreaDiff_60fps.avi & AVI & $19 \mathrm{MB}$
\end{tabular}

in supplemental files 


\section{APPENDIX M Experiment 2 Co-location}

Field differences at co-located grounding line positions for experiment 2 . The scalar fields include differences in thickness $(\mathrm{m})$, differences in surface gradient, and differences in driving stress (kPa).

Also included is an animation showing how the ROIs differ for the simulations in experiment 1. For this animation, a value of 1 indicated the B270 ROI area, a value of 2 indicates the G425 ROI, and a value of 3 indicates their union.

The resolution is $\mathbf{4} \mathbf{~ k m}$ for these files.

\begin{tabular}{lcc}
\multicolumn{1}{c}{ file name } & file type & size \\
\hline Experiment2_Thkdiff_40fps.avi & AVI & $11 \mathrm{MB}$ \\
Experiment2_GradSdiff_40fps.avi & AVI & $12 \mathrm{MB}$ \\
Experiment2_Dsdiff_40fps.avi & AVI & $12 \mathrm{MB}$ \\
Experiment2_AreaDiff_60fps.avi & AVI & $6.4 \mathrm{MB}$
\end{tabular}

in supplemental files 